\title{
Making a Market out of a Welfare State \\ Swedish Local Politicians' Perspectives on Elderly Care Marketisation
}

\section{Ming Guo}

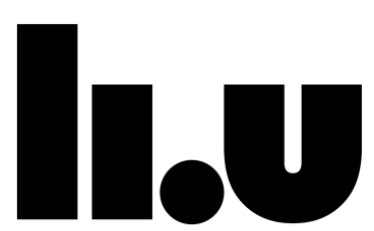

LINKÖPING UNIVERSITY

Linköping Studies in Arts and Science No. 731

Department of Culture and Communication

Faculty of Arts and Sciences

Linköping 2017 
Linköping Studies in Arts and Science · No. 731

At the Faculty of Arts and Science at Linköping University, research and doctoral studies are carried out within broad problem areas. Research is organized in interdisciplinary research environments and doctoral studies mainly in graduate schools. Jointly, they publish the series Linköping Studies in Arts and Science. This thesis comes from the PHOENIX Erasmus Mundus Joint Doctoral Program on Dynamics of Health and Welfare at the Department of Culture and Communication.

Distributed by:

Department of Culture and Communication

Linköping University

SE-581 83 Linköping

Sweden

Ming Guo

Making a Market out of a Welfare State

Swedish Local Politicians' Perspectives on Elderly Care Marketisation

Edition 1:1

ISBN: 978-91-7685-406-8

ISSN 0282-9800

(C)Ming Guo

Department of Culture and Communication

Cover: Designed by Jie Guo

Layout: Martin Pettersson

Printed in Sweden by LiU-Tryck, Linköping, Sweden, 2017 


\section{Contents}

$\begin{array}{ll}\text { Acknowledgements } & \text { iii }\end{array}$

List of illustrations vii

Part I. Introduction and Points of Departure

Chapter 1 Introduction 1

Chapter 2 Background: Market Development of Swedish Elderly care $\quad 21$

$\begin{array}{ll}\text { Chapter } 3 \text { Theoretical Framework } & 45\end{array}$

$\begin{array}{ll}\text { Chapter } 4 \text { Research Methods } & 65\end{array}$

Part II. Results Analysis and Discussion

$\begin{array}{lr}\text { Chapter } 5 \text { Production and Outsourcing Preferences } & 85\end{array}$

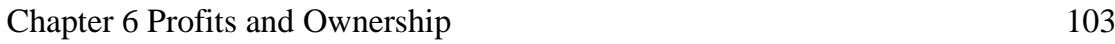

$\begin{array}{ll}\text { Chapter } 7 \text { Quality, Efficiency and Freedom of Choice } & 117\end{array}$

$\begin{array}{ll}\text { Chapter } 8 \text { Financing, Regulation and Beyond } & 137\end{array}$

Chapter 9 Rethinking Partisan and Political Preferences 163

Part III. Conclusion

$\begin{array}{ll}\text { Chapter } 10 \text { Conclusion and Final Remarks } & 181\end{array}$

$\begin{array}{ll}\text { References } & 203\end{array}$

Appendices

Appendix 1. Information letter to the survey respondents 227 
Appendix 3. Political parties' 2014 election manifestos regarding elderly care

Appendix 4. Development of the choice model in the Östergötland Region

Appendix 5. Within-party distributions of answers regarding an optimal distribution of various care providers

Appendix 6. Within-party distributions of answers to various questions discussed 


\section{Acknowledgements}

Now is the time for me to express my appreciation and gratitude to all of the people who helped me, inspired me, and accompanied me in this process.

At Linköping University, my utmost respect and thanks go to my supervisor Sam Willner for his patience, support, and encouragement when I was carrying out this study. Albeit new in the field, we together managed to endeavour ourselves in this incredible academic journey. I would like to thank the Erasmus Mundus Phoenix Programme for providing me the opportunity to pursue my studies in France and Sweden. And I would like to thank the consortium members Patrice Bourdelais, Laurinda Abreu, Ingemar Nordin, and Jan Sundin for their coordination work in the program.

One substantial part of my research is based on the survey. I would like to thank Marika Wenemark for her consultation on the methodology portion, and the pilot survey would not have been possible without assistance from Linköping Municipality: Malin Robertsson was extremely helpful in facilitating the survey design and collection, as well as my better understanding of the Swedish political system and local elderly care practices. I would like to extend my gratitude to Mats Eriksson and Mattias Bly as well for their input during the process. Much appreciation goes to all of the Swedish local politicians who participated in the survey.

Following a six-month study at EHESS in Paris, I returned to LIU, Campus US. John Carstensen, as head of Hälsa och samhälle, offered suggestions and consultation on certain statistical questions. His working morale also inspired me. Many thanks go to Ingemar Nordin and Bengt Richt, who arranged courses in Philosophy and Sociology for students from the program.

It was saddening that the division dissolved one year later, and we all had to move to different corners of the university. Officially registered at IKK, I moved to ISAK to better communicate with my supervisor. Therefore, I would like to extend my thanks to colleagues at ISAK history, for their company at fika time and their encouragement. At IKK, I would like to thank the Study Director, Eva Carlestål, especially for her efforts in carrying out the Gaia Project, where I got many useful suggestions from Karin Axelsson at IEI. 
Academically speaking, I did not have the luxury to access to a research group at LIU, which did create problems in receiving comments and suggestions to improve my writing. Gladly, I was able to be a member of the Normacare network, led by Marta Szebehely, and had the chance to present my research results at two separate times. I deeply appreciate their comments and suggestions, which were of great value for me on my way to publications of journal articles and further development of my $\mathrm{PhD}$ dissertation.

I am also extremely grateful to Swedish National Data (SND) for a scholarship that enabled me to spend one month at the ICPSR Summer Program in Quantitative Methods of Social Research, University of Michigan. This time was a valuable opportunity and an unforgettable part of my $\mathrm{PhD}$ life.

A special thanks to David Feltenius from Umeå University for being my opponent at the final seminar (slutseminariet). His helpful comments and suggestions contributed to a better version of the manuscript.

Going through such an arduous academic journey is not possible without the accompaniment of friends. Many of my Chinese friends have been a part of my life in Sweden: Wei Shuoguo, Wang Daqin, Yuan Kang, Chen Zhe, Chen Lujie, Zhan Ruidian, and many more. We shared hotpots, picnics, badminton games, and movies. I really enjoyed the time we spent together. During my time in Paris, I also got the chance to meet some wonderful and talented friends such as Zhou Mingchao. It was a great experience and I shall never forget it.

Since my current research topic is about Swedish politicians, the Swedish language became an important matter for me. Soon after I arrived in Linköping in 2013, I took night courses of SFI and made plans to conquer my third foreign language. The learning process was not easy. The more I learned Swedish, the more confused I became when proofreading my English manuscript. Doubts, uncertainty, and confusion were a part of the process. In the meantime, I continued my Swedish courses and was able to meet some wonderful classmates in the one-year intensive course. As foreigners in the classroom, we shared not only study tips but also exchanged life experiences about Swedish society. In this regard, I would like to thank my classmates for their company twice per week, and especially Mourin, for sharing information about how to become a medical doctor in Sweden. I would also like to thank Tomas Widholm and Sam Willner for their help in correcting my Swedish grammar. 
I would also like to extend my gratitude to Uncle Liu Peng for his encouragement and support during my pursuit of academic excellence. Thank you for putting faith in me!

Much appreciation also goes to Shi Jingrong, who is more than a French language teacher to me. I sincerely thank you and your husband, Dr. $\mathrm{Li}$, for all your valuable suggestions and encouragement that I have benefited throughout the process.

Last but not least, my thanks and gratitude goes to my dearest parents, who understand me and encouraged me along this process, whether it was my decision to study abroad, or when I changed my career path from a physician to a political scientist. It was through our frequent communication and interaction that it was possible for me to complete this $\mathrm{PhD}$ training. Thanks to you, Mom and Dad, for all your tender feelings and endless support and love for me!

\section{Ming GUO}

August 1, 2017

Linköping 


\section{List of illustrations}

\section{Figures}

Figure 2.1 A flow-chart of marketisation in care provision. 30

Figure 2.2 Elderly care triangle in the welfare state. $\quad 40$

$\begin{array}{ll}\text { Figure 6.1 Answers to Q19 "Profits allowed for private providers". } & 112\end{array}$

$\begin{array}{ll}\text { Figure } 7.1 \text { (i). Freedom, choice, and freedom of choice. } & 121\end{array}$

$\begin{array}{ll}\text { Figure } 7.1 \text { (ii). Freedom, choice, and freedom of choice. } & 121\end{array}$

Figure 7.2 Answers to Q24 "Important to be able to choose between private and public providers".

Figure 7.3 Answers to Q25 "Less resourced elderly might have difficulty

to choose".

Figure 7.4 Answers to Q16 "Competition leads to better care".

Figure 7.5 Answers on Q17 “Competition leads to better efficiency”.

Figure 8.1 Answers to "Financed by tax money" (Q14).

156

Figure 8.2 Answers to "Tax increase for the purpose of care quality" (Q15).

Figure 8.3 Answers to Q29 “Egenavgifter (Individual contribution) to influence care quality and content".

Figure 8.4 Answers to Q31 "Politicians should have insight and control". 


\section{Tables}

Table 2.1 The percent of private care shares from the year 1993 to 2013.

$\begin{array}{ll}\text { Table 2.2 Private care purchasing comparison. } & 24\end{array}$

Table 3.1 Several statistical models that explain welfare attitudes

and outsourcing.

Table 4.1 Survey response rate by gender.

Table 4.2 Response rate $(\%)$ by party affiliation.

Table 4.3 A distribution of municipalities from where survey respondents hail.

Table 4.4 Summary statistics of survey respondents.

Table 5.1 Response rate (\%) for different parties when asked:

Do you want more or less private elderly care in your municipality?

Table 5.2 Preferences for public and private providers in municipal elderly care in percentages of optimal share.

Table 5.3 Regression variables and data source.

Table 5.4 Binary logistic regression of private provider preference.

Table 5.5 Regression analysis of optimum share of various types of care providers.

Table 6.1 Profit-making by comparison.

Table 6.2 Answers to the question regarding whether profits should be allowed. 111

Table 6.3 Questions in negative formulations.

Table 6.4 Response rate for profit-related questions. 
Table 7.1 Evolution of ideal pictures of the market, the state, and civil society for Social Democrats and Moderates.

Table 7.2 Realistic problems perceived by Social Democrats and Moderates over time.

Table 7.3 Responses to "The elderly and their relatives should have a high influence on the quality of elderly care".

Table 7.4 Responses to "The elderly and their relatives should have a high influence on the content of elderly care".

Table 8.1 Swedish laws and legislation on elderly care issues.

Table 8.2 Responses to questions regarding marketisation.

Table 9.1 Market-related survey questions.

Table 9.2 Welfare State-related survey questions.

Table 9.3 Pro-market preference among various political parties.

Table 9.4 Pro-welfare state perceptions among politicians.

168

Table 9.5 Self-reported influence on politicians' marketisation attitude.

176 


\section{Part I: Introduction and Points of Departure}

\section{Chapter 1}

\section{Introduction}

The notion of using the market to provide for welfare services is an important aspect of current welfare politics. The last three decades have witnessed an increasing trend of market solutions that lean towards outsourcing public services such as elderly care, school education, and even health care in many Western countries (Blomqvist 2004; Green-Pedersen 2002); Sweden is no exception. It has been argued that one of the driving forces of this shift is neoliberal ideas such as New Public Management (NPM) (Megginson and Netter 2001).

Public welfare institutions have since embarked on a journey of transformation and reformation. Many new measures have been introduced, such as outsourcing, the introduction of a voucher system, and procurement based on bidding. These uses of market mechanisms to deliver care are among the most significant and contentious ways in which welfare states have been transformed (Gilbert 2002). Parallel to this market development, the ownership structure of the welfare system has also been radically transformed: the former dominance of 
the public sector has, to a large extent, been replaced by a mix of public and mostly for-profit private providers.

Despite a lack of consensus of the exact meaning of $\mathrm{NPM}^{1}$, proponents of this line of thinking often consider it to be 'a management tool for all seasons', which refers to its applicability in all areas of the public sector (Hood 1991; Manning 2001). Much of this style of 'new management' draws upon ideas from two sacred texts (Osborne and Gaebler 1992; Peters and Waterman 1982), which suggested a large-scale transformation from unresponsive, paternalistic and leaden bureaucracies to customer-driven, flexible, quality-oriented and responsive organisations for the future (Clarke and Newman 1997). Their core assumptions are that the public sector is inherently inferior to the market in its capacity to produce costefficient services and that it fails to satisfy citizens' demands (Hood 1991; Kettl 1993). Scholars of NPM believe that the decentralisation of power is necessary for affecting some degree of autonomy in lower-level units, and they recommend lower taxes, increased competition and further privatisation (Young 2000); better efficiency and quality are often used by NPM advocates to suggest a more deregulated yet marketised solution for traditionally state-dominated public services. Under this influence of liberal thinking and NPM, and prompted by the recent economic crisis, many governments began to privatise elements of the public sector, including health care, education and social care.

In the meantime, the role of the market in the welfare state remains a contentious subject. In terms of marketisation, care of the elderly in Sweden has been influenced most by NPM. Many discussions and debates have revolved around how to fit the market into a welfare state and how the market can deliver its promised quality and efficiency without

\footnotetext{
${ }^{1}$ The notion of NPM is more of a theory about management, like a tool that could be used in organising welfare issues such as elderly care. Economy, efficiency and even effectiveness are essential to this discussion, and NPM is often associated with the privatisation of welfare services in Sweden.
} 
detriment to the principles of the welfare state. Different arguments have been voiced in the marketisation debate. One example from the case of Sweden addresses the issue of profit in welfare services, and this theme has received more attention from policymakers in the last few years than ever before. According to Statistics Sweden (2015), as the market has grown, the private welfare sector has become more and more profitable: the average return on equity was $21 \%$ in all three areas (education, health care, and social care) compared to $11 \%$ in the service sector overall in $2013 .^{2}$ In public debates, this issue of profit is often considered to be linked to other counter-marketisation arguments, such as the deterioration of the quality of services or the wasting of taxpayers' money. Therefore, this issue became more and more subject to political debate, which eventually led to an investigation - a state commission, the Reepalu Commission, was designated in 2015 with the mission to investigate and propose regulations to limit profit-taking by private providers in welfare services. After working on the subject, the commission finally recommended the operating profit should be restricted to $7 \%^{3}$, and the commission also offered several other suggestions (SOU 2016; 2017).

Compared with the profit debate, the customer choice model seems to have been less contested: the number of municipalities with customer choice models increased from 45 to 158 from 2010 to 2016 (Socialstyrelsen 2015). As a tool to facilitate market advancement, freedom of choice has been increasingly popular in both theory and practice, and it has been used mostly in education and elderly care. In other words, the increasing implementation of

\footnotetext{
${ }^{2}$ To use school education as an example, in 2016, more than 60,000 children went to schools run by a private stock firm called Academedia. The Swedish Prime Minister Stefan Löfven (Social Democratic Party) then criticised the private company by stating: " 60,000 children and adolescents are for sale". News report based on the following resource: http://www.aftonbladet.se/nyheter/samhalle/article23825753.ab [accessed on November 10, 2016]

${ }^{3}$ The report suggested that the maximum permissible operating income be set to the government borrowing rate applied to the preceding fiscal year with an addition of $7 \%$ multiplied by the net assets from the previous fiscal year (SOU 2016, 26).
} 
choice models could be the result of increasing tolerance from left-wing political parties. Nevertheless, it can be observed that the intensity of policy debates about marketisation has varied. It thus becomes problematic to generalise that left-wing politicians (and their parties) are against marketisation whereas right-wing politicians are in favour of the process. Instead, scrutiny is recommended in order to reveal the nuanced attitude patterns and possible discrepancies among the preferences of individual politicians and their parties.

In Sweden, elderly care was one of the first areas of social services to be transformed into a welfare market since the 1990s. It has been about 25 years since Sweden introduced the elderly care provision to the market. I am interested in examining how local politicians view market-related issues and the differences that remain among political views regarding welfare attitudes, if such differences do exist.

Admittedly, some might argue that the marketisation issue is influenced by political interests and ideology. They could claim that the choice to privatise or marketise is solely determined by political ideology and the issue is only a matter of 'left-right' differences (en vänster/höger-fråga $)^{4}$ such that the leftist parties and politicians are against the shift to the market whereas their right-wing counterparts support the market. This view, however, seems to be problematic or at least inaccurate when considering an overview of the literature in the field.

On the one hand, Pierson $(1994,1996)$ argued that there is no room for partisanship matters in times of austerity, and the popular politics of welfare expansion and the unpopular politics of retrenchment should be distinguished. This new politics of welfare has been

\footnotetext{
${ }^{4}$ Esaiasson and Wängnerud (2016) offers one way of defining left-right issues: concerns proposals over taxation, state coordination of the economy, and social welfare policies. For them, other issues refer to a range of policy matters such as the environment, energy supply, migration and so on.
} 
accepted by many researchers (Busemeyer 2009; Castles 2007; Huber and Stephens 2001; Kittel and Obinger 2003; Zohlnhöfer et al. 2008). For instance, Schneider, Fink, and Tenbücken (2005) studied the changes in the shares held by the government of the dominant provider in three infrastructure sectors (telecommunications, electricity, and aviation sectors) between 1970 and 2000, and they found that partisan differences seen in the 1980s disappeared in the 1990s.

Bel and Fageda (2007) held the view that the ideological orientation of the municipality had no apparent influence on the privatisation decision, which is an idea supported by several other authors, for instance, Boggio (2016); Fernandez, Ryu, and Brudney (2008); Hefetz, Warner, and Eran (2012); Wassenaar, Groot, and Gradus (2013).

On the other hand, there is increasing evidence that suggests otherwise. Some scholars have expressed the view that political partisanship is still of great influence in the development of the welfare state; even in the time of welfare retrenchment, the "end of partisanship' theory seems unlikely (Allan and Scruggs 2004; Boix 1997). To provide a few examples, Bortolotti et al. (2003) presented evidence that the right-wing parties were more likely to privatise, whereas Belke et al. (2007) determined that there were partisan differences in opinions of privatisation in 22 advanced democracies in the 1990s. Obinger et al. (2014) summarised that political parties have continued to significantly shape national privatisation trajectories in line with the classical hypothesis of partisan distinction. Furthermore, Gerber and Lewis (2004) concluded that legislators regularly take positions that diverge significantly from the preferences of the median voter in their districts. For this reason, it is important to remain cautious in assuming that political preference always equals or represents the median voters' ideology. For example, Bhatti, Olsen, and Pedersen (2009); Elinder and Jordahl (2013); Plantinga, De Ridder, and Corra (2011); and Sundell and Lapuente (2012) all argued that ideological attitudes do play an important role in shaping the contracting out of services 
in the privatisation process.

Thus far, it seems rather debatable whether political ideology still matters in welfare state reform issues, and empirical data also present conflicting evidence in support of different claims. One possible explanation for this confusing pattern is that the findings of each study are case-sensitive, which means that different institutional settings might influence the findings. For instance, many previous outsourcing findings are based on U.S. data, which may not be appropriate for generalising and expanding to the situation in Nordic countries where the institutional settings for welfare services are quite different. Nevertheless, more research is needed to reconcile these conflicting theories and extend the current understanding of various empirical studies.

\section{Why local politicians and their political parties?}

Generally speaking, municipalities are viewed as the cornerstones of the Swedish welfare state since many of the country's social policies and public services are planned and carried out at the local level. As important administrative units, municipalities levy local income taxes and are responsible for delivering many welfare services, including elderly care. Moreover, there is a long tradition of municipal studies in Sweden for this reason (see Bäck 2000, 2003; Bäck, Erlingsson and Torbjörn 2015; Birgersson 1975; Johansson, Nilsson, and Strömberg 2001; Montin 1990, 1992; Nilsson 2002; Premfors 1991; Sannerstedt 1981). There are several motives for focusing on politicians and their affiliated political parties in the discussion of welfare state policy formation and politics.

Firstly, it could be argued that political parties and politicians are important to the overall system. Empirical evidence shows that partisanship was significant in the building of a welfare state. Social democratic parties in charge of governments, for instance, have been found to be more likely to increase social spending (Castles 2004), promote broad and 
universal welfare states (Esping-Andersen, 1990; Van Kersbergen, 1995) and support a more redistributive system (Bradley et al., 2003; Iversen and Cusack, 2006). ${ }^{5}$ It has been contended that political parties help shape macroeconomic and welfare policies, which likely have distinctive implications, namely income and employment. Leftist parties are traditionally progovernment and support egalitarian policies while their right-wing counterparts favour market-based solutions and less government intervention (Bobbio 1996; Dahlberg and Lunqvist 2013; Fredriksson et al. 2010; Mair 2007; Sørensen and Bay 2002). Political parties are key actors in pushing marketisation processes by using policy instruments (Spicker 2014, 35-36), and they select policies that promote the interests of social groups that support and are represented by them.

Second, the simple conclusion that the left is against the market and the right supports the market might be inaccurate. There is evidence to support that the left-of-centre parties retrench most and the left has had a greater effect in bruising the welfare state than the right (Green-Pedersen 2001; Ross 2000). The left-wing parties in corporate governance have often supported reforms that expand shareholder rights and the market orientation of firms (Cioffi and Hopner 2006). Some left-wing-dominated municipalities also introduced private alternatives as a consequence of either a strained economy or the influence of a neighoubouring municipality that already had a high share of private elderly care services (Stolt and Winblad 2009). Therefore, the role of the left-wing Social Democratic Party in this debate seems to be a bit more dubious than simple opposition (Green-Pedersen, 2002). To consider the marketisation of elderly care in Sweden, it was the Social Democrats who initiated elderly reform, which then paved the way for further privatisation in the 1990s (Stolt

\footnotetext{
5 "Whether or not the welfare state is understood as the provision of social protection, social services, or social insurances, the overall tendency is that 'more encompassing' generally implies increased redistribution" (Rothstein, Samanni, and Teorell 2012, 7-8).
} 
and Winblad 2009). ${ }^{6}$ Briefly speaking, the role of partisanship tends to be rather complicated. $^{7}$

Third, the distinction between the left and right sides of politics is hazy. As decisions about welfare are not necessarily the basis on which ideologies are formed, some rough generalisations could be made, but these should be treated with a great deal of caution; for instance, different countries might have an entirely different understanding of left and right than Sweden. ${ }^{8}$ Besides, it is clear that various political parties approach markets quite differently, and policies might not always benefit constituents of the right wing in terms of marketisation reform.

Fourth, it can be argued that the left and the right do not necessarily fight over fiscal policy per se (for instance, tax as principal is the financing of Swedish elderly care), but rather they disagree over how to structure particular types of spending or tax breaks to shape the labour market in ways that are favourable to their constituents. In this way, it can be argued that a simple differentiation between the left and right wings based on ideological dogmas should be subject to scrutiny in the current understanding and analysis of policies and attitudes.

\footnotetext{
${ }^{6}$ It is debatable whether this was merely a result of pragmatism or rather a symbol of change in political ideology. The economic crisis in the 1990s is often considered as an important factor that contributed to the adoption of market-oriented solutions (NBHW 2007).

${ }^{7}$ An interesting point can be made here about 'policy reversals' (Cukierman and Tommasi 1998): a social-democratic party has more credibility when it claims that welfare reforms, such as competitive tendering, will improve public service provisions. On the other hand, the same policy proposed by right-wing parties might be less popular because the public often associates these parties with a less government-friendly atttiude and potential cuts of welfare benefits.

${ }^{8}$ It should be noted that Swedish politics are strongly organised around the left-right dimension (e.g. Holmberg and Oscarsson 2004), which adds to the factors that facilitate agreement between citizens and their representatives (Esaiasson and Wängnerud 2016, 190).
} 
Last but not least, policy choices may not necessarily mirror those which the traditional partisanship approaches have emphasised. Even within the same political party, ideologies of individual politicians can still significantly vary on issues such as the profits allowed in elderly care. Certain parties, despite their traditional label of right or left, might converge with other opposing parties without noticing.

\section{Why and how attitudes?}

To begin with, marketisation as a type of public sector reform can be explained by a transformation of preferences and perceptions (Hira and Hira 2000). The importance of elected politicians' views arises not only in the sense that attitudes can reflect the opinions of political representatives per se, but also because these attitudes may be translated into actions such as policymaking. There may be credence to the notion that society reflects the views of the people. ${ }^{9}$

Attitude, according to the Oxford Learner's Dictionary, refers to "the way that you think and feel about somebody/something; the way that you behave towards somebody/something that shows how you think and feel" ${ }^{10}$ In addition, there are many other concepts akin to 'attitude', and Sørensen and Bay (2002) addressed several of these ideas in the discussion of attitude. They explained that while attitudes are normative beliefs about questions and situations (Oskamp 1991; Yankelovich 1991), perceptions rather deal with how individuals observe and interpret reality (Aalberg 2001; Sniderman et al. 1991; Zaller 1992). However, 'perception' actually has a broader meaning: "the way you notice things, especially

\footnotetext{
${ }^{9}$ This is the so-called 'Thomas theorem', formulated by William Isaac Thomas and Dorothy Swaine Thomas: If men define situations as real, they are real in their consequences, which suggests that the indication of a situation causes the action, and actions are affected by subjective perceptions of situations.

${ }^{10} \mathrm{http}: / / \mathrm{www}$. oxfordlearnersdictionaries.com/definition/english/attitude?q=attitude
} 
with the senses; the ability to understand the true nature of something; an idea, a belief or an image you have as a result of how you see or understand something". ${ }^{11}$

In this study, an absolute distinction of attitude and perception is not applied, which was decided for two reasons: most studies that involve welfare attitudes, such as Samhälle Opinion Medier (SOM) surveys, have a tradition of using the word 'attitude'. Moreover, attitude is often assumed to be an umbrella concept, thus it is broader and easier to discuss. Second, the definition offered by the above scholars indicates that perceptions are more linked to how reality influences one's understanding of certain phenomena or issues. In the case of marketisation, despite that not all municipalities have adopted this approach, knowledge of the market and market solutions are seemingly widespread throughout the country, especially among politicians. Consequently, it seems impossible that any politician would have completely independent perceptions of these concepts that are totally uncoloured by their values or other beliefs. Third, as listed above, 'perception' is also interconnected with attitudes due to the rich meaning of the word. Therefore, in this study, perceptions are treated as an appropriate equivalent to attitudes in describing politicians' conceptions and reflections on the issues of the market vis-à-vis the welfare state.

Researchers in the field should be aware of a possible gap between what elected representatives, officers, and fellow workers publicly claim and what they see as legitimate action in the field of policy, which is to say that politicians' view might not always reflect the public views that they are elected to represent. For instance, Lægreid and Christensen (2003), based on two surveys, one of the elite class in the year 2000 and another of average citizens in 2001, found that there are significant differences between the elites and the general population on these issues of privatisation: a great majority among the elites desire more privatisation and less political control; general citizens are more sceptical of privatisation and

\footnotetext{
${ }^{11} \mathrm{http} / /$ www.oxfordlearnersdictionaries.com/definition/english/perception?q=perception
} 
feel more positively toward political control than the elites. The authors argued that these variations in attitudes both among citizens and among elite groups, first of all, can be traced to which political party they sympathise with, but they also noted that there were correlations to sector affiliation, gender, age, and level of education.

There are also concerns of an obscure attitude pattern among the politicians. First, it is possible that elected politicians choose not to express their internalised beliefs about, say, the consequences of outsourcing. Instead, they may adopt pure opportunism, use various decision-making criteria strategically, and therefore make a case which operates to their convenience (Sørensen and Bay 2002). Second, due to the characteristics of the job of politicians, their party affiliation could also prevent them from expressing their individual opinions, especially on sensitive issues such as same-sex marriage, racism, or immigration. Politicians who hold differing views to those supported by the affiliated party might face challenges in their careers. ${ }^{12}$

It is notable that, compared with studies on public attitudes towards the welfare state, studies that directly tackle politicians' preferences are relatively limited (c.f. Edlund and Johansson Sevä 2013; Fredriksson et al. 2010; Giljam, Karlsson and Sundell 2010; Johansson Sevä 2010; Petersen, Houlberg and Christensen 2015; Sörensen and Bay 2002). Some scholars might assume that research that focuses on public attitudes will also inform the study of local politicians. Indeed, there may be some common trends that both groups share. Nevertheless, it should be acknowledged that voters and politicians often have different views in some respects (Ågren, Dahlberg, and Mörk 2007) and the factors that affect the public opinion and politicians' preferences may differ.

\footnotetext{
${ }^{12}$ A party is generally in favour of one unified political image or "trademark", as a lasting and consistent policy position conveys a clear vision to voters and enhances the party's electoral support. This mechanism could potentially lead to the suppression of opposing ideas from within.
} 
Among studies that focus on politicians, it is notable that political preferences have typically been studied on a more aggregated level; for instance, how political parties adopt various market reforms under fiscal stress (Kittel and Obinger 2003; Klitgaard and ElmelundPraestekae 2014) to either align with their political ideology or to meet the needs of the program constituency as median voters (Elinder and Jordahl 2013; Kang and Powell 2010; Pierson 1994, 1996; Zehavi 2012).

To further complicate matters, the importance of attitude remains somewhat moot even when considering outsourcing preferences among local politicians in the Nordic countries. There are contradicting study results about the influence of ideological attitudes on the issues of local privatisation.

For instance, Jensen and Lolle (2013) claimed that political factors such as the 'colour' of local government have no explanatory power regarding local variations in elderly care services. By contrast, Petersen, Houlberg, and Christensen (2015) argued based on Danish data that contracting out seems to be a matter of pragmatism for technical services in practice, whereas social services are contracted out more by conservative parties. Interestingly, both studies are based on data from Denmark, and they reach to two seemingly conflicting conclusions. This kind of dissension, therefore, supplies yet another reason to search for welfare attitude patterns and discuss the importance of ideological orientations in policymaking.

In theory, there are various factors that could influence attitude shaping: self-interest, partisan political ideology, the interests of the represented constituents, or even political opportunism. From a democratic point of view, politicians should be able to represent their constituents and defend their interests. Yet, it is clear that tensions can arise between the representatives and the represented, especially in the process of welfare reform. This 
feedback poses challenges to decision makers both in terms of policymaking and their adherence to the political philosophy for which they stand. In the case of marketisation, to what extent politicians still maintain their party identity and belief system remains to be investigated. It is logical to compare rhetoric with action and contrast reality with ideals; for instance, what politicians claim versus what policies they implement.

Given the complexity of attitude studies on politicians, it is worthwhile to conduct research on this topic. This study, in this sense, could be seen as a step in the process of mapping out attitude patterns and contributes toward a better policymaking process. This dissertation thus explores how Swedish politicians view the problems involved with crafting a market in a welfare state.

\section{Why Sweden?}

Sweden serves a compelling case to analyse welfare politics. Traditionally, the Swedish model is characterised by its universalism, egalitarianism, and generosity, with a high degree of de-commodification of labour (Esping-Andersen, 1990; Huber and Stephens, 2001; Huo et al., 2008; Orloff, 1996).

Under the influence of neoliberal thinking, such as NPM, and prompted by the economic crisis, Sweden, like many other governments, has begun to privatise elements of the public sector, including health care, education, and social care since the 1990s. As shown in detail in the next chapter, many discussions since the dawn of this privatisation have revolved around how to fit the market into a generous welfare state. From an international perspective, Sweden is quite advanced in introducing market mechanisms. ${ }^{13}$ In this sense, analysis of the Swedish case is useful as it might provide a more comprehensive

\footnotetext{
${ }^{13}$ Compared with social care and health care, the school sector is more privatised. For instance, in 2013, the proportion of upper secondary students attending independent upper secondary schools (friskolor in Swedish) was 26\% (Skolverket 2014).
} 
understanding of the dynamic interactions between markets and welfare states. In addition to Nordic countries, other countries that plan to introduce a market into their welfare system could benefit from this discussion of the Swedish case.

\section{Why elderly care?}

Sweden is one of the world's most generous countries when it comes to public spending on elderly care (Huber et al. 2009). The provision of elderly care is viewed as a cornerstone of the Swedish model (Andersson and Kvist 2015; Bergman et al. 2016) and consumes a relatively large amount of public resources. For instance, the cost of elderly care services was estimated to be SEK 90 billion in 2008, which is equivalent to $3 \%$ of the country's GDP (NBHW 2009).

In the elderly care field, the 1990s marked the dawn of a 'marketisation', which was opened up for new providers of service and care (private companies, cooperative associations, insurance companies, and more). Since then, several new market policies have been introduced, such as a customer choice model and a tax deduction on household services and personal care.

Andersson and Kvist (2015) concluded that the Swedish elderly care system has undergone significant changes during the last several decades from a publicly provided, comprehensive, and high-quality service available to all citizens based on need to a more diverse multidimensional system that has been influenced by neoliberal politics such as NPM. Challenges brought about by demographic changes (an ageing population, for instance), labour market reforms, and financial sustainability to fund the system are perceived to influence policymaking and welfare reforms. For policymakers, the means of creating a functional and efficient welfare service system of quality for its citizens has become an 
arduous task. ${ }^{14}$ As a matter of fact, elderly care has been subject to a series of market reforms in recent years: the Local Government Act of 1992, which enabled local municipalities to outsource tax-financed care services to both for-profit and non-profit organisations; Lag om offentlig upphandling (LOU) in 2007 and Lagen om valfrihetssystem (LOV) in 2009 were introduced to regulate the public procurement and the choice system in the public sector respectively, just to name a few examples.

\section{The aim of this thesis:}

This research explores the attitudes of Swedish politicians at the local level. Since social care for the elderly is mainly administered, financed, and organised by each municipality, my focus in this research is on local politicians. It is important to understand what policymakers mean by the marketisation of elderly care and how their opinions are shaped.

For the purpose of this study, I focus on the marketisation of elderly care in Sweden. I am interested in determining how local politicians view market-related issues and the difference that remain among them regarding welfare attitudes, if any. The influential factors of attitude patterns are also examined and discussed. I focus on three key aspects of the process: provider preferences, the financing perspective, and willingness for market regulation. It should be underlined here that I wish to maintain a relatively agnostic position regarding the role of political ideology in politicians' attitude formation as well as various arguments related to marketisation.

\footnotetext{
${ }^{14}$ How to provide elderly care in a welfare state is challenging. Many issues are to be taken into consideration: how to define care or assess needs, the quality follow-up to avoid scandals, fiscal stability to maintain the system, increasing burden of family care, or how to practice freedom of choice for those who are either physically or mentally challenged, just to name a few.
} 


\section{Research questions:}

Below, the primary questions that are to be probed and answered in this research are listed.

1. What are the local politicians' attitudes on marketisation of elderly care?

2. Where do local politicians stand on the various market arguments? To what extent do they differ, and is there some common ground?

3. How can the revealed attitude patterns be explained, and how can they be understood based on the discussions of the market and the welfare state?

My research objective is mainly to explore the attitude pattern of local politicians and expand the existing understanding of possible contributing factors to the shaping of preferences ${ }^{15}$. I approach this undertaking with an attempt to discuss the role that political ideology could potentially play in the related issues. Various arguments that are essential to the marketisation debates are included, and they serve as a starting point to gather responses from the decision makers. Attitude patterns are analysed with an objective to uncover potential evidence that sheds light on the discussion of the New Politics of Welfare, better known as the convergence theory that is discussed in Chapter 3. It should be mentioned that the question of how politicians' preferences are translated into action-policy is not my focus in this research.

\section{Contributions of my research:}

This research contributes to a comprehensive understanding of marketisation from politicians' perspectives. Different aspects of marketisation are probed, some of which have often been neglected. Important factors in shaping political preferences on the market vis-à-vis the welfare state are identified.

\footnotetext{
${ }^{15}$ It is true that many other factors, such as socio-demographic, political democracy or economic development of their municipality can shape the policy outcome.
} 
The methodology used in this specific research could be applied to other welfare studies, such as school education. A discussion of the market in elderly care can also shed light on debates in other fields. For instance, freedom of choice and profit are two common issues, even in school marketisation discussions.

The results of this research offer the ability to think beyond the left-right praxis and bear in mind the nuances and dynamics of political views. As shown later in the analysis, both similarities and differences exist within the left and right political blocs. Some market questions even tend to split up a party (as shown in within-party distributions). In the meantime, this research shows the importance of not being limited to the presumption that different politicians necessarily always think alike. ${ }^{16}$

Last but not least, this research helps to determine whether the Swedish model has already changed or lost its key features in the marketisation process. Suspicions of the market are, to a large extent, linked with the concerns that the welfare state will be undermined. In this regard, my analysis contributes to this discussion by offering another important perspective.

\section{Outline of the thesis:}

This thesis is organised in three parts: in the first part, there are three chapters. Chapter 1 introduces the readers to the research questions and explains why attitude, elderly care, and local politicians are of particular interest to investigate. Chapter 2 serves as a more detailed background of the various subjects involved in the research questions: the concepts of marketisation and its tie with privatisation, and the scope of elderly care in the Swedish

\footnotetext{
${ }^{16}$ One more point that adds to the complexity of studying attitudes is that there might be more than one dimension. For instance, one respondent could, in general, agree to privatise more in other municipalities or on a national level while being opposed to such measures locally.
} 
context and its institutional settings. This chapter continues with a discussion of motivations for marketisation at the local level as well as the critiques it incurs at the same time. These ideas could be thought of as a review of both for- and against-market arguments. Meanwhile, to be more case specific, the development of the market in the Swedish elderly care system is presented, which demonstrates, among other ideas, how various care providers compete with each other in this welfare sector.

Chapter 3 outlines the theoretical approach through which attitudes of the welfare system and market preferences can be studied and understood. Various ideas, including both individual characteristics and contextual factors, are examined in regard to the shaping of attitudes. Political orientation and political ideology are of specific relevance to the study objects of this research. Therefore, the theoretical discussion of ideology and the left-right praxis is an important aspect of this chapter. Furthermore, based on contentious evidence about the role that political ideology could have in affecting attitude formation and policymaking, the convergence thesis proposed by Pierson is reviewed and contrasted with the divergence or the difference thesis.

Part II includes five chapters and is where the research findings (mostly survey results) are presented. This part is where I engage with analyses and discussions based on the data and the literature. Due marketisation being a rather complicated process that covers many different areas, this part is organised based on several dimensions of marketisation: outsourcing preferences (Chapter 5), tensions between ownership and profit issues (Chapter 6), and expected outcomes such as freedom of choice (Chapter 7). As one easily neglected part of marketisation debates, the financing and regulation of the market are also included in this part in Chapter 8. 
The structures of these chapters are quite similar: Firstly, I introduce the specific question in mind and present background information. Then, I proceed with survey questions and results analyses, followed by a discussion on the partisan differences or similarities that are detected.

Chapter 9 highlights some findings that are not directly addressed in previous chapters; for instance, whether there is a within-bloc difference regarding marketisation attitudes in the left bloc or the centre-right bloc. The findings are organised using an index of welfare state consolidation-related questions and another index of pro-market questions. The purpose of this organisation is to highlight the differences and similarities found on an aggregate level; namely, to what extent do the leftist parties differ from their centre-right counterparts in their perceptions of the market vis-à-vis the welfare state in a welfare sector such as elderly care. This can be considered as an attempt to address the theoretical tensions between the convergence and divergence theories listed in Chapter 3. In this chapter, politicians' answers to open questions are also analysed.

In Chapter 10, the last part of this thesis, I summarise the entire research findings and comment on the left-right praxis that is used in studying marketization. Additionally, I discuss some potential implications of this study. Although it is not my intention to refute the convergence theory (mainly because of the data available), the findings of this research contribute to a better understanding of the ways certain ideas, including political ideology, interact in this post-austerity era. It is also my intention to remind readers that an overly simplistic conclusion, such as "the left opposes the market and the right supports the market" does have its limitations and may not be true at all times. The limitations of this study, as well as future study directions, are finally discussed. 


\section{Chapter 2}

\section{Background:}

\section{The Marketisation of Swedish Elderly Care}

Marketisation is a subject suitable for both multidisciplinary and interdisciplinary studies. There are different ways to study this process, for instance, by examining its economic input and output ${ }^{17}$, organisational structures, individuals' satisfaction with the services, their attitudes about the market, and so on.

The previous chapter explained the choice of elderly care as an example for investigation and also why Sweden was chosen as a case study. This chapter commences with a brief review of market development in the Swedish elderly care system to acquaint readers with the context of this study. Next, the concept of marketisation is introduced, with a

\footnotetext{
${ }^{17}$ Several economic explanations that could account for the welfare state development could be found in Marxist theories, industrialisation theories, Keynesian economics, postindustrialism, post-Fordism, and economic globalisation.
} 
discussion of its usage together with privatisation. Another part of this chapter outlines several social, economic, political, and demographic motivations that are potentially linked to the marketisation process. These motivations are considered as 'good reasons' to implement the market mechanism in a welfare state, yet they have been faced with critiques and scepticism. These opposing views, often summarised as the 'against' argument, are listed in this chapter. The last part of this chapter defines the scope of elderly care that is studied in the Swedish case together with a few words on the organisation of the case system. This section provides a clearer picture of the welfare sector that is included in this research, which may be beneficial for comparative purposes.

\section{A brief review of market development in elderly care}

Historically, the Swedish elderly care system developed mainly through three stages: a) Between 1918 and 1949, local elderly care was limited to care in homes for senior citizens; b) From 1950 to 1990, home help services were introduced and developed; c) From 1990 and onwards, the responsibility for home-based nursing has been transferred to the municipalities, and these have resulted in a higher degree of choice for organising elderly care (Edebalk 2010).

In the Swedish case, marketisation in elderly care field began in the 1990s. The market was then opened up for new providers of service and care, such as private companies, co-operative associations, and insurance companies. Regarding motivations, costs reduction and improved service quality, among other aspect, are often cited. The National Board of Health and Welfare (NBHW, 2007) pointed out two major reasons for elderly care reform in 1992: the economic recession in the 1990s and the technological development in health and care, which made outpatient and home-based care possible and available. However, it should also be noted that this opening was used primarily as a cost containment strategy through 
market competition, which formed the NPM reforms since the second half of the 1980s (Blomqvist 2004). ${ }^{18}$

From a legislative perspective, the Local Government Act of 1992 enabled local municipalities to outsource the provision of tax-financed care services to non-governmental actors - both for-profit and non-profit organisations. ${ }^{19}$ Since then, an increasing share of publicly financed elderly care has been run by private providers (Szebehely 2011). Over the years since then, the process of privatisation has continued. Moreover, it can be argued that marketisation proceeded in two ways: one through municipalities outsourcing to private and public providers on the service-delivery level following LOU, and the other through users' active choices according to LOV.

As shown in Table 2.1, in terms of the market development, the proportion of home care services and residential care provided by the private sector has increased from $4 \%$ and $5 \%$ in 1993 to $24 \%$ and $21 \%$ in 2013, respectively (Erlandsson et al. 2013; NBHW 2014). ${ }^{20}$ According to NBHW (2004), 90\% of private entrepreneurs in 2003 were for-profit associations. Simultaneously, in social services in general, the percentage of elderly care that was purchased by local municipalities increased from $11.6 \%$ to $17.4 \%$, with for-profit companies as the occupying the largest share (Table 2.2).

\footnotetext{
${ }^{18}$ It is evident that one objective of this reform was to increase the productivity of hospitals and initiate non-institutionalised social care rather than hospitalisation for the elderly, which served to cut costs and improve efficiency. Therefore, this reform could be viewed as significantly influenced by NPM.

${ }^{19}$ The expectations were mostly about increased efficiency and quality, as NPM scholars proposed.

${ }^{20}$ Of course, it should be noted that there are differences among various municipalities, such as geographical size, population, local economy, labour market, tax rate, and so on, let alone the dominating political majority in each place.
} 
The market development has been more heterogeneous and uneven among Swedish municipalities: In 2013, nearly two-thirds of all municipalities had less than $5 \%$ or none of their residential living or home care services provided by the private sector, while around 20 municipalities had more than $50 \%$ of their institutional housing provided privately (NBHW 2014).

Table 2.1 The percent of private care shares from the year 1993 to 2013.

\begin{tabular}{lllll}
\hline & 1993 & 2000 & 2010 & 2013 \\
\hline $\begin{array}{l}\text { Home help (share of service hours provided } \\
\text { by private providers) }\end{array}$ & 4 & 7 & 19 & 24 \\
& 5 & 12 & 19 & 21 \\
\hline
\end{tabular}

Source: Erlandsson et al. (2013); NBHW (2014); SOU (2016).

Table 2.2 Private care purchasing comparison.

$2006(\%)$ $2015(\%)$

\begin{tabular}{lcc}
\hline $\begin{array}{l}\text { Local government purchases of care services from } \\
\text { private providers }\end{array}$ & 11.6 & 17.4 \\
$\begin{array}{l}\text { of which from private companies } \\
\text { of which from non-profit providers }\end{array}$ & 9.5 & 15.7 \\
\hline
\end{tabular}

Source: SOU (2016) Ordning och reda i välfärden.

It should be remarked that polarisation within the private sector also takes place. For instance, SOU $(2016,207)$ stated that there are 4,600 companies that obtained the majority of their income (70\% and more) from public financing, and many are small businesses. At the 
same time, larger companies have increasingly dominated the market, which increases the risk of market monopoly. ${ }^{21}$

Compared with other advanced welfare states, there are some characteristics of elderly care privatisation that are particular to Sweden. First, the private sector is at present largely dominated by a few large for-profit companies, and nearly $96 \%$ of the workforce in the private home care sector and $85 \%$ in the private residential living sector for the elderly were employed by for-profit companies in 2010 (Szebehely 2011). Second, the share of nonprofit organisations is quite modest in the provision of elderly care services, accounting for $3 \%$ of the workforce (Johansson 2011) and mainly in-home care services (Konkurrensverket 2013). ${ }^{22}$ Third, there is a noticeable difference among private providers in terms of their size, number of employees, and profits made, with several companies dominating the market. ${ }^{23}$ Fourth, the development of the market in elderly care has varied among municipalities. ${ }^{24}$ In 2013, roughly two-thirds of all municipalities had no or less than $5 \%$ of their residential living or home care services provided by the private sector, while around 20 municipalities had more than $50 \%$ of their institutional housing provided privately (NBHW 2014). Moreover, the extent of privatisation is greater in densely populated municipalities in the

21 A development towards larger companies could have both positive and negative consequences. It means that a company can benefit from an expanded scale of economy to increase efficiency. It can also lead to decreased competition, lack of diversity, and fewer choices for users.

22 The reason for the relatively small share of elderly care provided by the non-profit sector is elusive. One explanation could be that Sweden has a strong public sector, so activities from non-profit organisations have been performed and organised in ways such as volunteering (Konkurrensverket 2013).

${ }^{23}$ The SOU $(2016,172)$ pointed out that the average yearly turnover for private companies is about 2.7 million SEK. At page 177, it listed the six largest corporations in social care services: Attentdo, Humana, Ambea, Frösunda, Team Olivia, and Förenade Care. Data about these private companies are also presented in the book by Werne and Unsgaard (2014).

${ }^{24}$ In this sense, it can be argued that home service is a local market (Kommunernas valfrihetssystem-med fokus på hemtjänst Slutrapport, Konkurrensverket. 2013). 
Stockholm area, while private providers of elderly care are far less numerous in small and sparsely populated municipalities (SOU 2016, 179). Irrespective of privatisation, Swedish elderly care is still largely financed by taxes (NBHW 2007) ${ }^{25}$, which also sets Sweden apart from systems where individuals must make out-of-pocket payments to access care.

\section{The concept of marketisation}

A clear definition of marketisation and its scope is necessary before delving into the analysis. In this research, marketisation refers to government measures that authorise, support, or enforce the introduction of markets, the creation of relationships between buyers and sellers, and the use of market mechanisms to allocate care (Brennan et al. 2012). It includes different forms, such as contracting service delivery to private providers (both for-profit and non-profit providers), financing users to be able to purchase services in the market, mandating insurance against social risks (such as the need for long-term care), and providing cash allowances or tax concessions to enable the employment of carers in the home. ${ }^{26}$

Marketisation, as a means of welfare state reform ${ }^{27}$, entails a question of political values and perceived consequences. Marketisation, together with decentralisation, NPM reforms, and output orientation (as opposed to procedural control $)^{28}$, have in many ways

\footnotetext{
${ }^{25}$ About $82-85 \%$ of the total cost is covered by local tax, $10 \%$ by national tax, and $5-6 \%$ by the elderly themselves. This was a more general description of funding for elderly care in Sweden. To our knowledge, more detailed data on municipality level is not available yet.

${ }^{26}$ Stolt and Winblad (2009) argued that privatisation is synonymous with marketisation or contracting out tax-funded public services to both for-profit and non-profit alternative providers. Nevertheless, a more holistic view is deemed necessary for the purpose of analysis.

${ }^{27}$ Welfare state reform is a "generic term to refer to political interventions that are meant to adjust existing welfare arrangements to changing social (e.g. ageing) and economic (e.g. globalisation) conditions, raining from the incremental fine-tuning and correction of policy instruments to radical measure such as the abolition of old social programmes and the introduction of new ones" (Caramani 2014).

${ }^{28}$ Ideas about deregulation, competition, and public-sector reforms are exported to the world from their Anglo-American origins through orgasmatrons such as the Organisation for
} 
resulted in more freedom for municipalities and contributed to increasing variation across municipalities (Bergmark and Palme 2003; Gustafsson 1987; Pollitt and Bouckaert 2004). These reforms have also profoundly affected the Swedish welfare state and Sweden's municipalities (Johansson Sevä 2009). A shift towards a more output-oriented public sector was noticeable at all levels of government. Public management, therefore, has striven to be effective and business-like (Gilljam, Karlsson, and Sundell 2010; Rönnberg, Strandberg and Winblad 2013).

Marketisation could also be seen as one wave in the general development of welfare pluralism ${ }^{29}$, which involves turning to the greater use of markets and voluntary and informal sectors. Brenton (1985), Mishra (1990), and Johnson (1999) described the trends towards greater pluralism and remarked that the market mechanism could play an increasingly important role in the welfare state.

Another concept that is closely linked with marketisation is privatisation. Historically, the idea of privatisation was first exported from the UK around the 1980s (Donahue 1989). Despite that the US is often used as a prime example of the privatised market, there was arguably quite little to truly privatise in the first place. ${ }^{30}$ Nevertheless, the process soon began to spread through many developed countries in the following decades.

In financing and delivery, privatisation refers to the distribution of power between public and private actors and the distribution of care expenditures between the state and its

Economic Co-operation and Development (OECD), the International Monetary Fund (IFM), the World Bank, and so on (Olsen and Peters 1996).

${ }^{29}$ Spiker (2014) defined welfare pluralism as both the situation in which services are provided from many different sources and the argument that they should be.

${ }^{30}$ Donahue $(1989,6)$ argued that America has never had very many government enterprises and assets. He even suggested that there are two types of privatisation: one that happens in the US and another that occurs elsewhere. 
citizens, as well as different forms of 'hidden' privatisation (Streeck and Thelen 2005). Stolt and Winblad (2009) reasoned that privatisation is synonymous to marketisation or contracting out tax-funded public services to both for-profit and non-profit alternative providers. In practice, it is common to use privatisation as a synonym to marketisation. Nevertheless, one difference between these two concepts lies in there are more dimensions to marketisation than privatisation, in which the focus is primarily on outsourcing. Instead, marketisation covers provisions, finance, and even regulations (Blomqvist and Rothstein 2000; Powell and Miller 2014).

In this regard, a simple use of outsourcing as an equivalent to marketisation should be avoided, as it constitutes merely one dimension of the market development. It should be mentioned that there are already several studies that have addressed contracting, market competition, and quality differences (Bel and Rosell 2016; Bergman et al.2016; Comondore et al. 2009; Fredriksson et al. 2010; Lien and Pettersen 2004; Petersen, Houlberg, and Christensen 2015; Sørensen and Bay 2002).

Due to the rich content of marketisation, I argue that a holistic view is necessary for examining political preference for the market. In this way, it is possible to avoid the neglect of other important aspects of the process. In the Swedish context, public financing of the care system forms the basis of the welfare $\operatorname{state}^{31}$, which suggests another reason to cover the financial aspect of welfare politics vis-à-vis the market development. ${ }^{32}$ Market regulation, which is commonly viewed as a hindrance for market development, is another dimension that should be addressed while exploring the marketisation process.

\footnotetext{
${ }^{31}$ It should be noted that in the Swedish context, elderly care is mainly financed by taxes. Elderly people pay a slight amount of costs (5-6\%), while $82-85 \%$ of the total costs are covered by local taxes. National taxes cover about 10\%, c.f. (NBHW 2007).

${ }^{32}$ More general questions which could be asked are: what kind of services can be privatised, to what extent, and at what cost? This is tightly connected to the understanding of what the market can and cannot achieve, as well as the conditions to make a market work.
} 
A flowchart (Figure 2.1) is presented here, which outlines some basic components of marketisation. As the input of the care system, funding is important as it preserves the foundation for services to be produced, maintains the labour force in the system, and ensures other resources (such as facilities for the elderly) are available. In the Swedish case, taxes are the primary source of financing. The second step listed here essentially displays that various care providers then produce products or delivery services. For municipalities, which have both private and public providers, a competition mechanism is often expected to lead to better efficiency and higher quality. The third step concerns quality, a concept that can be quite elusive to define. ${ }^{33}$ Nevertheless, the point here is that all politicians might agree that quality should be of great importance for the care users and the resources spent. For care providers, quality should also be their goal through which competition occurs, and they are often evaluated by this standard.

Input and output are two ends of the care service system, as shown in Figure 2.1. These two receive different focuses from different politicians. It can be observed that the Moderates, for instance, are more prone to emphasise how quality should be the priority, whereas the left-leaning parties highlight the fact that a lack of resources in the care system, such as a long waiting list to receive a place in the nursing home, should be addressed as a priority.

\footnotetext{
${ }^{33}$ This point is elaborated later in Chapter 7.
} 
Figure 2.1 A flow-chart of marketisation in care provision.

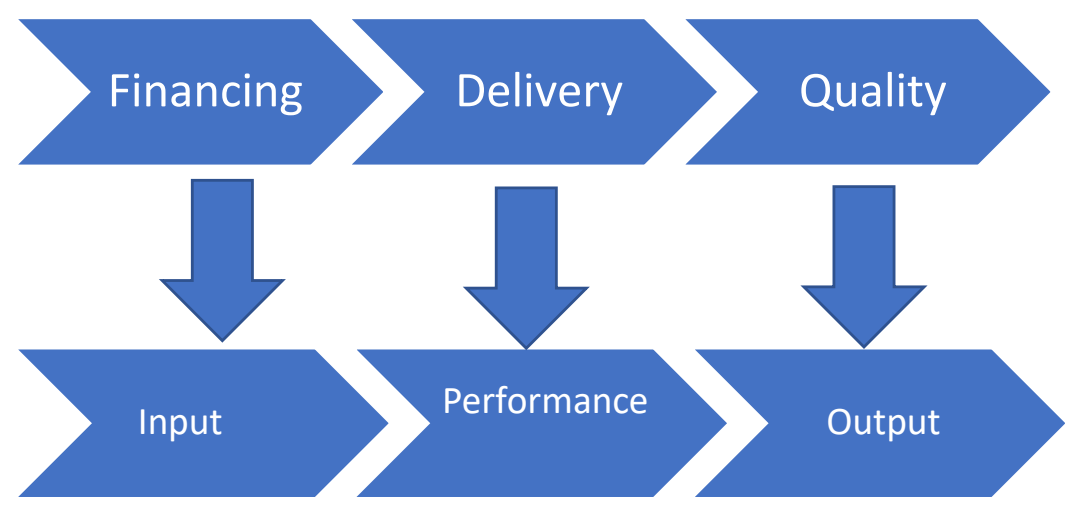

It is no doubt that input and output are interconnected. It is hardly possible to imagine a successful outcome of the care system, like the satisfaction of the care users, could derive from a low level of resources invested. Furthermore, output could also influence input through a feedback mechanism.

The emphasis here is that for policymakers, it is important to consider the entire picture and then discuss and negotiate in the process of policymaking. If two party politicians never directly engage with some issues, the democratic discussion process is much less likely to be productive. As shown in Figure 2.2, there are various stakeholders involved in the welfare quasi-market. Therefore, a point where all different parties' interests can be best aligned is likely to be the most productive and efficient. ${ }^{34}$

\footnotetext{
${ }^{34}$ In Game theory, Nash equilibrium (NE) is often used to help analyse the outcome of the strategic interaction of several players. In the elderly care case, it is therefore tempting to argue that such an NE point, if exists, could bring up the best outcome. So far, this is only an idea, which could be further pursued by collaborations with the economists. Nevertheless, it is fair to say that an agreement or a consensus between these different actors involved in the care is both necessary and needs to be achieved.
} 


\section{Driving forces of marketisation}

There are various reasons to prompt an introduction of the market into the traditional welfare state: demographic, political, and economic changes. ${ }^{35}$ Several driving forces to privatisation and marketisation are identified. For instance, Bel and Fageda (2017), after summarising 32 scholarly empirical studies, described four factors that significantly influence local privatisation: fiscal restrictions, economic efficiency, political interests, and ideological attitudes. The first two are about financial- and cost-related factors, whereas the others are more politically based.

In this part, I follow a similar line to discuss motivations for local privatisation, with a focus on political ideology and factors that are more pertinent to the Swedish case (rather than the US). It should be mentioned that there could be other motivations in the marketisation process, such as the desire to increase learning through different types of providers, the opportunity to gain more control over resources, a goal to increase user satisfaction, a way to motivate employees, and a wish to reduce the scope of the state (GreenPedersen, 2002; Peters, 1997; Stolt and Winblad 2009).

\section{1) Demographic change: increasing needs means increasing solutions}

Globally speaking, the proportion of the world's population over 60 years old will double from $11 \%$ to $22 \%$ between 2015 and 2050 , based on estimations from WHO. ${ }^{36}$ The number of people aged 60 years and over is expected to increase from 605 million to 2 billion over the same period. The same ageing process is also predicted to occur in Sweden. According to Statistics Sweden (2015), the elderly population (65 years or older) in Sweden reached $18.45 \%$

\footnotetext{
${ }^{35}$ Even elderly people as an interest group could be of importance in this market reform. ${ }^{36}$ Source: http://www.who.int/features/factfiles/ageing/ageing_facts/en/index.html Accessed on August 1, 2015.
} 
in 2010 and is estimated to reach to $20 \%$ by 2020 and $23.26 \%$ by $2050 .{ }^{37}$ For this reason, it has become paramount to address the increasing care needs of its ageing population. Many seniors will require long-term care, including home-based nursing or community, residential, and hospital-based care. Stolt and Winblad (2009) contended that municipalities with a large part of their elderly population eligible for home-help services or special housing accommodations may be more inclined toward privatisation since there is a great demand and high costs. ${ }^{38}$

\section{2) Efficiency with reduced costs (Fiscal restrictions and costs reduction)}

It is often expected that in times of a poor economy, local municipalities are likely to take austerity ${ }^{39}$ measurements to try to reduce costs (Bel and Fageda 2007, 2010; Boggio 2016; Geys and Sørensen, 2016). These arguments used by proponents of initiating the marketisation process present the view that market competition would lead to reduced costs and improved quality, in addition to increased freedom of choice for care users (SOU 2016, 306). This logic is also present in local outsourcing with non-profit organisations, which are characterised by their service accountability, professionalism, and community legitimacy, for instance (Feiock and Jang 2009). The real effects are, however, debatable (Meagher and Szebehely 2013).

37 Source: Statistics Sweden (Statistiska centralbyrån, SCB). 2015. Sveriges framtida befolkning 2015-2060 (The future population of Sweden 2015-2060). Available at: http://www.scb.se/Statistik/_Publikationer/BE0401_2015I60_BR_BE51BR1502.pdf

${ }^{38}$ Politicians are also in favour of more alternatives to public service production due to the inability to meet all of these care demands. Nevertheless, Stolt also mentioned the possibility that the elderly may reflect a political standpoint in opposition to private alternatives to which they are not accustomed.

39 The usage of 'austerity' is connected with slow economic growth, rising deficits, high levels of unemployment, and so on. There is no visible fiscal austerity in Sweden now. The terminology is however used in literature and also in Swedish discussions; see for instance, Lindbom (2016). 
Still, some new studies show that fiscal stress is not necessarily linked to more contracting out, which indicates that privatisation is done more when the economy is strong (Bhatti, Olsen, and Pedersen 2009; Foged and Aaskoven 2017). With these new studies in mind, it is clear that more research is needed.

\section{3) Political ideology and attitudes}

The importance of ideological attitudes was at first claimed to be irrelevant in the explanations of local privatisation decisions. For instance, Bel and Fageda (2007) demonstrated that the ideological orientation of the municipality had no apparent influence on the privatisation decision. Many studies thereafter seemed to confirm the effect that ideological attitudes have had no influence on the contracting out of services, c.f. Bel, Fageda, and Mur (2010); Boggio (2016); Hefetz, Warner, and Eran (2012); Wassenaar, Groot, and Gradus (2013).

However, the role that attitude could play in privatisation has been brought to attention in recent studies. Many recent analyses have questioned the validity of the statement that privatisation is only about pragmatism and have argued that ideology might also play an important role, especially in welfare services; see, for example, Bhatti, Olsen, and Pedersen (2009); Plantinga, De Ridder, and Corra (2011). Soresen and Bay (2002), based on data about local Norwegian politicians, showed that perceptions of elected politicians affect their own preferences for tendering in the case of residential care for the elderly and hospital services. Meanwhile, party affiliation, interest group background, and economic situation influence the perceptions and organisational preferences of elected politicians. Bhatti, Olsen, and Pedersen (2009) disputed the hypothesis that ideology had no significant effect on contracting out and instead suggested that ideology does indeed seem to matter.

Furthermore, a distinction between 'technical services' (such as waste management and roads) and 'social services' (such as care of the elderly, primary schools, and other public 
welfare-related services) is needed for analysing the effects of marketisation. For instance, Petersen et al. (2015) utilised a panel dataset that covered municipal spending on services in all 98 Danish municipalities to examine the importance of ideology, fiscal pressure, and size for the contracting out of technical and social services. The authors found that the frequency of contracting out is shaped by ideology in social services but not in technical services, which indicates that social services are the contemporary ideological battlefield of privatisation. Their analysis further revealed that economically prosperous municipalities are more likely to contract out social services, whereas the contracting out of technical services is not influenced by economic affluence. Additionally, it has been shown that larger municipalities contract out more in technical services but less in social services, which demonstrates that the size effect is contingent on the transaction cost characteristics of the service. Bel and Fageda (2017) therefore argued that by differentiating between technical and social services, these studies introduced a distinction that may prove useful in future research.

\section{Debates about marketisation}

Many issues concerning marketisation are still subject to debate. This section covers three aspects of the general debate on marketisation: the first discusses criticism regarding the expected outcomes made by NPM about marketisation, such as reduced costs, improved efficiency, and better quality; the second part briefly mentions the quasi-market concept and one important precondition in the market scenario, namely, fair competition; and the third part highlights critiques of the consequences brought about by marketisation.

\section{1) Suspicions of the expected outcome}

From Adam Smith, a market has been described as an important mechanism to best achieve goals by using its invisible hand to mediate needs and resources. Following this line of thinking, many NPM scholars suggested that competition in the market would overcome the 
limits of the government and achieve the perceived outcomes, such as reduced costs, improved quality, and increased freedom of choice for care users (Blomqvist 2004; Hood 1991; Lundsgaard 2002; Manning 2001; Osborne and Gaebler 1992; Savas 2000). ${ }^{40}$ Competition between for-profit providers could also lead to increased efficiency and product development innovations, which is essential to the economic development of society in the long term (Mueller 2015).

Nevertheless, critics against these claims do exist. To begin with, some scholars have raised concerns about marketisation in terms of whether it could deliver the promised gains, such as reduced costs, improved efficiency, or better quality. Regarding reduced costs, one source suggested an estimated number around 10-30\% (Sørensen and Bay 2002). However, in the Swedish case, the Swedish Agency for Public Management (Statskontoret) examined the impact of LOV on costs and the efficiency of using LOV in elderly care and found no evidence of cost reduction in the local authorities that had implemented the LOV Act. Instead, there was weak evidence that pointed toward cost increases in those municipalities that were at early stages of implementing the Act. ${ }^{41}$ Nevertheless, in the elderly care field, Meagher and Szebehely (2013) concluded that there was no evidence that showed lowered transaction $\operatorname{costs}^{42}$ or improved efficiency.

\footnotetext{
${ }^{40}$ It should be mentioned that Hood (1991) invented the term NPM itself, and the basic principles of NPM can be described best when split into seven different aspects: management, performance standards, output controls, decentralisation, competition, private-sector management, and cost reduction. As is later discussed, many of these principles are often raised in the marketisation debates.

${ }^{41}$ See, for instance, a report from Statskontoret in 2012 on how the LOV has influenced costs and efficiency in municipalities. Accessed on October 1, 2015: http://www.statskontoret.se/globalassets/publikationer/2012/201215.pdf

42 Transaction costs include administration of contracts, information compilation and dissemination, quality follow-up, and more.
} 
Another important argument forwarded by NPM is that market competition produces improved efficiency. ${ }^{43}$ The underpinned assumption in this argument is that the public sector is inferior to the market in its capacity to produce cost-efficient services, owing to the lack of competition and incentives for cost reduction (Hood 1991). Scholars of NPM have reasoned that government bureaucracy should be minimised to improve efficiency and the decentralisation of power is necessary for empowering lower-level units to achieve a certain level of autonomy; they recommended lower taxes, increased competition, and further privatisation.

Faced with critiques that public services are less efficient than private services, Spicker (2014) pinpointed common mistakes of confusing cost-effectiveness for efficiency. He contended that public services are meant to be cost-effective and not efficient. He claimed that, in reality, there is often a trade-off between efficiency and cost-effectiveness: efficiency relates to reducing the wastage of resources and making the best use of tax money, which does not necessarily guarantee a positive distributional effect among the vulnerable social groups; cost-effectiveness, on the other hand, compares and focuses on the relative costs and the outcomes and effects.

The quality of service, for instance, is another important issue to debate in a market context. ${ }^{44}$ Politicians who favour the market agree that market competition increases quality precisely as mentioned above. In brief, whether market competition can lead to improved

\footnotetext{
${ }^{43}$ In Swedish, kostnadseffektivitet is often used with a focus on how much work is done based on the money invested. The SOU $(2016,255)$ explained that efficiency studies are relatively rare because it is methodologically difficult to design and implement them. The difficulty rests in, among other aspects, that there is often a lack of knowledge about conditions before the reform was implemented and a lack of control groups, which makes it possible to isolate the impact of various reforms.

${ }^{44}$ I did not enquire too much about quality in this survey, and this aspect could be expanded in future studies.
} 
quality is non-conclusive, as research results are rather contentious (Meagher and Szebehely 2013). While neoliberal politicians use increasing quality as an argument for their policy development, their opponents tend to adhere to evidence that exemplifies the quality differences between various service providers. For instance, Comondore et al. (2009), based on their systematic review and meta-analysis, concluded that on average, not-for-profit nursing homes deliver higher quality care than for-profit nursing homes. Stolt et al. (2011) found that in the Swedish context, there indeed existed significant quality differences: private care providers in Sweden seemed to emphasise service aspects rather than structural prerequisites for care (such as the number of employees per resident).

\section{2) A quasi-market?}

It can be argued that markets in health care, education, and social care may not match economic models of perfect competition. Therefore, the welfare domain is not a conventional market (Välfärdsområdet är ingen vanlig marknad in Swedish). ${ }^{45}$ Instead, it is fair to use the term 'quasi-market' when discussing welfare markets. One important study in the field was conducted by Le Grand. In their book, Bartlett and Le Grand $(1993,10)$ asserted that welfare quasi-markets differ from conventional markets in at least one of three ways: non-profit organisations compete for public contracts, sometimes in competition with for-profit organisations; consumer purchasing power either centralised in a single purchasing agency or allocated to users in the form of vouchers rather than cash; and the consumers represented in the markets by agents instead of operating by themselves.

\footnotetext{
${ }^{45}$ In the context of Swedish elderly care, nursing homes are associated more with health care compared with home services. Therefore, it is likely to expect that privatisation receives less resistance in the home service area. The development of the market in the Swedish elderly care is reviewed in Chapter 2.
} 
Meanwhile, both policymakers and service providers should therefore be aware that a perfect market scenario might only exist in theory. Bartlett and Le Grand (1993) concluded that certain conditions need to be met so that quasi-markets in welfare services can achieve the goals of improved efficiency, responsiveness, choice, and equity. For instance, there should be many purchasers and many providers in terms of the market structure; both providers and purchasers should have access to accurate and independent information; transactions costs and uncertainty should be kept to a minimum. Regarding motivation, they argued that financial considerations should be at least considered by providers and user interests by purchasers. Nevertheless, there should be no incentive for providers or purchasers to discriminate against users and choose to accommodate those who are least expensive in terms of production costs.

It is understandable that all efforts in the marketisation process are intended to imitate an ideal market mechanism. In order to achieve efficiency and quality, fair competition is one of the most important preconditions. Two points can be made here: The first point is that private providers are not synonymous with efficiency. Without meeting some of the abovementioned conditions, such as competition and market tests, it is unlikely to expect that private providers would effectively pursue higher efficiency or quality. Another point is that, through market competition, public providers are also given real opportunities and incentives to improve their services. Theoretically speaking, fair market competition is beneficial to all types of providers and service users. Fair competition, along with other predictions as mentioned above, therefore, should be considered when applying the quasi-market in the welfare state and the evaluation later on. 


\section{3) Potential consequences of marketisation}

Opponents of marketisation policies have highlighted the limits of the market solution and its role in the erosion of both the capacity and power of the public, which can be considered as a detriment of citizens (Leys 2003; Suleiman 2003). There is a risk that adverse selection effects might occur: clients with sophisticated needs or simply in need of more care time could be disfavoured; instead, clients who are more lucrative for businesses are favoured (Sørensen and Bay 2002).

Sceptics of the market solution claim that marketisation would undermine and fundamentally change the welfare state by limiting both the size and nature of the extensive welfare state (Bergmark et al. 2000; Blomqvist 2004; Brennan et al. 2012; Clayton and Pontussson 1998; Huber and Stephens 2001), which could in turn undermine traditional democratic values (Boston 1991; Christensen 2001; Fredrickson 1996). Blomqvist and Rothstein (2000), Blomqvist (2004), and SOU (2016) all mentioned the segregation effect that the choice model could have. ${ }^{46}$ Even market failure is likely and harmful to the society and could endanger the users in the market. ${ }^{47}$

\section{Defining elderly care services}

Elderly care services might vary across countries in terms of content and organisation forms. As far as the Swedish case is concerned, the elderly care in this study is about nonhospitalised elderly care, which includes home-help services and institutionalised residential

${ }^{46}$ Of course, more critics are concentrated in the education field. Still, worsened working conditions and lack of human contacts with the elderly are often noted among critiques in the debates of marketisation in general.

${ }^{47}$ In school education, for instance, JB Education, one of Sweden's largest operators of publicly funded and privately managed free schools, declared bankruptcy in June 2013. This news received a lot of attention both domestically and internationally; see, for instance the Guardian's report: https://www.theguardian.com/education/2013/may/31/free-schoolseducation (Accessed on April 1, 2016). 
care (nursing homes or special housing for the elderly). In Sweden, home-care services include help with household tasks like cleaning, shopping, laundry, and cooking (or the delivery of ready-made food), as well as personal care such as bathing, dressing, and moving around. Basic medical tasks can be included, for example, insulin injections or the treatment of wounds. Emotional and social support is also regarded as an important aspect of the service. The level of home care can vary from help once a month to six or more visits per day (over 24 hours). ${ }^{48}$

\section{Figure 2.2 Elderly care triangle in the welfare state.}

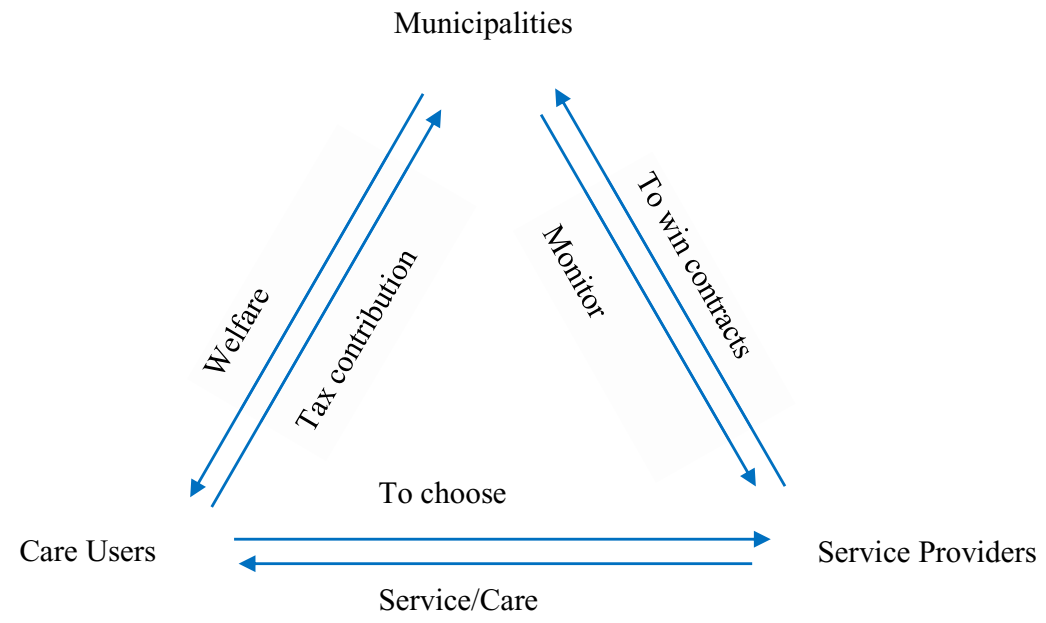

${ }^{48}$ On average, a home-care user receives around seven hours of help per week; the average is the same for younger and older age groups (NBHW 2009). The user fees cover only a fraction of the cost (4-5\% in aggregate), and the vast majority of elderly care expenditure comes from municipal taxes (around 85\%), while the remaining 10\% comes from national taxes (NBHW 2007). A national maximum fee reform was introduced in 2002, which capped user fees in home care. In 2011, the maximum fee was SEK 1,712. Municipalities still have discretion in setting the fees (up to the national maximum), and user fees are generally related to income and the amount of help provided (Meagher and Szebehely 2013).

A care manager at a municipality makes a needs assessment and therefore decides or approves what kind of help or assistance the elderly receive. The single individual could turn to a private firm for help with, for example, cleaning, washing, shopping, and personal care. The customer pays the full cost for the service but can take tax deductions each year. 
As shown in Figure 2.2, in the Swedish context, there are different actors involved in the provision of elderly care services: the local government might focus on how to manage the care system, in particular the monitoring system, and ensure the sustainability of the caring system. ${ }^{49}$ Care recipients (i.e. the elderly) voice their needs and receive the services they need. Whereas for service providers, seeking profits or trying to survive in the market are important goals, especially for private providers.

Although the central government could use tools such as legislation, policy declarations, state subsidies, and supervision to influence local practices, it is the 290 municipalities at the local level that are of greater importance in elderly care provision. ${ }^{50}$ The local government, made up of elected politicians, makes decisions regarding local taxation, set budgets, establish objectives and guidelines, exercise needs assessments, and organise provisions for home care services and residential care for elderly people. Moreover, local municipalities share relatively significant freedom regarding how to organise the care, which is stipulated not only by the law but also based on the notion that each municipality has the right to levy taxes to financially independently fund their elderly care. In terms of outsourcing and competitive tendering ${ }^{51}$, it is the local politicians who decide on this matter. If introduced, local government then acts primarily as a purchaser of services through procurement without direct engagement in daily service provisions, yet it can still exert some

\footnotetext{
${ }^{49}$ Strandberg (1995) offered a way to analyse the basic characteristics of a municipality: its purpose, ties to the state, and competence. Meanwhile, financing and services are of major concerns to local municipal management.

${ }^{50}$ There were about 2,500 municipalities in the 1950s and 290 since 2003 . The organisation of elderly care board may vary across municipalities. In some cases, it is another board, other than the elderly board, that is in charge of elderly care.

51 Several important aspects are separation between providers and orders, contracting procedures, performance-based resource allocation management, competition, and freedom of choice for users; see, for example, SOU (2016); Sørensen and Bay (2002); Van Dooren, Bouckaert, and Halligan (2010); and Whitfield (2001).
} 
influence on providers by setting requirements for the services procured and conditions that must be met.

Besides the important role played by the local government, there are two authorities involved: National Board of Health and Welfare (Socialstyrelsen) and Inspectorate for Health and Care (Inspektionen för vård och omsorg, IVO). One mission of Socialstyrelsen is to improve elderly care and the care for the mostly ill elderly people. ${ }^{52}$ The IVO oversees social services in general with the intention that individuals receive quality care and services that are in line with the laws and legislation (SOU 2016).

It should be mentioned that in the Swedish case, there are no statutory requirements for the elderly's children or relatives to provide care or financial security for their elderly parents. However, in reality, many families and next of kin provide care and support. ${ }^{53}$

\section{Conclusion}

Marketisation has been an object of discussion since the 1980s, and the case of Swedish elderly care follows the same trend. In general, political, economic, and demographic factors could all account for the implementation of a market in the welfare state to varying degrees. Past literature has shown that fiscal restrictions and cost reductions are important economic perspectives, in addition to an influence of political ideology regarding market-related issues, to name a few.

\footnotetext{
${ }^{52}$ It also publishes surveys regarding elderly people's satisfaction with care received, provides a database for comparisons of services between municipalities (Öppna jämförelser av äldreomsorg och hemsjukvård), an Elderly Guide (Äldreguiden), etc. For more details, please refer to the website: http://www.socialstyrelsen.se/aldre

${ }^{53}$ Szebehely and Trydegård (2012) argued that family careers provide an increasing amount of necessary care for the elderly - a 're-familialisation', which suggests shifting responsibility from the public to families to take care of the elderly.
} 
As illustrated, local municipalities are the cornerstone of the Swedish welfare state and are responsible for the planning and provision of elderly care. Many municipalities that chose to introduce a competitive market have likely been influenced by NPM, which claims that competitive tendering will lead to outcomes such as cost reduction, higher quality, and improved efficiency. Yet at the same time, critiques and suspicions of market practices have been raised that highlight the limits of the market solution and its potential side-effects.

As shown in the elderly care triangle, the role of politicians is of great importance and relevance in the discussion of marketisation. As explained, elderly care is the responsibility of local governments, and local politicians decide on whether to introduce competitive tendering, how to organise the structures, ensure the resources are allocated, and confirm the service quality is up to standard. So far, there are still 25 Swedish municipalities that have not introduced one marketisation tool - the freedom of choice model - and 22 municipalities that have yet to implement it. ${ }^{54}$ In this case, scrutiny of past market reform might shed some light on their decision making. For municipalities that have decided not to implement marketisation, their arguments presumably fall within certain aspects that are addressed in the debates section of this chapter. On the other hand, motivations that contribute to local privatisation and marketisation are predominantly economic, yet social and political factors might also play an important role in an ageing society.

The rise of the market brings some challenges to the welfare state, not least in the sense that private providers are introduced into the sector. Some debates are more 'technical', for instance, which sort of providers provide better quality, while others are more entangled with welfare state principles, such as equality (the elderly people are treated the same), universalism (all should have access to the care system irrespective of their socio-economic

\footnotetext{
54 These data were based on the latest report by Socialstyrelsen (2015) and may change over time.
} 
background), solidarity (cross-class support for the welfare system in tax contributions), and so on. Although some scholars might argue that competitive outsourcing is free of political features, the entire process of marketisation and privatisation is argued to include various dimensions that cannot escape political discussion.

In brief, partially because of internal tensions between market mechanisms and welfare state principles, doubts and suspicions of market capabilities are omnipresent. Many questions have been raised rather than answered: What kind of challenges does the market bring to the welfare state? Are welfare state principles undermined or have already lost their appeal to policy makers? Does a strong inclination to use a market contradict the basic principles of the Swedish model? Is it possible for them to coexist? If so, what is the ideal market? These questions are of great importance for the public, scholars, and politicians. For the sake of this study, it is intriguing to understand how politicians view these market-related issues in welfare provisions. 


\section{Chapter 3}

\section{Theoretical Framework}

After explicating the scope of marketisation and its implementation in Swedish elderly care system, it is possible to examine how attitudes of both welfare and marketisation are shaped in theory, in addition to empirical evidence that supports these claims. Various factors that are important for constructing the more favourable positions regarding the market or welfare are introduced and discussed. Many of these factors also apply to attitudes of public welfare, while a few characteristics, such as political orientation, are more pertinent to the study focus of this research (i.e. politicians).

In order to discuss attitudes toward marketisation issues, it is necessary to review briefly the welfare state theory to better illustrate the context in which the market exists and the Swedish model that is at stake. The welfare state theory also serves as a starting point for the explanation of different attitudes of the welfare state vis-à-vis the market. 
This chapter is organised as follows. First, I briefly introduce welfare state theories, discuss attitudes toward the welfare state, and explain how these theories have been essential to the understanding of the welfare state and the market. Next, I discuss various factors, including political ideology, that are essential parts of the shaping of attitudes. Afterwards, theories revolving around the importance of partisanship, political ideology, and political orientation that could play into welfare attitudes and welfare politics are discussed; such theories can be utilised in the later discussion of the research results. Among other ideas, the conflict between the convergence and divergence theses is highlighted and examined.

\section{Welfare state theory in a nutshell}

Before addressing welfare state attitudes, it is necessary to define the concept of the welfare state, since most of the attitudes about the welfare state are based on understandings of the scope, purpose, and organisation of the system. Nevertheless, it should be noted that welfare

states are complicated systems and therefore not easy to theorise 'in toto' (Rothstein, Samanni, and Teorell 2012).

The term 'welfare state' often refers to a state or political entity in which the government assumes primary responsibility for the welfare of its citizens. One provided definition describes the welfare state as "a type of democratic state, influenced by Keynesianism, which offers (some) protection to its citizens against the hardships of the (labour) market (e.g. unemployment) and life (e.g. sickness)" (Caramani, 2014). As an alternative definition, Spicker (2014) expressed it as the delivery of social services by the state; the strategy of developing inter-related services to deal with a wide range of social 
problems; an ideal in which services are provided comprehensively, and at the best level possible. ${ }^{55}$

Welfare states, both politically and economically, address institutionalised relationships between welfare programs and a government or nation, and welfare states are intended to enhance the quality of citizens' lives; support equality, justice, and human rights; and help develop and maintain a country's economy. Welfare states act to redistribute resources as well as operate as insurance against risks (Iversen 2005), which is because they offer welfare programmes that are meant to reduce poverty, increase equality, and minimise risks for both individuals and society. If generally available services such as basic education, day-care, elderly care, and health care are included in the discussion, the redistributive effects of welfare state policies are significant (Zuberi 2006).

It should be mentioned that variations exist across countries regarding the meaning, desirability, distribution, and scope of welfare - ranging from social democratic, liberal, and corporatist welfare (Esping-Andersen 1990) to the expansive welfare politics of social movements (Piven and Cloward 1993). In the last three decades, welfare states have been subjected to diverse pressure of which globalisation is the most powerful (Esping-Andersen 1996; Yeates 2001).

Welfare systems can be succinctly dichotomised as residual and institutional (Titmuss 1974). The major difference is that in an institutional system, welfare is not just for the poor: it is for everyone (Spicker, 2014). Gøsta Esping-Andersen's The Three Worlds of Welfare Capitalism is well-known nowadays and often used as an orthodox description of comparative analyses in this field. Based on an analysis of the arrangements between the

\footnotetext{
${ }^{55}$ Powell and Hewitt (2002) argued that the term welfare state is problematic. One reason for this argument is the term's various interpretations in different contexts. Here, I use 'welfare state' for discussion purposes without devoting too much attention to conceptual differentiations of several intertwined concepts, such as welfare society or welfare regime.
} 
market ${ }^{56}$, the state, and the family, Esping-Andersen categorised advanced capitalist societies into three types of institutional arrangements with each designed to reconcile economic development and include measures to protect citizens against the risks of the marketplace: the conservative regime (particularly in Germany and Austria), the liberal regime (primarily in Anglo-Saxon countries), and the social-democratic regime (in the Scandinavian countries). Building on Esping-Andersen's model, Leibfried (1992), Ferrera (1996), and Bonoli (1997) added a fourth variety, which is called 'Latin' or 'Southern', as it was found mainly in Southern European countries.

\section{Contributing factors to the attitude formation}

One means of studying welfare is to consider individuals' beliefs or attitudes about the welfare state. Individuals can perceive either positively or negatively about certain welfare programmes, and this study concentrates on their attitudes about the marketisation of elderly care. There are different contributing factors to attitude formation, which can be categorised into two sorts: individual-level factors and contextual ones.

Until quite recently, individual characteristics had often been the prime focus in studies on attitudes of welfare states. On the individual level, self-interest, identities, and adherence to a single social group might contribute to attitude formation. Many studies have confirmed the significance of individual-level characteristics as important factors in shaping welfare state attitudes; see, for example, Edlund (2006); Jaeger (2006); Sihvo and Uusitalo (1995); Svallfors (1996); Svallfors (1999); or van Oorschot (2002).

Past literature has shown that socioeconomic factors such as occupation, education level, and income level could also play a major role in shaping preferences (Edlund 2006;

56 This criterion is called de-commodification, which suggests freedom from market influences on welfare services. 
Svallfors 1989, 2004). For instance, public sector employees feel more positively toward public welfare provisions compared with people working in the private sector (Edlund 2006; Sørensen and Bay 2002) ${ }^{57}$ Private sector employees and self-employed people are believed to typically favour a small and efficient government sector. Individuals with lower incomes or less education also tend to be more supportive of public welfare (Blomberg and Kroll 1999; Svallfors 1989).

Some studies have highlighted the importance of social classes, as different social groups face different market-related risks and vary in their abilities to cope with market changes. Certain social groups that are often beneficiaries of welfare programmes, such as the disabled, are generally more supportive of a stronger welfare state (Johansson Sevä 2009; Svallfors 2004, 2011).

On an individual level, age is often considered to be essential in attitude studies. One reason for this view is that individuals at different stages of life might face different risks and therefore different welfare policies may appeal to them at different times. It might be true that in the case of elderly care, elderly people may be more concerned about marketisation compared with younger citizens. Some studies have claimed that older people are often more supportive of public welfare (e.g. Blekesaume and Quadagno 2003; Edlund and Johansson Sevä 2013; Jaeger 2006) and critical of competitive tendering (Sørensen and Bay 2002). Others, however, have asserted that attitudes are characteristics of certain cohorts or generations rather than age, per se, which suggests that attitudes or norms are shaped by

\footnotetext{
${ }^{57}$ This factor of occupation could also be considered self-interest related: It is thought that public-sector employees are friendlier towards a welfare state out of self-interest (Johansson Sevä 2009).
} 
major societal events during an individual's formative years, such as economic crises, progress, or political change (Becker 1990; De Vries 2005; Inglehart 1971). ${ }^{58}$

Regarding gender, several studies have shown that women tend to be more supportive of public welfare than men because of differences in self-interest and gender-related norms (e.g. Blekesaune and Quadagno 2003; Blomberg and Kroll 1999; Jaeger 2005; Svallfors 1989).

Besides these individual factors, it is frequently suggested that self-interest and normshaping are the most important explanatory mechanisms that link specific conditions to attitudinal outcomes (Blomberg and Kroll 1999; Johansson Sevä 2009). In the case of politicians, self-interest is more easily associated with holding a position and the attempt to maximise political goals. Of course, rent-seeking or other kinds of corruption could also be considered as related to self-interests. However, from a Swedish perspective, issues of political corruption or clientelism are quite rare. ${ }^{59}$ Therefore, this kind of 'self-interest' is not a focus in the current research.

Norm-shaping is closely tied with political orientation. Politicians' political orientation could reflect their belief system as well as the influence from experiences of party socialisation. The classification of a party as either left or right reflects an ideological divide, which could serve as a clue for discerning opinions on privatisation and outsourcing: leftwing parties are traditionally pro-government and aimed at egalitarian policies while rightwing parties favour market solutions and less government intervention (e.g. Bobbio 1996; Dahlberg and Lundqvist 2013; Fredriksson et al. 2010; Mair 2007; Sørensen and Bay 2002).

\footnotetext{
${ }^{58}$ However, some studies showed that support for public welfare measures may vary among different age groups, depending on the type of welfare area; see, for instance, Svallfors (1999).

${ }^{59}$ Compared to other European states, the Nordic states were historically less corrupt, less clientelistic, less prone to use violence against their citizens, and more open to popular influence (Frisk Jensen 2008; Heckscher 1952; Rothstein, 2007).
} 
The left-right ideological orientations are thought to arise from the splits between people with different professional and social relations to the means of production (Lipset \& Rokkan 1967). It could be argued that socioeconomic factors are accountable for the formation of ideological orientations. There are even studies that have shown family to have an influence on children's ideological orientations formation (Westholm 1991). Traditionally, it is viewed that the working class, lower income people, and those with lower education are central supporters of the leftist parties and stronger state intervention.

As explained by Kumlin (2002), the connection between political orientation ideology regarding state intervention ${ }^{60}$ and the welfare state is constituted by the notion that the size and nature of the welfare state arrangement strongly affects the degrees of the market economy, inequality, redistribution, and public ownership as the means of production in society. Regarding state intervention, the left usually supports a larger public sector, whereas their counterparts on the right are much less in favour of this setup. ${ }^{61}$ Kumlin argued that there even exists a value conflict between the new right, that values economic consumption standards and physical protection, and the new left, that emphasises non-material values such as quality of life, democratic principles, and a healthy environment ${ }^{62}$ (Inglehart 1977, 1990; Kumlin 2002; Minkenberg \& Inglehart 1989). This conflict would affect the meanings of leftright semantics and attitudes towards various topics including privatisation, decentralisation,

\footnotetext{
${ }^{60}$ State intervention orientations, as pointed out by Kumlin, are often measured by asking survey questions about the preferred size or form of welfare state arrangements, among many other aspects. In my survey, a question of optimal distribution was designed in a similar manner in which politicians' attitudes of the welfare arrangements could be discovered. Following this line of reasoning, the survey questions could be even categorised into two groups, as shown in Chapter 9: the first category is more about consolidation of the welfare state or more state intervention; the second category is about moving marketisation forward.

${ }^{61}$ Christian traditionalists hold positive attitudes towards 'Christian values' and family and align themselves more to the right (Kumlin 2002). In the Swedish case, Christian Democrats $(\mathrm{KD})$ is a member of the centre-right bloc Alliansen.

${ }^{62}$ The comparisons between two blocs shown in Part II of this research are intended to demonstrate possible value conflicts among politicians.
} 
democratic principles, and more. In terms of marketisation, for the new left, it is unreasonable to sacrifice values of democratic governance to improve efficiency. ${ }^{63}$

Among politicians, the position within the political system might affect their attitudes. For instance, according to May's law (e.g. Norris 1995), party politicians in top positions tend to be less radical than politicians at a lower level. One reason for this trend is that politicians who are directly responsible for actual policy decisions (in a higher position or representing the governing majority) might be inclined to be more cooperative and take less radical positions than politicians who do not have a direct political responsibility. Giljam, Karlsson, and Sundell (2010) tested May's law and showed that powerful leading politicians tended to adopt more right-wing attitudes in general, irrespective of their political orientation. Leadership takes place within institutions, and so power distribution, rules, and roles help to define leadership choices and affect preferences.

As much as citizens' direct experiences of interactions with various social policy programmes has a clear influence on their political opinions (Kumlin 2002), politicians' experiences with elderly care, whether they are direct service users themselves or have contact with others who are or know service users, might also influence their perceptions of marketisation. During contact with various service providers, politicians as care users could also formulate their stances on market issues by referring to these experiences as 'evidence'. These experiences could have either negative or positive effects on the politicians' attitudes regarding the market or care providers.

\footnotetext{
${ }^{63}$ As shown in a later analysis, the leftist parties focus more on welfare state principles, such as equality and solidarity. Although at the same time, they face the challenges of meeting care needs based on the resources they have at hand.
} 


\section{Contextual factors}

There are few studies that directly investigate the potential influence of the municipal context on marketisation attitudes. The potential for municipal conditions to affect individual attitudes has been revealed in studies of municipal service production and citizen evaluations of these services (see Birgersson 1975; Olander 1984; Sannerstedt 1981). Several studies analysed the direct impact of contextual factors - such as public policy, political climate, and socioeconomic conditions - on attitudes on public welfare. For instance, Blomberg and Kroll (1999) found that poor economic conditions, a low level of social and health expenditures, and a dominance of bourgeois parties were associated with less support among ordinary citizens for public welfare services in Finland. Johansson Sevä (2009) found more supportive attitudes toward public welfare prevalent in Swedish municipalities that are characterised by social problems.

Regarding political majorities, contentious results were found (see, for instance, Jensen and Lolle 2013; Søren 2003). Stolt and Winblad (2009) suggested that metropolitan areas dominated by left-wing parties are still subject to the influence of adjacent municipalities in their willingness to see the share of privatisation introduced or increased, irrespective of political orientation. However, conclusions about the less important role of the local political majority remain moot. One explanation could be that the findings of each study are specific to its own characteristics.

In addition to these macro-level factors, local institutional conditions, such as local public service privatisation, could also affect preferences regarding service delivery (Rothstein 1998). Some studies have also expressed that factors such as population density, tax power, educational level, and geographical proximity are associated with the degree of privatisation in various municipalities (Jensen and Lolle 2013; Petersen, Houlberg, and Christensen 2015; Sørensen and Bay 2002; Stolt and Winblad 2009). 
Some previous studies, especially those based on modelling, are summarised in Table $3.1 .^{64}$

${ }^{64}$ Note that this list here is not intended to be exhaustive. It manly includes several recent studies of marketisation and welfare state attitudes. 


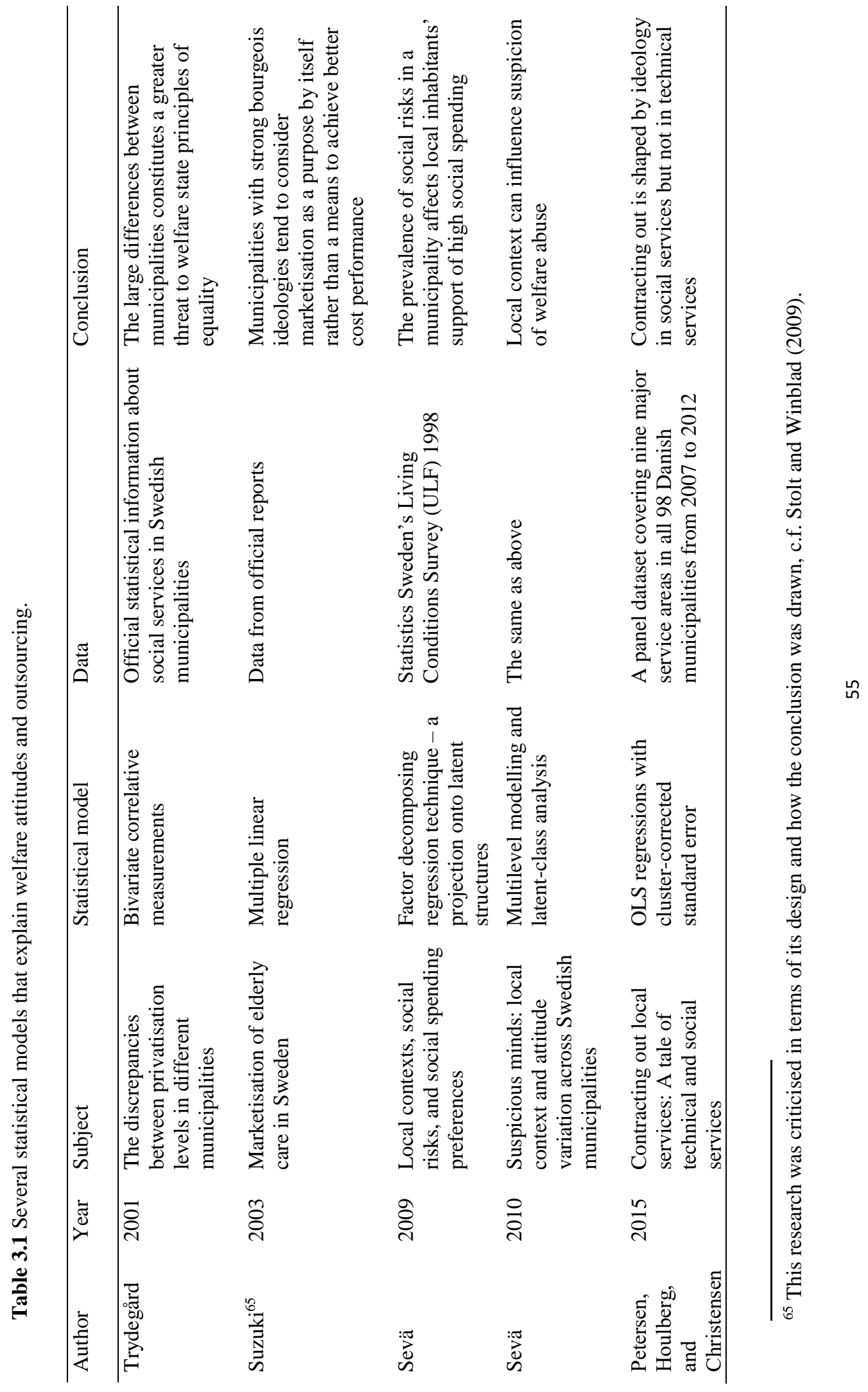




\section{A difference theory or a convergence thesis?}

Apart from the contentious empirical evidence on the role of political ideology on welfare attitudes, it is necessary to address additional theories that offer explanations or even predict the trend. This notion is intriguing because scholars typically aim to find consistency between theory and empirical data. If such a consistency does not exist, the theory should most likely be revised. If this consistency is found, then the theory is considered to be proven as valid. In addition, scholars are also interested in comparing various attitudes to determine if there is an overarching tendency toward one idea or another.

I address two different views - divergence and convergence - that predict different political preferences in terms of welfare reform. The first notion, coined as the 'difference thesis' or 'divergence thesis', claims that politicians that follow the left/right ideology have different welfare or market claims and contrasting attitudes regarding market solutions. The second thesis, mostly based on Pierson's ideas of new politics of welfare, argues quite the opposite: there is a much less room now for the different roles to exist, and a higher possibility of converged views should be the case.

Let me begin with the difference idea. From a theoretical perspective, the classical partisan theory claims that different political parties strive for various ideological goals, adopt different attitudes towards the welfare state, and promote the interests of the social groups that they represent. The left strives for the interests of lower-income groups through more extensive and redistributive social expenditure and pro-employment macroeconomic policy, whereas the right appeals to higher-income groups through more restrictive social transfers and pro-investor macroeconomic policies (Alt 1985; Hibbs 1977). Political partisanship, is argued to be essential to welfare expansion, which could also help shape the design and size of the welfare state. For instance, social democratic parties in control of governments are 
found to be more likely to increase levels of social spending (Allan and Scruggs 2004; Castles 2004) and promote large and universal welfare states (Esping-Andersen 1990) and a more redistributive system (Bradley et al. 2003; Iversen and Soskice 2006). This evaluation constitutes a 'difference' thesis or a 'divergence' thesis, compared to convergence.

Power resource scholars might hold on to this divergence thesis (Korpi 1978, 1983; Korpi and Palme 2003), as they have argued that there is still room for political ideology and partisanship to be important in contemporary welfare politics. The mobilisation of the lowermiddle class through commitment to the existing public business sector is a way to ensure high levels of public spending to appeal to less advantaged social groups (Boix 1997; Huber and Stephens 2001; Korpi 1983), which could potentially affect the fulfilment of long-term ideological goals, not least of all to secure election success. In the view of power resource scholars, the political battle between the left and right over distributive issues is essentially about the mobilisation of socio-economic cleavage (Korpi 2006), which in the long run, shapes the way that welfare develops; in this way, the restructuring of welfare will, in turn, influence the political balance. ${ }^{66}$

However, questions of the applicability of the difference thesis have been raised since the 1990s when a series of welfare reforms took place following the emergence of the austerity principle. Contrary to the difference thesis, the convergence theory claims that partisan politics have converged as a result of either structural changes such as ageing or free movement of labour and economic resources, globalisation, and ideational reasons (Huber and Stephens 2001; Kittel and Obinger 2003; Pierson 2001).

\footnotetext{
${ }^{66}$ In theory, the Social Democratic Party aims to have a cross-class spectrum of electorates. But in reality, this mobilisation of various social classes seems to be quite challenging nowadays: the prevalence of individualism and neoliberalism, the shrinking of trade unions, the shift of middle-low social classes towards a more split and divided group, and even a lack of trust of politicians has made it more difficult to achieve such a goal.
} 
The new politics of the welfare state (NP) emphasises the importance of policy structures, institutions, and vested interests by asserting that faced with challenges such as aging and budget limits, there is no room for partisanship in decisions over welfare policies in the 'era of austerity' ${ }^{67}$ (Pierson 1996, 2001). Pierson $(1994,1996)$ also declared that the popular politics of welfare expansion and the unpopular politics of retrenchment should be distinguished. Indeed, there are scholars with empirical evidence that support Pierson's new politics of welfare theory (Busemeyer 2009; Castles 2007; Huber and Stephens 2001; Kittel and Obinger 2003; Zohlnhöfer et al. 2008).

This convergence thesis might also get support from the path dependency theory, which emphasised the importance of how past policy arrangements as the chosen path exert their lasting effects on policy shaping. On the one hand, path dependency scholars consider markets to be institutionally determined, stable, and relatively apolitical. For instance, Pierson (1996) argued that mature welfare systems buffer themselves against changes and minimise new patterns of contestation. On the other hand, Pierson (1998) concluded that there is some contested evidence that 'politicians make a difference', and he offered three broad accounts that link political parties with the welfare state: the first focuses on mandate theory or the 'manifesto model of party government'. The second account is concerned with the median voter, and the third account applies public choice theories to adversary politics.

In a similar vein, the concept of "imprinting" could be used here. Marquis and Tilcsik (2013) implied that initial environmental conditions such as aging population, political power

\footnotetext{
${ }^{67}$ At this moment, the Swedish economy is performing quite well, at least at the national level. Still, with ageing populations increasing, more dementia being diagnosed, and even a migration crisis, local municipalities have to prioritise their expenditures in various social services. Elderly care costs the most in local budgets, around 19\%, according to statistics from SKL (2015). In total, around $80 \%$ of the municipal budget goes to utblidningsområdet (education field) and vård och omsorg (elderly care, care for the handicapped, etc.); see, for example, Gissur and Wänström $(2015,74)$.
} 
balance, economic development, and even a certain level of privatisation could leave a lasting mark on organisations like local municipalities and organisational collectives and continue to shape organisational behaviours and outcomes for a long time. Additionally, this view has been welcomed by some political economists, who have argued that elected politicians choose organisational solutions that promote their re-election prospects by limiting the changes to the status quo. Meanwhile, since individuals are sceptical of changes, they are also likely to favour solutions with which they are already familiar and maintain their familiar settings in life (Goul Andersen 1993).

Following the path dependency theory, it is tempting to conclude that political ideology (PI) shall not have a major role in the shaping of new welfare policies, as the 'inertia' might be too powerful to overcome.

The convergence theory could also find inspiration from Third Way scholars, such as Giddens (1998). They believed that the world has changed, so reform of the welfare state is necessary to make it relevant to current ways of life; the renewal of social democracy is not presented as a question of relinquishing the established values of the centre-left but of recruiting new means to their service. The welfare state can no longer be seen as part of a struggle for socialism, for the modern world is one in which there is no alternative to capitalism. In the view of the Third Way scholars, the political concepts of 'left' and 'right' are now breaking down for various reasons (Giddens 1998). ${ }^{68}$

\footnotetext{
${ }^{68}$ Within this context, Giddens argued that the main shift to which the welfare state must adapt is from 'simple' to 'reflexive' modernisation, and this is characterised in terms of the nature of risks that the welfare state must address. In the book Beyond Left and Right (1994), Giddens criticised market socialism and constructed a six-point framework for a reconstituted radical politics, and he also claimed that the way that welfare resource is being organised should be addressed.

The third-way theory was an important topic during Prime Minister Tony Blair's term in Britain and Bill Clinton's presidential term in the US.
} 
There are also other reasons to expect the convergence. For example, based on the 'Downsian' model (Hansen, Palfrey, and Rosenthal 1987), both left- and right-wing politicians are likely to converge on welfare policies that appeal to the majority of voters. By doing so, the political parties and politicians have more chances to maximise their votes. Another reason might be that political pragmatism is much more influential in terms of the policymaking process and its possible strong effects on decision makers. One consequence is that local politicians are more likely to lessen public welfare burdens and encourage private provisions (Ferris and Graddy 1986; Savas 2000).

\section{A new theory to reconcile?}

So far, it has been shown that there is a tension between the convergence and divergence thesis in accounting for the importance of political ideology and partisanship in contemporary welfare politics. There exists a theoretical disagreement on whether the importance of political partisanship for welfare reform has declined (Lindbom 2016, 39). Both sides have their theoretical foundations and empirical evidence as support. However, it is clear that tensions are intense between these two opposing views.

For some seemingly counterintuitive cases where it is not possible to see a clear promarket and anti-market approach, one explanation that Ross (2000) provided suggests that parties not only provide a principal source of a political agency but also serve as designers of strategies, thereby conditioning opportunities for political leadership. It could also be argued that the ambiguous effects of political parties and politicians on welfare reforms are not only possible because of the NP, but rather as a result of mixed influences, such as campaign strategies or policy feedback which are received from previous governments. Furthermore, Starke, Kaasch, and Van Hooren (2014) asserted that political conflict in these more generous 
welfare states is concerned with the extent to which expansion or retrenchment is necessary, which makes a clear-cut partisan impact often unobservable.

A theory of 'constrained partisanship' might be of value here. Proposed by Gingrich (2011), this theory has several key arguments: first, this theory rejects the idea that partisan action is always derived from voter preference and argues that parties seek to maximise electoral success within ideological constraints. Second, this theory contends that existing institutions do not fully determine outcomes, even though they might pre-structure the political opportunities that the parties face. Third, this theory claims that political parties introduce different markets to achieve distinct goals and always operate within the constraints presented by the particular programme they are reforming: the left's preference for more redistribution and upholding the welfare state leads to its support of markets that draw lowerand higher-income citizens and ensure the fiscal and political sustainability of the welfare state, whereas the right side intends to tie citizens to more differentiated or limited programmes and private sectors.

In short, this constrained partisanship still inhabits some aspects of the pathdependency theory, while taking into consideration other factors of real-life politics. It has the potential to reconcile the convergence/divergence debate, but more empirical data are needed to fully develop and test this thesis in future studies.

\section{Conclusion}

This chapter began with theories about the welfare state, attitude formation, and contributing factors to how attitudes about the welfare state are formed, both on the individual and structural levels. In addition, different views about the importance of political ideology and partisanship in welfare politics were discussed, namely, the convergence and the divergence theses. 
On an individual level, factors such as gender, age, income, and education are of great importance. These socioeconomic factors form the basis of norms and self-interests that are often viewed as essential in explaining welfare and market attitudes. Regarding the public, it is viewed that working class, lower income, and less educated people are inclined to favour greater state intervention and support a more generous welfare state with equal access. Since politicians are democratically elected, they are supposed to represent their electorate's interests, and many factors that help determine the public perception of the market vis-à-vis the welfare state are expected to have similar effects on politicians. ${ }^{69}$ Meanwhile, contextual factors, such as the economic prosperity of the municipalities, also influence the possibility of introducing a market in the welfare sector and could later on affect individuals' perceptions of marketisation, whether this means their views about care providers or the proclaimed benefits of the market.

Of great relevance, political ideology is necessary to take into consideration in terms of welfare attitude shaping despite a lack of consensus on its exact influence. The New Politics of Welfare, for instance, claims that PI no longer matters and suggests a convergence of partisan stance on welfare and market issues. This view seems to emphasise the apolitical nature of welfare reforms and indicates that the importance of political ideology gives way to factors such as pragmatism. By contrast, there are still studies that demonstrate the important role that political ideology could play in shaping market-related welfare policies (attitude included) to varying degrees. One reason for such contradicting research conclusions is because of the characteristics of politicians: there is no doubt that politicians could act on their own interests, on behalf of their parties, or as democratic representatives of their constituents under different circumstances. In doing so, their attitudes, strategies, and

\footnotetext{
${ }^{69}$ As mentioned before, studies that direct tackle politicians' attitudes, not to be confused with political strategy, are far from adequate.
} 
political behaviours can become easily tangled and are less likely to display a clear pattern.

Having said that, whether difference theory or convergence theory triumphs in welfare politics nowadays is far from settled. Furthermore, difference theory and convergence theory do not directly provide the answers on how political preferences are shaped nor what they indeed are, especially when specific welfare programmes are analysed. All of these theoretical debates about the role of partisanship in welfare reforms make it more attractive to look at politicians' attitudes towards marketisation. 


\section{Chapter 4}

\section{Research Methods}

In an attitude study of marketisation, it must be determined whether a qualitative or a quantitative approach is more appropriate, especially because it is true that many research questions can be studied in either way. For the sake of this research, this chapter discusses the quantitative study method and, in particular, how a survey approach could be useful in gathering data about an attitude pattern. Meanwhile, this chapter concerns how survey questions and answer options are formulated and how various factors that are essential to attitude formation are defined and used as variables in the survey questions and, later, the analysis. The use of a survey is to display preference patterns among the studied groups local politicians - as well as to explain how these patterns are connected to local privatisation. The response rate of this survey is discussed in detail to avoid research bias. Additionally, 
research ethics in this study are discussed with a focus on the no-harm and anonymity principles.

\section{Three steps of research}

Researchers aim to see this world in the same manner as research participants - from the inside, through the best method. Methods extend and magnify our views of studied life and serve to broaden and deepen what we learn of it and know about it (Rovai et al. 2013). Although researchers cannot claim to replicate the views of respondents or reproduce their experiences, we try to enter respondents' settings and situations to the furthest extent possible. Seeing from the inside gives a researcher many previously unobtainable views.

Following Creswell (2012), research could be designed in three steps: pose a question, collect data to answer a question, and finally present an answer to a question. Step one deals with the research question, which often faces the problem of being either too broad or too specified. To better formulate a research question, a literature review is often necessitated, not only to avoid the possibility of recreating existing studies, but also to obtain a relatively comprehensive view of the research field.

A literature review is defined as a process of reading, analysing, evaluating, and summarising scholarly materials about a particular topic (Fink 2013). It includes the current knowledge about the topic and can be based on either theoretical or empirical findings. The review process could also be beneficial to setting the framework of a particular study and defining its potential contributions. In this research, I have reviewed previous research on marketisation, especially those studies that explain how NPM theory has played an important role in pushing the market forward. Theories of the welfare state, NP, and the convergence and divergence theories are mentioned and discussed as well. 
Certain official policy documents are included as sources in this research, both in reference and analysis; for instance, reports from Socialsstyrelsen (National Board of Health and Welfare, NBHW) and Statistiska Centralbyrån (Statistics Sweden). Political claims, such as political election manifestos, are also included. Additionally, rules and regulations centring around market reform in elderly care in Sweden are summarised and discussed.

Step two deals specifically with the methods to be applied. It is reasonable to argue that the methods of choice are shaped by the research question. Both quantitative and qualitative research methods have their own advantages and disadvantages. ${ }^{70}$ In some cases, research problems could also indicate using several combined or sequential data collection approaches (Charmaz 2014).

Step three involves presenting an answer to the question asked. In order to analyse data, statistical methods can be used, including both descriptive and analytical methods such as regressions. The discussion of the statistical methods and their findings are listed in the respective chapters.

\section{Quantitative approach}

Quantitative research can be defined in one way as a systematic investigation of social phenomena using statistical techniques. Quantitative methods are appropriate for a type of research in which the investigator uses scientific enquiry to examine descriptions of

\footnotetext{
${ }^{70}$ Of course, there are often critics of each approach, be it quantitative or qualitative. For instance, three critiques of statistics in terms of causal analysis were provided by Spicker (2014): the first weakness is that the statistical techniques that are used cannot tell us for certain that there is a causal link - that one event makes another happen. What we look for instead is a statistical association, where one event is unlikely to happen at the same time as another by chance. An association often suggests a relationship, but it is not proof of one. The second is that the approach can produce accidental results. The third is the way that variables are identified and defined.
} 
populations or phenomena, differences between groups, changes over time, or relationships between variables; predictions may even be included.

Creswell (2003) addressed the assumptions of quantitative research as follows: the world is eternal and objective; reality is seen as one and therefore by dividing and studying its parts, the whole can be understood; phenomena are observable facts or events; and all that occurs in nature can be predicted according to reproducible laws. Furthermore, he noted that variables can be identified, and the relationship between variables can be measured. The researcher and the components of the problem under study are perceived as independent and separate. A variable is any characteristic or quality that varies, and it can be either continuous or discrete.

When using quantitative methods (Rovai et al. 2013), there are several possibilities to bear in mind. Firstly, there is a potential for sampling error, which occurs when researchers work with sample data rather than population data and consists of two types: random errors (tend to cancel each other out and have a minimal impact on overall statistical results) and systematic errors (can impact statistical results). In this research, statistical analysis includes standard error of the mean (SEM), and this study follows the suggestion to limit SEM to 5\%. Additionally, non-sampling errors, such as specification error, coverage or frame error, nonresponse error, measurement error, and processing error (Biemer and Lyberg 2003), have been taken into consideration in the question formulation through consultation with an expert, which resulted in a reminder to boost the response rate and check the collected data multiple times. Since inadequate sample sizes can lead to low statistical power to reject a false null hypothesis (Type II error) and a low response rate, which introduces the possibility of bias, I strived to collect as many valid responses as possible for the survey research. 
Statistical conclusion validity refers to the degree to which one's statistical analysis enables correct decision making regarding the truth of the null hypothesis. External validity is the generalisability of the study findings to the target population (Campbell and Stanley 1963). One kind is population validity that describes how well the sample represents the target population (Bracht and Glass 1968). Internal validity is to what extent one can accurately state that an intervention produced the observed effect, which reflects the extent of control over confounding variables in a research study (Campbell and Stanley 1963). The survey result analysis in this thesis focuses more on external validity, and I try to avoid overinterpreting the data.

\section{Survey method}

As previously mentioned, both quantitative and qualitative research methods have their own advantages and disadvantages. The survey, often used in a quantitative approach, inherits some general features of quantitative methods and their shortcomings.

As a tool to help gather information from individuals about themselves (Rossi et al., 2013), surveys can be categorised into different types according to their contribution to the

existing knowledge (Fowler Jr, 2008; Singleton Jr et al., 1993). There are different kinds of surveys: descriptive, exploratory, and confirmatory (also known as a theory-testing survey). Descriptive surveys are designed to focus primarily on the 'what' questions, and less so on the 'how', 'when', or 'why' questions. An exploratory survey is often used when there is limited knowledge in the research field. The third category, which can be considered as confirmatory, explanatory, or theory-testing, often departures from certain theories and is designed to answer 'how' and 'why' questions.

My research is a cross-sectional design that focuses on politicians' attitudes, opinions, or beliefs of marketisation. Since there is no secondary data on this exact topic, at least on a 
national level, a survey was deemed necessary and appropriate. Therefore, a national survey was designed and used in order to gather an overview of how Swedish local politicians viewed elderly care marketisation.

Of course, one common difficulty is how to frame the questions. The ways that questions are formulated not only aim to capture the subject of enquiry but also must be neutral, subjective, and rather straightforward. ${ }^{71}$ In this study, the questions formulated for the survey were based on the common arguments have been raised during the political debate. Some questions were inspired by the SOM Institute's survey of public welfare opinions (see, for example, Nilsson [2014], [2015]) and the Swedish Welfare State Surveys (Svallfors 1989). ${ }^{72}$ For instance, questions in the survey about whether profits should be allowed were based on their counterparts in the SOM Institute ${ }^{73}$ survey: "Vinstutdelning ska inte tillåtas inom skattefinansierad vård, skola och omsorg" (Profitmaking should not be permitted in the tax-financed health care, school, and social care). The way in which questions are formulated verbatim was firstly noted by a specialist in survey methodology and then tested in a pilot study with the aim to improve the quality of probing questions and their coverage. I tried to capture the major aspects of the marketisation debate, but I also intended to keep both the depth of the questions and the number of questions to an appropriate level. ${ }^{74}$

\footnotetext{
${ }^{71}$ It is even possible that the same question can be interpreted in various ways among the respondents.

${ }^{72}$ In 1986, the first survey was conducted, which laid the groundwork for analyses of patterns of welfare attitudes.

${ }^{73}$ Samhälle Opinion Medier (SOM), translated as "Society Opinion Media", has conducted surveys to collect research data and presented annual trend analyses on public opinions and media habits in Sweden since 1986. National SOM surveys include a large number of questions related to politics, society, media, and social background, and a survey about public welfare attitudes is included.

${ }^{74}$ Not all politicians are expected to have an extensive understanding of the target issues to be studied, at least not from an academic point of view. This point is why questions must be straightforward and easy to understand and answer. The second point here is that if a survey
} 
A balance of questions on different aspects of the market and the welfare state was also taken into consideration. For some issues, both positive and negative formulations of questions were used. For instance, Q19 asks whether profits are allowed for private owners, while Q20 states that profit should not be allowed. Another example is Q21 and Q22, which take either a positive or negative standpoint regarding whether competition between private and public providers could be beneficial to care workers. The detailed questions can be seen in the appendix.

A few important topics, such as the philosophical concepts of freedom and choice, were not directly addressed in the survey for two reasons. On the one hand, the framing of these questions also hinges on the survey respondents' knowledge and ways of interpreting and understanding the questions. Since many local politicians are not engaged in politics full time, it would be somewhat unreasonable to expect all of them to be well acquainted with different theoretical discussions of freedom, choice, and other concepts as such. On the other hand, some themes relevant to marketisation might be difficult to frame because of their complexity. Questions regarding the philosophical concepts of freedom and choice might seem too sophisticated to be probed with a few multiple-choice questions. Taking these factors into consideration, the questions were intended to be easy to understand and answer. Although some nuances might have been lost, focusing on the major issues of the marketisation debates and posing questions in such a way that the respondents had little trouble answering them was the most sensible path.

Most questions were accompanied by multiple choices. In this survey design, a Likert scale was used; for instance, strongly disagree, somewhat disagree, neither agree nor disagree, somewhat agree, and strongly agree. I also included another answer option: do not know or covers too many questions, it might be too time consuming and less appealing to the respondents, which can lead to a low response rate. 
want to answer. The Likert scale is a unidimensional, summative design approach to scaling (Hopkins 1998). It consists of a fixed-choice response format to a series of equal-weight statements regarding attitudes, opinions, or experiences. The use of a Likert scale operates under the assumption that the intensity of the reactions to the statements is linear, and it is typically measured in five or seven points. In this survey, I added one category as 'do not know or do not want to answer' in the answer options in addition to the five-level scale that is common to attitude research. This additional answer was provided in order to offer more options to the respondents.

Jonson $(1997,284)$ argued that a researcher should strive toward an objective collection of data and interpretation of resultant findings by engaging in "reflexivity, which means that the researcher actively engages in critical self-reflection about his or her potential biases and predispositions". I am acutely aware of this thought and, during the research process, I was open to critiques and suggestions not only on questions formulations but also interpretations.

In terms of how to interpret data and draw a conclusion based on statistics, a common error is to confuse correlation and causation. A correlational design examines relationship (i.e. correlation, association, co-variation) between two or more existing variables, but it does not explain why the variables are related. Therefore, I tended to be cautious while interpreting the data and drawing conclusions from regression models.

\section{Defining variables}

Local politicians' attitudes towards marketisation and privatisation in elderly care are of primary concern and were investigated by asking the respondents about their preferences for more or less private provisions in their home municipality as well as by asking for their views about the optimum share of private for-profit, non-profit, and public provisions in elderly 
care. ${ }^{75}$ These two notions constitute two dependent variables in regression models later on. Besides these two major questions, politicians' attitude regarding other aspects of marketisation were also probed in the questionnaire.

\section{Independent variables}

The survey questions covered major explanatory factors that were mentioned in previous studies. ${ }^{76}$ Individual variables include age, gender, party affiliation, political position, and numbers of terms served. ${ }^{77}$ Contextual factors focused on the economic, geographic, and political context of municipalities as well as the level of privatisation achieved. All independent and dependent variables used in the analysis are explained in this chapter, and a table can be found in the next chapter, which also presents the variables and how they were coded. $^{78}$

The first category focuses on the individual level. The term of service is one variable that was included in the questionnaire. As local policy makers, Swedish politicians ${ }^{79}$ are democratically elected and are responsible for local issues, such as organising welfare services like elderly care and school education. They face elections every four years, the

\footnotetext{
${ }^{75}$ Regarding the second dependent variable in Table 5.5 in Chapter 5, namely, the optimal distribution of private and public providers, I must admit that such a perfect point might not actually exist in the economic models because of externalities, multiple principals, and information asymmetries (Barr 2012; Hindriks and Myles 2006).

76 The income and education level were not deemed to be significant factors to probe in this study. Another intention was to avoid any potential intrusion of privacy. However, these socio-economic factors could be included in future studies to generate a more comprehensive picture of individual factors and their roles in attitude formation.

${ }^{77}$ No multicollinearity of independent variables was detected in the following regression analyses.

${ }^{78}$ Please refer to Table 5.3 for details.

${ }^{79}$ The division of labour between politicians and civil servants exists. Civil servants normally prepare documents and are in charge of daily tasks while the politicians are mostly involved in decision making.
} 
same as central government politicians. The terms they have served could be used as a reflection of the experiences that they have accumulated in their political lives and their views and knowledge about market issues.

The position served by the politicians is another factor that was investigated. At the local level, politicians could either be full-time employees of municipalities or only engage themselves part of their time in local politics. Besides the members that sit on the board, there are also 'ersättare' (translated as alternate member, or substitute) politicians in case the incumbent is absent for reasons such as sick leave. Typically, specific committees consisting of local politicians, the Äldrenämnden (elderly board) for example, are responsible for decision making. In some municipalities, it could be Socialnämnd or Omsorgsnämnd that are equivalents to $\ddot{A} l d r e n a ̈ m n d e n$, depending on the local organisation structure. ${ }^{80}$

Political orientation was determined by asking the politicians for their party affiliations. ${ }^{81}$ The left-right scale is defined as follows: the left-wing parties or the RedGreens include the Social Democrats, the Greens, and the Left Party, whereas the right-wing bloc (Alliansen) consists of the Moderates, Liberals ${ }^{82}$, Centre Party, and Christian Democrats. Politicians from other parties were also given the possibility to indicate their party affiliations. $^{83}$

\footnotetext{
${ }^{80}$ For information on how local municipalities are organised, see, for instance, Chapter 6 , Sa kan kommuner organisera sig, by Gissur and Wänström (2015).

${ }^{81}$ In this study, no specific question about self-identification was asked. The reason for this choice was that politicians elected are expected to maintain their party affiliations and the values thereof. Although there might be a difference between where they position themselves on the scale and where scholars place them, the use of the left-right scale may still be useful for categorisation and comparison.

${ }^{82}$ The Folkpartiet changed its name to the Liberals (Liberalerna) on November 22, 2015. Yet in many parts of this research, FP is used instead of L for continuity.

${ }^{83}$ However, for discussion purposes, the politicians from smaller parties are excluded partially due to their small numbers in the survey response.
} 
The second category of independent variables focuses on the municipality level or contextual factors. Contextual factors include the political majority in spring 2014 (as an example of institutional factors), taxation powers, privatisation level, population density, and whether the politicians were located in Stockholm (geographical proximity).

The political colour of the governing majority in a municipality reflects the ideological orientation of government, and based on previous literature, it is included in the survey despite its dubious roles in welfare policymaking. Taxation power reflects the fiscal ability to levy taxes in a municipality. It can be used as an indication of the economic prosperity and local government's fiscal capacity. As the literature indicated, the economic perspective of municipalities is relevant in the marketisation process.

The degree of privatisation is measured by the average of hours of home care by private providers and the percentage of private providers in institutional living to generate local privatisation level. ${ }^{84}$ Population density may influence the privatisation issue. It has been found that municipalities with a low population density may discourage private providers. In addition, the population in one area is also relevant for considering the demographic influence. ${ }^{85}$

In the Swedish context, the Stockholm area has the highest level of marketisation, with many private providers. Some literature, for instance, Stolt and Winblad (2009), indicated that geographical proximity is an important factor in influencing privatisation decisions, and this point has been taken into consideration.

\footnotetext{
${ }^{84}$ Here, privatisation level is considered to be an independent variable, which could potentially influence politicians' attitudes on marketisation issues. Nevertheless, the opposite could be argued: it is politicians' attitudes or views that determine the outcome of privatisation. Due to the nature of this survey, it is hardly possible to fully test these two different claims.

${ }^{85}$ Both population density and population in log were checked in the models for potential risk multicollinearity. The results free us from this concern.
} 


\section{Data collection}

By the time of this survey study, early 2014, 108 out of a total of 290 municipalities were governed by centre-right parties, 107 by left-green parties, and 75 by coalitions between left and right (SKL 2015). In terms of the 2014 general election results, the voting rate for the Social Democrats was $31.01 \%, 23.33 \%$ for the Moderates, and $12.86 \%$ for the Sweden Democrats $\%{ }^{86}$

By using SurveyMonkey ${ }^{\circledR}$, a survey link was sent by email to local politicians who were responsible for elderly care in Swedish municipalities. A pilot study was initiated in Linköping, which served as a basis for redesigning and revising the questionnaire. From the beginning of March 2014, I sent a request for cooperation and consent to participate in the survey to all Swedish municipalities based on the information provided by the Swedish Association of Local Authorities and Regions (Sveriges Kommuner och Landsting, SKL).

An introduction letter was sent to the respondents, which can be seen in Appendix 1, with the aim to introduce the study purpose of the survey, familiarise the respondents with the context, and form consent to participate. In terms of the questionnaire, all survey questions were expressed in Swedish to facilitate responses and are listed in Appendix 2. There are five parts of the survey. Section A asks about respondents' background information, such as gender, age, and their political position within a municipality. These six questions were compulsory to answer. Section B enquired into respondents' views on the elderly care in their own municipality, such as the general impression in the area. If there were markets involved in local care services, the respondents were meant to answer questions 11 and 12, which are

\footnotetext{
${ }^{86}$ Source: http://www.val.se/val/val2014/slutresultat/R/rike/, accessed on January 1, 2016. Sweden used to have a stable two-bloc political system (Elinder 2010). Recently, this political landscape has shifted largely because of the increasing momentum of the Sweden Democrats (SD).
} 
about whether the elderly are offered information to choose home services or nursing homes. Section $\mathrm{C}$ asks the respondents to take a stand on various arguments that stem from marketisation debates, both positive and negative. Much of this part is based on the motivations and critiques that marketisation faces, as discussed in Chapter 2. Section D required the politicians to reflect on possible influences they received from sources such as political work or research papers. Section E provided opportunities for the respondents to address issues they think were missing in the survey as well as their suggestions to improve the quality of the survey.

The data were collected between December 2013 and August 2014 with the intention to minimise any possible effects that the 2014 national election could have on responses. ${ }^{87}$ Meanwhile, it was my intention for this survey study to remain neutral and purely academic so that it would not be seen as a tool to facilitate political campaigning. All of the politicians with valid email addresses were sent a brief introduction of the survey and a link to the detailed questions. A reminder was sent out in the month of May 2014 to all politicians surveyed. In total, 3,340 on-line survey question samples were sent out and 1,362 were considered as valid replies, which yielded a response rate of $41 \%$. In this survey, both politicians on duty and their substitutes were contacted if they were sitting on the local board responsible for elderly care. Responses came from 238 out of 290 municipalities. In the meantime, questions and enquiries from the politicians about the survey were answered promptly and carefully.

\footnotetext{
${ }^{87}$ The general election took place on September 14, 2014. As of 2016, Social Democrats and Moderates are two important political parties in power, while the Sweden Democrats gradually surpassed the Moderates in public opinion polls. A public opinion poll, which included 4,008 respondents from March 20, 2017 to April 16, 2017 showed the following party sympathy figures: $28.2 \%$ for Social Democrats, $19 \%$ for Sweden Democrats, and $16.4 \%$ for the Moderates, see, for instance, https://www.svd.se/novus-sd-nast-storst--m-tapparytterligare (Accessed on June 30, 2017).
} 


\section{Response rate and missing values}

The survey is considered to be representative of the targeted group in general. The response rate is acceptable when compared with some recent studies in other Nordic countries. ${ }^{88}$ Moreover, the data that was collected is rather representative of the targeted population. Nevertheless, the response rate could have been higher if more reminder letters had been used or even telephone calls. ${ }^{89}$

When considering gender, female politicians were slightly overrepresented compared with their male counterparts, as shown in Table 4.1. In terms of political parties, the respondents to the survey reflect the population targeted, with a slight overrepresentation from the Moderates $(+1.99 \%)$, the Liberals $(+1.9 \%)$, and the Centre Party $(+0.64 \%)$, as shown in Table 4.2. Within the left-wing bloc, the Social Democrats were less represented ($4.33 \%)$ as well as the Green Party $(-0.76 \%)$.

\footnotetext{
${ }^{88}$ A Norwegian study reached a higher response rate of $61 \%$ and the data was collected in 1998 (Sørensen and Bay 2002). More recently, Fredriksson et al. (2010) conducted a Finnish study based on a survey sample of 364 and the final response rate was $41 \%$. The data used in this research were collected in 2008.

${ }^{89}$ The data collection was intended to be completed before the general election campaign intensified in 2014. Therefore, a deadline for survey completion was decided to be the end of August. The reminder was sent in May and June, which should have given respondents enough time to complete the survey. Theoretically, more rounds of reminders could have increased the response rate. At the time of conducting this local level study on politicians, a survey was sent to politicians at Riksdagen (National Parliament) with two reminders, and the response rate did not raise significantly after the second reminder. The reason could be that the politicians were not interested in answering questions or they were simply too busy. Meanwhile, more rounds of reminders and phone calls to track thousands of politicians would require a significant pool of resources, which was almost impossible in my study. Having said that, response rate is always an issue to be considered in survey studies.
} 
Table 4.1 Survey response rate by gender.

\begin{tabular}{lllr}
\hline & Male & Female & N \\
\hline Population number & 1,417 & 1,923 & 3,340 \\
Percent & 42.44 & 57.56 & 100 \\
Survey response number & 592 & 770 & 1,362 \\
Percent & 43.47 & 56.53 & 100 \\
\hline
\end{tabular}

Table 4.2 Response rate (\%) by party affiliation.

\begin{tabular}{llllllllllll}
\hline & C & FP & KD & MP & M & S & SD & V & Other & Left & Alliance \\
\hline Population & 11.61 & 7.98 & 6.62 & 4.97 & 20.64 & 36.54 & 1.4 & 6.24 & 3.99 & 47.75 & 46.86 \\
& & & & & & & & & & & \\
Survey data & 12.25 & 9.88 & 6.52 & 5.73 & 22.63 & 32.21 & 1.48 & 6.23 & 3.06 & 44.17 & 51.28 \\
\hline
\end{tabular}

I also checked to what extent all Swedish municipalities were represented in the survey. It should be noticed that the left column indicates populations per municipality. As shown in Table 4.3, there was a lower representation of politicians from the first three categories of municipalities, namely, metropolitan areas, major cities, and their neighbouring suburban municipalities. The response rate of politicians from the remaining categories is somewhat higher.

Since there are no statistical data about the numbers of politicians in different categories of municipalities, a direct comparison is unlikely. Rather, it is possible to get a view of where these survey respondents came from, based on SKL's categorisation of municipalities. Again, this is not an indication of whether the politicians surveyed are representative or not. 
Table 4.3 A distribution of municipalities from where survey respondents hail.

\begin{tabular}{|c|c|c|}
\hline & $\begin{array}{r}\text { Population } \\
\% \\
\end{array}$ & $\begin{array}{r}\text { Survey } \\
\text { Responses } \\
\%\end{array}$ \\
\hline Metropolitan areas (3 municipalities) & 18.08 & 15.91 \\
\hline Suburban municipalities to major cities (38 municipalities) & 16.28 & 12.62 \\
\hline Major cities (31 municipalities) & 29.87 & 17.98 \\
\hline Suburban municipalities to major cities ( 22 municipalities) & 3.38 & 6.12 \\
\hline Commuting communes (51 municipalities) & 7.3 & 11.32 \\
\hline Tourism and tourism industries (20 municipalities) & 2.99 & 3.6 \\
\hline Commodity producing municipalities (54 municipalities) & 8.27 & 14.08 \\
\hline Sparsely populated municipalities (20 municipalities) & 1.67 & 1.91 \\
\hline $\begin{array}{l}\text { Municipalities in densely populated regions ( } 35 \\
\text { municipalities) }\end{array}$ & 8.85 & 11.94 \\
\hline Municipalities in the rural population (16 municipalities) & 3.3 & 4.51 \\
\hline Total & 100 & 100 \\
\hline
\end{tabular}

Background information of the politicians surveyed is listed in the following table (Table 4.4). 
Table 4.4 Summary statistics of survey respondents.

\begin{tabular}{|c|c|c|c|c|}
\hline & & Frequency & Percent & $\begin{array}{r}\text { Cumulative } \\
\text { Percent }\end{array}$ \\
\hline \multirow[t]{3}{*}{ Gender } & Female & 736 & 54.0 & 54.0 \\
\hline & Male & 623 & 45.7 & 99.8 \\
\hline & Neutral & 3 & 0.2 & 100.0 \\
\hline \multicolumn{5}{|l|}{ Age } \\
\hline & $18-29$ & 41 & 3.0 & 3.0 \\
\hline & $30-39$ & 106 & 7.8 & 10.8 \\
\hline & $40-49$ & 183 & 13.4 & 24.2 \\
\hline & $50-64$ & 549 & 40.3 & 64.5 \\
\hline & 65 and above & 483 & 35.5 & 100.0 \\
\hline \multicolumn{5}{|l|}{ Term } \\
\hline & This mandate & 469 & 34.4 & 34.4 \\
\hline & 2 terms & 282 & 20.7 & 55.1 \\
\hline & 3 terms & 212 & 15.6 & 70.7 \\
\hline & 4 or more terms & 399 & 29.3 & 100.0 \\
\hline \multicolumn{5}{|l|}{ Position } \\
\hline & $\begin{array}{l}\text { Local government } \\
\text { commissioner }\end{array}$ & 160 & 11.8 & 11.8 \\
\hline & Chairperson & 233 & 17.1 & 28.9 \\
\hline & Ordinary member & 969 & 71.1 & 100 \\
\hline & Total & 1362 & 100 & 100 \\
\hline
\end{tabular}

\section{Research ethics}

At the most fundamental level, ethical research should embody the following characteristics: informed consent, voluntary participation, avoidance of harm, confidentiality, and protection of vulnerable populations (Rovai et al. 2013).

An informed consent document was sent to the respondents in the introduction letter (See Appendix 1). The purpose of this process was to follow the principle of informed consent. The respondents were informed about the purpose of the study, how the data would be collected and used, and how their anonymity would be maintained. By voluntary participation, the politicians themselves decided whether to personally participate in the 
survey. Moreover, they were permitted to withdraw or terminate their participation at any point without explanation to the survey conductor, penalty, or loss of benefits in any way. It also should be mentioned that there were no monetary rewards or other repayments for completing the questionnaire.

One major aspect of research ethics is to prevent harm, which could be either physical or mental, or even both. As far as this research is concerned, the politicians as public figures are subject to public enquiry. A survey is deemed harmless as long as it remains neutral, scientific, and not intrusive to privacy. ${ }^{90}$ One example here is that even in the design of questions, I offered three options for politicians to answer their genders, which shows considerations and respects for certain groups of people in the society. Another example is that no aggressive reminders were sent, as opposed to some studies which simply care more about the response rate rather than the quality of the answers or potential harassment of the respondents.

Confidentiality is highly valued in this research process: there were no names collected and no possibility to track answers to individual respondents. ${ }^{91}$ It is understood that politicians might be subject to blame or pressure from their fellow colleagues, be it from the same or opposing political parties. During the entire survey period and afterwards, all respondents were kept anonymous even to each other. This process was accomplished by sending survey links and questions to the respondents separately. Even in the publication of these research results, all respondents remain anonymous.

\footnotetext{
${ }^{90}$ This is also the reason that why their personal data, such as salary, were not collected.

${ }^{91}$ This creates some problems for the researchers, for example, a low response rate, which means sending reminders only to the respondents who have not answered is impossible. By contrast, a reminder to all participants is required, which takes more time and calls for more resources.
} 
During the period of this survey, the general discussion of Sweden Democrats was a relatively delicate issue. Therefore, all politicians, including those from Sweden Democrats were guaranteed anonymity so that they could feel free to express their true attitudes regarding marketisation and the welfare state. Finally, this project received no public or private funding. As a scientific study, the purpose and usage of this study does not serve any political campaign purposes.

\section{Conclusion}

This chapter has addressed the survey method that was used in the data collection and analysis in the development of this thesis. As a quantitative approach, the survey method could provide important information regarding the local politicians' positions on various issues of marketisation.

To enquire about their stances on the issues of making a market out of a welfare state, the survey addressed many important arguments and evidence raised in the public debates. Meanwhile, framing questions was one important step in conducting this research. All survey questions reflected common arguments that have been observed and reflected in the public and political debate. A few questions included in the survey were inspired by the SOM welfare attitude studies. Some concepts such as freedom, choice, or various aspects of quality $^{92}$ are quite difficult to measure or capture in a few simple survey questions. To address this problem and avoid research bias, a few open-ended questions were offered to the respondents at the end of survey. Meanwhile, the questions and answer options were

\footnotetext{
92 The SOU $(2016,249)$ summarised several ways to measure quality: structural quality, which reflects the conditions for the business, such as financial resources, staffing, staff skills, and so on; process quality, which refers to reflections of what is being carried out, such as risk assessments, establishment of plans, controls of dental hygiene, or customer attitudes; result quality is related to the objectives of the business, which can be the prevalence of bed sores (pressure ulcers) in elderly care. Yet, it is difficult to agree on which measurements are most suitable to compare and evaluate quality.
} 
reviewed from the respondents' points of view so that the questionnaire would be clear to understand and answer from a cognitive perspective.

Many important variables, both independent and dependent, that are essential to the understanding of marketisation preferences are explained in previous chapters and included in the questionnaire. On an individual level, the focus was given to factors such as age, gender, political position, and affiliation. On the municipal level, the privatisation achieved, the economic and demographic of a local municipality, and its political colour were of interest. Admittedly, the survey here did not include questions about personal education backgrounds or income levels, and these personal data would have been helpful in further explaining the variances in politicians' attitudes.

The response rate is always an issue while using the survey method. It concerns the extent to which the survey sample could reflect the population group and the validity and reliability of the results. As discussed, this survey is considered to be reflective of the target group - Swedish local politicians and their stances on the issue of marketisation, with a relatively large sample ( $\mathrm{N}=1362$ as of respondents, 238 municipalities covered). Furthermore, this survey response rate could even be raised in future studies. With a relatively large sample at hand, the collected data could lead to useful conclusions in the end.

Last but not least, this study follows the ethics of research, and many efforts were made to ensure the anonymity of respondents and the confidentiality principle. Both informed consent and voluntary participation were essential to the conducting of the survey. The survey results are used only for academic purposes. 


\section{Part II. Results Analysis and Discussion}

\section{Chapter 5}

\section{Production and Outsourcing Preferences}

Past literature on marketisation has focused heavily on outsourcing preferences, specifically whether there is a certain preference among decision makers to distribute welfare tasks to various providers and, if so, possible explanations for this trend. With increasing regulations to support fair competition, preferences on certain types of care providers alone are hardly likely to decisively influence the final policy outcome.

Nevertheless, the topic of outsourcing preferences remains important to marketisation: the matter of outsourcing preference is relevant to the perceptions of different characteristics of public or private and for-profit or non-profit care providers. As shall be argued later, private and public providers do not always share the same features, such as their focus on efficiency or cost-effectiveness. Furthermore, market development could also influence and 
shape politicians' perceptions and attitudes. After 20 years of marketisation, it is intriguing to see how politicians nowadays perceive different providers in the market.

Outsourcing is connected to service production and delivery. In terms of production, there are public providers and private providers. There also exists formal care and informal care. ${ }^{93}$ What I intend to discuss here is how politicians view formal care providers, whether they are private, public, for-profit, or non-profit. In particular, I am interested in whether politicians want more private care providers in general, to what extent they welcome these various types of providers in market shares, and what the contributing factors are that could explain these preferences.

This outsourcing discussion is also connected to the issue of profits, which is discussed in another chapter. This chapter is organised as follows: firstly, I deal with the provider comparison between public and private providers, and then I move on to the survey data regarding private/public preferences. In addition, some statistical analysis including regression models are presented to help forward the discussion. ${ }^{94}$

\section{Public versus private}

As service producers, public and private providers are responsible for producing and delivering services, both as 'producers' and 'deliverers'. Public providers in Sweden are often referred to municipality owned companies that provide various sorts of care for the elderly, and profiting from the business is not assumed to be the primary goal. On the other hand, 'private provider' is an umbrella term, which includes profit-seeking firms, non-profit

\footnotetext{
${ }^{93}$ In terms of informal care, friends, neighbours, and families, or usually women in families, play a role in caring for their elderly. One emerging and pressing issue is how to provide care for people experiencing dementia. Due to the focus of this research, informal care is not discussed in detail.

${ }^{94}$ Much of this chapter has been based on one of my publications: Guo and Willner (2017).
} 
corporations, voluntary service organisations, religious and neighbourhood organisations, and so on (Dohanhue 1989, 9). In the Swedish context, the distinction between non-profit and forprofit providers is also noticeable. For instance, SOU $(2016,256)$ defined providers as follows: for-profit includes limited companies, partnerships, and certain sole proprietorships; non-profit includes economic associations, non-profit associations, and foundations. ${ }^{95}$

Apart from the ownership difference, which is discussed in the next chapter, many comparisons have focused on the performance difference; namely, how public and private providers offer services that are of different quality. Regarding performance difference, SOU (2016, p286) tried to determine whether there are significant differences between private and public providers because objective measurements are sometimes limited in the field. The report mentioned that there was no significant difference in terms of complaints filed between the customers of public and private providers.

Another survey in 2012 that covered elderly people in 17 municipalities showed no significant differences in terms of their satisfaction with care (Socialstyrelsen 2012, 26). Three years later, there was only a small difference between public and private providers in nursing homes, and the difference was almost non-existent in terms of home service (SOU 2015). ${ }^{96}$

\footnotetext{
${ }^{95}$ In Swedish, for-profit: Aktiebolag, handelsbolag och enskilda firmor betraktas vanligen som vinstsyftande. Non-profit: ekonomiska föreningar, ideella föreningar och stiftelser betraktas som icke-vinstsyftande.

96 Socialstyrelsen (The National Board of Health and Welfare) considered that user perspectives are of the utmost importance and therefore arguably placed more emphasis on the elderly satisfaction survey.
} 
Regarding structural differences, public providers perform more strongly at structural quality, such as personnel density ${ }^{97}$, competence, and housing standards. In the meantime, private providers offer services that are better suited to customers' time schedules compared with public providers. Most private providers have more protocols than public providers, such as for how to react if care workers are suspicious that an elderly patient is suffering from malnutrition (SOU 2012). International studies also suggested that non-profit companies have higher quality (Comondore et al. 2009).

Whether to address to the difference between public and private care providers has been a subject of debate. On the one hand, some view that discussions of difference are meaningless. For instance, from a pragmatic point of view, as long as the system works (i.e. services are produced and delivered with a certain level of quality), the ownership of the producers should not matter and emphasis should be placed on the contract design ${ }^{98}$ and market competitions. In this line of thinking, the output of service is key.

\section{Non-profit and for-profit}

Some of the major arguments deployed by proponents of initiating the marketisation process echoed the NPM and insisted that market competition would lead to reduced costs and improved quality, as well as increased freedom of choice for care users. This logic is also present in local outsourcing with non-profit organisations, which are characterised by their service accountability, professionalism, and community legitimacy, for instance (Feiock and Jang 2009). In their seminal contribution, Glaeser, and Shleifer (2001) argued that non-profit

\footnotetext{
${ }^{97}$ Arwidsson and Weserberg (2012) also showed that for-profit companies might lag in terms of personnel density and education level. Nevertheless, personnel density is not recommended by Socialstyrelsen for comparison for some reasons.

${ }^{98}$ Since issues that are not specified in the contract are subject to ignorance, it is important for the municipalities to make sure all important requirements of services, including quality and content, should be laid out clearly.
} 
provisions can have some advantages as there is less room for shirking on quality than in the case of powered incentives that result from profit maximisation.

The role of non-profit organisations in Swedish rural areas so far is quite limited in terms of its size and share of the market. The share of non-profit organisations is quite modest in the provision of elderly care services, accounting for $3 \%$ of the workforce (Johansson, O. 2011) that mainly operates home-care services (Konkurrensverket 2013). The reason for the relatively small share of elderly care provided by the non-profit sector is elusive. One explanation could be that Sweden has a strong public sector and activities from non-profit organisations have been performed and organised in other ways, such as through volunteering (Konkurrensverket 2013).

Traditionally, non-profit care providers in Sweden have been linked to church charities. Moreover, they face increasing competition with large private for-profit companies in the marketisation process nowadays (Meagher and Szebehely 2013).

\section{Survey results:}

1. Descriptive data about preferences of private or public care provision.

As shown in Table 5.1, there are substantial differences among the political blocs regarding preferences of the quantity of private providers in their municipality ${ }^{10}$. Only $2 \%$ of left-wing politicians preferred more private care, compared with nearly $70 \%$ of right-wing politicians. On the other hand, $58 \%$ of left-wing politicians favoured less private care, while only $2 \%$ of right-wing politicians felt the same.

Furthermore, there were also substantial differences within the blocs. The Left Party politicians were the most critical of private care in the left bloc, while the Moderate Party was the most supportive of private care in the right bloc. Both left- and right-wing politicians did not fully converge in their preference for private care provision. 
Table 5.1 Response rate (\%) for different parties when asked: Do you want more or less private elderly care in your municipality?

\begin{tabular}{lcccc}
\hline & $\begin{array}{l}\text { Slightly or } \\
\text { much more }\end{array}$ & Good as it is & $\begin{array}{l}\text { Slightly or } \\
\text { much less }\end{array}$ & N \\
\hline $\begin{array}{l}\text { Left-wing bloc } \\
\text { Left Party }\end{array}$ & 2 & 40 & 58 & 589 \\
$\begin{array}{l}\text { Social } \\
\text { Democratic }\end{array}$ & 1 & 16 & 82 & 89 \\
Green Party & 9 & 44 & 55 & 413 \\
Right-wing bloc & 70 & 46 & 45 & 87 \\
Centre Party & 66 & 27 & 2 & 667 \\
The Liberals & 64 & 31 & 3 & 154 \\
$\begin{array}{l}\text { Christian } \\
\text { Democrats }\end{array}$ & 69 & 28 & 5 & 75 \\
The Moderates & 76 & 24 & 1 & 309 \\
\hline
\end{tabular}

Regarding the optimum share of private versus public care provision ${ }^{99}$, the left bloc preferred an 85/15 share of public/private providers, while the right bloc desired a 50/50 split (Table 5.2). Preferences for profits also varied significantly between the two blocs: the rightbloc parties were more supportive of for-profit provisions, especially the Moderates $(36.96 \%)$ whereas the left-wing parties indicated the opposite. In terms of private non-profit providers, the Green Party politicians expressed a more positive attitude than the left bloc, and even more so than most right-wing parties except for the Christian Democrats. The distribution of each party for these three different categories of providers can be found in Appendix 5.

\footnotetext{
${ }^{99}$ I understand that this question might need some clarification. Regarding an optimum share, it is intended that there should be a good balance between public and private care providers in an individual municipality, which is based on local population structure-care needs, fiscal capability to be able to afford a market service, and enough care providers - public or private.
} 
Table 5.2 shows that the difference between the left and right bloc regarding preferences for shares of private and public providers remains distinctive: the left-green bloc is in general suspicious of private for-profit providers, with an indicated ideal distribution of this kind of provider being only $1.23 \% .^{100}$

Table 5.2 Preferences for public and private providers in municipal elderly care in percentages of optimal shares.

\begin{tabular}{lccc}
\hline & For-profit & Non-profit & Public \\
\hline Left-green bloc (430) & 1.23 & 13.33 & 85.44 \\
Green Party (67) & 3.36 & 23.13 & 73.51 \\
Social Democrats (296) & 1.03 & 11.71 & 87.26 \\
Left Party (67) & 0 & 10.38 & 89.62 \\
Right-centre bloc (360) & 30.76 & 19.87 & 49.37 \\
Centre Party (81) & 21.7 & 19.38 & 58.92 \\
Liberals (78) & 29.78 & 19.6 & 50.62 \\
Christian Dem. (40) & 26.05 & 25.4 & 48.55 \\
Moderate Party (161) & 36.96 & 18.86 & 44.18 \\
\hline
\end{tabular}

When considering general preferences for privatisation in the survey data, a clear difference between the political blocs can be identified: Red-Greens demonstrated very strong support for public elderly care and a very low preference (almost none) for for-profit providers, whereas the Alliance favoured more private and for-profit care providers.

${ }^{100}$ Not all politicians specified numbers for all of these three providers. Therefore, different $\mathrm{N}$ sizes in these tables are displayed. 


\section{Theoretical modelling}

After showing the distinct partisan approach to privatisation, logistic regression ${ }^{101}$ models were utilised to examine how different individual and contextual factors might have influenced preference shaping. The independent and dependent variables used are shown in Table 5.3. Meanwhile, ordinary least-squares (OLS) regressions were performed in the analysis of optimum share question, and the results are presented in Table 5.5. ${ }^{102}$

\footnotetext{
101 The dataset seems to bear the problems of heteroscedasticity, and data are not distributed normally. Therefore, I chose the Huber-White method in the new analysis, which releases the assumptions of normal distribution and homoscedasticity. There are only minor changes in the "standard error", confidence intervals and p-values, compared with OLS regression models. In addition, I performed some goodness-of-fit tests: Hosmer-Lemesbow tests for logit estimations and $\mathrm{R}^{2}$ for normal regressions.

102 "Multilevel models are a useful tool for quantitative analysis when the problem under investigation has a multilevel structure when a process is thought to operate at more than one level or scale, or when the researcher is particularly interested in variability and heterogeneity and not just overall average values" (Jones and Duncan 1998).
} 


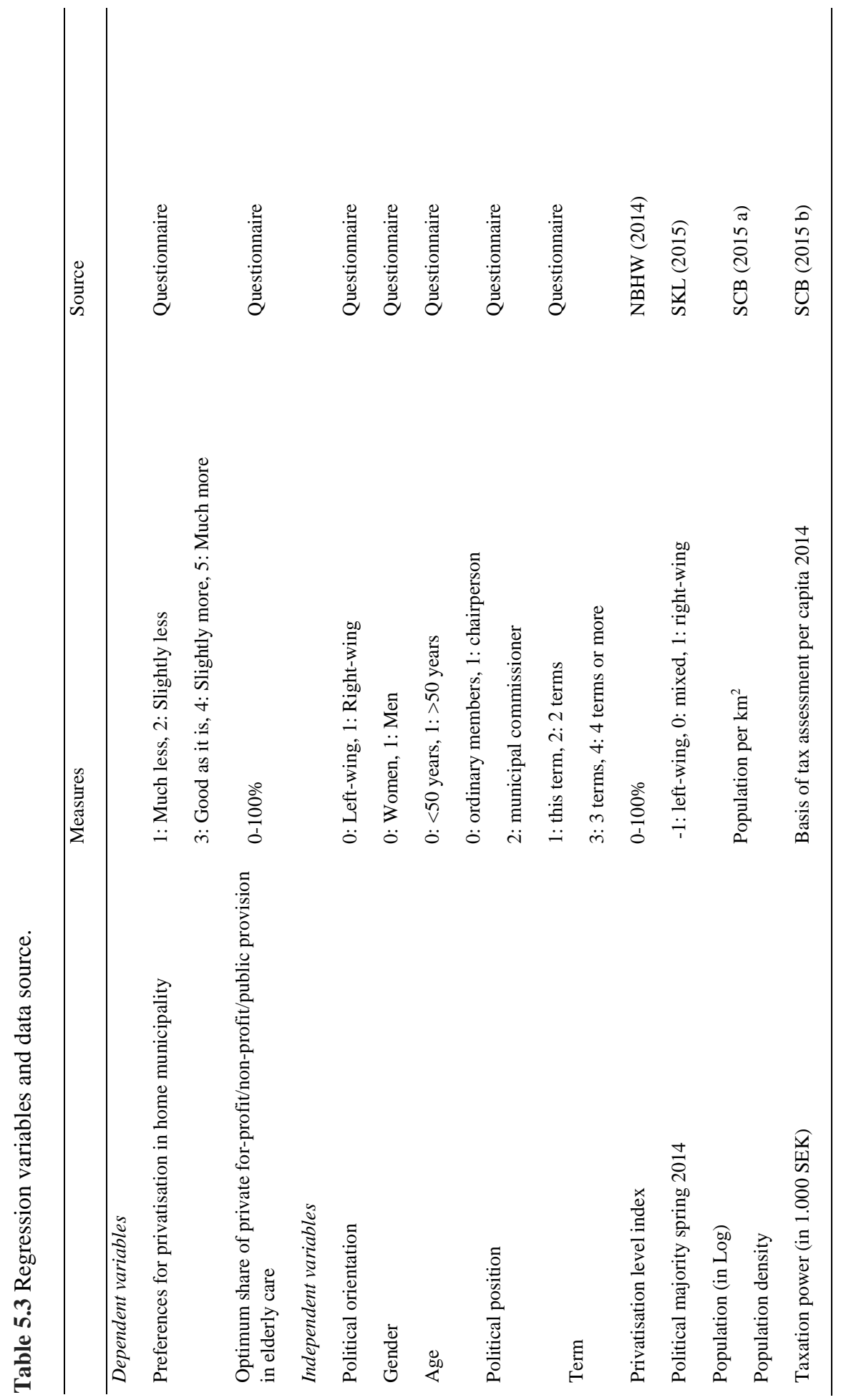


Table 5.4 presents models of politicians' willingness to have more private providers in their municipalities. Model 1 includes only individual factors, and political orientation is shown to be of great significance, whereas age, gender, and other individual attributes did not affect the preference shaping. Privatisation level in local municipality might also influence attitudes, and it was chosen to include this factor in Model 2 and Model 4. Model 2 shows both political orientation and local privatisation as significant covariates. It is notable that the general fitness of regression model decreases as the Hosmer-Lemeshow test significance drops from 0.931 to 0.605 .

Model 3 covers both individual-level and municipality-level factors, excluding degree of privatisation. The significance result suggests that political orientation and majority are two important factors that could account for preference as a dependent variable. Taking degree of privatisation into consideration, Model 4 shows that three covariates are statistically significant: political orientation, political majority, and privatisation level. To be more specific, right-wing political orientation is positively associated with a preference for more private providers, whereas a right-wing majority and a higher degree of local privatisation negatively affect this preference.

Table 5.5 explores how different factors might account for the preferences for each kind of care providers. It can be noticed that age, gender, and political orientations play an important role in shaping for-profit provider preferences. The population density of a municipality and political majority could also shape the preference. 


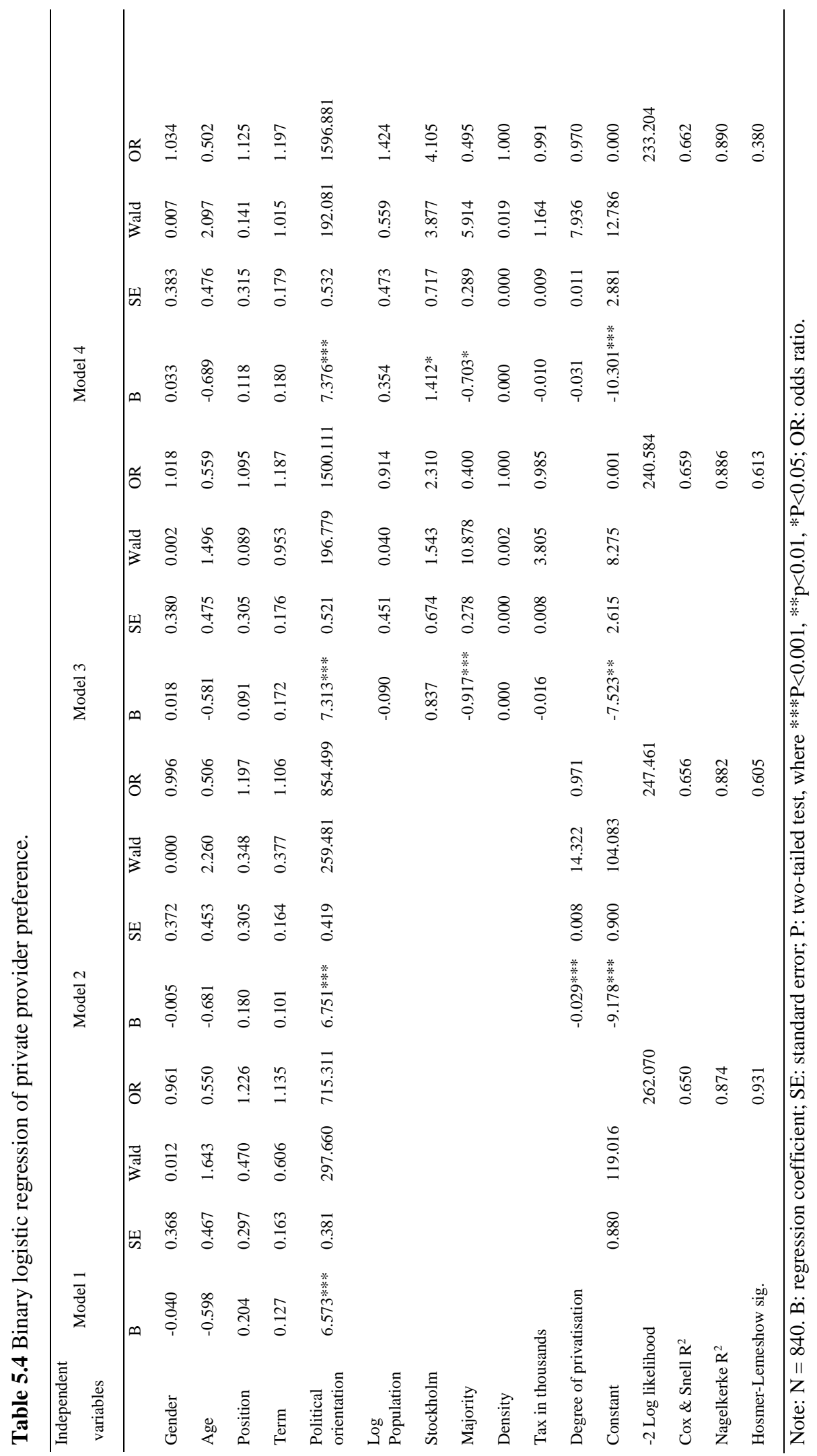




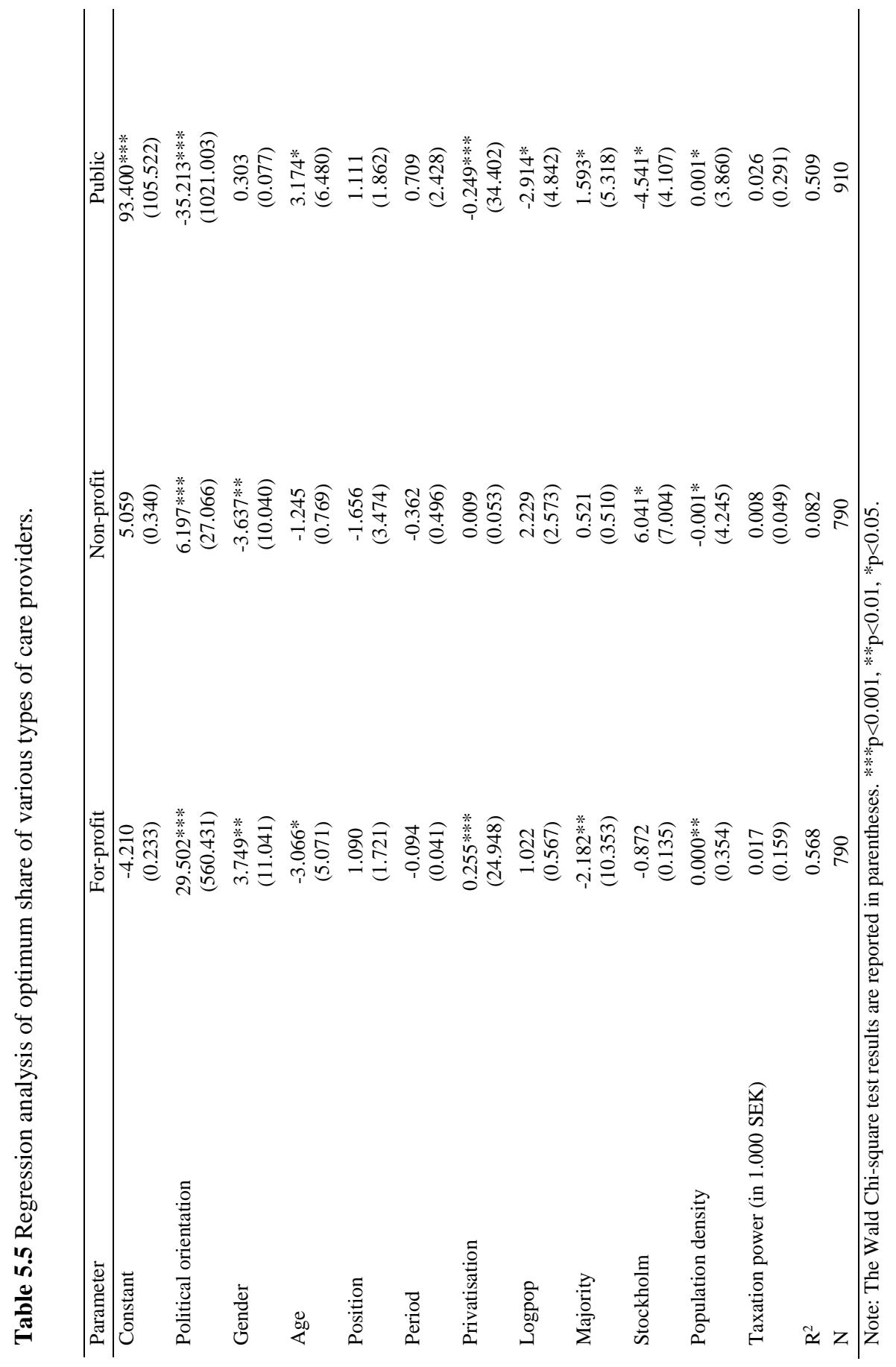




\section{Discussion}

The above analysis displays a substantial difference between local politicians from two political blocs regarding their preferences for elderly care privatisation. Descriptive statistic data show that left- and right-wing politicians embrace various service providers to a different extent, and the same data reveal the distinctive attitude patterns for private for-profit providers: $1.23 \%$ from the left versus $30.76 \%$ from the right. On the one hand, this could result from distinct political orientation and policy goals. On the other hand, the reason for this distinct preference could stem from in the tax-funded nature of the Swedish elderly care system and the notion that some political parties are critical of profiting from the publicly funded system. Therefore, a debate about ownership is more likely to be transferred into a debate revolving around profit-making and public funding.

Based on the regression models (both in Table 5.4 and Table 5.5), political factors are important and could account for attitude patterns. On an individual level, neoliberal political orientation is positively associated with preferences for private providers and how resources should be distributed in the system. This result may not be surprising when considering what traditional partisanship theory claims: right-wing politicians embrace more neoliberal and market-oriented solutions compared with their left-wing counterparts. In this way, the diminishing influence of the political orientation argument is questionable. It can even be concluded that Swedish local politicians' preferences for private providers appear to be due in large part to their political orientation, which also interacts with non-political factors such as family values or belief in religion.

It is somewhat surprising to see that political majority negatively influences the private provider preference: a right-wing-dominated local government is more likely to be associated with negative preferences for private providers (Table 5.4). It is curious why 
political majority at the municipality level negatively affects such preferences. I offer some plausible explanations here. First, a compromise argument: right-wing politicians in charge of government might be more pragmatic and willing to compromise, which renders their attitudes less radical compared to when they are in opposition (Gilljam and Karlsson 2015). Rustow (1957) once saw Sweden as the epitome of the "politics of compromise", and Petersson (1994, page 33) explained that "an emphasis on compromise and pragmatic solutions has led to the development of a political culture based on consensus."

Second, blame avoidance: political parties in the majority are more careful about pushing forward more drastic market reforms for which they could be held responsible. Third, more privatisation also tends to weaken the basis for political control as it reduces the local authority's scope for exerting influence. I remain open to the discussion of political majority, as the interaction between local government majority and minority might be dynamic and complex.

Regarding non-profit provider preferences, my analysis also confirms the importance of political factors, as has been shown by other studies (Feiock and Jang 2009; Warner and Hefetz 2012). In the Swedish context, the very nature of the public funding system might compel local politicians, as gatekeepers of the welfare system, to be stricter about market entry conditions for providers. Smaller and less populated areas might have limited capacity to build a public care system. In this regard, the introduction of a customer-choice (voucher) system seems both feasible and favourable, as the system then only relies on elements of market competition and can still provide publicly subsidised care without limiting user choice. Indeed, a marked increase in numbers of non-profit providers of social services has been reported after the introduction of a voucher system in several other countries (Warner and Gradus 2011). 
Privatisation level is another significant covariate in this study's findings, which is measured as an average of both home service hours and special housing provided by private providers. ${ }^{103}$ As shown in Table 5.4, the addition of this index seems to lower the fitness of the model, which compelled us to test other alternative independent variables. For instance, when the percentage of private nursing homes was used in Model 4, the Hosmer-Lemeshow test significance increased from 0.38 to 0.809 , which suggests that this new measurement of privatisation level is better.

Table 5.4 also shows that the actual privatisation level likely negatively affects the expressed preferences for more private elderly care in one's municipality. This seemingly intriguing result could be interpreted in different ways: first, for some municipalities, it may become impossible to increase the share of private providers if the private sector already runs $100 \%$ of elderly care. Second, a rather tempting explanation is that local politicians might be aware of the limitations of the market solution and therefore do not want to accelerate the privatisation process, which could also explain the relatively low degree of privatisation nationwide (around 21\% regarding home services and nursing homes). A third explanation is that municipalities in rural areas are less attractive to private providers because of the smaller market and less potential profit.

Admittedly, the causal relationship between political orientation and level of privatisation in a municipality is hard to determine based on our data. The question could be simplified by inquiring as to what extent political factors account for the degree of privatisation, both on an institutional and individual level.

Table 5.5 presents the results of the preferences using multiple regression models. I divide the preference for private providers into two subcategories: for-profit and non-profit.

${ }^{103}$ SOU $(2016,288)$ : the content and variations of home service might vary from one municipality to another, in terms of both scope and content. 
The regression results show that age, gender, and political orientation on an individual level are important factors to explain for-profit provider preference.

Age, on the other hand, is negatively associated with preference: the older group (over 50 years old) reported feeling more negatively about choosing private-for-profit providers to deliver elderly care. Female politicians also expressed more scepticism about private providers. Positions and served terms did not seem to influence the results. At the municipal level, the regression model shows that political majority is negatively associated with privatefor-profit preference: right-wing-dominated municipalities tend to accompany negative views about private-for-profit providers.

As the coefficient of determination $\left(\mathrm{R}^{2}\right)$ is quite low in the model for non-profit providers, I remain cautious about the interpretations. Similar to the previous model for forprofit, political orientation and gender seem to be important individual factors. Regarding other contextual factors, Stockholm area appears to be associated with a positive attitude toward non-profit providers whereas higher population density is likely to negatively influence attitudes.

Regarding public provider preference, I noticed that political orientation, privatisation level, and a local government majority are important factors. Furthermore, older age is positively linked with positive public provider preferences, similar to previous study results. Although higher population density favours a preference for public providers, population size (in the $\log$ ) in general is negatively associated with more public provisions, which suggests that the higher the population is, the more likely there is support for various provisions.

In brief, right-wing politicians, especially younger male ones, tend to favour more forprofit private providers. A right-wing political majority in the municipality as well as a 
relatively higher privatisation level already achieved locally are likely to restrict local politicians' willingness to privatise further.

\section{Conclusion}

To conclude, it seems that different preferences of private or public providers and for-profit or non-profit providers continue to exist. Meanwhile, family contributions to care are not highly supported by the politicians as a result of heavy reliance on a public care production system.

My survey results demonstrate that local politicians' preferences still diverge between political blocs, with left-wing politicians being more cautious about private and for-profit care providers compared with their counterparts in the right-wing bloc. Local politicians are still, to a large extent, driven by their political orientation in engaging with issues of privatisation. In this sense, the traditional conceptualisation of left and right is still useful as a simple marker for identifying market preferences.

Past literature has shown that personal factors such as age, gender, and socioeconomic factors could shape attitudes toward welfare. Among the contributing factors that were investigated, political affiliation of the individual, the political majority at the time, and the degree of privatisation already present in their home municipality were identified as the most important factors in explaining the distinct preferences for private for-profit care providers. This finding is in line with previous studies (Bel and Fageda 2007; Hefetz and Warner 2012) and acts as a reminder of the importance of contextual factors in shaping not only politicians' preferences but also in explaining the various level of privatisation across municipalities. 


\section{Chapter 6}

\section{Profits and Ownership}

The issue of profit is deemed as a rather contentious and has received much attention from both the left and the right-wing parties. Despite the market advancement in past years, debates about the role of the market and its implications in the welfare state have not ceased to disappear. In the Swedish case, the issue of profit in welfare services was somewhat neglected previously but now receives much more attention than ever before.

It is generally perceived that the left stands against profits and the right is supportive of profits in a welfare market. Still, it is debatable whether it can be expected that an intolerance of profits is existent within the left-wing politicians and their parties. As far as the right-wing politicians are concerned, it is almost impossible to entirely abandon the welfare state and fully pursue their optimal market system due to the legacy of the welfare state. 
Bearing this in mind, it is then intriguing to determine what level of profit from a welfare state is acceptable in their opinion and what kind of comprise they are willing to make with market opponents.

In this chapter, I first briefly review the debate about profit, and discuss why the issue of profit is not only important but also controversial. Then, I present patterns of attitudes regarding profit from the survey results. Finally, I address some issues relevant to the discussion of profit-making from a theoretical perspective to recapture what ideas are involved in the debate really.

\section{A brief review of the profit debate}

Profit is a rather debated issue in market reform. A brief review of profit in the welfare state illuminates this discussion. According to Statistics Sweden (2015), the private welfare sector is very profitable: an average return on equity was $21 \%$ in all three areas (education, health care, and social care), compared to $11 \%$ in the service sector overall in $2013 .{ }^{104}$ The comparison of profit levels is shown in Table 6.1.

Still, it should also be noted that small- to medium-sized care providers may not be capable of reaching the profit level listed here. It is often larger companies that benefit more from the business scale. Even for the procurement process, smaller companies can find themselves in a more vulnerable position when competing with larger companies that are more resourceful (Meagher and Szebehely 2013). Having said that, it is fair to say that the profit margin still varies across the sector.

\footnotetext{
${ }^{104}$ It should be mentioned here that there are different ways of understanding the 'profits' in question. Some might argue that as long as operational gains are reinvested, then the use of profit is inappropriate. In the meanwhile, it has to be pointed out here that larger private companies find it easier to compete with smaller ones, with a consequence being that their shares in the market and net profits exceed those of the smaller ones.
} 
Table 6.1 Profit-making by comparison.

\begin{tabular}{llll}
\hline & Social Care & Welfare in total & The Service Sector \\
\hline $\begin{array}{l}\text { Total return capital } \\
\text { (percent) }\end{array}$ & 15.8 & 13.4 & 7.4 \\
$\begin{array}{l}\text { Return on equity } \\
\text { (percent) }\end{array}$ & 36.9 & 27.5 & 14.3 \\
\hline
\end{tabular}

Source: SOU (2016: 78). Ordning och reda i välfärden.

\section{Different views about profiting}

From SOU (2016), it can be noted that a profit-driven focus can have some problematic risks. For example, it could result in only delivering such quality and properties as are actually measured and replaced. Strong financial incentives could also contribute to segregation because a company might select user groups that are associated with low costs.

Much of this discussion resembles the discussion of outsourcing preferences. To some extent, the key difference among care providers lies in the perception of how to define profitseeking in the welfare state. This difference is precisely one defining characteristic between left- and right-wing political parties, even though the line can be somewhat blurry.

In the party election manifesto 2014, the Swedish Social Democrats sharpened their stance about profit-making in the elderly care field. In general, they aimed to stop the pursuit of profits in health care and social care, raise the quality of provided care, and guarantee the elderly choices and diversity of services. They came out in opposition to the right-wing parties' tax cuts and privatisation motives and practices for various reasons: care is necessarily stressful work, and there need to be more skilled care workers who can spend enough time caring for the elderly; corporate profits were put first in the market rather than care needs. The Social Democrats also opposed the forced privatisation of elderly care in Sweden, noting that the elderly are entitled to much better welfare. 
On the other hand, the Moderates shaped their policy as follows: the elderly should not be treated in the same way in terms of care; have a fair pension system and reasonable economic situation; feel safe and as agented participants; and feel free and independent with their own interests, desires, and needs. The care system should be financed by taxes and function as a patient-centred or user-centred system. ${ }^{105}$

In the left bloc, the Left Party announced itself as more critical to the current care system. They wrote that since the 1990s, the least resources have been allocated, with care workers having insufficient time to provide suitable care and families adopting an increasing care burden. Instead, they have argued for an accessible, equitable, and high-quality system, with more nurses, staff, and continuity. They claim that no profits should be allowed and more resources should be invested to offer more care homes, hire staff, and offer training jobs. Furthermore, they desired for the elderly to be empowered and supported to improve life quality. The Green Party did not specify their stance on profits in their manifesto. One focus was to ensure the elderly have opportunities to be active and make their own choices. The elderly should also be able to have easy access to the surrounding environment and society.

${ }^{105}$ Some studies that concern party manifestos have shown that the Alliansen parties are more conservative than liberal, c.f. Jesslén (2015). Although I do not discuss the liberalism and conservatism in the right-wing bloc, this might be an interesting topic to pursue in future research. One reason for this is that privatisation per se is often considered as a neoliberal way of organising and providing provisions of products. In the Swedish context, it is centreright wing parties, often perceived as more conservative, that push forward privatisation. Therefore, the question arises: how do neoliberal ideas interact with conservatism? Another intriguing question is to compare new liberalism with neoliberalism in the Swedish case. It is argued that there are differences regarding these two sets of liberalism, despite that both terms end with 'liberalism'. Referring to literature such as Adams (2001) or Springer et al. (2016), neoliberalism is often associated with laissez-faire economic liberalism and policies such as privatisation, fiscal austerity, deregulation, and free trade. New liberalism, a synonym for social liberalism, endorses a market economy and the expansion of civil and political rights and liberties without denying the legitimacy of the government. The government addresses issues such as poverty, health care, and education and engages in the development of a welfare state. In the Swedish context, Social Democratic and Liberal parties might serve as two interesting cases to determine which liberalism could potentially affect party ideology and policymaking. 
The rise of the for-profit sector gradually became a subject of political debate, which culminated in the government investigation of profits. A government commission, the Reepalu Commission, was designated in 2015 with the mission to investigate and then propose a regulation to limit profit-taking by private providers in welfare services. The proposal suggested that operating profit (operativ kapital) should be limited to maximum 7\% (SOU report 2016) with only a few exceptions. On February 22, 2017, the Social Democrats backed these suggestions and proposed that school education should be the first area to impose such profit limits, meaning that profits in health care and social care would not be limited in the near future. ${ }^{106}$

\section{The importance of discussing profit}

For some politicians, profiting is in conflict with the principles of the welfare state. There are several points to explain why profit has been a major issue besides its popular appearances in different debates. First, it is relevant to the ownership form of care providers and their motivation to stay in the market. Razavi (2007) argued that the logic of market provisions concerned with profit seeking is one important aspect of care. ${ }^{107}$ Secondly, profit-driven attitudes are often associated with bad morals or ethics in care delivery and are seen as explanations for the occurrence of scandals. With care scandals reported on occasion, the

\footnotetext{
106 This is related to the lack of political support from the $\mathrm{S}$ side. Alliansen parties do not agree on the profit limits, and Vänsterpartiet favours a total ban on all three sorts of welfare services. Nevertheless, local politicians in the Social Democratic Party congregation 2017 expressed more willingness to push forward profit limits to all welfare sectors.

${ }^{107} \mathrm{He}$ coined the term 'care diamond', which highlights four important logics related to elderly care: a) The logic of market provision concerned with profit-seeking through competition; b) The logic of state provision to meet citizens' social rights operating through formal or public institutions and state bureaucracies; c) The logic of associations working through formal, private, or non-profit bodies whose rules originate in ethical norms and codes; d) And the logic of the informal, a private family provision whose rules and practices are embedded in moral or personal obligation and emotional or social relations.
} 
public is concerned with the quality of care they receive and will receive in future. ${ }^{108}$ Some politicians express their concern that the market mainly serves profit-making opportunities for private owners of care companies, and the generous public funding system is subject to abuse. Profits are used as an argument to increase government control over the market. Thirdly, compared to other aspects of marketisation, such as freedom of choice, profiting is a much more tangible issue that is less sophisticated and susceptible to garnering public attention and even electorates' supports. Compared with quality, profits are much easier to measure, especially from an economic point of view, and are easier to subject to regulations, at least in theory. Last but not least, relevant to the welfare state discussion in this research, the profit issue is entangled with inner principles of the welfare state such as equality and solidarity, which often cause certain tensions in reality. The rapid increase in profits from the welfare state is arguably detrimental to the legitimacy of the welfare state and could lead to inequality and segregation, among many other possibilities.

\section{Why ownership?}

The ambiguity of quality differences or a lack of compelling evidence to show the strengths of different provider in various aspects of care seems to have an influence on political opinions on the issue of ownership. There are several reasons to account for the importance of the ownership question besides the contended quality differences among various types of providers. The ownership issue, in my view, is not only linked with providers' motivations to

\footnotetext{
${ }^{108}$ For instance, in October 2011, it was revealed that elderly residents were mistreated at Koppargården, one of several special housings for the elderly run by the private company Carema. The company was then criticised for being profit-driven and putting the elderly in jeopardy. This scandal attracted enormous attention across society. Investigations were followed and sanctions were imposed. As a result, the company lost many contracts as well as its credibility, which resulted in a change of its brand name to Vardaga. See, for instance, Teneliu and Selling (2016).
} 
compete and stay in the market but also operates as a question of responsibility and accountability.

For instance, in current debates, the right bloc parties have insisted on the importance of service outcomes, mostly quality concerns, while not engaging directly in discussions on the differences between private and public providers, which was a major focus for the leftwing parties. Examples could be found by examining party election manifestos (see, for instance, Appendix 3). There could be several explanations for this right-wing position: the right-wing may not want to explicitly tackle this private/public ownership debate, as it is now a 'cliché'; they may assume that this debate is quite driven by political ideology and thus it is difficult to change existing views; or they may consider that there are other alternative ways to appeal to elderly voters and personnel working in the field, be it private owners or care workers.

Meanwhile, different characteristics of public, private, for-profit, and non-profit providers are essential to policy-making discussions. Several distinct features that public and private providers share can be highlighted here:

First and foremost, public services are not meant to operate in the same manner as traditional businesses as they often have other goals besides commercial interests. For instance, public social care cannot reject problematic cases that are bad for business and leave someone unattended. By contrast, private care providers, if driven only by commercial efficiency or profits, can produce service units at the lowest unit cost without necessarily covering problematic cases. Second, exiting from the market is not an option for public providers for the public's sake (Spicker, 2014). Whether it is a universal welfare system or a residual one, the public system often serves as a safety net and last resort for the needy. 
Thirdly, the relationship between users ${ }^{109}$ and service providers is shaped differently in the market. The elderly receive public services to fulfil their needs and are treated more as citizens, while private providers tend to treat them as customers (e.g. Clarke 2006; Meinow et al., 2011). The relationship in the first scenario is based more on general redistributive purposes, and economic gains are the focus in the latter.

Moreover, it might be the case that public care providers lack motivation regarding cost containment, less bureaucracy, and higher efficiency in the first place. Nevertheless, it could be argued that when there is market competition, both public and private $\mathrm{b}$ providers could increase their efficiency.

In brief, public services provided by the public sector are not always the same as those offered by the private providers. It is possible that policy-makers push public or non-profit sectors to mimic private production without fully acknowledging these differences.

\section{Survey results presented:}

Question: Should profits be allowed for private providers in tax-financed elderly care?

Regarding the profit question, the results show that differences between left and right parties remains. In general, nearly $76.9 \%$ of right-wing politicians accept the idea that profiting should be possible from elderly care services despite its publicly funded nature.

I devised two questions to test and confirm these answers about profits, Q19 and Q20, which are positive and negative formulations of profits permission for the private providers, respectively. The results display consistency. The two questions, Q21 and Q22, also probe whether competition leads to better or worse working conditions for care professionals. The

${ }^{109}$ Omsorgstagare/brukarna/avnämarna are used in Swedish to denote users. 
exact percentage breakdown of answers to each question are presented Figure 6.1 and can be found in detail in Appendix 6.

Table 6.2 Answers to the question regarding whether profits should be allowed.

\begin{tabular}{lrcrcrr}
\hline $\begin{array}{l}\text { Profits } \\
\text { allowed }\end{array}$ & $\begin{array}{r}\text { Strongly } \\
\text { agree }\end{array}$ & Agree & Neutral & Disagree & $\begin{array}{l}\text { Strongly } \\
\text { disagree }\end{array}$ & N \\
\hline & & & & & & \\
Left & 1.68 & 7.28 & 5.22 & 18.28 & 67.54 & 536 \\
Right & 32.3 & 44.59 & 10.49 & 8.03 & 4.59 & 610 \\
\hline
\end{tabular}

Table 6.3 Questions in negative formulations.

No. Questions

Q20 Profits should not be allowed within publicly financed elderly care.

Private profit in the elderly care is likely to lead to deterioration of the working

Q22 conditions of the staff.

Q23 Private profit in elderly care is likely to lead to poorer quality.

Table 6.4 Response rate for profit-related questions.

\begin{tabular}{llccccccccc} 
& & V & S & MP & Left bloc & C & FP & KD & M Right bloc \\
\hline Q20 & Agree & 91 & 81 & 83 & 83 & 32 & 31 & 31 & 20 & 26 \\
& Disagree & 8 & 16 & 12 & 14 & 47 & 53 & 52 & 67 & 58 \\
Q22 & Agree & 98 & 92 & 80 & 91 & 18 & 12 & 11 & 8 & 12 \\
& Disagree & 0 & 1 & 8 & 2 & 64 & 69 & 73 & 80 & 73 \\
Q23 & Agree & 96 & 86 & 72 & 86 & 16 & 9 & 11 & 6 & 10 \\
& Disagree & 0 & 2 & 11 & 3 & 72 & 77 & 70 & 86 & 79 \\
\hline
\end{tabular}




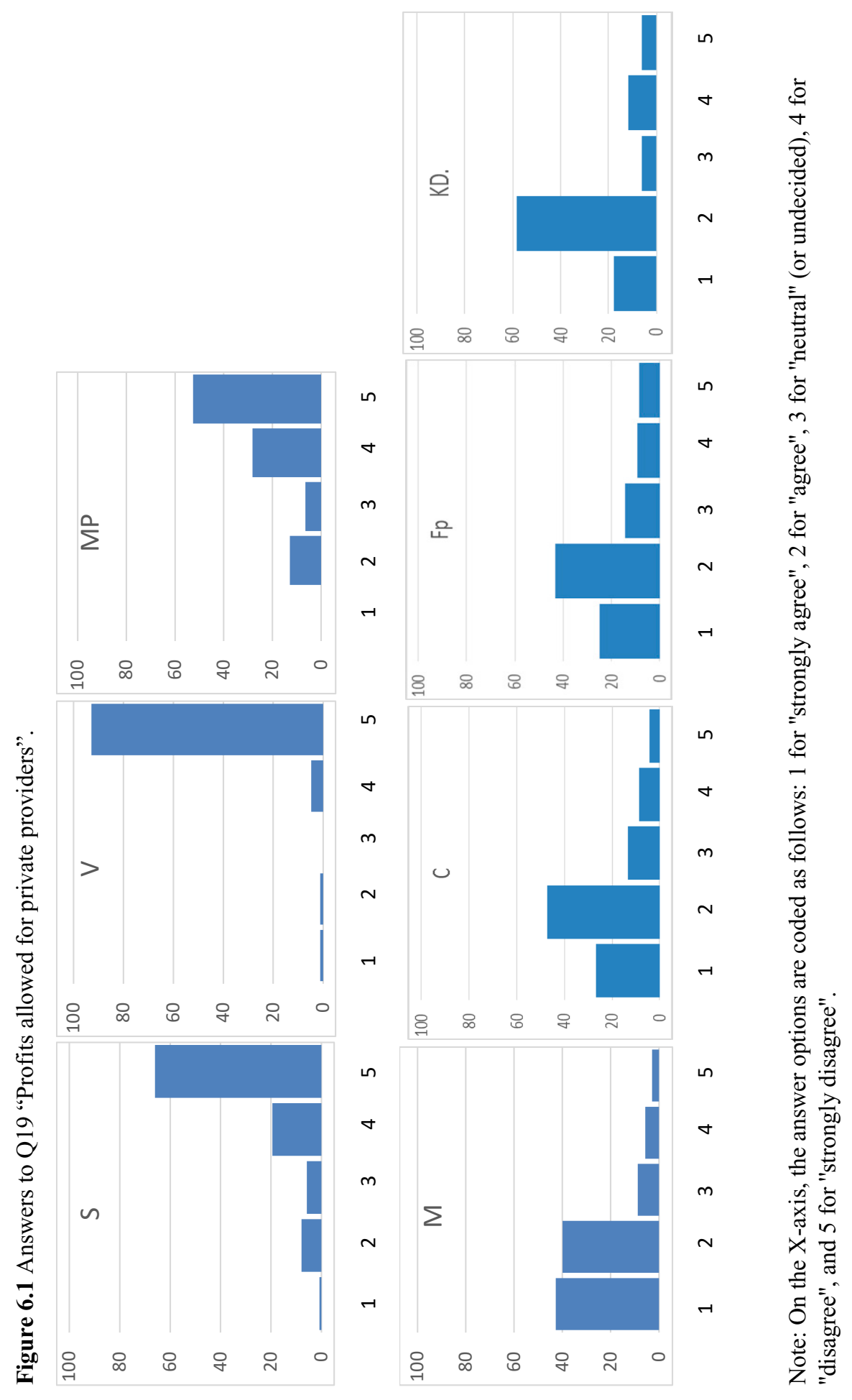




\section{Discussion}

1. The left and right-wing parties differed entirely in their answers to profit-related questions. One explanation for this difference is that the profit issue, in general, is heavily ideologically charged. The general differences among various political parties' perceptions on the issue of capitalism and socialism seem to be persistent in their ideas on profits: left-wing politicians are less supportive of commercial interests, especially out of a public financed domain, whereas right-wing politicians are more tolerant of making profits in the welfare sector. ${ }^{110}$ As argued next, the explanations of this pattern of attitudes about profits share some common reasoning as those of the ownership issue.

It should be noted that 'profit' and the related debate have different dimensions. One dimension deals more with how for-private care providers' motivations could influence their performance; for instance, whether profiting is given priority while quality of care is sacrificed. Another dimension revolves the concept of 'profit'. Some have argued that as long as the surplus is reinvested in the business, it is problematic to use the word 'profit'. ${ }^{111}$ Relevant to this discussion, it is nowadays hotly debated as to how much profit should be allowed (SOU 2016).

This question of profit is essential to the marketisation debate as the consequences of allowing or forbidding profits are more relevant to market restructuring than to influencing

\footnotetext{
${ }^{110}$ I also noticed from the survey, in the open questions section, that some politicians were convinced that ownership was of no importance to the general discussion, whereas quality as an output should be focused upon. It is understandable that "unless service quality can be identified, specified, and monitored, there is a risk for quality deterioration" (Sørensen and Bay 2002). Quality as an output is very much emphasised in the discussion of marketisation. However, up to now, there has been no substantial evidence indicating that a significant quality difference exists between these various providers (Meagher and Szebehely 2013) nor a consensus of how quality should be measured.

${ }^{111}$ Public providers can also have surpluses that they tend to reinvest in their operations. By contrast, a common critic of the for-profit providers is that they put money in their own pocket and sometimes hide in an offshore tax haven.
} 
care workers in the field. If profiting is allowed in elderly care, a more appropriate question to ask would enquire into what level should profits be allowed, which is again subject to political debate. Recent political debates about setting up a limit for profits from the welfare services draw increasing attention among politicians and also private care providers.

\section{About ownership.}

Meanwhile, this discussion of profit is connected to issues of private or public ownership. What I try to focus on here is the interconnection of profit questions with the ownership discussion.

As is often argued, profits are not a goal for public providers in Sweden. The public sector is the most important service provider and the provider of last resort services, which refers to the offering of services when no other provider will (Spicker 2014). One rationale for limiting profits is that tax money should be used for elderly care instead of contributing to private profits, and even if there are profits, they should be reinvested into the welfare state. The same argument applies to non-profit private providers as well, despite its relatively small influence on the market. ${ }^{112}$

I offer some possible explanations here to account for this difference. To begin with, the left-leaning parties have deep historical and institutional ties with public sector producers. Despite the loosening ties between them, the left parties still advocate on their behalf (Howell, 2001). Therefore, this difference could be attributed to the left's residual ideationally motivated suspicion of market-based solutions, despite the advent of the "third way" (Le Grand, 2007). Addressing connections between political parties and their represented social groups is essential to understanding the various provider preferences, as suggested by the

112 The non-profit private sector comprised 3\% of the workforce, according to Johansson (2011). 
traditional partisanship theory. Zehavi (2012) also asserted that these enduring differences between left and right are attributable to the differential effect of programme constituencies. In the case of social care, the elderly are often viewed as a rather vulnerable social group, so it then becomes important for left-wing political parties to identify with this constituency and represent their interests. Meanwhile, the strong support of private and for-profit providers on the right bloc might also hinge on the ideas that a public monopoly should be avoided and various suppliers should be able to compete in the process of contracting out.

\section{Conclusion}

The debate about whether profits should be allowed has become more intensified in recent years. The profit argument could be considered as a dividing line between two different ideological directions. The Red-Greens have been more consistent in refusing profits in publicly funded elderly care, while the Alliance parties are tolerant and even encourage private gains from care businesses. The left block, especially the Left Party, believes that profits are not appropriate if drawn from the publicly funded field and reject that idea that private shareholders should obtain financial gains at the expense of the government and taxpayers (Bergmark et al., 2000); this result is in line with the parties' political ideologies. The right-wing parties favour entrepreneurship and argue that allowing profit-making would not only attract private providers to participate in the care field, but also encourage them to stay in the market. In this discourse, profit is thus conceived by the right-wing parties as a legitimate and practical means of offering diverse care options.

The ownership issue is an important part of the debate between the left and right parties. As mentioned above, previous studies in the literature indicated the right's goals of lower taxes and limited public services as well as their support for more individual

responsibility concerning access to services. When considering general preferences for 
privatisation in this study's survey data, a clear difference between the political blocs can be identified: lefts demonstrated adamant support for public elderly care and very low preference (almost none) for for-profit providers, whereas the Alliance favoured more private and for-profit care providers. The results here support the difference thesis.

From this point, it is important to consider how to further the discussion rather than allow it to be an endless debate. My understanding is that if private providers are introduced, profit is allowed de facto. Unless the market solution is entirely abandoned or reversed, which is hardly likely in those municipalities that have introduced the market mechanism, profit-seeking has cause to remain. If that is the case, then the question to consider is what level of profit is acceptable. A balance of various interests, including the taxpayers, municipalities, and care providers, must be found.

Of course, I do not claim that different political parties and politicians will soon discard the question about whether profits should be prohibited nor will they quickly come to an agreement of the perfect percentage of profits allowed for the business. What I intend to comment on is that in a market context, the tension between commercial interests and some welfare state principles, such as solidarity, equality, and democracy, must be reconciled. As a decisive player in the game, at least in the case of Swedish elderly care, local politicians and their views matter. 


\section{Chapter 7}

\section{Quality, Efficiency, and Freedom of Choice}

Freedom of choice could be considered as one important tool that is used to facilitate market development. From the user perspective, the elderly have the possibility to choose among various care providers, be they public, private, for-profit, or non-profit providers.

As shown in Chapter 2, a quasi-market is marked with problems about information or agent - principle issues. For customers to be able to choose, they must have access to information about care services. Moreover, the same logic applies to the municipality, as they need information to assure that market competition works and quality standards are met. Since the elderly do not directly pay for the care ${ }^{113}$, nor do they set up the requirements to

\footnotetext{
${ }^{113}$ It is meant here that the costs of elderly care services are mainly covered by the municipal tax, and the elderly do not pay for the home services the same way as they pay for products in a supermarket or get a haircut. In terms of special housing for elderly people, a certain fee
} 
allow market entrance for care providers, their agents - civil servants and politicians - have a task to make sure the system works.

This chapter discusses perceived gains of the market mechanism, specifically better quality and efficiency, as well as the issue of freedom of choice. A brief discussion of the concepts around freedom, choice, and freedom of choice is intended to bring philosophical reasoning to the debate. Both advantages and disadvantages of the choice model are discussed.

\section{Introduction}

Many NPM scholars have argued that competition in the market would overcome the limits of the government and achieve the perceived outcomes, such as increased quality, efficiency, and freedom of choice for care users, among many other possibilities (Blomqvist 2004; Hood 1991; Lundsgaard 2002; Manning 2001; Osborne and Gaebler 1992; Savas 2000). Perceptions of these market gains have been advocated by NPM scholars and used to initiate welfare reforms and an increasing use of market mechanisms.

Millares (2015) has compared how political parties, mostly the Social Democrats (S) and the Moderates (M), view the dynamic relationship between civil society, the state, and the market as shown in Table 7.1. ${ }^{114}$ It is clear that the Moderates' view of the market and civil society and how they perceive the 'real problems' with the state or government have remained unchanged. Their version of state should include freedom, equality, and unity. According to Millares' analysis, the Social Democrats' view on the ideal picture of the state and its problems has remained mostly unchanged as well. This party's perceptions of

could be charged based on the evaluation of the individuals' pensions. Of course, there are variations among different municipalities.

114 These tables are adapted from and based on figures 2.1, 2.2, 2.3, and 2.4 from Millares (2015). 
potential problems linked with the market have always been associated with the segregation effect and market monopoly. Based on Millares' analysis, it is somewhat surprising to notice that the Social Democrats' current vision of the market is the same as the Moderates: freedom, efficiency, creativity, and diversity. This might suggest that both parties have formed a similar view on the ideal formation of the market.

Table 7.1 Evolution of ideal pictures of the market, the state, and civil society for Social Democrats and Moderates.

\begin{tabular}{|c|c|c|c|c|c|c|}
\hline & \multicolumn{2}{|c|}{ Market } & \multicolumn{2}{|l|}{ State } & \multicolumn{2}{|c|}{$\begin{array}{l}\text { Civil } \\
\text { Society }\end{array}$} \\
\hline & before & after & before & after & before & after \\
\hline S & & $\begin{array}{l}\text { efficiency } \\
\text { freedom } \\
\text { creativity } \\
\text { diversity }\end{array}$ & & $\begin{array}{l}\text { lom } \\
\text { ice } \\
\text { cracy } \\
\text { arity }\end{array}$ & & \\
\hline M & free & $\begin{array}{l}\text { of choice } \\
\text { iency } \\
\text { tivity } \\
\text { rsity }\end{array}$ & & $\begin{array}{l}\text { unity } \\
\text { equality } \\
\text { freedom }\end{array}$ & & $\begin{array}{l}\text { nunity } \\
\text { ne care } \\
\text { intary }\end{array}$ \\
\hline
\end{tabular}

Source: Millares (2015) Att välja välfärd Politiska berättelser om valfrihet.

Yet, as I previously argued, there are more aspects to take into consideration when comparing the Moderates and the Social Democrats in this era. For instance, the profit issue is subject to further debate by the Social Democrats, and there is also a concern of a shift of market monopoly from the public to some of the largest private care companies (SOU 2016). On the other hand, some Moderates have emphasised more on the output of market, like the quality, rather than on allocating more resources. Therefore, I argue that both parties' views on marketisation are more complex and worth exploring. 
Freedom of choice is strongly supported by the right-wing parties. For example, the Liberal Party claimed: "Since the change of government in 2006, the elderly also had a greater influence on home care services and greater choice in elderly care through the Act on System of Choice (LOV)...the RUT deduction for household services facilitate everyday life for many elderly". ${ }^{115}$ Different politicians and political parties might argue whether freedom of choice is a goal or just a means to an end. Freedom of choice and competition are even used as solutions to the welfare state crisis (Blomqvist and Rothstein 2000, 51).

As illustrated in Table 7.1, freedom or freedom of choice seems to be accepted by both left- and right-wing parties in Sweden.

\section{What is known about freedom of choice?}

Freedom of choice, in itself, is arguably instrumentally beneficial in the sense that more freedom is undoubtedly better than limited freedom. However, thorough scrutiny of the concepts, such as freedom, choice, and freedom of choice might be necessary if to further the current understanding. In the Swedish context, it might be assumed that people understand freedom of choice more like an umbrella concept, which includes both freedom and choice (shown in Figure 7.1.[i]). It could be argued in another way, which suggests one has freedom of choice if certain requirements are met (shown in Figure 7.1.[ii]). Even for theoretical analysis purpose, the nuanced and clear definitions and interrelations of these three concepts are somewhat complex and remain debated.

It might be difficult to measure choice (Gustafsson 2010, Sebastiano 2004, Karin 2012), and different approaches could be adopted in this pursuit. In my view, examination of the choice model also requires one to consider several important issues: the nature of the

115 http://www.folkpartiet.se/politik/politik-a-o/aldreomsorg/ Accessed on January 2, 2015. 
subject involved and the real-life situation of the choice. For instance, to implement the choice model into school education, the principles such as equality (jämlikhet) have to be considered, especially due to the segregation effect to which the choice model can lead. When elderly care is the focus, the expected outcomes of the choice model should be regularly examined so that the model can be improved and the discussions enriched. This idea is elaborated later on in this chapter.

Figure 7.1 (i) Freedom, choice, and freedom of choice.

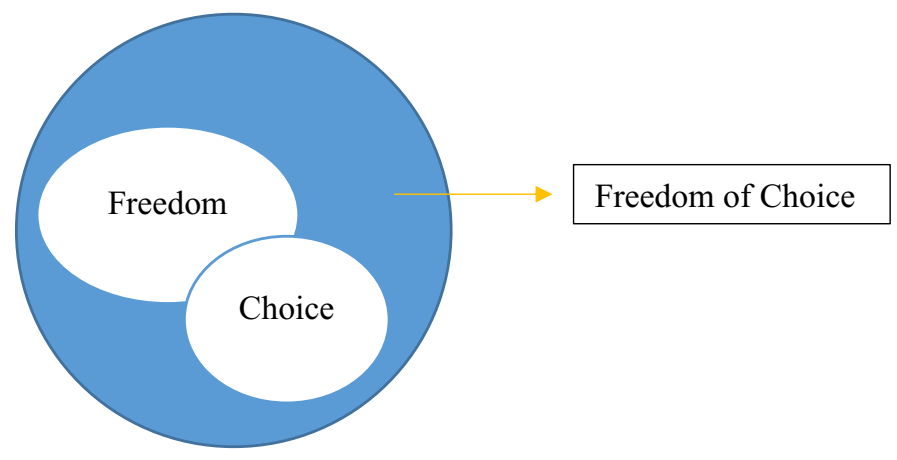

Figure 7.1 (ii) Freedom, choice, and freedom of Choice.

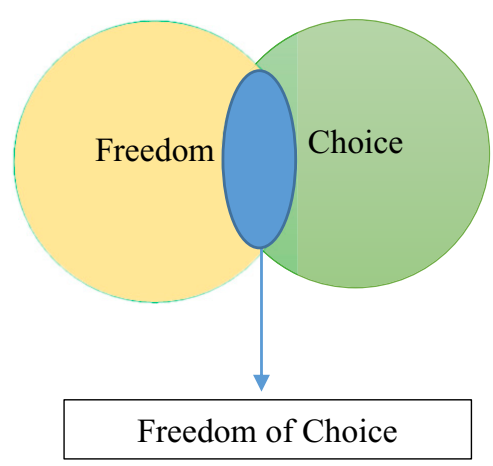


Carter (2004) has argued that economists and political philosophers have so far either ignored or conceptualised freedom and freedom of choice incorrectly. He proposed a distinction between 'freedom' and 'freedom of choice':

"Having freedom: A person has freedom if and only if she lacks constraints on the performance of an action (or set of actions).

Having choice: A person has choice if and only if she lacks constraints on (i) the reasoned selection and performance of one or more of the items on an action-menu or (ii) the reasoned selection of one or more such items that would, if selected, be performed by another person or persons" (Carter 2004, 68).

Having freedom of choice: "A person has freedom of choice iff she lacks constraints on the reasoned selection and performance of one or more of the items on an action menu" (Carter 2004, 69).

I argue that in Swedish elderly care, one argument to introduce the choice model is based on the following hypotheses:

Hypothesis 1: Elderly people with freedom of choice are better off compared to those who do not have this freedom.

Moreover, this assumption is closely in linked with another one:

Hypothesis 2: More choice is better than less choice.

To examine the aforementioned hypotheses, some scholars developed different arguments and reached distinct conclusions; for instance, Yiannis (2015) expressed freedom to choose as an illusion, and Markus and Schwartz (2010) warned of the risks of having too much choice. 


\section{How the choice model is implemented}

In 2009, the Act on System of Choice in the public sector (in Swedish: LOV, Lagen om valfrihetsystem) was implemented within health care and the social services, including elder care, and its implementation was optional for municipalities. The goals were meant to benefit all: increased citizens' freedom of choice, improved quality of care and efficiency, better working conditions for the care professionals, and reduced costs for the municipality. An additional reason to introduce LOV was to eliminate local differences in organising customer choice (Government Bill 2008/09:29). This act regulates the conditions under which individuals are allowed to choose a service provider from a list of approved providers. The LOV act applies for both home-based and residential services. However, it did not place explicit requirements as for how to structure the local choice system.

Customer choice means that a user can choose an approved provider to deliver care following a needs assessment. The intention is that users could exert influence over their received service and, if unsatisfied, have the flexibility to switch providers. It is assumed that this market-choice system promotes competition among different providers and leads to user satisfaction of service and optimisation of resources.

In the elderly care field, the free choice system is applied more in home care services. Only a few local authorities have adopted the system for various forms of residential care (Konkurrensverket 2012; Socialstyrelsen 2012). In December 2012, 133 of 290 municipalities had introduced LOV, primarily for home care services (Meagher and Szebehely 2013). In December 2013, 150 of 290 total municipalities had introduced the model, and an additional 27 decided to introduce free choice (SOU 2014). It is interesting to note that the number of municipalities that chose not to introduce the choice model increased 
from 35 to 42 from 2012 to $2013 .{ }^{116}$ As one example of the various developments of LOV, a diagram of the introduction of the choice model in the Östgötland Region can be found in Appendix 4.

\section{Problems and implications of the choice model}

Even after having made this promising statement, concerns about the actual implementation of the choice model and its potential impact on the elderly continue to arise, and political parties have their views on the real problems, see Table 7.2.

To start with, one question that is often posed is whether there are indeed options of both care services and providers from which the elderly can choose. For example, private companies might not wish to enter rural areas with a low population density, thereby resulting in very few care options available for the elderly residents there.

Another relevant question is whether service and provider information is easily accessible, as it could be used by the elderly to make choices. For example, Stockholm has over 100 home service providers, so it might be quite challenging for care users to compare and select the best option. According to one report (SOU 2014, 2), the elderly may find it difficult to choose and distinguish among providers, hence care services are recommended to provide easily accessible and quality-assured information for care users. ${ }^{117}$

\footnotetext{
116 Data from the year 2013 were quoted here mainly because my survey was conducted between the years 2013 and 2014. At the time of survey, the data from 2014 from SOU was not applicable or available. The latest data from the year 2014 is as follows: 155 have introduced, 25 decided to introduce, 22 have not reached a decision yet, and 57 decided not to introduce the model at all. For detailed information, please refer to the statistics by SOU (2014).

117 There might be another sort of discussion regarding agency to make rational choices. Young (1998) argued that we should refrain from assuming that agents (elderly people in this context) are 'hyper-rational', or have close to perfect information. Instead, it should be realised that agents 'base their decisions on fragmentary information, they have incomplete models of the process they are engaged in, and they may not be especially forward looking'
} 
The third issue regards the elderly's capabilities of making choices in the first place. Meinow et al. (2011) showed that elderly with cognitive and physical limitations are hardly able to make a rational choice. Fourth, as dementia becomes more and more present, it would be difficult to ask them to make a choice. Even language and cultural aspects should be taken into consideration (Mirnesa 2014). In the Swedish context, Glenngård et al. (2011) further suggested that individuals were rather passive in their search for information and tended to choose providers with whom they had previously been in contact.

Last but not the least, a rather philosophical question can be asked in general: should we always welcome more (even indefinite) choices? Indeed, the elderly are entitled to make a sound choice in their best interest. However, this does not intrinsically result in introducing more private for-profit care providers in a municipality, particularly because it can be argued that choices can exist even for public providers without necessarily having to turn to private alternatives.

In brief, these criticisms of the choice model need to be taken into consideration when explaining the different partisan approaches reflected in our data. To move this debate forward, the consequences of the choice model must be evaluated and serve as a cornerstone for future policy reform. ${ }^{118}$

(Young 1998, 6). Following this line of reasoning, Rothstein, Samanni, and Teorell (2012) suggested that since the welfare state is a mega-sized collective action problem and involves strong normative standpoints regarding ideas like justice, obligations, and fairness, the individuals' utility functions are not only based on calculations about individual utility (what's in it for me?), but also at least as much on expectations about how the other agents play (who are the others?). As far as this study is concerned, the same logic might also apply: since politicians are not always well-informed of facts or evidence about marketisation, or perhaps the information is sometimes contradictory (for instance, debates about cost reduction, as shown before), they might also have to base their decisions on certain normative standpoints, which are often closely linked to the ideology they hold.

118 Blomqvist (2004), for instance, argues that a socially segregating dynamic prompted by the introduction of consumer choice undermines Swedish notions of "People's home" and its 
Table 7.2 Realistic problems perceived by Social Democrats and Moderates over time.

\begin{tabular}{|c|c|c|c|c|}
\hline & Market & \multicolumn{2}{|l|}{ State } & $\begin{array}{l}\text { Civil } \\
\text { Society }\end{array}$ \\
\hline & before & before & after & before \\
\hline \multirow[t]{2}{*}{$S$} & $\begin{array}{c}\text { segregation } \\
\text { monopoly }\end{array}$ & & $\begin{array}{l}\text { ucracy } \\
\text { ues }\end{array}$ & $\begin{array}{c}\text { arbitrariness } \\
\text { inequality } \\
\text { dependent }\end{array}$ \\
\hline & $\begin{array}{l}\text { increased } \\
\text { inequality } \\
\text { rectifying/ } \\
\text { standardis } \\
\text { ation }\end{array}$ & corrup & & \\
\hline M & & & $\begin{array}{l}\text { ucracy } \\
\text { ues } \\
\text { l control }\end{array}$ & \\
\hline
\end{tabular}

Source: Millares (2015) Att välja välfärd Politiska berättelser om valfrihet.

Regarding the influence of the choice model on care management, Windblad et al. (2009) showed that the introduction of the choice model makes needs assessment offices more complex and time-consuming. When more providers arise, it is more problematic for needs assessors to grasp and offer recommendations (Norman 2010). The Stockholm area has over 100 home service providers, and this may result in too much information to comprehend for individual service users, not to mention the transaction costs in administering it. Even the report (SOU 2014) noticed that the elderly may find it difficult to choose and distinguish among various providers. As a result, SOU (2014) recommended easily accessible and quality-assured information (and greater freedom of choice).

uniform, high-quality services provided by the state to all citizens regardless of income, social background, or cultural orientation. 


\section{Survey questions and results:}

Here are some notes to the formulated questions: Regarding Q24, one type of understanding is that there is no need to have choices if private providers are excluded in welfare provisions. A similar view could be that public providers could offer various options so that a care user can choose. Regarding Q25, as illustrated previously in this chapter, the choice model to some extent leads to the inequality, segregation, and even detriment to the principle of democracy, primarily argued to be true in school education field. The question phrased in this study's survey did not go to that extent, but rather focuses on the possible consequence such as inequality. Furthermore, Q16 and Q17 use positive formulations to enquire about politicians' perceptions of two market benefits: better care and higher efficiency. The exact percentage of answers to each question are shown in Figures 7.2, 7.3, 7.4, and 7.5 and can be found in Appendix 6.

In the meantime, there are two questions designed to probe politicians' views on to what extent the elderly and their relatives should influence both the quality and the content of the care services. The results are shown in Table 7.3 and Table 7.4. 


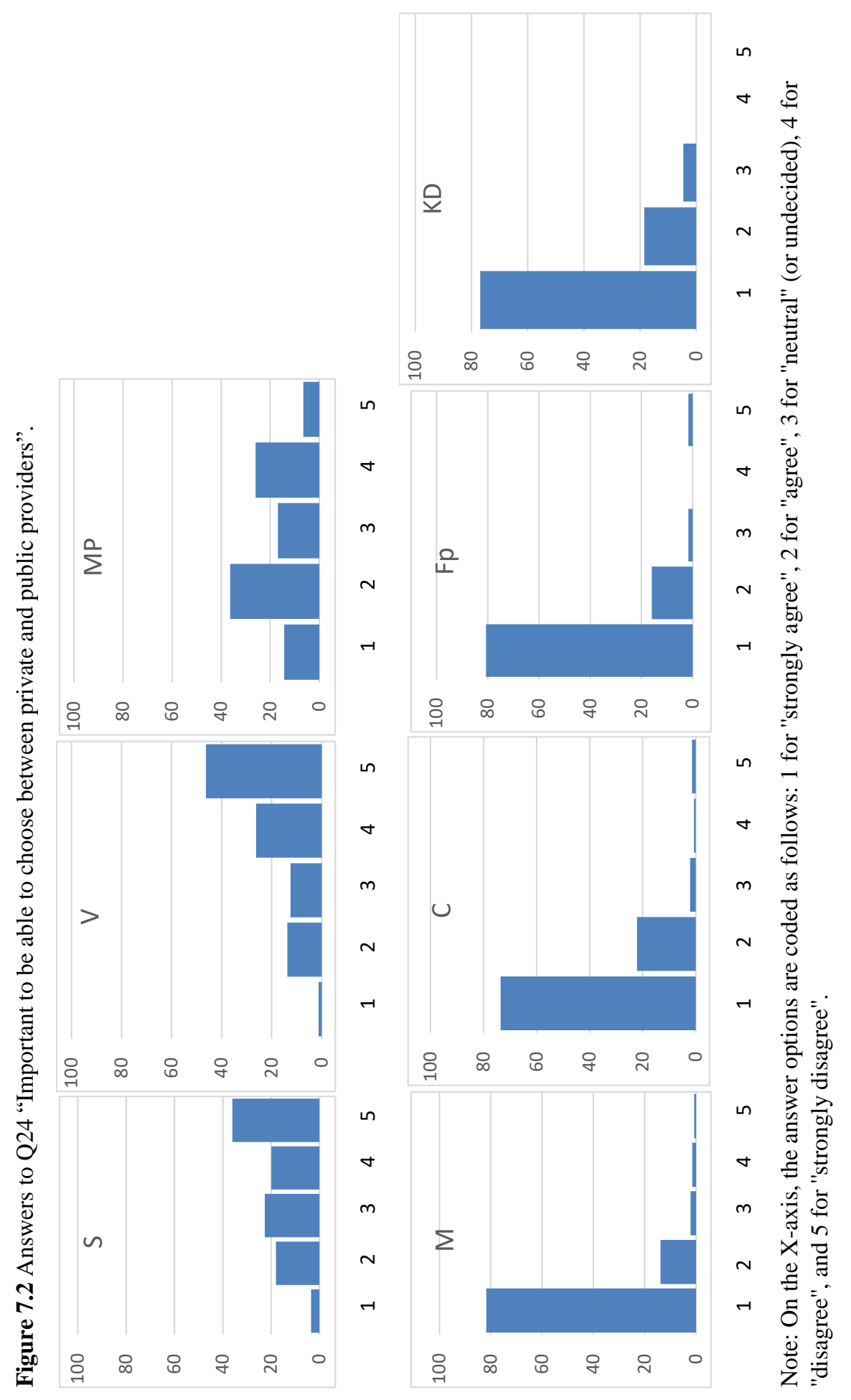

$\stackrel{\infty}{\sim}$ 


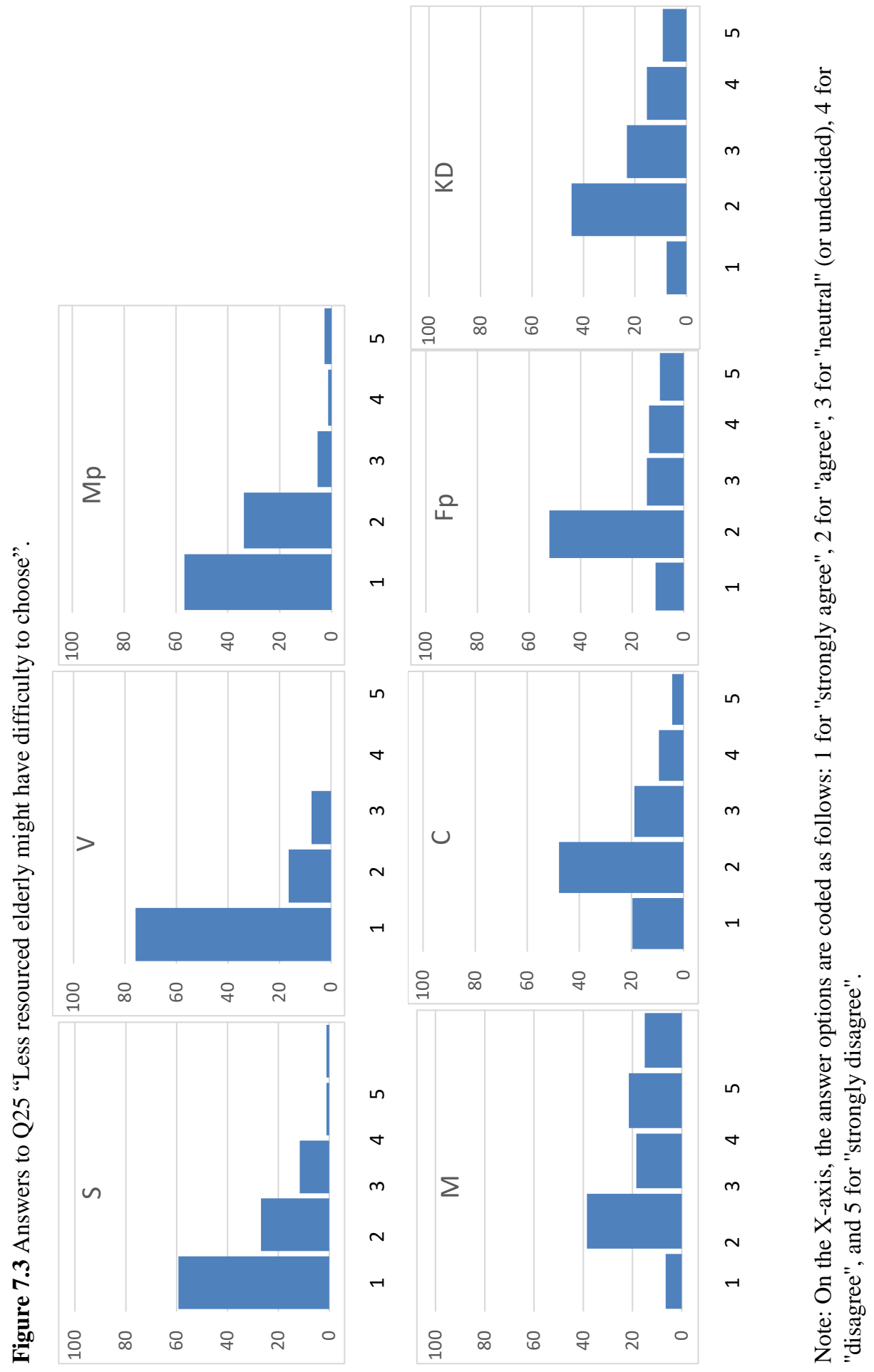




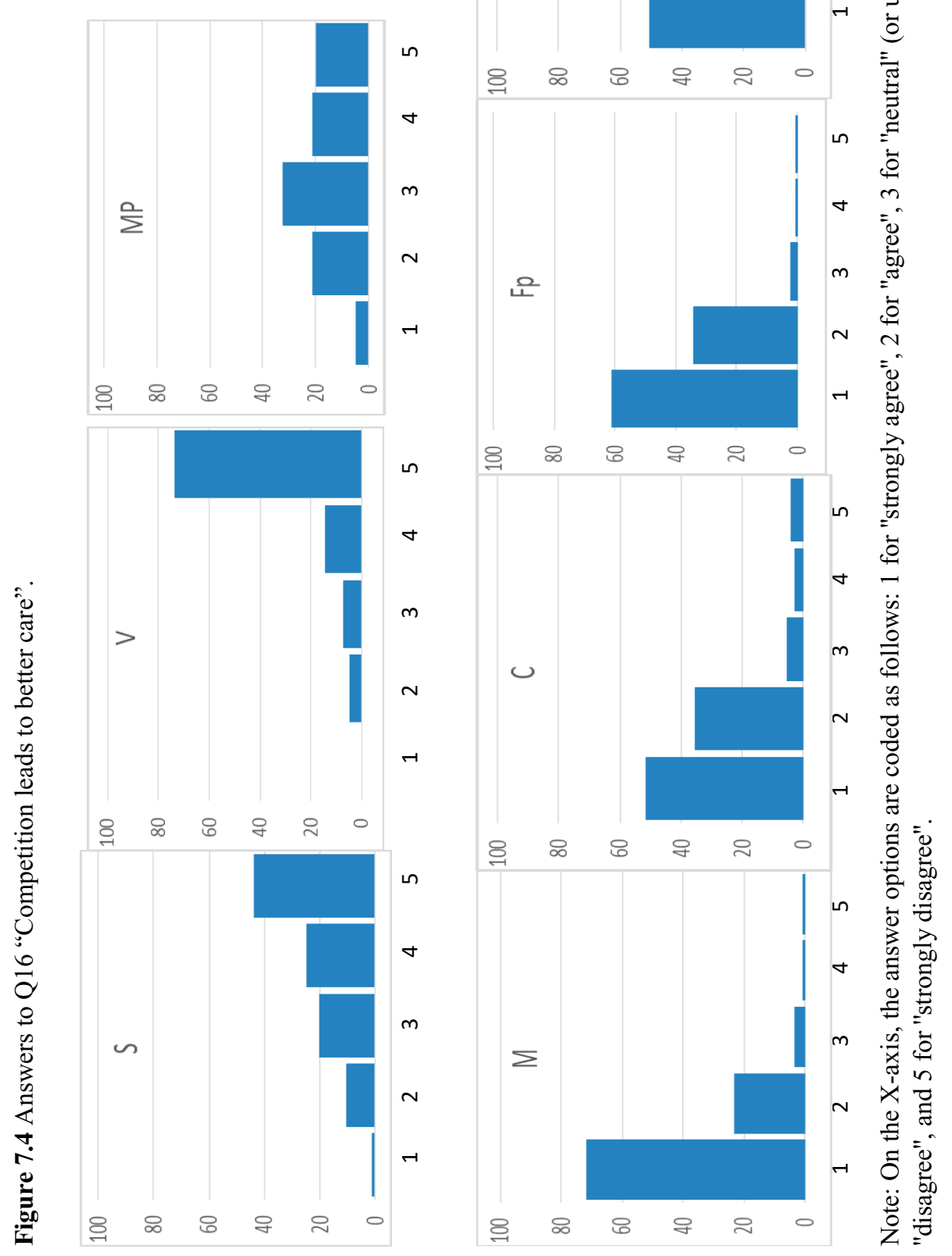



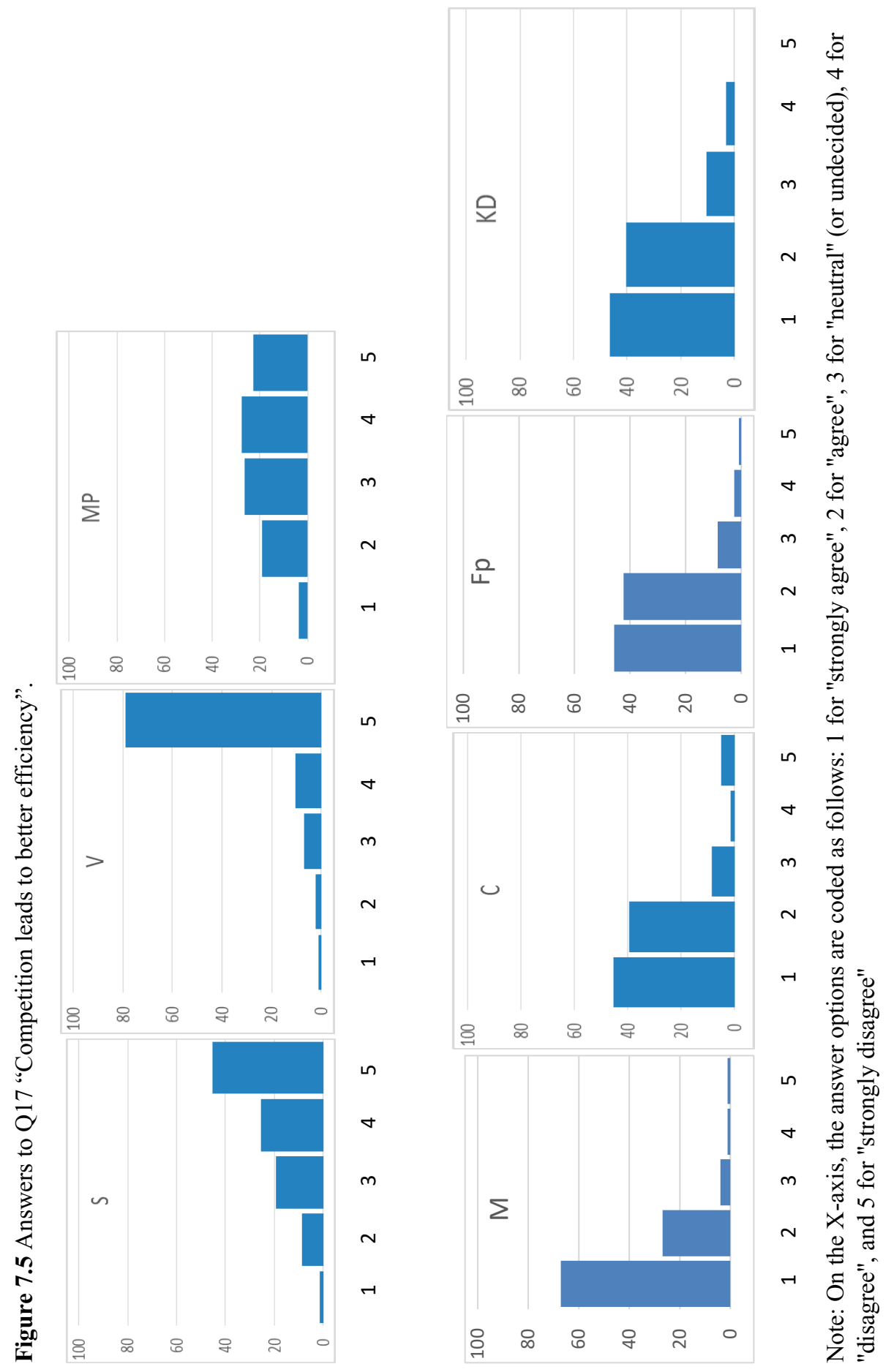

$\vec{m}$ 
Table 7.3 Responses to "The elderly and their relatives should have a high influence on the quality of elderly care".

\begin{tabular}{lcccc}
\hline & Agree & Disagree & Neutral & N \\
\hline $\mathrm{S}$ & 92.48 & 2.15 & 5.38 & 372 \\
$\mathrm{~V}$ & 98.79 & 1.2 & 0 & 83 \\
$\mathrm{MP}$ & 90.92 & 0 & 9.1 & 77 \\
$\mathrm{M}$ & 94.83 & 0.37 & 4.8 & 271 \\
$\mathrm{C}$ & 91.49 & 0 & 8.51 & 141 \\
$\mathrm{Fp}$ & 93.27 & 0 & 6.72 & 119 \\
$\mathrm{KD}$ & 96.92 & 1.54 & 1.54 & 65 \\
\hline
\end{tabular}

Table 7.4 Responses to "The elderly and their relatives should have a high influence on the content of elderly care".

\begin{tabular}{lcccc}
\hline & Agree & Disagree & Neutral & N \\
\hline $\mathrm{S}$ & 92.16 & 1.35 & 6.49 & 370 \\
$\mathrm{~V}$ & 97.56 & 1.22 & 1.22 & 82 \\
$\mathrm{MP}$ & 89.47 & 0 & 10.53 & 76 \\
$\mathrm{M}$ & 92.16 & 2.24 & 5.6 & 268 \\
$\mathrm{C}$ & 91.43 & 0.71 & 7.86 & 140 \\
$\mathrm{Fp}$ & 92.37 & 1.69 & 5.93 & 118 \\
$\mathrm{KD}$ & 92.19 & 3.13 & 4.69 & 64 \\
\hline
\end{tabular}

\section{Discussion}

a. Perception of the choice model

Admittedly, more detailed questions could have been developed to capture politicians' views on the choice model, or these views could have been better gathered through interviews. It is generally assumed that the abstract and ideal concept of freedom and choice are hard to 
object to, at least on a theoretical level. What makes the discussion more complicated to a larger extent connects to choice options, asymmetric information, or ability to choose, as mentioned in the introduction.

Here, based on the survey data, the right-wing politicians reacted very positively to the option for the elderly to make a choice by either picking a public or a private care provider. The attitude pattern, however, is quite different among the left-wing political parties. One interpretation is that the left-wing politicians' objections may rest in the logic that there is no need to introduce private care providers and the public providers can also offer more choice options. A second explanation could be that of the consequence of the choice model, which is sometimes linked to inequality and segregation effects. The result is somewhat surprising.

Based on the results of Q27 and Q28 (Table 7.3 and Table 7.4), it is evident that political parties, left or right, are in favour of a high level of influence from the care users' side on the services that they receive, both in terms of the content and the quality. It is true that the elderly people, as care users, should be put at the centre, and their views of services and how they should be organised are of great importance. To put in another way, this concept is related to empowerment: the elderly should have a say in what services they receive and how the services are provided or even customised based on their needs. Meanwhile, these two questions are also relevant to the choice discussion, as the elderly could exert their influence much more easily if there are options to choose from: private, public, non-profit, or profit. In this regard, the satisfaction of quality might surpass other factors.

b. Perceptions of quality and efficiency improvement

It is quite surprising to uncover that the politicians have an entirely different understanding of potential benefits brought up by market competition. After all, better quality and improved 
efficiency are two key reasons to initiate market reform or to justify the use of the market solution. Here, it can be seen that the left-wing politicians are not particularly convinced about better quality or efficiency.

Since no detailed answers from the politicians' perspectives were gathered to explain the results, I offer some possible explanations. First, competition alone might not be sufficient enough to ensure higher quality. There are other factors that might also form these conditions, such as fair rules and regulations. Second, some politicians might be convinced that the strong quality of public services in Sweden might leave no great need to create private alternatives to purposefully compete with the public services. It is generally agreed that public services in Sweden are of high quality. Thirdly, the private providers include both for-profit and non-profit options, and for-profit providers' focus on improving quality is doubted. Occasional scandals seem to reinforce this kind of doubt and therefore lead to a conclusion that tax money is wasted and misused.

It should be pointed out that 'efficiency' has different meanings. In the previous chapter, I highlighted the difference between efficiency and cost effectiveness. Here, I would like to mention that there is a slight change of meaning: when NPM criticises the public sector, efficiency is directly targeted at the bureaucracy of the government. Whereas in the Swedish context, efficiency is more related to a discussion of how to best use the tax money (for which aspects and in what ways) with less emphasis on improving how the public sector operates or how to improve their working efficiency.

\section{Conclusion}

Freedom of choice (FOC) can be considered as one influential ideal that furthers market development, as the underpinning logic implies an affluent set of choice options for the 
customers or service users. If in working order, the choice model should increase the seniors' freedom to choose whichever services might best suit them.

Nevertheless, it is important to be aware that choice does not mean that people get what they want. Rather, it means that they can choose a preferred option from a necessarily limited range and take on the potential opportunity cost, which refers to the sacrifice of another idea or option that might have been desirable but is less preferred (Spicker 2014, 266).

It became apparent that the model has its flaws, especially regarding how to make an informed choice. As customers or service users, it is not easy to make a decision because of a lack of information regarding care providers or too much information about care providers. One example that is often used relates to Stockholm, in which there are more than 100 care providers available to choose from, which seems to be too many.

The diverged opinions of possible market gains such as efficiency, quality, and freedom among local politicians to a larger extent can be explained or understood from their ideological orientation. Nevertheless, the complexity of concepts such as freedom, choice, and freedom of choice and the lack of evidence-based knowledge about how freedom of choice functions in reality might also explain the different views and lack of consensus. Therefore, more studies should focus on clarification of these interrelated abstract concepts. Together with their actual meanings in practice, these notions could be beneficial and help form common ground for public discussion.

From a practical point of view, there might be several implications for introducing and not introducing choice models locally. Freedom of choice can also be considered as a right for the elderly as a way to empower them. From this policy feedback perspective, once people perceive it as a right and benefit from it, more claims for the preservation of the choice model follow. Soss and Schram (2007), for instance, have sought to forestall an 
interpretation that public sentiment related to social provision is immovable or that policies cannot produce mass feedbacks. Furthermore, decision makers are also subject to this policy feedback (Lindbom 2016).

As for each municipality, the pros and cons of the choice model have to be carefully examined. In terms of long-term effects, it can be argued that the introduction and implementation of the choice model could potentially reshape the dynamic relationship between care users, service providers, and municipalities to various degrees, with the intention of more user influence on the care they receive. 


\section{Chapter 8}

\section{Financing, Regulation, and Beyond}

Much discussion has focused on outsourcing preferences and other arguments about market gains. As emphasised previously, a holistic view is necessary to form a comprehensive understanding of the crux of the marketisation debate and the reasons to further market development. I now turn to two other important dimensions of marketisation: financing and regulation.

Public funding is essential to the foundation and development of the Swedish welfare state. The importance of public funding in the debate is represented by several aspects: Firstly, funding maintains the system and its viability. The welfare state is built upon financing from the public and without taxation to support it, the system would fail or at least be unable to provide generous welfare services of the same quality and price. Second, public willingness 
to pay taxes hinges on the potential benefits to which the public is entitled from the welfare state. Citizens are only likely to accept social policies, such as privatisation of elderly care, if they believe that the services are accessible and that the taxation system operates in a fair, uncorrupted, transparent, non-discriminatory, impartial, and competent manner (Scholz, 1998). Similarly, the increase of tax levels must be justified and wage earners need to be convinced. Third, public funding is also entangled with the debate about profits. Some might argue that profiting is contradictory to the welfare state principles and undermines the public willingness to support welfare state.

In this regard, it may be reasonable to expect the same kind of attitudinal difference on public financing as shown in questions such as profit-making. It can be questioned whether it makes sense for the elderly themselves financially invest in order to exert more active influence on their choices. Finally, under the influence of a market, it is important to determine what kind of resources should be utilised to fund the system and who should be responsible for which part.

It is tempting to assume that the right-wing politicians are against regulations and all interference from the government and aim for a more liberal, free, and self-sufficient market. This may suggest a desire to deregulate the market. On the other hand, if market regulations are indeed deemed necessary in this quasi-market, the questions remain of how to go about regulating it and what aspects to regulate: price $^{119}$, competition rules, or other aspects. This chapter discusses public financing and regulation in the pursuit of answering these questions. In order to craft a general picture of what the general privatisation debate is about, in the results part, I present and comment on some of the issues deemed important by politicians before moving on to the general comparison and conclusion in the next chapters.

${ }^{119}$ One idea to introduce multiple care providers is to create competition based on quality rather than on price (Blomqvist 2004; Stolt and Winblad 2009). 


\section{Public financing and legitimacy}

One characteristic of Swedish elderly care is that the system is funded mainly through taxes. Sweden has a high level of taxation, which is accepted by the citizens with the assumption that the money is used for welfare purposes. The welfare state should also be universal, which is to say that all citizens should be granted access to facilities, services, or other benefits.

It can be argued that maintaining the welfare state hinges on the solidarity principle, which is manifested in the citizens' support of the welfare system and their willingness to supply its financial base by paying taxes (Bergmark et al. 2000). Lindbeck et al. (2000) also argued that this solidarity principle of public financing is not only important but also necessary in the welfare services. Meanwhile, since the government maintains responsibility for providing the tax-funded financing to the services, this implies that all citizens, regardless of income level, have equal access to public services (Sørensen and Bay 2002).

Politicians' views on financing and regulating the welfare state should reflect those of their electorates. Therefore, a few words about the public view on this issue should be mentioned. In the SOU (2015), it is summarised that the willingness of the public to support public funding for a welfare state is interconnected with the expectation that the services are quality and that tax money will not be wasted or used for other purposes. Moreover, public trust in public institutions and access to welfare services are meaningful for society to function as a whole. ${ }^{120}$

\footnotetext{
${ }^{120}$ There are prerequisites for this public willingness to finance the welfare system by paying tax. One theory, the Quality of Government (QoG), stresses the importance of trustworthy, impartial, and uncorrupted government institutions as a precondition for citizens' willingness to support policies for social insurance (Rothstein, Samanni, and Teorell 2012).
} 
In fact, public opinions about the financing and organisation of the Swedish welfare system have been stable since the 1980s, with the majority in favour of financing insurance and services by taxation ${ }^{121}$ and even stronger support for the public sector as the most suitable producer of different services (Svallfors 1999, 2011). Several opinion polls have shown that the majority of citizens oppose the idea of profiting from the welfare state. For instance, Nilsson (2014) based on a national survey from 2013, showed that even respondents who directly or indirectly use private services felt negatively about the profit motive. ${ }^{122} \mathrm{~A}$ survey from the SOM Institute in 2015 revealed that almost 59\% of the Swedish citizens were against the idea of turning profits from public sector services such as health care, schooling, and social care (SOM 2016, 49).

In this sense, it is interesting to ponder whether the public opinion could be represented by elected politicians and reflected in the policies. If so, the democracy principle would then be upheld, and politicians would face little pressure from their electorates. Having said that, studies on politicians' attitudes in this regard are rather limited.

\section{Why regulation and what to regulate?}

There are several reasons to regulate the market or quasi-market in a welfare state. To begin with, public services such as school, health care, and social care are mainly funded through taxes. If public funding is the foundation of these welfare services, then there must be a limit

${ }^{121}$ Katalys, a think-tank affiliated with the Trade Unions and Social Democratic Party in Sweden, also reported their survey data in this regard: $80 \%$ of the public agreed that the operating form of welfare services is of great importance and $67 \%$ expected that the public sector would play a major role. Additionally, $90 \%$ preferred profiting to be forbidden, limited, or reinvested, whereas only $8 \%$ are okay with profitmaking; $96 \%$ considered that quality is important or very important and $94 \%$ agreed that the volume of resources from taxes that fund the welfare state remains an important question. Finally, 59\% were willing to pay for higher tax if the school, health care, and social care required. The survey was conducted in 2013. c.f. Välfärden är vinsten. 2013 page 34.

${ }^{122}$ At the same time, $70 \%$ of survey respondents held the idea that it is important to have freedom of choice within childcare, schooling, and elderly care. 
as to what extent and for which aspects the money could be used (SOU 2016). Certain goals, such as profiting, among care providers in the market might be intrinsically incompatible with the values for which the welfare state stands. Unlimited profit-making could damage public willingness to support the welfare state. A system with many private providers therefore must be steered in a way that is different from a public provider only system (SOU 2016, 255).

Second, as there are potential negative effects of competitive tendering and related reforms (see Chapter 2, for instance), regulations may be a way to prevent accountability being a major issue. That is to say, providers that move away from trying to meet citizens' needs would be subject to scrutiny, and potential damage or harm to the elderly and abuse of the welfare system would be avoided. Meanwhile, regulation tools, by protecting public interest, also minimise the risk that the public trust in government gets undermined.

Third, as marketisation takes place and outsourcing is introduced, the influence of elected representatives is weakened in the sense that they are excluded from directly making service production decisions. ${ }^{123}$ Rather, politicians maintain their roles as purchasers and managers, but not as supervisors of service production on a daily basis (Sørensen and Bay 2002). Therefore, politicians' need to exert their influence through regulation is explained.

It is important to take into consideration the trend of decentralisation in Sweden. A political structure of de-regulation loosens the role of the central government in several fields,

\footnotetext{
${ }^{123}$ It could also be argued that in the meantime, the position of the citizens is weakened, but the position of the consumer is strengthened. In a Social Democratic welfare state (Esping 1990), the de-commodification level of 'care' is high, which suggests that care users are regarded as citizens with rights. Meanwhile, care services are not viewed as commercial products and not traded based on individuals' ability to purchase. Whereas in a market scenario, these views are challenged: elderly people are more thought as customers, and the ability to purchase becomes relevant. See, for instance, Clarke (2006); Meinow et al. (2011); Sørensen and Bay (2002).
} 
but meanwhile, it requires that local government should be capable of regulating certain issues on their own.

Regarding the content to be regulated, there are several areas that might be subject to regulations: availability and accessibility of information, quality and efficiency, costs, and so on. Moreover, the government could regulate the market in different ways, such as regulating providers, implementing licenses for market entry, or regulating competition through proper rules and legislations. An alternative to gain control is to develop measurements to monitor quality ${ }^{124}$ that care providers deliver. By using these various tools, the central government could either further market development or set limits on it; for instance, a proposal for profit limits. Briefly speaking, the state plays a pivotal role in the regulation of welfare - it establishes the rules and settings under which welfare services operate (Spicker 2014, 14). Currently, the means of examining and steering the market varies among different municipalities. Nevertheless, it is expected that municipalities must have some form of control to fulfil their responsibilities (SOU 2016, 167). ${ }^{125}$

Furthermore, SOU (2016) proposed a need for simpler and more flexible regulations in terms of welfare services, including a more flexible regulatory framework for the procurement of welfare services, the ability to reward non-profit operators through procurement, capitalise on the added value and social responsibility that the non-profit

\footnotetext{
${ }^{124}$ It begs the question here, however, of who will determine these standards and follow up on the quality. One option is IVO (Inspektionen för vård och omsorg), which oversees social services in general to ensure that individuals receive care and services that are of proper quality and in line with laws and legislations. On the other hand, Socialstyrelsen only sets the fundamental principles, and it is the responsibility of municipalities to manage and operate the specifics. Local municipalities might have difficulty in following up on the quality, among many other aspects; SOU (2017) addressed this issue and offered some suggestions.

${ }^{125}$ One task remains: to define the context and refine the standards. What I mean by this is that demands from each side of care providers should be heard. For instance, private providers demand 'lika vilkor' (same treatment) and no discrimination.
} 
organisations can contribute ${ }^{126}$, implement a new LOV to encourage diversity and partnership between non-profit and public, and so on.

To better understand politicians' stances on marketisation, a brief review of laws and legislations is necessary. Several laws and regulations that affect elderly care are listed in Table 8.1.

${ }^{126}$ It seems that greater attention is paid to the promotion of non-profit providers. 


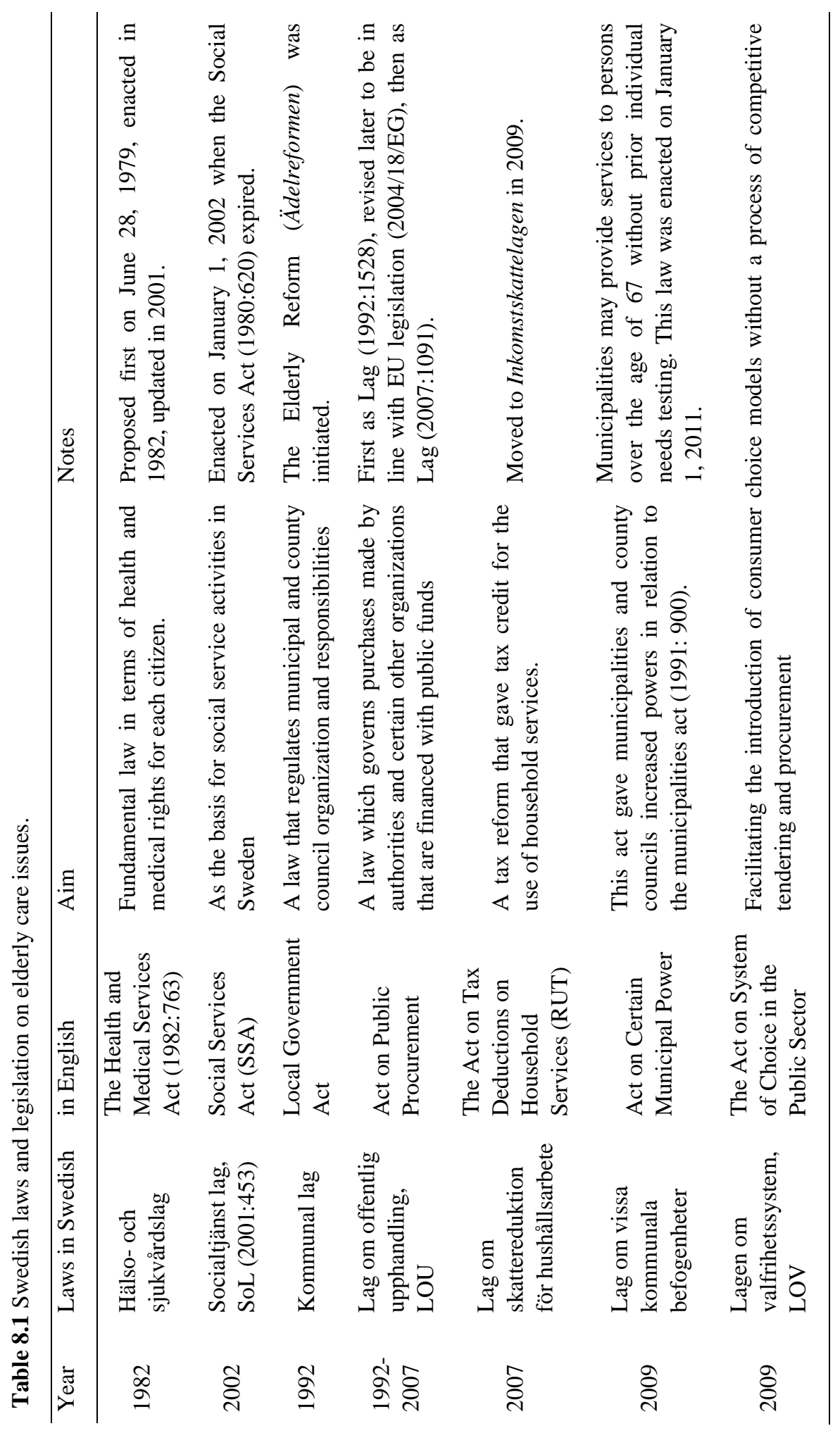

J 
In addition to the listed laws and regulations, it is worthwhile to mention Lex Sarah, which is applicable in the field of social services. ${ }^{127}$ According to this rule as well as the Social Services Act (SoL) and Law on support and service to the disabled (LSS, Lagen om stöd och service till vissa funktionshindrade), employees should immediately report maladministration and significant risk of maladministration to operators. The law explains that the person conducting the business should then investigate and remedy or eliminate the reported maladministration without delay. If it appears that the maladministration is serious, it should be reported as soon as possible to the IVO.

\section{Survey questions and results (I):}

The aspects were taken into consideration when conducting the survey: public financing to support the care system, the importance of public financing (Q18 about democracy), individual payments, increases of taxes, and a need to regulate and gain insight ${ }^{128}$ into market development. The exact percent of answers to the questions listed in Figures 8.1, 8.2, 8.3, and 8.4 can be found in Appendix 6.

1. Partisan preferences in the question of funding, including tax funding, increasing taxes if necessary, and individual contributions are shown in Table 8.2.

The results indicate that both blocs agreed that taxes should be the major source of financing for the elderly care system, although the extent to which they agreed varied. Regarding the

\footnotetext{
${ }^{127}$ Socialsyrelsen added further explanations to the rule in 2011, see: Socialstyrelsens föreskrifter och allmänna råd om lex Sarah, http://www.socialstyrelsen.se/Lists/Artikelkatalog/Attachments/19339/2014-1-24.pdf
}

In health care, a similar rule is Lex Maria, according to which caregivers shall report events that have caused or could have caused a serious injury to the Inspectorate for Health and Care (IVO). c.f. http://www.socialstyrelsen.se/lexmaria

${ }^{128}$ Insyn was used in the survey, which could be translated as insight in English. Another word that occasionally pops up in the welfare state discussion is tillsyn, which is understood as inspection or supervision. 
question of increasing taxes, there were more opposing views within the right-wing bloc. In the meantime, around one-third of the respondents responded neutrally in the right-wing bloc. Several possible explanations are presented: first, the question is difficult to answer, as it is hypothetical and does not specify the exact percent of tax increases. Second, the opinions of the politicians might contradict partisan ideology. Third, there could be a trade-off here where the higher the tax rate is, the more difficult it is for a government to justify the reasons to increase further, not to mention it is important to find a balance between elderly care and other social expenditures. Meanwhile, the tax rate should be bearable for the public and yield to the expectations of citizens. Nevertheless, politicians within the left bloc were more determined to increase tax if necessary.

\section{Individual contribution and influence}

One line of thought suggests that if the system is indeed a market, then it should be possible and reasonable for customers to pay out of pocket. This idea has at least two implications: first, customers pay for services that they themselves deem the most appropriate with the option to choose from various providers; second, providers will have to compete to attract customers, meaning the market efficiency is likely to improve.

It must be pointed out that there may be different understandings of 'egenavgift'. Egenavgift could be translated as national insurance contribution or as payroll tax, which is about individuals' tax contributions to the welfare system. This meaning, however, was not intended in the survey. Rather, it is meant to be an individual contribution. Note that in the Swedish context, users could purchase certain services first and then receive subsidies by using tax deductions on household services (RUT). Furthermore, in a market discourse, the individual contribution could also mean that care users pay for services entirely out of pocket and receive no further deduction. In this scenario, it is argued that active choice-making and 
private payments could also have an influence on both the content and the ways that service products are organised and provided. In brief, the question was intended to enquire as to what extent politicians were open to the idea that individual contributions should be allowed and for what purposes. It could be further argued that if public financing is at work, there is no further need to ask citizens to pay for services. This might be one argument for why some politicians are against the idea of individual contributions.

3. Partisan preferences for political influence on the system, namely monitoring and controlling of the system.

As reflected in Table 8.2, both blocs expressed a very high level of willingness to oversee and control the care system: $92.6 \%$ of the right bloc agreed, as did $98.7 \%$ of the left bloc. Therefore, it can be concluded that on a local level, politicians and political parties, left or right, do want to oversee market reform and the care system. Whereas politicians at the central level achieve this goal by passing and adopting new legislations or government bills, local politicians might decide on their own to implement rules or engage themselves in concrete care issues. Local politicians could also inform their party members at the central government level, as well as those in the Parliament, to help fulfil their political agendas. It can even be assumed that right-wing politicians would push forward more market tools and solutions if they receive this insight and control, and the left-wing parties are assumed to do quite the opposite. Nevertheless, differences among these political parties regarding having insight and some degree of control of the market are rather slight. 
Table 8.2 Responses to questions regarding marketisation.

\begin{tabular}{|c|c|c|c|c|c|c|c|}
\hline & & $\begin{array}{r}\text { Strongly } \\
\text { agree }\end{array}$ & Agree & Neutral & Disagree & $\begin{array}{l}\text { Strongly } \\
\text { disagree }\end{array}$ & $\mathrm{N}$ \\
\hline \multicolumn{8}{|l|}{$\begin{array}{r}\text { Tax } \\
\text { financing }\end{array}$} \\
\hline & Left & 88.7 & 10.19 & 0.56 & 0.37 & 0.19 & 540 \\
\hline & Right & 53.13 & 35.86 & 6.09 & 3.95 & 0.99 & 608 \\
\hline \multicolumn{8}{|l|}{$\begin{array}{r}\text { Increase } \\
\text { tax if } \\
\text { necessary }\end{array}$} \\
\hline & Left & 59.11 & 30.48 & 8.36 & 1.3 & 0.74 & 538 \\
\hline & Right & 16.01 & 25.8 & 34.7 & 16.01 & 7.47 & 562 \\
\hline \multicolumn{8}{|l|}{$\begin{array}{l}\text { Individual } \\
\text { contribution }\end{array}$} \\
\hline & Left & 5.07 & 8.58 & 13.26 & 22.03 & 51.07 & 513 \\
\hline & Right & 16.7 & 40.35 & 21.91 & 11.3 & 9.74 & 575 \\
\hline & Left & 88.51 & 10.15 & 1.15 & 0.19 & 0 & 522 \\
\hline & Right & 68.95 & 23.77 & 3.43 & 2.78 & 1.07 & 467 \\
\hline
\end{tabular}

All within-party distributions are presented in Figures 8.1 to 8.4. The figures demonstrate that the left and the right bloc parties shared a similar view regarding Q31, whereas on the other three questions, the parties mostly followed the left-right praxis, where the right-wing party politicians diverged more on these questions; for instance, Figure 8.2. This result reflects that there are different perceptions of raising taxes. ${ }^{129}$

\section{Survey questions and results (II):}

As mentioned earlier, two open questions were designed in the survey: Q34 and Q35 were intended to give the respondents a possibility to address some issues that were possibly

\footnotetext{
${ }^{129}$ It could also result from difficulties in understanding the hypothetical condition and choosing an answer option. Nevertheless, it is clear that the left-wing politicians are more determined to increase the tax level.
} 
missing in the discussion of the marketisation of elderly care in general as well as in the survey.

Regarding important issues in the general discussion of elderly care privatisation, dozens of respondents offered their views. Several themes were addressed, ranging from how the care is provided based on needs to the controversial role of profit.

Here is a brief summary of the most frequent concerns:

- How different forms of nursing homes could be established;

- Care workers' motivation, engagement, education level, ability to be employed fulltime, and salary level;

- Non-profit providers and their role;

- How care services are managed, organised, and led at the individual unit level;

- Concerns about the development and future of care because of ageing processes, influx of migrants, the reliance on the labour force to provide care;

- Quality, priority, rights, continuity, and equality;

- Care efforts from relatives.

Indeed, there were many issues brought up by the respondents in the open-ended questions. Due to the scope of this research, detailed questions about how service should be performed are not discussed here. Instead, some topics that are more relevant to privatisation and marketisation perspectives are explored in conjunction with the critiques of survey questions according to a few respondents. Nevertheless, from the list above, it is possible to get a sense of the important issues aside from those aforementioned in previous chapters.

Relevant to the discussion of control or follow-up of care, one politician wrote:

"There exists a dilemma that private providers need to be regulated in terms of their practice and quality performance, as it is taxpayers who order the services." 
Building on that, another politician expressed the need to have enough resources and tools to be able to follow up on the quality of care in local municipalities.

"Politicians at the local level should have sufficient resources, as the increasing level of governing and controlling requires it."

Meanwhile, politicians were argued to be more responsible and competent in doing their jobs. One said,

"The politicians have not made requirements nor have they made proper procurement. Instead, they just introduced private entrepreneurs. Of course, there are bad private entrepreneurs - just like there are bad politicians."

Another claimed:

"Something about political trust for those who work in elderly care, their skills and integrity, etc. [should be questioned]."

\section{Survey questions and results (III) ${ }^{130}$ :}

Politicians were given the option to comment on the questions and the survey in the openended questions. Some of their answers, critiques, and suggestions are listed here as part of survey results. Since these survey responses also reflect some of the politicians' views on certain important aspects of marketisation, I decided to include a few quotations to better illustrate their points.

Regarding the survey, the majority of respondents were satisfied with the way the survey was designed and how the questions were phrased. However, the major points of critique could be categorised into two sorts: the first one is that some respondents argued that

\footnotetext{
${ }^{130}$ Since topics such as profit and ownership have been discussed in previous chapters, I only provide a few more thoughts on these topics based on what politicians added in the open questions.
} 
certain questions are biased; the second type referred to how the survey expressed only leftright questions.

a) Several politicians expressed doubts about the discussion of private/public providers.

Here I list three different views that argue that the ownership issue should not be a major focus in the survey:

"It is the content of the care you want to choose [that is important]. Whoever drives it is not crucial."

"The optimal distribution between private/public care for the elderly is not relevant to the quality of care for the elderly."

"It is the quality that determines."

The first quotation argued the importance of the content of care, while the second and the third placed emphasis on the quality of care, rather than the driving forms. This is in line with the view from the right-wing politicians on the priority of ownership and quality in the marketisation debate nowadays.

b) Regarding profit issues, at least three different views could be observed: support, opposition, and a claim to reinvest the gains or profits.

One approving attitude read as follows:

"I think it is ok to have profits in welfare as well as in other tax-financed activities such as construction companies, transport, road maintenance, etc. It is the quality that is important."

One opposing view was written as follows:

"Is it reasonable to take 140 billion from tax money just to give it to private providers when there is apparently infinite eagerness within the care sector?"

A somewhat moderate view was to call for the reinvestment of business profits: 
"Surplus shall be reinvested in the care."

c) Critiques regarding how the survey is "only about left-right questions".

One politician argued that there were more important questions, like quality and good leadership, which should be the focused. This politician wrote:

"The questionnaire was just about the old common right-left questions about financing and the view of private providers. However, there are so many other questions about what really creates quality, and what really stands in the way of quality! What distinguishes good nursing homes from bad ones in Sweden, in my opinion, is mainly about local leadership. Good boss, good care. Bad boss and care can be so bad. It is clear that the resource supply is important,

but two nursing homes with the same budget can have enormously different quality."

However, not all respondents agreed with this point, and one even suggested that more space to criticise private for-profit companies should have been offered. One politician commented:

"I do not think that the survey gave me an opportunity to highlight my scepticism with venture capital companies in health care and social care."

\section{Discussion}

The survey data show that similar to the public, politicians from parties of both blocs agreed that elderly care should essentially be financed by taxes - a consensus was found.

1. Where the consensus exists.

Tax policy is a political sphere of high importance and remains a delicate issue: it can place high pressure on the labour market and it can increase government revenue. The data show that similarly to public opinion, politicians from various parties agreed that elderly care should essentially be financed by taxes, which is a consensus that could be somewhat perplexing. On the one hand, it is reasonable to argue that politicians should share a similar view to that of the various social groups that they represent, meaning that in the Swedish 
context, continuous public funding support from politicians' side is plausible. In this regard, the path-dependency theory might be applied here to account for the consensus (Krasner 1984; Pierson 2000). In the Swedish context, a strong welfare state legacy that involves past policy structures, institutions, and vested interests helps to shape policy options for the rightwing parties. As mentioned previously, the welfare state as a legacy left behind by the Social Democrats consolidated itself and influenced partisan preferences and policy choices even when Alliansen held the majority in the government ${ }^{12}$.

Since the cost of elderly care might increase over time for reasons such as an ageing population and lack of care workers, I investigated the political willingness to raise taxes for care if necessary. The results show that both blocs felt positively towards this move, with an apparently stronger willingness from the leftist parties. ${ }^{131}$ This interesting finding to some extent challenges the idea that governments use the right to deploy tax strategies to undercut the long-term financial viability of the welfare state (Klitgaard and Elmelund-Præstekær 2014), and thus this idea is worthy of further investigation.

Based on his analysis of the history and structure of tax policy in Sweden, Steinmo (2002) argued that Sweden has indeed adapted and changed in recent years in the face of globalisation, without necessarily abandoning its high-tax regimes and generous social welfare systems. In this regard, the low level of willingness to increase taxes from the rightwing parties (roughly 42\%) can be understood. It could also be assumed that the unwillingness might lie in the concern that a further increase in taxes is detrimental to the growth of the private sector. Meanwhile, it also makes perfect sense to argue that an extensive welfare state must consider alternative ways of limiting public expenses and lessen the public tax burden.

${ }^{131}$ Of course, if that is the case, the increase of tax levels needs to be justified; after all, taxation rates in Sweden are already quite high compared with other developed countries. 
2. Why the consensus?

One explanation could be derived from the path-dependency theory (Krasner 1984; Pierson 2000) as past settings policy structures, institutions, and vested interests help shape the current policy. As mentioned above, the welfare state as a legacy left behind by the Social Democrats consolidates itself and influences partisan preference and policy choices. Another explanation could be based on the power resource theory. As Lindert (2004) once said, welfare state expansion requires higher taxation and state interventions in the market, and welfare programmes constitute a significant share of overall government spending, which later benefit and empower the lower- and middle-working classes. Indeed, a consensus on using taxes as public funding for the care system is found to be surprisingly intact at present, but the political divide still remains.

3. Why overseeing and regulation?

At first glance, the result of Q31 in Table 8.2 seems puzzling: 92.72\% of the right-wing politicians agreed that a high level of monitoring and control in the care market should exist. As indicated before, neoliberal ideals suggest a lower tax rate and less or no government interference, such as laissez-faire economics. Considering this line of thinking, the answers to Q31 are incoherent. By contrast, it can be seen that Swedish right-wing politicians reach such a high percentage of 'consensus'. The first explanation is that even for the right-wing parties, to ensure that they can achieve their aims in policy reform, it is better to have some level of political control over privatisation issues. Another explanation is that the right-wing parties face a relatively strong ideological opponent in the Swedish case, meaning that power struggles and party competitions are intense. To reform the market in the way they intend, right-wing politicians, therefore, may act more 'aggressively' and show a high level of interest for political control. One more possible explanation, which not only applies to the right-wing parties, could be that the right-wing politicians are concerned with the downsides 
of the market and are careful to take responsibility to oversee the market. The consensus on market control might help explain the intense debates and power struggles between the left and right on market issues. 


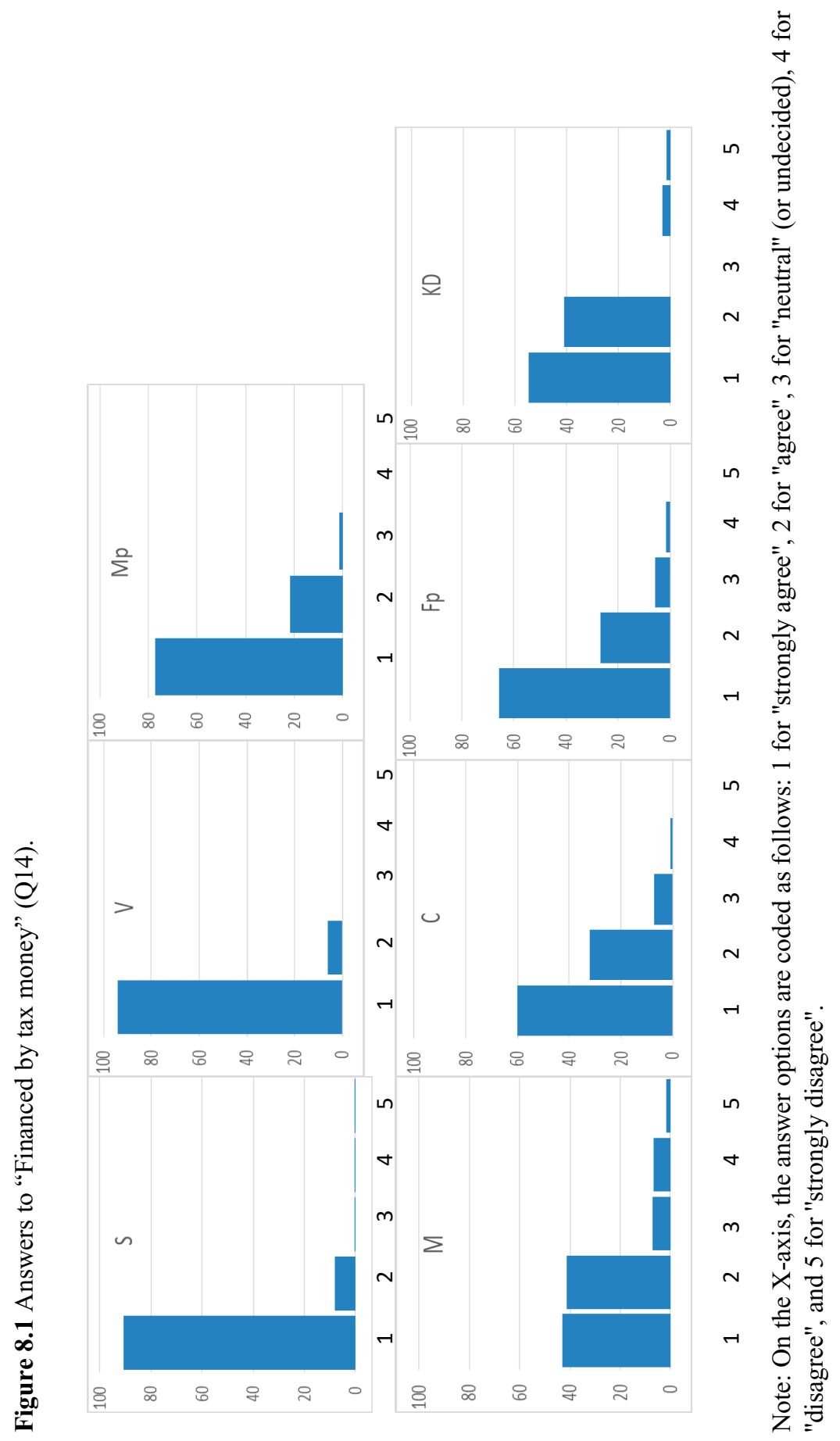




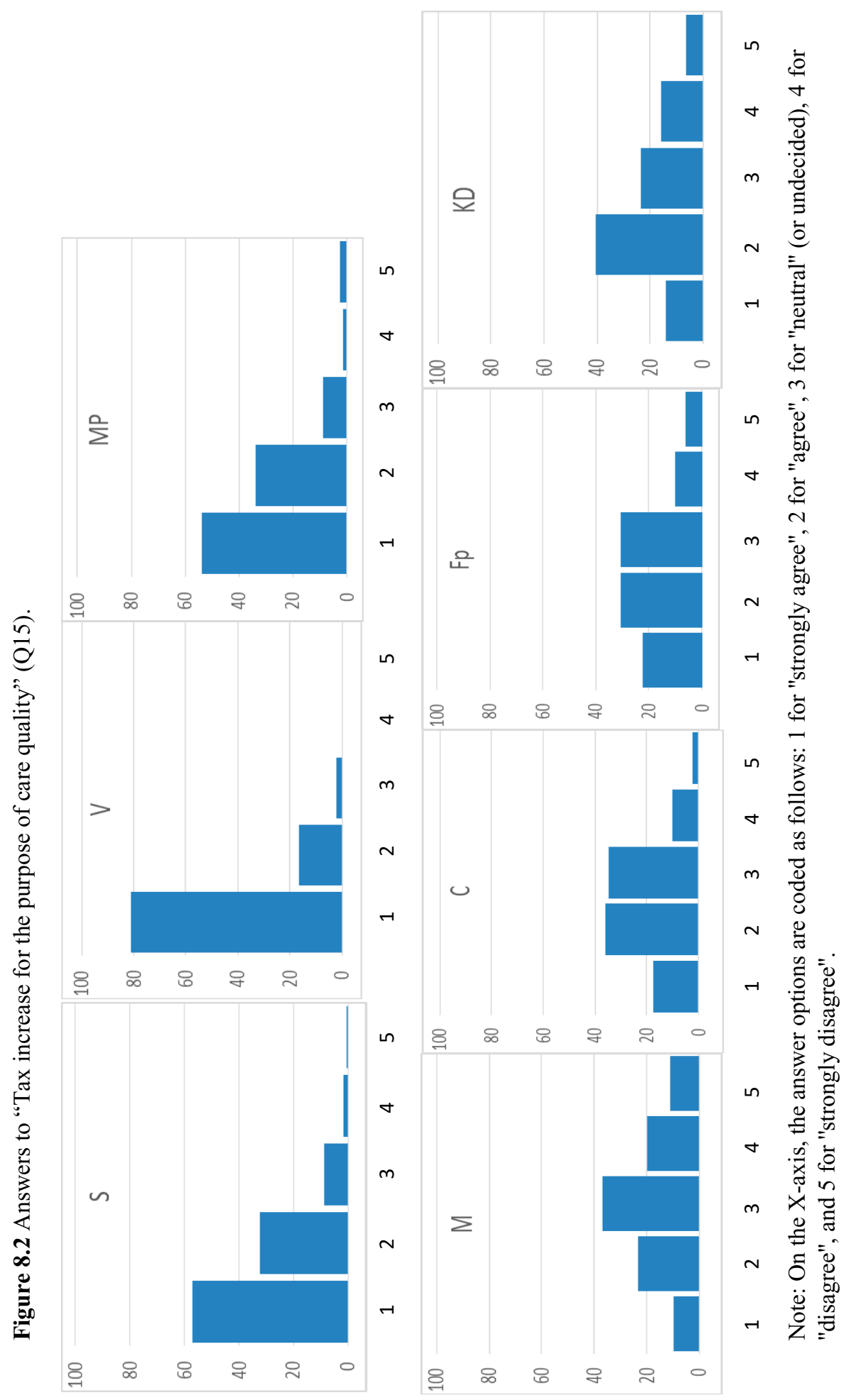




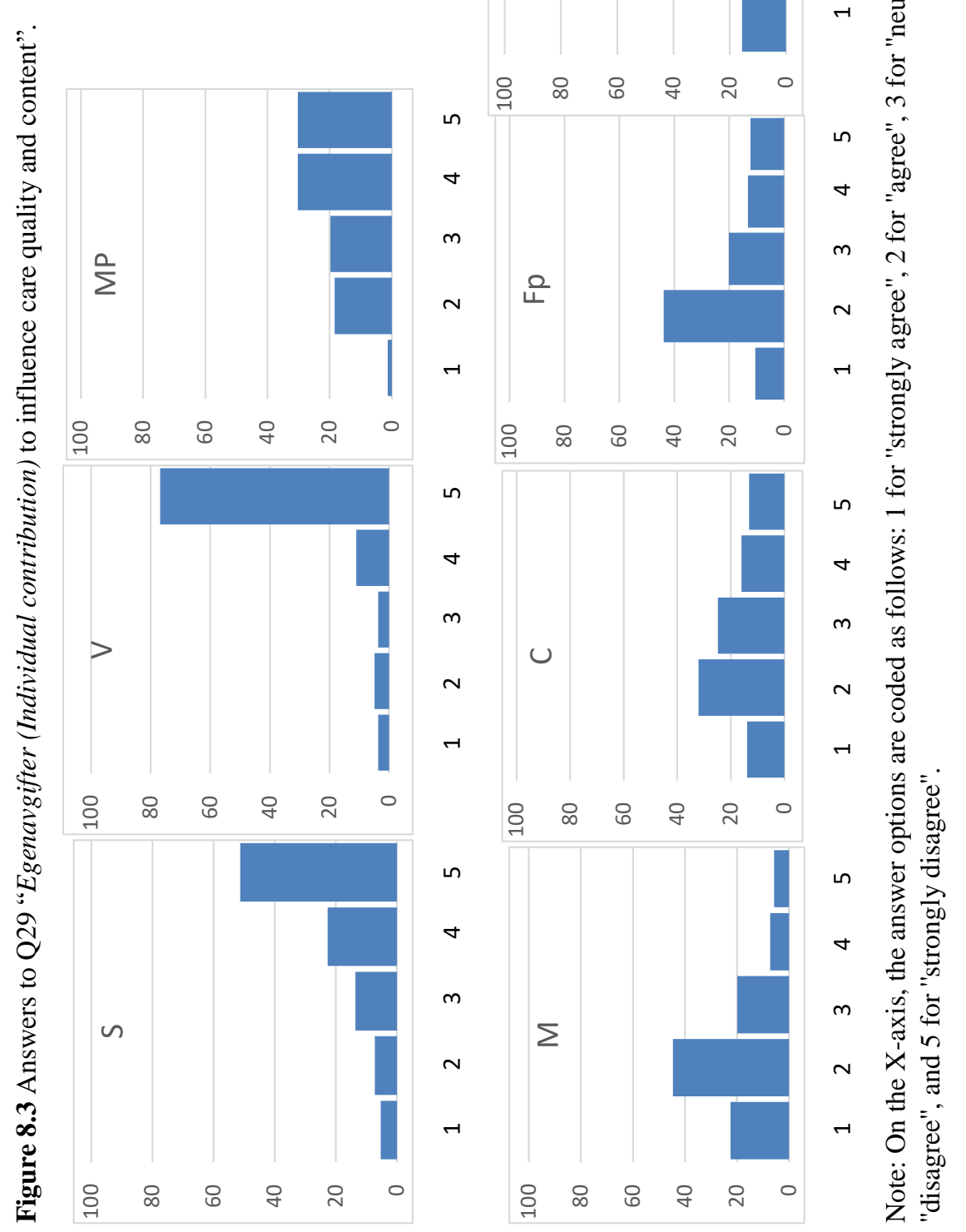




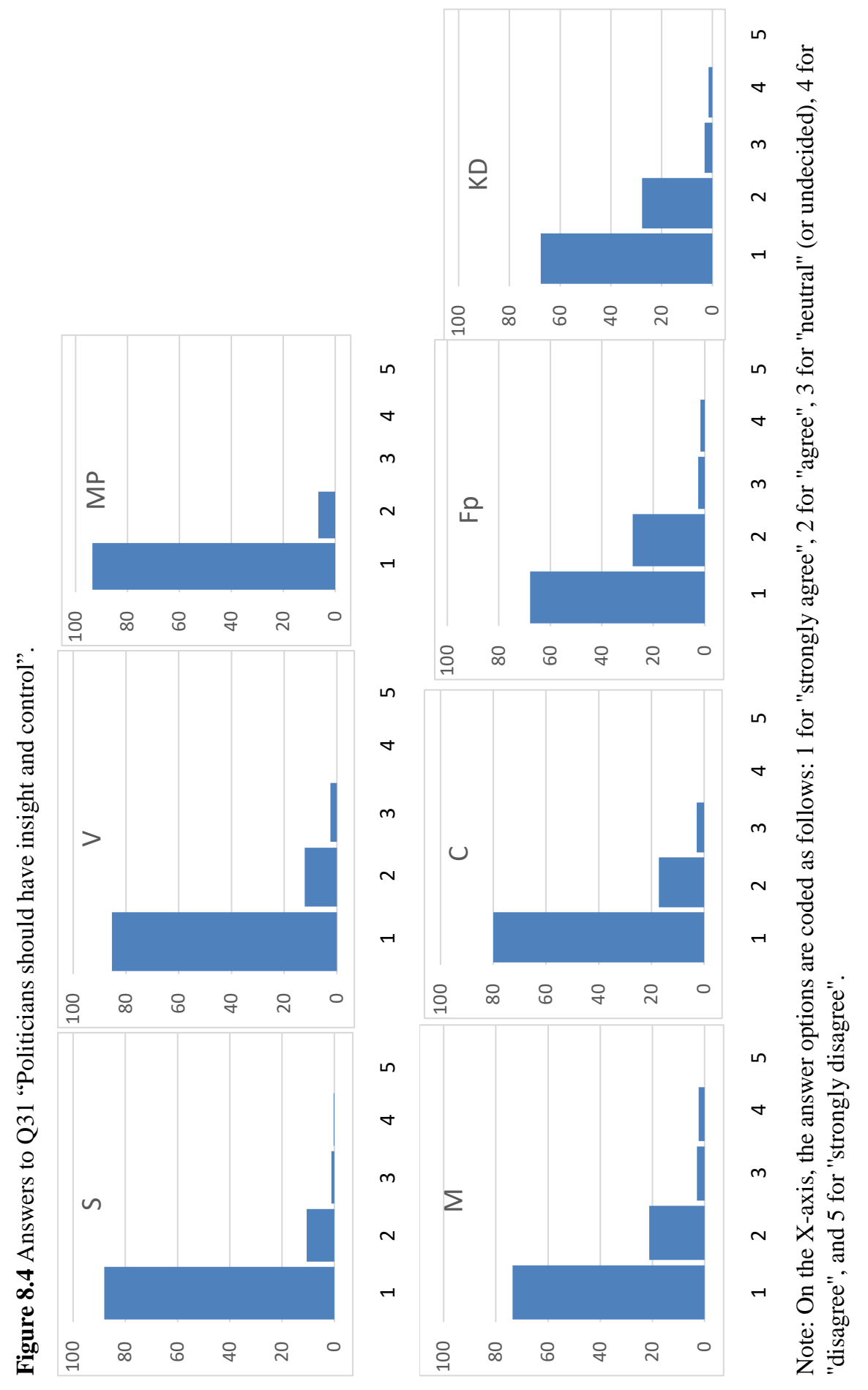

兽 


\section{Discussion of answers to open-ended questions}

My answers to the criticism raised by the respondents are as follows: firstly, as mentioned in the methodology section, certain marketisation arguments were designed to be examined in both negative and positive formulations, such as competition and its consequences. As a matter of fact, during the phase of the pilot study, I also consulted a survey expert to make the questions to be more neutral, especially in the ways in which they were formulated.

Nevertheless, I remain corrected that a few questions, such as Q15, could have been clearer. I also understand that some questions were formed in a very rigid manner and therefore might sound 'absolute'. For instance, Q23 enquired about the possibility that profits could lead to deteriorating quality of care. It is arguable that many other factors, such as the personnel's skills or the organisation of the care provisions, could be much more influential than the ownership. It is also true that for-profit private care providers can perform rather well or quite the opposite. The same can be said about public care providers. In this sense, the question was phrased in a rather debatable way and might be judged as biased.

Secondly, regarding the critique that the survey only included 'left-right' ideologically charged questions, it might be true that many survey questions could be viewed as direct 'left-right' questions; for instance, questions about profits in Q22 and Q23. However, it was not my intention to include merely left-right questions in the survey in the first place. All of the questions in the survey referred to issues that were primarily addressed in the marketisation debate. The intention was to determine how politicians, irrespective of their party affiliations, craft their positions on various issues of marketisation, not only on profitrelated issues. As shown in the results, some questions pertinent to the marketisation were not left-right questions, such as in the case of the financing of the care system. Moreover, the survey results revealed that even within a single party, answers to a single question can vary 
significantly, which might be surprising if operating on the deduction that market-related questions are only about left-right ideologies.

As discussed previously in Chapter 2, there are various motivations to move market development forward or to discourage it. Sometimes, political ideology alone is not compelling enough to motivate policy choices. Evidence-based knowledge, such as the segregation effect of the free choice model, is argued to be of importance in shaping politicians' attitudes and policymaking. In this sense, the marketisation question should be more than a question of left-right. This is also the justification as to why we should consider how politicians view the market issues vis-à-vis the welfare state.

The third point is to be cautious of the meaning of the left-right praxis, which could have different usages and coverage in various contexts. It is understandable that a single party could be readily associated with a left or right ideological orientation, but this is not always the case. Some parties claim to be in the middle, and a left-right praxis might not always be useful for describing these dynamics. The Feminist party in Sweden, albeit not in the scope of this research, even argued that they belong to another dimension. ${ }^{132}$

\section{Conclusion}

I started this chapter by explicating two important dimensions of marketisation: financing and regulation. Do politicians perceive public financing to be necessary? Alternatively, do they want to keep politicians' or government interference or intervention of the market as little as possible, or even a laissez-faire approach?

Somewhat surprising, the survey data showed a relatively high level of consensus across the political spectrum on opinions of using taxes to fund the care system. In the

${ }^{132}$ See, for instance, Vanliga frågor och svar om $F i$, https://feministisktinitiativ.se/om/fragor-och-svar/ Accessed on September 18, 2017. 
Swedish case, public financing also leads to the justification of the governments' oversight and regulatory role in the care system. Meanwhile, politicians across the political spectrum are positive about more control and management of the system with more transparency. Yet, the questions about what to regulate and how to regulate might still be up for political debate.

There are many discussions about the resilience of the welfare system and many scholars have pondered the fate of welfare state under the influence of globalisation, Europeanisation, and even the migration crisis. Some have had quite positive views in their belief of the welfare state's resilience (c.f. Lindbom 2001; Steinmo 2002). The results here have revealed relatively strong support for public elderly care service from various parties, which might be interpreted as a sign of welfare state resilience ${ }^{133}$. Elderly care is deemed as a public service and should not fall on individual shoulders, which also implies that the welfare state should not be a residual one in Sweden. This consensus could also help explain the current marketisation level that exists in Sweden: a result of negotiations and compromises made between various political parties. The Swedish right-wing politicians also expressed a relatively high level of belief in maintaining the Swedish model together with their leftist counterparts.

Based on answers provided in relation to the open-ended questions, I do not reject that marketisation in its entirety is apolitical. Quite the contrary, political elements and features are quite significant in this process. Nevertheless, it is somewhat misleading to provide an oversimplified answer that suggests the market issues always fall into a left-right binary option such that the left is always against the market and the right against the welfare state.

\footnotetext{
${ }^{133}$ In the light of the differences between the left and right political blocs, it is better to be cautious to draw the conclusion that the consensus on the funding mechanism alone can shape the future of the welfare state.
} 


\section{Chapter 9}

\section{Partisan Preferences and Political Ideology}

This study aims to explore and discuss how politicians conceive marketisation, a process in which welfare state principles and market mechanisms intertwine. During the process of using a market to provide welfare services, local politicians form their own attitudes and opinions about what a market should look like and how it should work.

Previous chapters have illustrated that left- and right-wing politicians do not share the same attitudes of service providers in production processes nor do they similarly tolerate profit-seeking in the publicly funded welfare system. However, they do share similar views on certain aspects of the marketisation debate, such as public financing or the importance of focusing on the needs of the elderly people. 
So far, attitude patterns have been displayed and discussed based on the three dimensions of marketisation: outsourcing, financing, and regulation. Still, there remain questions about local politicians' views on the market vis-à-vis the welfare state and what conclusions can be drawn when the views of all of the political parties on these issues are compared. For instance, perhaps all of the left-wing politicians embrace the welfare state and oppose the market to the same level. These questions, and more, are addressed in this chapter.

With the above in mind, this chapter deals with two issues. First, this chapter reveals politicians' views on the welfare state and the market by contrasting the two blocs. In particular, I am concerned with how politicians' attitudes on marketisation issues within either the left bloc or the centre-right bloc differ or correspond. Some within-party differences, an idea which has not yet been discussed in previous chapters, is mentioned, and their implications are discussed. The second part of this chapter is dedicated to the discussion of the role of political ideology in shaping attitude based on the answers to the self-reported question. This survey result also speaks to the regression models that I have performed previously by illuminating the significance of political ideology. Pragmatism, often said to be contradictory to political ideology, is discussed as well.

\section{Welfare state or market?}

To better illustrate and compare politicians' attitudes, I selected several questions from the survey and sorted them into two categories. The first category reflects on various aspects of the market (Table 9.1), while the second regards the welfare state (Table 9.2). The first set of questions focused on market discourse, mostly positively perceived market outcomes, such as 
improved cost-efficiency, quality, and freedom of choice. The second set of questions addressed issues that are key to welfare states, such as public funding and inequality. ${ }^{134}$

The original answers are coded as follows: agree to a larger extent is scored as 10 points, agree to some extent is 5 points, neutral is 0 , disagree to some extent is -5 points, and disagree to a larger extent is -10 points. The points signify to what extent the respondents agreed with the statement in the question. No response or the response of "Do not want to answer" were treated as missing values. Individual answers were sorted out and categorised based on their political party affiliation.

Table 9.1 Market-related survey questions.

\begin{tabular}{ll}
\hline & Questions \\
\hline Q16 & Competition between private and public providers in elder care leads to better care. \\
Competition between private and public performers in elderly care leads to efficient \\
Q17 \\
use of taxpayers' money. \\
Q24 $\begin{array}{l}\text { It is important that older people have the opportunity to choose from both private } \\
\text { and public operators in elderly care. }\end{array}$ \\
Q21 $\begin{array}{l}\text { Staff will have better working conditions if there are both private and municipal } \\
\text { employers in the elderly care sector. }\end{array}$ \\
Q19 $\begin{array}{l}\text { Those engaged in private elderly care financed by tax money should also be able to } \\
\text { make a private financial gain. }\end{array}$ \\
P22 $\begin{array}{l}\text { Private profit in elderly care is likely to lead to poorer quality. } \\
\text { conditions of the staff. }\end{array}$ \\
Q25 $\quad \begin{array}{l}\text { A problem with the “customer choice model” is that resource-poor elderly have } \\
\text { problems finding information or making informed decisions. }\end{array}$
\end{tabular}

${ }^{134}$ Original numbers of survey questions are used in this chapter. All questions presented in the tables are organised based on their meaning and connections to each other. For instance, Q19, Q23, and Q22 in Table 9.1 focus on profits and the possible consequences. The questions are not listed nor analysed following a simple order from the Q16 to Q31. 
Table 9.2 Welfare state-related survey questions.

\begin{tabular}{ll}
\hline & Questions \\
\hline Q14 & Elderly care should essentially be financed by taxes. \\
Q30 & Public funding is important to counter increasing social gaps in care for the elderly. \\
Q15 & $\begin{array}{l}\text { Municipal tax should be increased rather than reduced if elderly care service level is } \\
\text { lowered. }\end{array}$ \\
Q18 & $\begin{array}{l}\text { It is important that elderly care is operated by the public sector to guarantee } \\
\text { democratic transparency and control of the business. }\end{array}$ \\
Q31 & $\begin{array}{l}\text { Political leaders and civil servants should have a high level of insight and control of } \\
\text { the elderly care system. }\end{array}$
\end{tabular}

Table 9.3 shows how politicians view on various aspects of market-related issues, ranging from cost-efficiency, to freedom of choice, and working conditions. As shown in the results, a polarised pattern was found among left- and right-wing politicians, with the rightwing politicians expressing much more acceptance of many of the market benefits claimed by NPM. On the other hand, the left-wing politicians were more suspicious of whether a market indeed can lead to better working conditions for workers, a higher level of freedom of choice for the care users, or a higher level of cost-efficiency for the municipality. The difference between the left and the right blocs are of statistical significance.

Table 9.4 shows how politicians perceive several key aspects related to welfare state discussions, namely, public financing, public control, equality, and inequality. In terms of financing, both left- and right-wing politicians agree on public provision - continuous funding through taxes, irrespective of the existence of a market in the welfare sector. Politicians from both blocs agree that equality is important in the elderly care services. Nevertheless, they disagree on the importance of keeping public service provisions. Both leftand right-wing politicians would prefer a high level of monitoring of the system. 


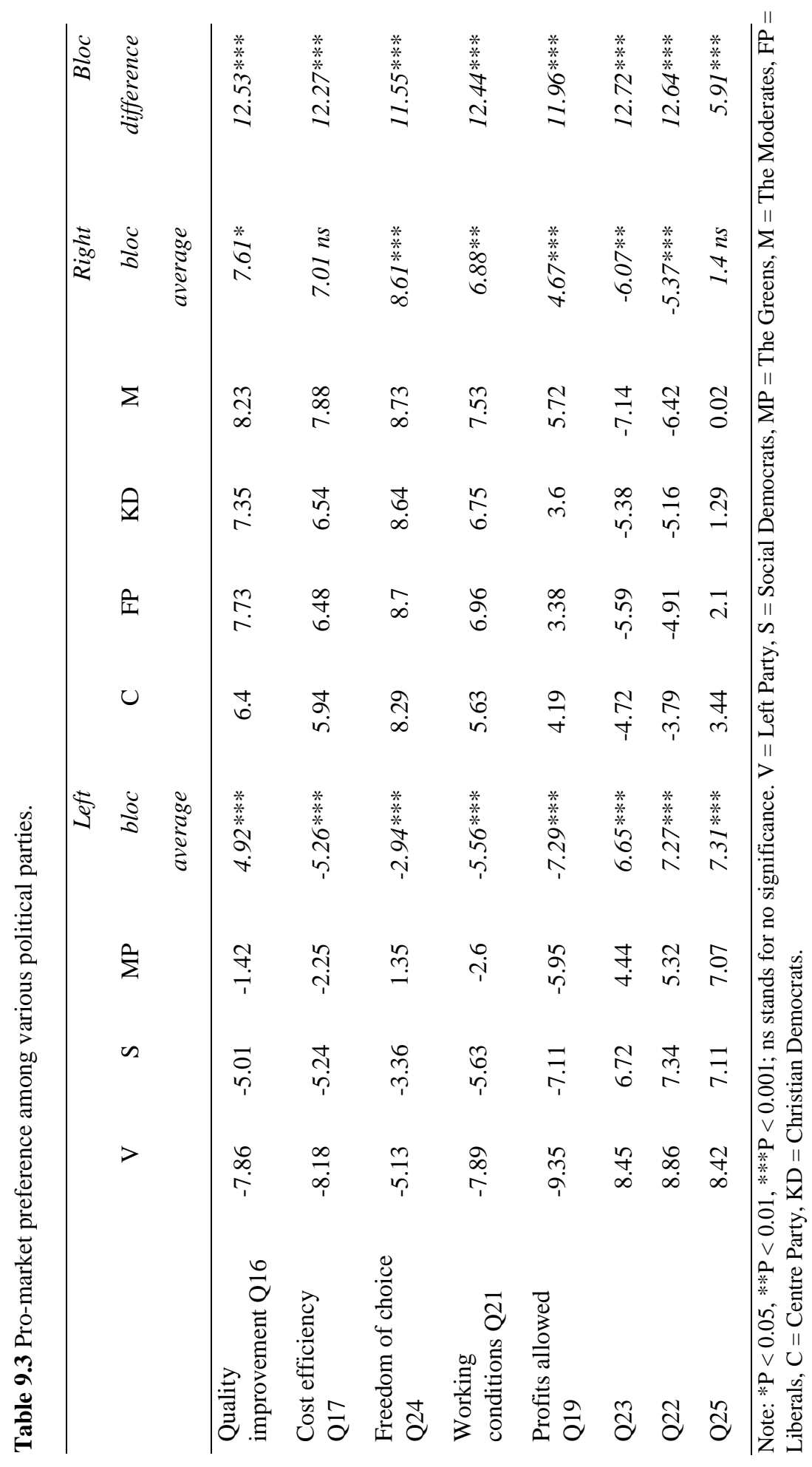




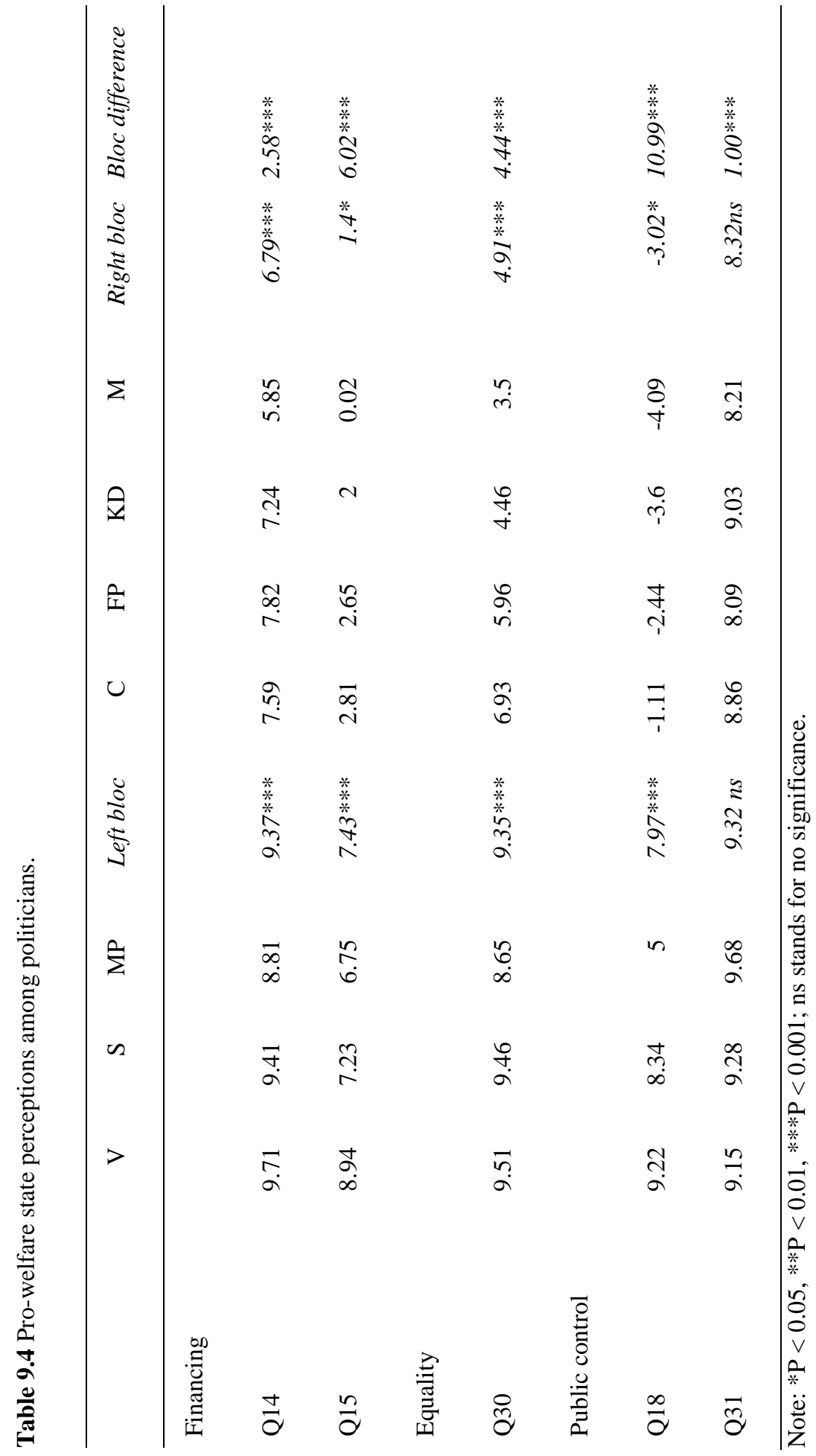




\section{Discussion}

1. Different views about market

As shown in Table 9.3, there is a divided view about perceived benefits of the market among politicians. First of all, the difference between left- and right- blocs were marked. All of the questions related to pro-market perspectives, such as issues of quality, efficiency, and better working conditions, received quite opposing views. When using the mean of all answers to conduct statistical analysis (one-way ANOVA was used), the division was statistically significant $(\mathrm{P}<0.001)$. Secondly, there were noticeable differences within each bloc. For instance, on profit-related issues, the Left Party within the left bloc seemed to be more opposed to profit-making in the welfare sector than the Social Democrats and Greens.

To some extent, politicians' views about the market can be easily categorised by their political party affiliations. This result returns the discussion to partisanship issues in welfare policymaking, as mentioned in the introduction.

The partisan difference was found in the responses to most market-related questions, not only between the left and right blocs but also within each political bloc, which highlights the political dynamics and sheds light on how each political party reacts and collaborates with others in policymaking. In this regard, the right-wing political parties seem to share more common ground (allow for profit generation, possible lack of information related to the choice model, and political oversight of the care) than the Red-Greens. It could also be expected for political parties to collaborate across blocs on certain issues if they share more similar preferences, irrespective of which bloc they come from.

This divided preference pattern indicates that individual political parties may shape markets in different ways and with various redistribution consequences. Nevertheless, a consensus on using tax money to fund the care system is found across the political spectrum, 
which could be seen as a sign of welfare state resilience and even explain the marketisation process status quo.

2. Welfare state principles:

a. Universalism is intact ${ }^{135}$

As mentioned before, universalism is one key characteristic of the Swedish model. Based on these results, it can be seen that politicians across the political spectrum demonstrate a high level of belief in this principle: A publicly financed, high-quality services should be available to all citizens according to their needs.

As argued in Chapter 8, one explanation of the consensus might be a result of pathdependency (Krasner 1984; Pierson 2000), since past settings such as policy structures, institutions, and vested interests help shape the current policy. Even though the welfare state was pushed forward mainly by the Social Democrats, its universal access principle is apparently accepted even by their right-wing counterparts. As citizens are accustomed to this universal coverage, it is arguably difficult to change the status quo, at least not without potential electoral risks. The Swedish model is known as one prime example of institutional social welfare, which takes the approach that the welfare should be provided as a public service and be accessible for all. If these welfare services are only in place for a select group of people, for instance only the poorer elderly, the universalism principle is likely to be weakened and the welfare state is likely to shift towards a residual one.

b. Awareness of equality being at risk.

The equality principle is an important factor in this debate. As mentioned before, in the marketisation process, the elderly group is likely to be subject to inequality in terms of

${ }^{135}$ Universalism is a rather complex concept and is discussed quite briefly here. For a more nuanced discussion, see, for example, Anttonen, Häikiö, and Kolbeinn (2012). 
information access or even benefit levels. Based on their answers to Q13, all left-wing parties are aware that the choice model might have a certain effect of selectivity. Namely, the elderly who are at a lower socio-economic status might find it difficult to make informed choices. Answers from the right-wing bloc are not negative, which suggests that these parties are not strongly opposed to the statement. The respondents' answers to Q30 show that both blocs agreed that public funding in elderly care is important to counter widening social gaps. As reforming the care sector would impact care recipients to various extents and therefore influence the welfare state, handling this redistribution tool is always a matter of concern for political parties, as many stakes are involved and certain trade-offs must be made (Korpi and Palme 2003). Linked with the previous discussion in Chapter 5, it could be argued that politicians from the left-wing parties are more adamant about using public service providers to help reduce inequality and prevent deterioration of the quality of services.

\section{c. Care responsibility}

Elderly care is a part of welfare state services, which essentially deals with the question of resource redistribution. It could be argued that there are certain risks that only the state can handle or operate more effectively than any other organisation in terms of redistributing resources (Barr 1992; Boadway and Keen 2000). In theory, the extent to which a public welfare system provides for care helps define whether it is a residual or institutional welfare system.

As shown in Table 9.4, the role of the public system and public providers are viewed very differently. For the left-wing politicians, the existence of public care providers not only satisfies care users' needs but also promotes equality through resource redistribution and universal access. Meanwhile, the right-wing politicians seemingly reject the idea and argue 
for a more liberal system for private care providers, which is in line with their traditional political ideology.

3. Within-block distribution results:

Within the left-bloc, the Left Party expressed the most opposition to market solutions, which can be corroborated by their party manifesto as well. It was also noticeable that the Greens were the least against market solutions (as shown in Table 9.4), and they reported more tolerance toward several market-related issues. These three parties' attitudes (positive or negative) to most index questions pointed in the same direction but to different levels, which suggests that the acceptance of pro-welfare arguments still varies among the Red-Greens. Furthermore, no significant difference was found in the answers to Q31, which signifies that all the three parties agreed on the importance of political oversight of the care system.

On the other hand, within the right-wing bloc, the Moderate Party (M) appears to be the most supportive of the market solution. Svallfors (2011) pointed out that the Moderate Party moved sharply towards the middle in its rhetorical appeal in the 2006 election and embraced several key tenets of the social democratic welfare state, which paved their way to electoral success. In this aspect, it is important to distinguish between what parties claim and what policies they implement. To compare the attitude pattern and the party election manifesto, it is safe to say that the Moderates are clear and consistent with their pro-market preference. The dataset also shows that not all bourgeois parties embraced privatisation to the same extent. The exact explanations remain elusive, but one explanation could be the evolution of partisan ideology over time.

Besides these within-bloc differences, it is also fair to say that right-wing parties converge on the belief that competition between private and public service providers would lead to efficient use of tax money and that profits should be allowed. In the meantime, their 
understanding of the possible implications of the choice model (Q25) tended to be quite similar. These three arguments could be considered as the very fundamental claims that unite these four parties. It can be seen that the right-wing parties share more common ground than the left-wing bloc, which possibly suggests a more stable coalition in the right-wing bloc. It could be seen as a signal that outsourcing-related market issues are more consistent with right-wing ideologies than with left-wing ones. Apart from the similar general trend in answering market-related questions, the levels of preference varied significantly across these parties, which implies a more diversified preference system within the bloc.

It should be noted that studies on the differences and similarities among parties within a left or right bloc are quite scarce. One important reason could be that it is more important for political parties within a bloc to show their unity and solidarity rather than express a division of policy views, if such a division exists, to the public. Nevertheless, for democratic reasons, a lack of understanding about these within-bloc differences might render it more difficult for citizens to vote for the party that best reflects and represents their personal ideologies and interests.

By comparing different attitudes, even from the same general political orientation, it is possible to better understand on what grounds which parties are likely to collaborate or refute each other. For instance, SOU (2016) suggested a strengthening role of non-profit providers in the welfare state. ${ }^{136}$ Based on the survey, this could be agreed upon by all leftwing parties. Alternatively, it can be seen from the survey results that there is more common ground within the Alliansen.

136 This does not occur through reservations to non-profit providers because of EU rules and national laws. All providers should be treated equally. 
4. Within-party distribution

Many within-party distributions have been shown in previous chapters. It is notable that even with a political party, different opinions about marketisation and preferences exist. ${ }^{137}$ It is also worthy of mention that some parties' politicians expressed rather consistent views on certain issues, for instance, Vänsterpartiet (The Left Party) on profit issues, compared with other parties.

From a democratic point of view, it is logical to have more than one viewpoint on certain policy issues. There should be no monopoly of any single politician or small group in dictating what fellow party members should believe, nor should there be a hindrance on the freedom to express different views. Even within a political party, local politicians might also have different views as opposed to their colleagues in the central government. All of these different views could contribute to a clearer policy stance on issues of sensitivity or ambiguity.

These different views within political parties are also indicative of how complex the issue of marketisation in a welfare state can be. Even though politicians within a party could, in principle, agree on their goal to advance their ideological pursuits, they might differ in the use of various means to do so, either by a market, a welfare state, or a combination of both. Of course, these variances within political parties are also reflections of how macro-level factors and micro-level factors could differently shape attitudes, as analysed in Chapter 5.

The dynamic attitude pattern within political parties might also indicate a possible change or shift in partisan ideology or belief system. This shift could either be conscious or

\footnotetext{
137 For instance, on the issue of profit limits, Lars Stjernkvist (S) from Norrköping municipality found it difficult to accept the profit limit proposal. See, for instance, a television debate between Lars Stjernkvist and Jonas Sjöstedt (V). https://www.svt.se/agenda/agenda-5-februari
} 
unconscious: politicians and their parties may actively react to various policy proposals and adjust their positions accordingly, or they may not be fully aware of the changed belief system. If tensions and conflicts within a party are reconcilable - say, whether to impose a limit on profits - then the political party is able to show its unity and present a clear and unified response to the debated issues. ${ }^{138}$ The need to unify politicians' views, or at least present limited opposing views, may be of great importance for a political party to send clear and consistent signals to its constituents. Otherwise, inconsistency or contradictory opinions could be seen as a lack of visions, clearness, and unity, which could potentially undermine the political party's public trust. ${ }^{139}$

\section{Political ideology or pragmatism?}

Frankly speaking, this study does not directly interpret the parties and their policy choices, rather it simply focuses on the attitudinal expressions. Nevertheless, the importance of political ideology in shaping attitudes (and arguably later in forming policies and making decisions) is found in various aspects. To complete the statistical findings, there was another question that probed politicians' self-evaluations of their market attitudes. The results show that, according to politicians themselves, political ideology is of great importance. The result table follows:

\footnotetext{
${ }^{138}$ It should be recognised that such a consensus within a political party sometimes is rather difficult to achieve. It happens that contradicting voices are sometimes mediated, and the political party must react as swiftly as possible to handle the 'crisis'.

${ }^{139}$ It was observed that a certain percentage of Moderate voters switched to Centerpartiet, for instance, in March 2017, possibly due to the confusion and dissatisfaction of the Moderates' new political rhetoric regarding cooperation with the Sweden Democrats. Compared with the public, although politicians do not often change their party affiliations, it is still possible.
} 
Table 9.5 Self-reported influence on politicians' marketisation attitude.

\begin{tabular}{lccccccc}
\hline Party & $\begin{array}{c}\text { Older } \\
\text { relatives }\end{array}$ & $\begin{array}{l}\text { Working } \\
\text { experiences }\end{array}$ & $\begin{array}{l}\text { Political } \\
\text { work }\end{array}$ & $\begin{array}{l}\text { Political } \\
\text { ideology }\end{array}$ & $\begin{array}{l}\text { Mass } \\
\text { media }\end{array}$ & $\begin{array}{l}\text { Research } \\
\text { reports }\end{array}$ & $\begin{array}{l}\text { Scientific } \\
\text { articles }\end{array}$ \\
\hline \multicolumn{2}{l}{ Red-green bloc } & & & & & & \\
Mp & 51 & 37 & 90 & 72 & 41 & 65 & 56 \\
$\mathrm{~S}$ & 67 & 37 & 93 & 93 & 27 & 66 & 56 \\
$\mathrm{~V}$ & 66 & 30 & 96 & 87 & 34 & 81 & 71 \\
Right-centre bloc & & & & & & \\
$\mathrm{C}$ & 73 & 33 & 88 & 74 & 17 & 50 & 50 \\
$\mathrm{Fp}$ & 73 & 32 & 87 & 80 & 21 & 70 & 62 \\
$\mathrm{KD}$ & 72 & 45 & 95 & 85 & 25 & 67 & 64 \\
$\mathrm{M}$ & 75 & 32 & 88 & 69 & 16 & 63 & 60 \\
\hline
\end{tabular}

The figures listed in this table indicate how many percent politicians agree to the importance of each factor in attitude shaping. ${ }^{140}$ Several factors, including personal experience, position-related work, media influence as well as scientific knowledge, were probed. It could be observed that for most parties, political work and political ideology were considered to be the most influential factors, whereas the influence of mass media was reported to be the least. ${ }^{141}$

Of course, there are different views regarding the importance of partisanship in contemporary welfare politics. Based on the regression models and survey questions shown in previous chapters, it is obvious that political ideology is important in accounting for the marketisation development in the case of Swedish elderly care. Meanwhile, it is possible that political ideology sometimes must yield to other factors, such as being intertwined with

\footnotetext{
${ }^{140}$ Note that the data here do not distinguish among different levels of agreement.

${ }^{141}$ The only exception here is the Green Party: for them, working experience was the least important factor.
} 
economic issues or political pragmatism during policymaking. Nevertheless, these aspects cannot refute the importance of political ideology.

Yet at the same time, it is important to remain cautious in the interpretation of the significance of political ideology in policymaking. One important factor to consider is political pragmatism. Ormerod (2006) once mentioned that pragmatism is a theory about meaning that is characterised by weak values and uncertain cognitive frameworks. The author believed that there are no abstract principles such as individual liberty, freedom, equality, or beliefs about the market economy are involved in the development of society. By contrast, ideology is marked by strong values and firm cognitive systems, and ideological politics is embedded within belief systems full of principles, normative ideals, and other cognitive frameworks.

Based on the results shown previously, it seems plausible that the leftist parties and politicians are more affected by their political ideology, which emphasises the values and principles that underpin the welfare state, such as equality and solidarity. On the other hand, the centre-right parties and affiliated politicians embrace more 'neoliberal' ideas, which emphasise thinking and acting based on pragmatism - as long as it works, there is no need to forbid the market or profits.

It appears that these dimensions of marketisation are political in nature: outsourcing or competitive tendering could be apolitical as long as the procurement and bidding processes follow the rules, but the question of whether to outsource or not is essentially a political decision at the start. Financing and regulating the market are two issues that are arguably more political. The former controls the economic foundation of the system and involves public trust of the state and politicians. The latter more refers to a question of state intervention and to what extent a government should exert its influence on market operations. 
Politicians and their parties have to make choices while taking into consideration both pragmatism (short-term insights) as well as values and ideologies in the long run. More often, political parties try to introduce policies that achieve their ideological goals while appealing to a broad group of voters. Yet, simultaneously, they have to constantly balance between long-term ideological goals and short-term ones such as to win a local or national election. Arguably, the intention to stay in power by winning an election will influence what kind of policies, rhetoric, or propaganda these politicians disperse to the public to appeal to their constituents. Besides political calculations, there are other considerations that politicians must address. For example, in terms of marketisation, politicians should consider the existing forms of care provisions, budgets, local labour markets, and more in order to make informed decisions.

The importance of political ideology in real life may also be weakened for other reasons. For instance, in the Swedish case, there are local governments that are based on a coalition between left and right-wing parties. In this case, it is much more difficult for a single party to fully implement its policies, like marketisation, as it intends. Instead, compromising is very likely to exist. Politicians from different political backgrounds need to make concessions in order to cooperate with one another. All of this complicates and confuses the possibility of understanding the connection between what politicians say and what they actually do.

Still, when discussing the importance of political ideology or pragmatism in welfare politics, it is worthwhile to make a distinction between different components of policymaking: politicians' attitudes, influences from affiliated parties (both ideology and socialisation with other affiliated members), party campaign strategies, politicians' behaviour later on (policymaking), and eventually policy outcomes. 


\section{Conclusion}

The last two decades have witnessed further market or quasi-market development in the elderly care sector in Sweden. On a policy level, new initiatives such as RUT, LOU, and LOV have been introduced, and the central government has pushed forward reforms like freedom of choice. On the local level, as demonstrated in the data of this study, left- and right-wing politicians still have their own perceptions of what a market can or cannot do in a publicly funded welfare state. All policy makers seem to understand that care needs should be satisfied, but they disagree to what extent a market can be accepted. The current development of marketisation can, therefore, be perceived as a result of political compromise.

With market development, welfare state principles are being challenged. A shift from public provision of welfare services towards a mixed use of market providers does not only symbolise a transfer of care provision or delivery but also poses challenges as for how to deal with questions such as relocation of resources, care responsibility, quality of care and sustainability of the care system, among others. Policy makers, based on our national survey, seem to be aware of the potential conflicts between market and welfare principles.

Despite these varying views about what a market can really achieve, we conclude that based on our survey with our national survey data, it seems plausible that welfare state foundation has not been entirely compromised in elderly care. Of great importance, the consensus to use tax (on a relatively high level) to fund welfare system is found to be true, which is essential to care provision and welfare state, despite local variations of market development.

In this regard, it seems that welfare pluralism is the trend. NBHW $(2007,12)$ wrote that: "Today's political choices consist of allocating resources that seldom suffice to fulfil the needs of the population. The future perspective on elderly care points to a need to rethink the 
structure of the system of welfare for the elderly - in Sweden - as most other countries. The new policy initiatives further sustain a development towards a more mixed system of welfare for elderly people in Sweden."

Internal conflicts between the welfare state and the market, such as commodification and de-commodification, have not been significant issues partially because of the mechanism of public funding. Nevertheless, extra services purchased by more affluent social groups or a lack of care resources in some municipalities could potentially intensify the tensions between the welfare state and the market and increase the gaps among various social groups.

There are many debates about the resilience of the welfare system, and many scholars have pondered the fate of the welfare state under the influence of globalisation, Europeanisation, and even the migration crisis. Some have felt quite positively and held to the belief in the welfare state's resilience (c.f. Lindbom 2001; Steinmo 2002). The results of this research reveal relatively strong support for continual public elderly care services from various parties, which may be interpreted as a sign of welfare state development. The system is very likely to continue to evolve as a mix of public and private providers in the market with the support of patrons (customers) and political parties (even lobby groups). Finally, bearing in mind that partisan political preferences could change over time and space, more research on welfare policymaking is needed. 


\section{Part III. Conclusion}

\section{Chapter 10}

\section{Conclusion and Final Remarks}

In this chapter, I firstly summarise the findings of this research and highlight the importance of political ideology in the marketisation discussion. Then, I move on to theoretical implications by offering some reflections and critiques of the New Politics of Welfare, the socalled convergence thesis. Meanwhile, the attitudinal differences found among Swedish local politicians are discussed.

I also feel it is necessary to discuss the left-right praxis that is frequently mentioned in this thesis, as most of the results and discussions are built upon this categorisation; there are both pros and cons of this praxis. Several policy implications of this research are addressed as well. At last, I discuss the limitations of my research and future study directions. 


\section{A brief reiteration of the findings}

This thesis provides original and interesting survey data regarding the attitudes of local politicians about marketisation in Sweden. I opted to focus on the specific policy area of elderly care - an area in which there is growing societal and political importance both in Sweden and beyond, as populations continue to age and challenges build.

The real scope of the thesis is more descriptive of elite attitudes in terms of their perspectives in the various marketisation issues, such as how to manage profiting and outsourcing. My data show that similar to the public opinion, politicians from various parties agree that elderly care should essentially be financed by taxes, which is a consensus that deserves attention.

The survey results show that local politicians' preferences still diverge on several aspects of marketisation, with left-wing politicians expressing much less favour of the presence of for-profit care providers, compared with their counterparts in the right-wing bloc. As shown in Chapter 5 and 6, outsourcing preferences are closely linked with issues of ownership and profit-making. It is not completely surprising that the left-wing socialist parties insist on using the means of nationalised production to distribute welfare resources while the right wing tends to favour more private for-profit care providers by encouraging entrepreneurship and the pursuit of profit. Nevertheless, this case study goes a step further by showing a more diversified pattern of local politicians' market preferences in elderly care and highlighting the tension between the public funding system in a welfare and the ability to make profits in the market.

The emphasis from the left-wing politicians on public provisioning of the welfare system and a desire to set a limit on profiting could be understood in different ways. One argument is that because only by providing services itself can the state guarantee access to 
high-quality social services for all citizens (Blomqvist 2004). Meanwhile, one important feature of the welfare state is its public financing and the solidarity principle. Unlimited profiting therefore is viewed as detrimental to this foundation and creates mistrust of the welfare state. Some scandals in which for-profit companies sacrificed quality for profits not only triggered moral resentment from the public but also put pressure on politicians to justify their outsourcing decisions.

For scholars who believe in the importance of political ideology and traditional partisanship theory, some results of this study may not be surprising. It can be seen that local politicians are still, to a large extent, driven by their political orientation in engaging with issues of marketisation. Despite that marketisation was introduced by the central government in the 1990s and there have been various efforts to push forward market solutions, there are still many differences regarding acceptance of a market in a welfare state and ideas of how it should operate.

My survey data also confirm that ownership issues divide the two political blocs: the right-wing parties feel more positively towards an increase in private provision and argue for limited state power to claim more freedom for both private enterprises and care users; they also support profit-making. However, the left-wing parties promote extensive government intervention in the economy and focus more on welfare state principles, such as equality and universal access to welfare services.

Regarding explanations for the preferences of supporting private providers, individual-level factors such as age, gender, and socioeconomic status play a certain role. Among the contributing factors that I investigated, the political affiliation of the individual, the current political majority, and the degree of privatisation already present in their home municipality were identified as the most important factors for explaining the distinct 
preferences for private for-profit care providers. Both regression models and self-revealed answers confirm the significance of political ideology in shaping these attitudes.

Besides these substantial differences, some common ground was found when politicians' views on financing and the need to keep control of the market were analysed and compared. Irrespective of which parties they come from, all politicians seemed to share the similar view that monitoring of the system is necessary. ${ }^{142}$ Furthermore, almost all politicians across the political spectrum agreed that public financing should be the primary source of the elderly care system, and they believed that the needs of the elderly should be addressed, which could be considered as a sign of welfare state resilience and even explains the current marketisation level in Swedish elderly care.

The consensus reflects the existence of a degree of path dependency, which suggests that policy legacies (and generated feedback) as existing programmes might be decisive in constraining future policy options (Krasner 1984; Pierson 1996, 2000). In the Swedish context, a strong welfare state legacy that involves past policy structures, institutions, and vested interests, helps to shape policy options for the right-wing parties. Although the welfare state is a legacy from the Social Democrats, the Alliansen government still develops the welfare state without wholly abolishing all previous policies. ${ }^{143}$

Some points can be made here: first, the influence of political ideology, despite three decades of privatisation practices and the firm influence of NPM, still plays a significant role in shaping market-related attitudes. The rise of market reform has not marked an end to traditional theories of the welfare state, nor has it created a preference for the non-political

\footnotetext{
142 This might be a sign that neo-liberalism is not as powerful as expected in the Swedish case. ${ }^{143}$ Admittedly, this does not mean that the bourgeois parties agree with all of the policy directions of their predecessors. An incremental change might still be more feasible when it comes to policy reform.
} 
feature of privatisation. It might be naïve to expect that as the market develops, doubts and suspicions would automatically vanish. Furthermore, it could be argued that in fields that tend to be more politicised, such as health care or school education, the strong influence of political ideology might also prevail.

This study therefore aligns with other literature that have rejected the "end of partisanship" theory and demonstrated the continued existence of a substantial partisan effect even during an era of welfare state retrenchment (Allan and Scruggs 2004; Amable, Gatti, and Schumacher 2006; Belke et al. 2007; Boix 1997; Bortolotti et al. 2003; Obinger et al. 2014; Palme and Korpi 2003; Zehavi 2012).

In the meantime, I remain open-minded to the suggestion of other plausible explanations for the formation of the attitudes discussed here, since there may be other personal or contextual factors that could shape an individual politician's attitude towards privatisation. It is also likely that politicians' preferences and even political ideologies could change over time, which makes this topic worthwhile of continued research.

\section{Theoretical implications}

This study is based on empirical data, and the primary focus is not to propose a new theory at all. Still, many discussions and analyses are based on the debates about the market or the importance of political ideologies in market reform in a welfare state.

At the beginning of this thesis, I reviewed some theories that are pertinent to the discussion of welfare attitude formation and welfare politics, namely, the difference theory or the convergence thesis. One interesting question referenced whether the convergence theory trumps the difference theory in contemporary debates of welfare politics. Based on the survey results, the answer is possibly negative. In this part, I intend to address some issues that are mostly connected to the New Politics of Welfare theory, or the so-called convergence thesis. 


\section{On the convergence thesis}

The New Politics of Welfare perspective proposed that there has been a decline in party polarisation over redistributive issues since the 1970s and argued the diminished importance of partisanship in the shaping of welfare policies. Pierson $(1996,2001)$ claimed that the political situation today is fundamentally different from the situation during welfare state expansion, and he also mentioned that the welfare state has created its own political support that makes it quite resilient to retrenchment.

Empirically speaking, as I gathered only a cross-section of political preferences of Swedish local politicians in 2014, it is not sufficient to fully test and refute Pierson's view of the importance of partisanship in welfare reforms. Even more, in order to find a pattern that either supports or rejects the convergence thesis, a panel data or longitudinal data is needed. Nevertheless, the data here cast some doubt on the convergence thesis in several ways.

First, the validity of a conclusion of 'convergence' depends on the observation period. Most of Pierson's observations were made in the 1990s and were mostly based on the discussion of pension systems. ${ }^{144}$ As time passes, the validity of his theory must be tested based on new datasets. It could be quite possible that the convergence was indeed the case at the end of his observation period but shifted later on, which indicates more divergence and differences. Meanwhile, based on the literature, it can be assumed that the left- and rightwing politicians departed from very different stances on the issue of market and welfare state before the market mechanism was introduced in the 1990s. After nearly three decades of

\footnotetext{
${ }^{144}$ It was during the austerity era that Pierson made his observations and analyses, which culminated in the non-importance of partisanship that he drew later. Although it is inappropriate to say that Sweden is under austerity now, it is necessary to point out that welfare states in post-austerity live under the influence of austerity, particularly in terms of retaining the costs. Meanwhile, it is important to ensure the quality, accessibility, affordability, and expectations of welfare services.
} 
marketisation, based on the findings in this research, two political blocs still express more differences than similarities, which could be used as a rebuttal to the convergence thesis. That being said, the NP thesis should be able to address the dynamics of the market and welfare state development over a longer period.

Second, many welfare state reforms are contextually based, and this poses questions to the explanatory ability of the theory. Some might argue that a Swedish case is not appropriate for testing this theory because of the contextual differences between Sweden and the US, where the theory was firstly developed. However, if this is the case, then the New Politics thesis needs to be developed to set up boundaries, both theoretical and geographical, regarding its applicability. By contrast, if this thesis is valid and all-encompassing, it should be able to offer explanations to the polarised party system in Sweden, similar to that of the US. On the other hand, Pierson's theory might be too complex to fully test in any way (Lindbom 2014). It is my view that Pierson's thesis should be revisited and revised by at least specifying the applicable policy areas with updated data.

Third, political ideologies evolve. Politics is a dynamic process, not a static one. This suggests that political parties and their stances and politics on welfare issues could either converge at some point or diverge later under various influences. One example used by Lindbom (2016) is that the Moderates actually shifted their tough position on public childcare in the past decades. The NP thesis seems to indicate the end of partisanship in welfare politics and might make this conclusion too hastily.

Whether one should hold on to the thesis of partisanship in welfare or embrace the New Politics of Welfare is highly debated. Proponents of the difference theory have often argued that because of the existence of distinct social classes that the left and the right rely on as constituencies, different policy preferences are formed accordingly. The survey data here 
seem to support the difference theory while at the same time reveal that a certain level of consensus does exist, which is interesting for future studies.

Suffice to say, policymaking in real life as political action is subject to influence from many other factors, including pragmatism, political compromise, local fiscal ability, and so on, while not necessarily directly reflecting politicians' actual preferences. Political preferences can then be either disguised or obscured.

\section{Understanding the differences}

As argued previously, many of these research findings indicate the substantial differences that exist between the two political blocs. It seems fair to conclude that in the marketisation debate, the right-wing parties have focused more on the economic perspective, for instance, creating jobs, whereas the leftist parties seem to have been more concerned about welfare state principles. ${ }^{145}$ Still, how to understand these different stances on the market vis-à-vis the welfare state is worthy of discussion.

1. These differences regarding marketisation issues could be seen as a reflection of different attitudes towards state intervention and to what extent a local government should be involved in service production, delivery, and regulation.

Kumlin (2002) stated that there is a conceptual kinship between orientation on state intervention and the welfare state, which is constituted by the fact that the size and nature of welfare state arrangements strongly affect the degrees of the market economy and public ownership of the means of production. The left-wing socialist parties insist on using the means of nationalised production to distribute welfare resources, while the right wing tends to

\footnotetext{
${ }^{145}$ See, for instance, one article written by local politicians in Gothenburg, Vi tar ansvar för ekonomin och prioriterar välfärden (We take responsibility of economy and prioritise the welfare state). Accessed online on June 12, 2017: http://www.gp.se/nyheter/debatt/vi-taransvar-f\%C3\%B6r-ekonomin-och-prioriterar-v\%C3\%A4lf\%C3\%A4rden-1.4355486
} 
favour more private for-profit care providers by encouraging entrepreneurship and the pursuit of profit. For leftist politicians, their focus is to secure the viability of the welfare state and assist weaker members in society. Therefore, public ownership and a certain level of state intervention are vital to ensure the sustainability of public programs and prevent negative consequences. On the other hand, the right-wing politicians often favour less state interference and more market freedom. ${ }^{146}$ Their preference for privatisation indicates a market-oriented redistribution of welfare resources. It is, therefore, safe to say that the conflicts and differences also reflect that the capital or labour conflict upon which traditional partisanship theory build is still relevant to the marketisation discussion.

2. These differences are also reflections of a different understanding of the capabilities of the market or a 'quasi-market'.

Even though it can be seen that leftist politicians are also influenced by the management theories such as NPM, their understandings of the market in a welfare state still differ from their right-wing counterparts. Both parties might agree on the importance of 'quality' as an 'output' of care systems, but they still hold different beliefs about what a market can offer, its side effects, and what costs are appropriate (both literally and figuratively). For some politicians from the Left Party, a market seems likely to exploit human freedom and capabilities, which can lead to increasing social inequality and a neglect of vulnerable groups such as the sick old people with less social or economic capital. By contrast, the Moderates might argue quite the opposite: marketisation creates possibilities for the service quality to improve, empowers the elderly with more freedom of choice, and is also good for the economy in that it creates jobs in the care sector. These fundamentally different views of the

146 This study shows that Christian Democrats tend to favour more generous state funding and a fair share of family responsibility for the elderly. 
advantages and limitations of a market to a larger extent explain the ideological differences shown in the previous chapters.

It should also be noted that care scandals occurred in the elderly care, and different politicians blamed these scandals on different factors. The left-wing politicians tended to argue that the outsourcing choice is to blame and seemingly indicated a causal relationship: outsourcing to for-private providers resulted in the scandals. By contrast, the right-wing politicians disagreed with this logic and argued that poor quality or scandals can happen anywhere and the outsourcing decision is thus not directly culpable. As a counter-argument, the leftist politicians might go further and argue that if public production and provision of care services already work, then it would be a bother to introduce private care providers. ${ }^{147}$ This kind of debate is quite common nowadays in welfare reforms and is hardly likely to cease. For municipalities that have not made their decisions to privatise or marketise, these questions are possibly inescapable. Even for municipalities that have introduced the choice model and private providers, it is possible that the local governments still resort to public providers as a backup plan in the event of a scandal. ${ }^{148}$ Therefore, a co-existence of both private and public providers is likely even in municipalities that have already marketised.

3. Suspicions of the outcomes of marketisation and a fear of uncertainty.

So far, it is relatively safe to say that marketisation in elderly care has not led to catastrophe. By comparison, the bankruptcy of private schools caught more attention, and there are concerns about the irreversible process of marketisation and potentially negative consequences, as highlighted in Chapter 2.

${ }^{147}$ The Swedish welfare state is famous for its high-quality public services even before the era of marketisation. Therefore, this kind of argument is not rare.

${ }^{148}$ As an example, Leanlink in the Linköping municipality is a public provider that can step in if another provider has its contract with the municipality terminated because of failing to deliver the agreed services. 
Rothstein, Samanni, and Teorell $(2012,9)$ wrote: "Citizens have to trust that when they are in a situation in which they need and are entitled to support, the system will actually deliver. In some cases, especially when we are dealing with long-time horizons (pensions, elderly care), we must think of this as quite a problematic 'leap of faith'”.

Both the public and the politicians are required to take this 'leap of faith'. As Sørensen and Bay (2002) argued, traditional public governance means that local government is a producer and politicians can interfere in nearly all aspects of service provision. Management is conducted using appropriations, instructions, and possible contacts with other institutions. In market scenarios, local government becomes a purchaser of services, and contracts are key as they stipulate the requirements of the amount and standards of the services to be procured. Once privatised, politicians have fewer possibilities to exert influence on care provisions and regulations. Should market failure occur, whom to blame and how to solve the problems are issues that the politicians would have to address. ${ }^{149}$

\section{The hazard of an over simplification.}

It is my intention to emphasise that attitudes about marketisation are far more complex, and it should not be concluded that "the left is against the market, and the right is for the market" nor that "social democrats will be against competitive tendering regardless of their perceptions, and right-wing parties will be in favour of it regardless of their perceptions" (Sørensen and Bay 2002, 366).

\footnotetext{
149 This might also be a concern for politicians who ponder whether to introduce market mechanism locally, such as the freedom choice model. To avoid blame and strengthen public support for the politicians and their parties are factors to take into consideration, especially when there is a lack of consensus on the exact benefits of marketisation. Pierson (1994) also argued that politicians must pursue strategies of obfuscation and division when dealing with the unpopular politics of welfare retrenchment. The 'blame avoidance' strategy is considered to be the only way of retrenching without losing votes through hiding the fact that politicians are doing it (Hering 2008; Pierson 2001; Weaver 1986).
} 
The hazard of relying on these narrow evaluations is three-fold: first, it makes it easier to neglect the existing deviations within each bloc, not to mention the varying attitude patterns within each single party. Second, this single generalisation fails to predict the consensus that was found in the survey and dissuades the search for further grounds between both blocs, which is detrimental to the democratic decision-making process. Third, such a generalisation ignores the various factors that contribute to the formation of attitude patterns, many of which are subject to change. By this, it is meant that as many independent variables (not limited to the those included in the regression models) can change, the general attitude about market preferences might change as well.

\section{Some remarks on the left-right praxis}

Empirical findings show that in Sweden, the left-right categorisation is rich in meaning and useful for the public to perceive policies and politics around them (Gilljam \& Holmberg 1993; Holmberg 2000; Petersson 1977; Svallfors 1999). Knutsen (1995, 86-87) argued that "the left-right semantics have an impressive absorptive power. This is an overarching spatial dimension capable of incorporating many types of conflict lines, and with different meanings to different people." Oscarsson's (1998) results showed that the left and right continuously seem to be defined by industrial-age questions concerning the extent of state intervention, the size of the public sector, and the extent of privatisation.

This left-right distinction might also make it easier for voters to associate with certain political parties and vote for them. The identities of political parties can be seen as trademarks that assist the voter in the decision-making process (Kiewiet \& McCubbins 1991, 37-43). Left-wing parties are seen as pro-government with egalitarian policies; while right- 
wing parties are associated with less redistribution and less government intervention. ${ }^{150}$ Hagevi (2015) also claimed that voters' identification with political blocs are important, and a declining party identification has been replaced by a bloc identification of voters, which means it is important to analyse these results using the two-bloc system.

Some scholars have criticised this praxis for its inability to detect a clear division in partisan stances or because it has led to some counterintuitive findings, as shown in Chapter 1. Therefore, a few points regarding the left-right praxis should be made here. ${ }^{151}$

First, the praxis of left-right does not dictate constant differences between different politicians or political parties on every issue, which means that both parties could have a similar stance on certain policy issues. Meanwhile, the left and right do not have to be single homogenous schools of thoughts. Quite the contrary, both the left and right could encompass very broad coalitions of interests that agree on some issues and disagree on others. ${ }^{152}$ For instance, the Greens are included in the left political bloc, yet the attitude pattern suggests that they are more tolerant about market solutions that favour non-profit providers compared to the other two parties in the bloc.

The major split between socialist and non-socialist ideology is rooted in the conflict between capital and labour (Listhaug 1989). Moreover, traditional left-right ideologies do not necessarily offer specific guidance about competitive tendering (Sørensen and Bay 2002),

\footnotetext{
${ }^{150}$ Institutional theory rejects the idea that ideology is a trademark. Instead, they argued that the ideological affiliation of politicians reflects stable belief systems; their perceptions are influenced by party socialisation (Sørensen and Bay 2002).

151 The left-right praxis in this entire research is based on the categorisation of the politicians' party affiliations. It was not measured by using self-identification questions, where politicians would be asked to place themselves on a scale from 0 (as 'far to the left') to 10 ('far to the right').

${ }^{152}$ Parties make considerable efforts when introducing reforms, and they are the key actors during market reform. The major difference between the left and the right is argued to be mainly associated with how to allocate and distribute resources.
} 
which is a major part of marketisation. This means that politicians from different ideological orientations might reach similar conclusions regarding certain non-political aspects. For instance, they could all agree that quality of care services matters or that elderly people should be put in the centre of these services.

In the case of marketisation, the differences among various political parties exists mainly in the different stances on the scope of state intervention. As argued before, the centre-right parties often try to limit the role that government plays in the welfare services, whereas the leftist parties consider government oversight to be a necessary means to guarantee the procedural fairness of welfare services and avoid potential side-effects of market failure; such failures may be a waste of tax money in the form of profit or an erosion of democratic principles.

Second, the left-right scale alone cannot determine attitudes on the market vis-à-vis the welfare state issues. There might be multiple factors that could be important 'causes' of shaping attitudes and behaviours.

There are different views regarding the importance of partisanship in contemporary welfare politics. As indicated by its significance in the regression models in Chapter 5, political ideology is one important factor that can explain the current privatisation level of elderly care in Sweden. In the self-reported section shown in Chapter 9, politicians also revealed that political ideology is important to the shaping of their attitudes of the market. Furthermore, during the comparison of policy claims from different political parties, their different emphases and claims also suggest that political ideology plays has a significant influence. Therefore, I argue that political ideology is important in accounting for both politicians' attitudes and the development of a market in the traditional welfare state. 
It is possible that political ideology occasionally must yield to other factors, such as political pragmatism in the phase of policymaking. Nevertheless, these other factors cannot negate the importance of political ideology. Market reform, intertwined with economic issues, has a political nature that should not be neglected. To what extent politicians still maintain their party identities and belief systems remains questionable. However, this question does not necessarily diminish the importance of political ideology.

The role of pragmatism could be important in real life politics as well. Pragmatism is often seen as a conservative virtue that is based on the idea that as long as a policy works, it is beneficial and should be the chosen option; the policy does not necessarily have to fit preconceived notions, and it is the outcome that matters the most. Politicians who follow this line of thinking and working principle are prepared to try various methods regardless of the political perspective, and the result is generally an amalgamation of different approaches rather than a single, consistent pattern. To use pragmatism as an explanation for the ambiguous findings of political influence in policymaking is quite common. ${ }^{153}$

Third, besides the common polarised left-right scale discussion, a so-called political centre exists. In some countries with a two-party system, the political centre might be too weak to be noticeable. In some cases, however, especially when a coalition government exists, the role of centre parties cannot escape be ignored.

In the latest development of French politics, La République en marche! ("The Republic Onwards" in English), founded by Emmanuel Macron, swiftly gained huge success

\footnotetext{
${ }^{153}$ Nevertheless, in my opinion, pragmatism is sometimes used to include too many ideas that are not fully understood, which might neglect other important factors and mechanisms that influence attitude formation and policymaking.
} 
in the 2017 general election (both presidential and parliamentary). ${ }^{154}$ This party is centrist in such a way that it is economically liberal but progressive on social issues, and the party's stance on welfare reform and marketisation issues are yet to be observed. By comparison, it is intriguing to determine if other centrist parties will flourish in other countries, including Sweden. Literally, Centerpartiet, by name, should be a centrist party, yet it has had strong ties with other parties, such as the Moderates and is a member of the Alliansen. ${ }^{155}$

In the case of elderly care marketisation, Centerpartiet was found to be closer in alliance to the right-wing bloc, as shown in previous chapters (primarily Chapter 9). In political rhetoric, their stances are also closer to the right-wing members in the Alliansen. Therefore, it might be true that the Swedish version of Centre party has its characteristics and historical origins, which makes it more interesting to follow up on their stances and policy claims on the issue of welfare reforms in general and marketisation specifically.

Fourth, additionally, it is important to bear in mind that the preferences of left- and right-wing parties are not fixed across time and space ${ }^{156}$ (Gingrich 2011). The left-right

154 Source: http://elections.interieur.gouv.fr/legislatives-2017/FE.html La République En Marche! (REM) in alliance with the centrist Democratic Movement (MoDem), together securing 350 seats out of 577 of the $15^{\text {th }}$ National Assembly of the French Fifth Republic.

${ }^{155}$ In the latest development of politics in Sweden in 2017, the Centre Party received its highest voter support in 34 years, with 14.2\%. Source: Sifo opinion poll, accessed at: http://www.gp.se/nyheter/sverige/centern-p\%C3\%A5-v\%C3\%A4g-att-g\%C3\%A5-ommoderaterna-1.4201616

At the same time, the figure for the Moderates dropped to $18.4 \%$. Later in May, the Centerpartiet was $13.4 \%, 15.9 \%$ for the Moderates (the Moderates performed their worst since 2003). See: https://www.svt.se/nyheter/inrikes/ny-matning-moderaterna-ochcenterpartiet-snart-lika-stora The dropping popularity is explained by the fact that voters for the Moderates switched either to Centerpartiet or Sweden Democrats. Sweden Democrats became the second-largest party in Sweden, based on the opinion poll, at 18\%. Source: https://www.svd.se/svd-sifo-moderaternas-samsta-siffror-pa-14-ar/om/m-krisen All of these websites were consulted in June, 2017.

${ }^{156}$ In the USA, the Republicans have troubles to accept Obamacare and President Donald Trump is easier to abolish the care. We just could not assume that Swedish right-wing parties, the Moderates, for instance, would get rid of universal health care in Sweden. This is an 
dimension in politics is probably not of the same importance across countries, and its exact meaning could change over time. The fact that the substantive meaning of the left-right dimension is specific to context has considerable implications for its use or could changes its meanings over time and space (see, for example, Huber and Inglehart 1995; Inglehart and Klingemann 1976). One reason is that there is a more intertwined net of factors such as the economy, ideology, and geographical proximity that could influence local politicians and partisan preferences (see, for example, Kitschelt 1994; Przeworski and Sprague 1986; Sørensen and Bay 2002). Meanwhile, an overly simplistic deduction that the left favours more state control and the right opposes welfare expansion should be avoided, despite that this praxis of left and right could serve as a starting point in an analysis of welfare policies.

All of these factors can inspire new questions: how can political parties and their ideologies be defined and categorised, and what kind of knowledge exists about their stances on welfare politics? With social and economic changes and globalisation, new questions arise that may shape the way the public and politicians perceive various issues such as the marketisation of welfare services. It is essential, therefore, to advance the existing knowledge and continuously update comprehension of what politicians believe, what they say, and what they do (Mair 2007).

\section{Policy implications}

The survey results indicate that there are still clear and consistent differences between political parties in their stances regarding market solutions in publicly funded elderly care. This divided preference pattern indicates that different political parties may shape markets in

example to show that the left-right praxis might have rich and complex meanings under different contexts. 
various ways and with various redistribution consequences, especially in light of the recent political debates about profit margins from welfare services.

As explained previously, the market development of elderly care is quite uneven among Swedish municipalities. For municipalities that have already introduced market solutions such as LOV, a reverse of this policy may not be necessary or simple, depending on how the marketisation effects are evaluated locally. For municipalities that have not decided yet, they must study and learn from existing examples. Local politicians should find answers to these important questions: What are the best reasons to introduce a market? What are the potential consequences? The difficulty lies in that many of these questions so far have received quite different views.

The ongoing debates in national and local politics also reflect a division of attitudes on marketisation issues. The left bloc's scepticism towards private provision also underlies the ongoing government investigation on how to regulate the public funding of private services. Stepping back into history, the central government between the years 2006 and 2014 actively tried to increase the number of private providers in health and elderly care. Indeed, the trends of private provision increased even more between the years 2005 and 2015, based on data from Konkurrensverket and Socialystyrelsen. This information is a sign that a government could serve as a key actor in pushing forward market reforms in a welfare state.

For the minority government now in 2016 , the limit on the profit proposal is unlikely to pass and affect a real influence on the marketisation of the welfare sectors, predominantly because of its relatively weak position in the parliament. The plan has met with strenuous oppositions not only from the Alliansen parties but also from the private sector. The political landscape after the 2018 election in Sweden will shape the marketisation trajectory. 
Besides the differences observed and found in the dataset, some common ground among the perspectives of both blocs has emerged. Swedish local politicians from various parties agreed that elderly care should essentially be financed by taxes, which is a consensus that deserves attention. Some might argue this consensus alone does not necessarily lead to a consensus about the tax levies and how public funding as resources or 'input' of the system should be allocated. Nevertheless, this consensus is still useful in cross-bloc negotiations and policymaking. One way to compromise could be to encourage more non-profit providers in the care sector (SOU 2016).

\section{The limitations of the study}

This study has a few limitations. Firstly, as a case study, one limitation is about its generalisability, which regards whether its conclusion is applicable in other cases. This thesis focuses exclusively on data from Sweden. As a case study, it is equally important to discuss whether its characteristics extend far beyond. Lessons of marketisation are useful not only in within a country, such as the 290 municipalities in Sweden, but also beneficial on the national level. It is interesting to ask whether there are some common features that Sweden shares with other countries in terms of marketisation and whether the lessons learned in Sweden could be used to form policy recommendations for other countries that are planning to embark on a marketisation process.

Meagher and Szebehely (2013) listed and compared four Nordic countries, Sweden, Finland, Denmark, and Norway, in terms of the consequences of marketisation in residential care. They analysed and compared several aspects: costs, quality for users, employment and working conditions, and other consequences. The findings are still highly contested, and they recommend more research in the future. Regarding the studies of welfare attitudes of politicians, it is still relatively rare to find comparative studies on this topic. 
As argued earlier, the Swedish model does have some of its own features, which might limit the possibility to generalise the research results to a wider context. Nevertheless, the study of the prime example of the Social Democratic type of welfare state could shed light on the issue of making a market within a welfare state, identify what tensions exist, and determine possible solutions.

Secondly, this study includes politicians from the Sweden Democrats (SD), but I later chose not to place too much emphasis on this political party, which should be addressed in future studies especially in the light of its recent momentum in Swedish politics.

In this study, I excluded detailed analysis of Sweden Democrats for mainly two reasons: the sample size of politicians from SD was relatively small $(\mathrm{N}=22)$, and the data collection was completed before the 2014 national election. Before 2014, it was quite rare to see Sweden Democrat party governing at the local level in Swedish municipalities.

Currently, the populist Sweden Democrats Party has 49 seats in the Riksdag (National Parliament) which accounts for $15 \%$ of the total seats, yet their influence is questioned due to a lack of support from both the Red-Greens and the Alliansen. On the local level, Sweden Democratic parties face more obstacles as to govern locally, at least not without collaboration with other parties. As a party that mostly engages in migration politics, their stance on other welfare state and market issues remain to be explored. ${ }^{157}$

Third, little is known about the respondents who did not participate in the survey. Even for some politicians who chose 'Do not want to answer' as an option to some survey questions, the reasons behind remain unknown. If possible, it would be interesting to explore and determine if there are any patterns to these types of response and what the likely

${ }^{157}$ I read through party manifestos and more specifically political parties' elderly care policy claims. Interestingly enough, SD policy advocated for lower or no tax for the pension and calls for more resource invested in the elderly care field, as shown in Appendix 3. 
covariates are. In this sense, knowledge about those who did not participate in the survey could be complemented with other similar studies or continuous surveys with a higher response rate.

\section{Interesting study directions}

There are different ways to study the marketisation phenomenon and the internal tensions between a market and a welfare state. This study chose an attitude angle and focused on politicians' perspectives. The theoretical framework and methodology could be applied in similar studies, and the results have prompted new research questions that are of interest.

First, it is worthwhile to follow up on these attitude patterns and see how they change over time. Since this research is mainly based on data from 2013 to 2014 , just before the 2014 general election, it would be interesting to repeat the survey in the near future, even before the 2018 election. The point is that with recently increasing debates on welfare issues, whether there is a shift in politicians' attitudes is worthy of note.

Similar studies in other sectors, such as health care and education, could be conducted in a similar fashion. It is possible to map out the attitude patterns and compare and understand the logic and perceptions behind different levels of support, either regarding the market or the welfare state. This kind of knowledge not only deepens current understandings of the market in other welfare sectors, but also contributes to better policymaking.

Second, more topics relevant to the discussion of welfare state vis-à-vis the market could be included in the future surveys. The future survey studies could benefit from inclusions of question such as a quality check of elderly care services, as well as some other concerns raised by local politicians in this study (for instance, how to deal with increasing care demands or various forms of housing for the elderly). By doing this, more detailed answers could be obtained and could sharpen our views on certain complex issues within the 
discussion of marketisation. Methodologically speaking, even interviews are helpful in the sense that it provides more detailed and nuanced understandings of the topic.

Third, one more direction for the future could be to compare politicians' perceptions with those of the public. There is a rich set of data on public attitudes towards the welfare state in Sweden, and it would be fruitful to make comparisons between politicians' attitudes with those of the public and then discuss potential outcomes. One finding of this research is that all of the politicians share the same view on using taxes to fund the care system, which is in accordance with the results from the public. Many other aspects of marketisation could be studied by contrasting both views, for instance, politicians' and the public's understanding of the choice model or perceptions of care quality brought up by various care providers.

Finally, the complexity of marketisation thus requires a holistic view and a multidisciplinary study approach. Although this study has focused on local politicians, it is also meaningful to complement it with perspectives of central government politicians, civil servants, and care users. Perspectives of care providers are also of importance. Meanwhile, the study of marketisation and welfare state can benefit from a collaboration of political scientists, economists, philosophers, sociologists, social workers and so on. All of these different approaches could be taken to boost our understanding of elderly care marketisation process and bring forward the discussion of how to build a market out of a welfare state. 


\section{References}

Ågren, H., M. Dahlberg, and E. Mörk. 2007. "Do Politicians' Preferences Correspond to Those of the Voters? An Investigation of Political Representation." Public Choice 130 (1): 137-162. doi: 10.1007/s11127-006-9077-1.

Aalberg, T. 2001. Comparative Public Opinion on Distributive Justice: Ideal, Perceptions and Policy Attitudes. Trondheim: NTNU.

Adams, I. 2001. Political Ideology Today. Manchester: Manchester University Press.

Allan, J. P. and L. Scruggs. 2004. "Political Partisanship and Welfare State Reform in Advanced Industrial Societies.” American Journal of Political Science 48 (3): 496512.

Alt, J. 1985. "Political Parties, World Demand, and Unemployment: Domestic and International Sources of Economic Activity." American Political Science Review 79 (4): $1016-40$.

Andersson, K., and E. Kvist. 2015. "The Neoliberal Turn and the Marketization of Care: The Transformation of Eldercare in Sweden.” European Journal of Women's Studies 22 (3): 274-287.

Arwidsson, J., and J. Weserberg. 2012. Profit Seeking and the Quality of Eldercare: An Empirical Study of Private Equity's Impact on the Swedish Eldercare Market: Implications for Financial Performance and Quality of Care. Stockholm School of Economics. Accessed on April 1, 2017: http://arc.hhs.se/download.aspx?MediumId=1473

Bäck, H. 2000. Kommunpolitiker i den stora nyordningens tid. Stockholm: Liber.

Bäck, H. 2003. "Party Politics and the Common Good in Swedish Local Government." Scandinavian Political Studies 26 (2): 93-123. doi:10.1111/1467-9477.00081

Bäck, H., G. Ó. Erlingsson, and L. Torbjörn. 2015. Den svenska politiken: strukturer, processer och resultat. Stockholm: Liber.

Barr, N. 1992. "Economic Theory and the Welfare State: A Survey and Interpretation." Journal of Economic Literature 30: 741-803. 
Barr, N. 2012. Economics of the Welfare State. Oxford: Oxford University Press.

Bartlett. W., and J. Le Grand. 1993. "The Theory of Quasi-markets". In Quasi-markets and Social Policy, 13-34. Basingstoke: Macmillan Press.

Becker, H. A. 1990. Dynamics of Cohort and Generation Research. Amsterdam: Thesis Publishers.

Beganovic, M. 2014. Hur vill äldre invandrare ha sin äldreomsorg? FOU Arbetsrapport 17.

Bel, G., and X. Fageda. 2007. "Why Do Local Governments Privatise Public Services? A Survey of Empirical Studies." Local Government Studies 33 (4): 517-534. doi:10.1080/03003930701417528.

Bel, G., and X. Fageda. 2009. "Factors Explaining Local Privatization: A Meta-Regression Analysis.” Public Choice 139 (1): 105-119. doi:10.1007/s11127-008-9381-z

Bel, G., and X. Fageda. 2010. "Partial Privatisation in Local Services Delivery: An Empirical Analysis of the Choice of Mixed Firms.” Local Government Studies 36 (1): 129-149. doi:10.1080/03003930903435856.

Bel, G., and X. Fageda. 2017. "What Have We Learned from the Last Three Decades of Empirical Studies on Factors Driving Local Privatisation?” Local Government Studies 43 (4): 503-511. doi: 10.1080/03003930.2017.1303486

Belke, A., F. Baumgärtner, F. Schneider, and R. Setzer. 2007. "The Different Extent of Privatization Proceeds in OECD Countries: A Preliminary Explanation Using a Public-Choice Approach.” FinanzArchiv / Public Finance Analysis 63: 211-43.

Bergmark, Å. 2008. "Market Reforms in Swedish Health Care: Normative Reorientation and Welfare State Sustainability." J Med Philos 33 (3): 241-261. doi: 10.1093/jmp/jhn010

Bergmark, A., and J. Palme. 2003. "Welfare and the Unemployment Crisis: Sweden in the 1990s". International Journal of Social Welfare 12: 108-122.

Bergmark, Å., M. Thorslund, and E. Lindberg. 2000. "Beyond Benevolence - Solidarity and Welfare State Transition in Sweden.” International Journal of Social Welfare 9 (4): $238-249$. 
Bhatti, Y., A. L. Olsen, and L. H. Pedersen. 2009. "The Effects of Administrative Professionals on Contracting Out." Governance 22 (1): 121-137. doi:10.1111/ j.14680491.2008.01424.x.

Biemer, P. P., and L. E. Lyberg, 2003. Introduction to Survey Quality: Wiley Series in Survey Methodology. Hoboken, N.J.: Wiley.

Birgersson, B O. 1975. Kommunen som serviceproducent: kommunal service och serviceattityder i 36 svenska kommuner. Stockholm: Statsvetenskapliga institutionen, Stockholms universitet.

Blekesaume, M., and J. Quadagno. 2003. "Public Attitudes toward Welfare State Policies: A Comparative Analysis of 24 Nations.” European Sociological Review 19 (5): 415-427. doi: 10.1093/esr/19.5.415.

Blomberg, H., and C. Kroll. 1999. "Do Structural Contexts Matter? Macrosociological Factors and Popular Attitudes towards Public Welfare Services.” Acta Sociologica 42 (4): 319-335. doi: 10.1177/000169939904200403.

Blomqvist, P. 2004. "The Choice Revolution: Privatization of Swedish Welfare Services in the 1990s." Social Policy and Administration 38 (2): 139-55. doi:10.1111/j.14679515.2004.00382.x

Blomqvist, P., and B. Rothstein. 2000. Välfärdsstatens nya ansikte: demokrati och marknadsreformer inom den offentliga sektorn. Stockholm: Agora

Boadway, R. and M. Keen. 2000. "Redistribution", in A. Atkinson and F. Bourguignon (eds) Handbook of Income Distribution, 677-790. Amsterdam: North Holland.

Bobbio, N. 1996. Left and Right: The Significance of a Political Distinction. London: Polity Press.

Boggio, M. 2016. "From Public to Mixed Ownership in Local Public Services Provision: An Empirical Analysis." Local Government Studies 42 (3): 420-440. doi:10.1080/ 03003930.2016.1146138.

Boix, C. 1997. "Privatizing the Public Business Sector in the Eighties: Economic Performance, Partisan Responses and Divided Governments." British Journal of Political Science 27 (4): 473-96. 
Bonoli, G., V. George, and P. Taylor-Gooby. 2000. European Welfare Futures. Oxford: Polity Press.

Boston, J. 1991. "The Theoretical Underpinning of Public Sector Restructuing in New Zealand” In J. Boston, J. Martin, J. Pallot and P. Walsh (eds.) Reshaping the State. New Zealand's Bureaucratic Revolution, 1-26. Auckland: Oxford University Press.

Bortolotti, B., M. Fantini, and D. Siniscalco. 2003. "Privatization Around the World: Evidence from Panel Data.” Journal of Public Economics 88: 305-322.

Boyne, G. A. 1998. "Competitive Tendering in Local Government: A Review of Theory and Evidence." Public Administration 76: 695-712.

Bracht, G. H., and G. V. Glass. 1968. "The External Validity of Experiments.” American Education Research Journal 5: 437-474.

Bradley, D., E. Huber, S. Moller, F. Nielsen and J. D. Stephens. 2003. "Distribution and Redistribution in Postindustrial Democracies.” World Politics 55 (2): 193-228.

Brennan, D., B. Cass, S. Himmelweit, and M. Szebehely. 2012. "The Marketisation of Care: Rationales and Consequences in Nordic and Liberal Care Regimes." Journal of European Social Policy 22 (4): 377-391.

Brenton, M. 1985. The Voluntary Sector in British Social Services. New York: Longman.

Brown, L. T., and M. Potoski. 2003. "Contract Management Capacity in Municipal and County Governments." Public Administration Review 63 (2): 153-164.

Busemeyer, M. R. 2009. "From Myth to Reality: Globalization and Public Spending in OECD Countries Revisited.” European Journal of Political Research 48: 455-482.

Campbell, D.T., and J.C. Stanley. 1963. "Experimental and quasi-experimental designs for research on teaching". In Handbook of Research on Teaching, edited by N.L. Gage, 171-246. Chicago, IL: Rand Mcnally.

Caramani, D. (ed). 2014. Comparative politics. 3rd edition. Oxford: Oxford University Press.

Carter, I. 2004. "Choice, Freedom, and Freedom of Choice.” Social Choice and Welfare 22 (1): 61-81.

Castles, F. G. 2004. The Future of the Welfare State. Oxford: Oxford University Press. 
Castles, F. G. (ed). 2007. The Disappearing State? Retrenchment Realities in an Age of Globalisation. Cheltenham, UK: Edward Elgar.

Charmaz, K. 2014. Constructing Grounded Theory. 2nd edition. London: Sage Publications.

Christensen, T. 2001. "Markedsorienterte reformer i den offentlige forvaltningen. Global nødvendighet eller trussel mot demokratiet?" [Market-Oriented Reforms in Public Adminsitrations: Global Necessity or a Threat towards Democracy?], in Baldersheim, H., Hagivet, B. and Heidar, K. (eds) Statsvitenskapelige utsyn: Politiske tema og tenkemåter i en oppbrudstid, 115-122. Kristiansand: Høyskoleforlaget.

Cioffi, J., and M. Hopner. 2006. "The Political Paradox of Finance Capitalism: Interests, Preferences, and Center-left Party Politics in Corporate Governance Reform." Politics and society 34 (4): 463-502.

Clarke, J. 2006. "Consumers, Clients or Citizens? Politics, Policy and Practice in the Reform of Social Care." European Societies $8 \quad$ (3): 423-442. doi:10.1080/14616690600821966

Clarke, J., and J. Newman. 1997. The Managerial Sate. London: Sage Publications.

Clayton, R., and J. Pontusson. 1998. "Welfare State Retrenchment Revisited: Entitlement Cuts, Public Sector Restructuring and Inegalitarian Trends in Advanced Capitalist Societies.” World Politics 51 (1): 67-98.

Comondore, V. R. et al. 2009. "Quality of Care in For-profit and Not-for-profit Nursing Homes: Systematic Review and Meta-analysis." BMJ, 339, b2732. doi:10.1136/bmj.b2732

Converse, P. 1964. "The Nature of Belief Systems in Mass Publics." In Ideology and Discontent, edited by D. Apter, 206-261. New York: Free Press.

Creswell, J. W. 2003. Research Design: Qualitative, Quantitative, and Mixed Methods Approaches. 2nd edition. Los Angeles: Sage.

Creswell, J. W. 2012. Educational Research: Planning, Conducting, and Evaluating Quantitative and Qualitative research (4th ed.). Boston, MA: Pearson.

Cukierman, A. and M. Tommasi. 1998. "When Does It Take a Nixon to Go to China?" American Economic Review 88: 180-196. 
Dahlberg, M., and H. Lundqvist. 2013. "Politikers egenskaper och privatisering av välfärdstjänster." [Politicians' Attributes and Privatisation of Welfare Services]. In: Välfärdstjänster i privat regi: Framväxt och drivkrafter [Welfare Services in Private Enterprises: Growth and Incentives], edited by H. Jordahl, 165-188. Stockholm: SNS.

De Vries, M. S. 2005. "Changing Policy Views at the Local Level: The Effect of Age, Generations and Policy-Periods in Five European Countries." European Journal of Public Research 44 (1): 1-15. doi: 10.1111/j.1475-6765.2005.00216.x.

Denzin, N. K., and Lincoln, Y. 2000. "Introduction: The discipline and practice of qualitative research". In N.K. Denzin and Y. Lincoln (eds) Handbook of qualitative research (2nd ed., pp.1-17). Thousand Oaks, CA: Sage Publications.

Donahue, J.D. 1989. The privatization Decision: Public Ends, Private Means. New York: Basic Books.

Downs, A. 1957. An Economic Theory of Democracy. New York: Harper Collins.

Edebalk, P. G. 2010. "Ways of Funding and Organising Elderly Care in Sweden". In T. Bengtsson (eds), Population Ageing - A Threat to the Welfare State? pp.65-80. Springer: Verlag Berlin Heidelberg. doi: 10.1007/978-3-642-12612-3_5.

Edlund, J. 2006. "Trust in the Capability of the Welfare State and General Welfare State Support: Sweden 1997-2002." Acta Sociologica 49 (4): 395-417. doi: 10.1177/0001699306071681.

Edlund, J., and I. Johansson Sevä. 2013. "Is Sweden Being Torn Apart? Privatization and Old and New Patterns of Welfare State Support." Social Policy and Administration 47 (5): 542-564. doi: 10.1111/spol.12021.

Elinder, M. 2010. "Local economies and general elections: the influence of municipal and regional economic conditions on voting in Sweden 1985-2002.” European Journal of Political Economy 26: 279-292.

Elinder, M., and H. Jordahl. 2013. "Political Preferences and Public Sector Outsourcing." European Journal of Political Economy 30: 43-57. doi:10.1016/j. ejpoleco.2013.01.003. 
Edmark, K. 2015. Hur påverkar vinstmotivet och konsolideringen av skolmarknaden skolans verksamhet? In J. Eklund (Eds), Swedish Economic Forum Report 2015: Vinster, välfärd och entreprenörskap, 71-87. Stockholm: Entreprenörskapsforum.

Enflo, K. 2012. Measures of Freedom of Choice. Uppsala: Uppsala University.

Erlandsson, S., P. Storm, A. Stranz, M. Szebehely, and G-B. Trydegård. 2013. "Marketising Trends in Swedish Eldercare: Competition, Choice and Calls for Stricter Regulation." In Marketisation in Nordic Eldercare: A Research Report on Legislation, Oversight, Extent and Consequences, edited by G. Meagher and M. Szebehely, 23-75. Stockholm: Stockholm University.

Erlingsson, G. Ó., and J. Wänström. 2015. Politik och förvaltning i svenska kommuner. Lund: Studentlitteratur.

Esaiasson, P. and L. Wängnerud. 2016. "Political Parties and Political Representation”. In The Oxford Handbook of Swedish Politics, edited by J. Pierre, 188-205. Oxford: Oxford University Press.

Esping-Andersen, G. 1990. The three worlds of welfare capitalism. Cambridge: Polity.

Feiock, R. C., and H. S. Jang. 2009. "Nonprofits as Local Government Service Contractors." Public Administration Review 69 (4): 668-680. doi:10.1111/j.15406210.2009.02016.x

Fernandez, S., J. E. Ryu, and J. L. Brudney. 2008. "Exploring Variations in Contracting for Services among American Local Governments Do Politics Still Matter?" The American Review of Public Administration 38 (4): 439-462. doi:10.1177/ 0275074007311386.

Ferraz-Nunes, J. 2002. "Hälsa, sjukvård och befolkningsuppfattningar”. In Flernivådemokrati i förändring: SOM-undersökningen Västsverige 2000, edited by L. Nilsson, 123-131. Göteborg: SOM-institutet.

Ferris J., and E. Graddy. 1986. "Contracting Out: For What? With Whom?" Public Administration Review. July/August: 322-343.

Fink, A. 2013. Conducting Research Literature Reviews: From the Internet to Paper. Thousand Oaks, CA: Sage Publications. 
Foged, S. K., and L. Aaskoven. 2017. "Public Sector Unions and Privatization: Evidence from the Eldercare Sector in Danish Municipalities.” Journal of Public Administration Research and Theory 27 (1): 135-149. doi:10.1093/jopart/muw040.

Fowler, F. J. 2008. Survey Research Methods. Thousand Oaks, CA: Sage Publications.

Fredrickson, H. G. 1996. "Comparing the Revinventing Government Movement with the New Public Administration.” Public Administration Review 56: 263-271.

Fredriksson, S., H. Olli, M. Mattila, and H. Wass. 2010. "The politics of competitive tendering: Political orientation and attitudes towards contracting out among Finnish local politicians." Local Government Studies 36 (5): 637-654. doi:10.1080/03003930.2010.506977

Frisk Jensen, M. 2008. Korruption og embedsetik: Danske embedsmands korruption $i$ perioden 1800 till 1886. PhD thesis. Aalborg: Aalborg Universitet.

Gall, M. D., J. P. Gall and W. R. Borg. 2007. Educational Research: An introduction. (8th ed.). Boston: Pearson.

Gay, L. R. 1987. Educational Research: Competencies for Analysis and Application. 3rd ed. Columbus, OH: Merrill.

Gerber, E. R. and J. B. Lewis. 2004. "Beyond the Median: Voter Preferences, District Heterogeneity, and Political Representation.” Journal of Political Economy 112 (6): 1364-83.

Geys, B., and R. J. Sørensen. 2016. "Revenue Scarcity and Government Outsourcing: Empirical Evidence from Norwegian Local Governments.” Public Administration 94 (3): 769-788. doi:10.1111/padm.12262.

Gingrich, J. R. 2011. Making Markets in the Welfare State: The Politics of Varying Market Reforms. Cambridge: Cambridge University Press.

Gilbert, N. 2002. Transformation of the Welfare State: The Silent Surrender of Public Responsibility. Oxford, UK: Oxford University Press.

Gilljam, M. 1996. "Det kluvna Sverige?” In Ett knappt ja till EU: Väljarna och folkomröstningen 1994, edited by M. Gilljam and S. Holmberg, 167-210. Stockholm: Norstedts Juridik. 
Gilljam, M., and S. Holmberg. 1993. Väljarna inför 1990-talet. Stockholm: Norstedts.

Gilljam, M., D. Karlsson, and A. Sundell. 2010. Politik på hemmaplan: tiotusen fullmäktigeledamöter tycker om politik och demokrati [Ten Thousand Councillors Deliberate on Politicis and Democracy]. Stockholm: SKL Kommentus.

Gilljam, M., and D. Karlsson. 2015. "Ruling Majority and Opposition: How Parliamentary Position Affects the Attitudes of Political Representatives." Parliamentary Affairs 68: $555-572$.

Glaeser, E., and A. Shleifer. 2001. "Not-for-profit Entrepreneurs." Journal of Public Economics 81 (1): 99-115.

Green-pedersen, C. 2002. "New Public Management Reforms of the Danish and Swedish Welfare States: The Role of Different Social Democratic Responses." Governance 15 (2): 271-94.

Glenngård, A. H., A. Anell, and A. Beckman. 2011. "Choice of Primary Care Provider: Results from A Population Survey in Three Swedish Counties.” Health Policy 103 (1): $31-37$.

Government Bill 2008/09: 29. Lagen om valfrihetssystem [Act on System of choice in the Public Sector].

Green-Pedersen, C. 2002. "New Public Management Reforms of the Danish and Swedish Welfare States: The Role of Different Social Democratic Responses.” Governance 15 (2): 271-294.

Guo, M., and S. Willner. 2017. “Swedish Politicians' Preferences Regarding the Privatisation of Elderly Care." Local Government Studies 43 (1): 1-21. doi: $10.1080 / 03003930.2016 .1237354$

Gustafsson, J. E. 2010. "Freedom of Choice and Expected Compromise.” Social Choice and Welfare 35 (1): 65-79.

Gustafsson, L. 1987. "Renewal of the Public Sector in Sweden." Public Administration 65 (2):179-192. 
Hansen, S., T. R. Palfrey, and H. Rosenthal. 1987. "The Downsian Model of Electoral Participation: Formal Theory and Empirical Analysis of the Constituency Size Effect." Public Choice 52 (1): 15-33.

Hagevi, M. 2015. "Bloc Identification in Multi-Party Systems: The Case of the Swedish Two-Bloc System." West European Politics 38 (1): 73-92. doi:10.1080/01402382.2014.911480

Heckscher, G. 1952. Svensk statsförvaltning i arbete. Stockholm: Norstedt.

Hefetz, A., and M. Warner. 2012. "Contracting or Public Delivery? The Importance of Service, Market and Management Characteristics." Journal of Public Administration Research and Theory 22 (2): 289-317.

Hefetz, A., M. E. Warner, and V.-G. Eran. 2012. "Privatization and Intermunicipal Contracting: The US Local Government Experience 1992-2007.” Environment and Planning C: Government and Policy 30 (4): 675-692. doi:10.1068/c11166

Hering, M. 2008. "Welfare State Restructuring without Grand Coalitions: The Role of Informal Cooperation in Blame Avoidance." German Politics 17: 165-183. doi:10.1080/09644000802075757

Hibbs, D. A. 1977. "Political Parties and Macroeconomic Policy." American Political Science Review 86 (3): 658-74.

Hindriks, J., and G. D. Myles. 2006. Intermediate Public Economics. Cambridge, Mass.: MIT Press.

Hira, A. and Hira, R. 2000. "The New Institutionalism: Contradictory Notions of Change." American Journal of Economics and Sociology 59 (2), 267-282.

Hodge, G. A. 2000. Privatization: An International Review of Performance. Boulder: West view Press.

Holmberg, S. 2000. Välja parti. Stockholm: Norstedts juridik.

Holmberg, S. and H. Oscarsson. 2004. Väljare: svenskt väljarbeteende under 50 år [Voters: Fifty Years of Voting Behaviour in Sweden]. Stockholm: Norstedts.

Hood, C. 1991. “A Public Management for All Seasons?” Public Administration 69 (1): 3-19. 
Hopkins, J. D. 1998. Educational and Psychological Measurement and Evaluation. Needham Heights, MA: Allyn and Bacon.

Huber M., R. Rodrigues, F. Hoffmann, K. Gasior and B. Marin. 2009. Facts and Figures on Long-Term Care. Europe and North America. European Centre, Vienna.

Huber, E., and J.D. Stephens. 2001. Development and Crisis of the Welfare State: parties and policies in global markets. Chicago, IL: The University of Chicago Press.

Huo, J., M. Nelson, and J. Stephens. 2008. "Decommodification and Activation in Social Democratic Policy: Resolving the Paradox.” Journal of European Social Policy 18 (1): $5-20$.

Inglehart, R. 1971. "The Silent Generation: Intergenerational Change in Post-Industrial Societies.” American Political Science Review 65 (4): 991-1017.

Inglehart, R. 1977. The Silent Revolution: Changing Values and Political Styles among Western Publics. Princeton: Princeton University Press.

Inglehart, R. 1990. Cultural Shift in Advanced Industrial Society. Princeton: Princeton University Press.

Iversen, T. 2005. Capitalism, Democracy, and Welfare. Cambridge: Cambridge University Press.

Iversen, T. 2006. "Capitalism and Democracy”, In Oxford Handbook of Political Economy, edited by B.G. Weingast and D.A. Wittman, 601-623. Oxford: Oxford University Press.

Iversen, T., and D. Soskice. 2006. "Electoral Institutions and the Politics of Coalitions: Why Some Democracies Redistribute More than Others." American Political Science Review 100 (2): 165-181.

Iversen, T., and D. Soskice. 2015. "Politics for Markets." Journal of European Social Policy 25 (1): 76-93.

Jaeger, M. M. 2005. "Welfare Regimes and Attitudes Towards Redistribution: The Regime Hypothesis Revisited." European Sociological Review 22 (2): 157-170. doi: 10.1093/esr/jci049. 
Jæger, M. M. 2006. "What Makes People Support Public Responsibility for Welfare Provision: Self-interest or Political Ideology? A Longitudinal Approach." Acta Sociologica 49 (3): 321-338. doi: 10.1177/0001699306067718.

Jensen, P. H., and H. Lolle. 2013. "The Fragmented Welfare State: Explaining Local Variations in Services for Older People.” Journal of Social Policy 42 (2): 349-370. doi: 10.1017/S0047279412001006.

Jesslén, J. 2015. Är vi borgare? En ideologianalys av Alliansens valmanifest 2006-2010 och 2014-2018. [Are We Bourgeois? An Ideological Analysis of the Alliansen's Election Manifestos 2006-2010 and 2014-2018]. Kalstard: Kalstard University.

Johansson, F, L. Nilsson, and L. Strömberg. 2001. Kommunal demokrati under fyra decennier. Malmö: Liber.

Johansson, O. 2011. Tjäna eller tjäna? Om vård eller vinst [Serve or Earn? On Care or Profit]. Stockholm: Famna.

Johansson Sevä, I. 2009. Welfare State Attitudes in Context: Local Contexts and Attitude Formation in Sweden. Umeå: Umeå University.

Johansson Sevä, I. 2010. "Suspicious Minds: Local Context and Attitude Variation across Swedish Municipalities.” International Journal of Social Welfare 19 (2): 225-235. doi: 10.1111/j.1468-2397.2009.00656.x.

Johnson, N. 1999. Mixed Economies of Welfare. London: Prentice Hall Europe.

Jones, K., and C. Duncan. 1998. "Modelling Context and Heterogeneity: Applying Multilevel Models". In Research Strategies in the Social Sciences: A Guide to New Approaches, edited by E. Scarbrough and E. Tanenbaum, 95-123. Oxford: Oxford University Press.

Joppe, M. 2000. The Research Process. Available at: https://www.uoguelph.ca/hftm/glossary Accessed on January 23, 2017.

Jørgen Goul, A. 1992. "Sources of Welfare-state Support in Denmark: Self-interest or Way of Life?" International Journal of Sociology 22 (4): 25-48.

Kettl, D. F. 1993. Sharing Power: Public Governance and Private Markets. Washington DC: Brookings Institution Press. 
Kiewiet, D. R. and M. D. McCubbins. 1991. The Logic of Delegation. Congressional Parties and the Appropriations Process. Chicago: University of Chicago Press.

Kitschelt, H. 1994. The Transformation of European Social Democracy. Cambridge: Cambridge University Press.

Kittel, B., and H. Obinger. 2003. "Political Parties, Institutions, and the Dynamics of Social Expenditure in Times of Austerity." Journal of European Public Policy 10 (1): 20-45. doi: 10.1080/1350176032000046912

Klitgaard, M. B., and C. Elmelund-Præstekær. 2014. "The Partisanship of Systemic Retrenchment: Tax Policy and Welfare Reform in Denmark 1975-2008.” European Political Science Review 6 (1): 1-19.

Knutsen, O. 1995. "Value Orientations, Political Conflicts and Left-Right Identification: A Comparative Study.” European Journal of Political Research 28 (1): 63-93.

Konkurrensverket. 2012. Kommnernas valfrihetssystem-så fungerar konkurrensen [The system of choice in Swedish municipalities-the competition situation]. Stockholm: Slutrapport.

Konkurrensverket. 2013. Kommunernas valfrihetssystem - med fokus på hemtjänst [Local government system of choice - with a focus on home care]. Stockholm: Slutrapport.

Korpi, W. 1978. The Working Class in Welfare Capitalism: Work, Unions and Politics in Sweden. London: Routledge \& Kegan Paul.

Korpi, W. 1983. The Democratic Class Struggle. London: Routledge and Kegan Paul.

Korpi, W. 2006. "Power Resources and Employer-centered Approaches in Explanations of Welfare States and Varieties of Capitalism: Protagonists, Consenters, and Antagonists." World Politics 58 (2): 167-206.

Korpi, W., and J. Palme. 2003. "New Politics and Class Politics in the Context of Austerity and Globalization: Welfare State Regress in 18 Countries, 1975-95." American Political Science Review 97 (3): 425-446

Krasner, S. 1984. "Approaches to the State: Alternative Conceptions and Historical Dynamics." Comparative Politics 16 (2): 223-46. 
Kumlin, S. 2002. The Personal and the Political: How Personal Welfare State Experiences Affect Political Trust and Ideology. Göteborg: Göteborgs universitet.

Lægreid, P., and T. Christensen. 2003. "Politisk styring og privatisering: holdninger i elitene og befolkningen" [Political Governance and Privatization: Attitudes in the Elites and the Population]. Norsk Statsvitenskapelig Tidsskrift 19: 385-411.

Le Grand, J., and W. Bartlett. (eds). 1993. Quasi-markets and Social Policy. Basingstoke: Macmillan Press.

Leys, C. 2003. Market-driven Politics: Neoliberal Democracy and the Public Interest. London: Verso.

Leibfried, S. 2001. Welfare State Futures. Cambridge: Cambridge University Press.

Lien, S., and P. A. Pettersen. 2004. "Local Government and Welfare Generosity: Municipality Spending on Social Welfare.” Scandinavian Political Studies 27 (4): 343-365. doi:10.1111/j.0080-6757.2004.00112.x

Lindbom, A. 2001. "Dismantling the Social Democratic Welfare Model? Has the Swedish Welfare State Lost Its Defining Characteristics?” Scandinavian Political Studies 24 (3): 171-193.

Lindbom, A. 2014. "Waking Up the Giant? Hospital Closures and Electoral Punishment in Sweden". In Staffan Kumlin and Isabelle Stadelmann-Steffen (eds), How Welfare States Shape the Democratic Public: policy feedback, participation, voting, and attitudes, 156-180. Cheltenham: Edward Elgar.

Lindbom, A. 2016. "Political Partisanship and Policy Feedback: The Swedish Welfare State after Eight Years of Center-Right Government.” In The Oxford Handbook of Swedish Politics, edited by J. Pierre, 37-56. Oxford: Oxford University Press.

Lindbeck, A. 2000. Politisk makt med oklart ansvar: Ekonomirådets rapport 2000. Stockholm: SNS

Lindert, P. H. 2004. Growing Public: Volume 1, The Story. Cambridge: Cambridge University Press.

Lipset, S. M., and S. Rokkan. 1967. Party Systems and Voter Alignments: cross-national perspectives. New York: The Free Press. 
Listhaug, O. 1989. "Gamle og nye modellar i valforskinga: Eit oversyn" [Old and New Models in Election Studies: A Review]. Tidskrift for Samfunnsforskning 4, 339-60.

Lundsgaard, J. 2002. Competition and Efficiency in Publicly Funded Services. Paris: OECD.

Mair, P. 2007. "Left-Right Orientations." In The Oxford Handbook of Political Behaviour, edited by J. D. Russell and H.D. Klingemann, 206-222. Oxford: Oxford University Press.

Manning, N. 2001. "The Legacy of the New Public Management in Developing Countries." International Review of Administrative Sciences 67 (2): 297-312.

Markus, H. R., and B. Schwartz. 2010. "Does Choice Mean Freedom and Well-being?" Journal of Consumer Research 37 (2): 344-355.

Marquis, C., and A. Tilcsik. 2013. "Imprinting: Toward a Multilevel Theory." The Academy of Management Annals 7 (1): 195-245. doi: 10.1080/19416520.2013.766076.

Martinsson, J. 2004. "Varför är inte stockholmare som andra svenskar?" In Kampen om euron, edited by H. Oscarsson and S. Holmberg, 281-298. Göteborg: Göteborgs universitet.

Meagher, G., and M. Szebehely. 2013. Marketisation in Nordic Eldercare: A Research Report on Legislation, Oversight, Extent and Consequences. Stockholm: Stockholm University.

Megginson, W. L., and J. M. Netter. 2001. "From State to Market: A Survey of Empirical Studies on Privatization.” Journal of Economic Literature 39 (2): 321-389.

Meinow, B., M. G. Parker, and M. Thorslund. 2011. "Consumers of Eldercare in Sweden: the Semblance of Choice." Soc Sci Med 73 (9): 1285-89. doi:10.1016/j.socscimed.2011.08.015

Minkenberg, M, and R, Inglehart. 1989. "Neoconservatism and Value Change in the USA: Tendencies in the Mass Public of a Postindustrial Society." In Contemporary Political Culture, edited by J. Gibbins, 81-109. London: Sage Publications.

Mishra, R. 1990. The Welfare State in Capitalist Society: policies of retrenchment and maintenance in Europe, North America and Australia. London: Harvester Wheatsheaf. 
Montin, S. 1990. "Den kommunala multiorganisationen - om nya normer och institutioner i kommunerna under 1980-talet." Statsvetenskaplig tidskrift 93: 247-260.

Montin, S. 1992. "Privatiseringsprocesser i kommunerna - teoretiska utgångspunkter och empiriska exempel.” Statsvetenskaplig tidskrift 95: 31-57.

Mueller, D. C. 2015. "Profits, Entrepreneurship and Public Services" in Vinster, välfärd och entreprenörskap, edited by M. Andersson and J. Eklund, 17-34. Örbro: Entreprenörskapsforum.

National Board of Health and Welfare (NBHW). 2004. Konkurrensutsättning och entreprenader inom äldreomsorgen - Utvecklingsläget 2003. Stockholm: Socialstyrelsen.

NBHW. 2007. Current Developments in Care of the Elderly in Sweden. Stockholm: Socialstyrelsen. Accessed on September 2013. http://www.socialstyrelsen.se/Lists/Artikelkatalog/Attachments/9296/2007-13140_200713140.pdf

NBHW. 2013. Äldre och personer med funktionsnedsättning-regiform år 2012 [Older and disabled persons-management forms, 2012]. Stockholm: Socialstyrelsen. Accessed on October 10, 2013. http://www.socialstyrelsen.se/publikationer2013/2013-3-23

NBHW. 2014. Äldre och personer med funktionsnedsättning - regiform år 2013 - Vissa kommunala insatser enligt socialtjänstlagen [Older and disabled persons-management forms, 2013]. Stockholm: Socialstyrelsen.

NBHW. 2015. Öppna jämförelser 2014. jämförelser mellan kommuner och län [Open comparisons 2014: comparisons between municipalities and counties]. Stockholm: Socialstyrelsen.

Nilsson, L. 1996. "Medborgarna och den lokala välfärdsstaten”. In Västsvenska perspektiv. SOM-rapport $n r$ 17, edited by L. Nilsson, 123-140. Göteborg: SOM-institutet.

Nilsson, L. 2002. Flernivådemokrati i förändring: SOM-undersökningen Västsverige 2000. Göteborg: SOM-institutet.

Norman, E. 2010. Biståndshandläggare-att vakta pengar eller tillgodose behov. Stockholm: Stiftelsen Stockholms läns Äldrecentrum. 
Norris, P. 1995. “May’s Law of Curvilinear Disparity Revisited: Leaders, Officers, Members and Voters in British Political Parties." Party Politics 1(1): 29-47.

Nygard, M. 2006. "Welfare-Ideological Change in Scandinavia: A Comparative Analysis of Partisan Welfare State Positions in Four Nordic Countries, 1970-2003.” Scandinavian Political Studies 29 (4): 356-385.

Obinger, H., C. Schmitt, and Zohlnhöfer, R. 2014. "Partisan Politics and Privatization in OECD Countries." Comparative Political Studies 47 (9): 1294-323.

Olander, L-O. 1984. Staten, kommunerna och servicen: Tiden kring kommunreformen i ett ekonomiskt-geografiskt perspektiv: Lunds universitet, Geografiska institutionen.

Olsen, J. and B. G., Peters. 1996. "Learning from Experience.” In Lessons from Experience. Experiential Learning in Administrative Reforms in Eight Democraccies, edited by J. Olsen and B.G., Peters, 1-35. Oslo: Scandinavian University Press.

Ormerod, R. 2006. "The History and Ideas of Pragmatism." The Journal of the Operational Research Society 57 (8): 892-909.

Orloff, A. 1996. “Gender in the Welfare State.” Annual Review of Sociology 22: 51-78.

Osbore, D., and T. Gaebler. 1992. Reinventing Government: How the Entrepreneurial Spirit Is Transforming the Public Sector. Reading, MA: Addison Wesley Publishing Company.

Oscarsson, H. 1998. Den svenska partirymden. Väljarnas uppfattningar av konfliktstrukturen i partisystemet 1956-1996. Göteborg: Göteborgs universitet.

Oskamp, S. 1991. Attitudes and Opinion. Englewood Cliffs, NJ: Prentice Hall.

Peters, B. G. 1999. Insitutional Theory in Political Science. London: Printer.

Petersson, O. 1977. Väljarna och valet 1976. Stockholm: Statistiska centralbyrån.

Petersson, O. 1994. The Government and Politics of the Nordic Countries. Stockholm: Fritzes.

Petersen, O. H., K. Houlberg, and L. R. Christensen. 2015. "Contracting Out Local Services: A Tale of Technical and Social Services.” Public Administration 75 (4): 560-570. doi:10.1111/puar.12367. 
Pierson. C. 1998. Beyond the Welfare State. $2^{\text {nd }}$ edition. Cambridge: Polity Press.

Pierson, P. 1994. Dismantling the Welfare State?: Reagan, Thatcher and the Politics of Retrenchment. Cambridge: Cambridge University Press.

Pierson, P. 1996. “The New Politics of the Welfare State.” World Politics 48 (2): 143-79.

Pierson, P. 2000. "Increasing Returns, Path Dependence, and the Study of Politics." American Political Science Review 94 (2): 251-67.

Pierson, P. (ed). 2001. The New Politics of the Welfare State. Oxford: Oxford University Press.

Piven, F. F., and R. Cloward. 1993. Regulating the Poor: The Functions of Public Welfare. Updated Edition. New York: Vintage Books.

Plantinga, M., K. De Ridder, and A. Corra. 2011. "Choosing Whether to Buy or Make: The Contracting Out of Employment Reintegration Services by Dutch Municipalities." Social Policy Administration 45 (3): 245-263. doi:10.1111/j.14679515.2011.00767.x.

Pollitt, C., and G. Bouckaert. 2004. Public Management Reform: A Comparative Analysis. Oxford: Oxford University Press.

Powell, M. A., and M. Hewitt. 2002. Welfare State and Welfare Change. Buckingham: Open University Press.

Premfors, R. 1991. "The 'Swedish Model' and Public Sector Reform". West European Politics 14 (3): 83-95.

Przeworski, A. and J. D. Sprague. 1986. Paper Stones. Chicago: University of Chicago Press.

Rauch, D. 2006. "Institutional Fragmentation, Institutional Engineering and the Development of Elderlycare and Childcare in Sweden.” Scandinavian Political Studies 29 (4): 285307. doi:10.1111/j.1467-9477.2006.00153.x

Ross. F. 2000. "Beyond Left and Right: The New Partisan Politics of Welfare." Governance 13 (2): 155-183.

Rossi, P. H., J. D. Wright, and A.B. Anderson. 2013. Handbook of Survey Research. Burlington: Elsevier Science. 
Rothstein, B. 1998. Just Institutions Matter: The Moral and Political Logic of the Universal Welfare State. Cambridge: Cambridge University Press.

Rothstein, B. 2007. Anti-Corruption: A “Big-Bang”' Theory. QoG Working Paper Series, 3.

Rothstein, B., M. Samanni, and J. Teorell. 2012. "Explaining the Welfare State: Power Resources vs. the Quality of Government." European Political Science Review 4 (1): 1-28. doi:10.1017/S1755773911000051

Rovai, A. P., J. D. Baker, and M. K. Ponton. 2013. Social Science Research Design and Statistics: A Practitioner's Guide to Research Methods and SPSS Analysis. 2nd edition. Chesapeake, Virginia: Watertree Press.

Rustow, D. A. 1957. The Politics of Compromise. 2nd Edition. Princeton: Princeton University Press.

Rönnberg, L., U. Strandberg, E. Wihlborg, and U. Winblad. 2013. När förvaltning blir business: marknadiseringens utmaningar för demokratin och välfärdsstaten. Linköping: Linköping University Electronic Press.

Sannerstedt, A. 1981. Attityder till kommunal service. Rapport 9 från Kommunaldemokratiska forskningsgruppen. Stockholm: Liber Förlag/Allmänna förl.

Savas, E. 2000. Privatization and Public-Private Partnerships. New York: Chatham House.

Schneider, V., S. Fink, and M. Tenbucken. 2005. "Buying Out the State - A Comparative Perspective on the Privatization of Infrastructures." Comparative Political Studies 38 (6): 704-727.

Schustereder, I. J. 2010. Welfare State Change in Leading OECD Countries: The Influence of Post-Industrial and Global Economic Developments. Wiesbaden: Gabler.

Schwzrtz, B. 2004. The Paradox of Choice: Why Less Is More. New York: Ecco.

Sebastiano, B. 2004. "Measuring Freedom of Choice: An Alternative View of A Recent Literature.” Soc Choice Welfare 22 (1): 29-48. doi: 10.1007/s00355-003-0275-1.

Sihvo, T. and H. Uusitalo. 1995. "Economic Crises and Support for the Welfare State in Finland 1975-1993." Acta Sociologica 38 (3): 251-262.

SKL (Sveriges Kommuner och Landsting). 2016. Kommunernas kostnader och intäkter. Available at: 
https://skl.se/ekonomijuridikstatistik/ekonomi/sektornisiffror/diagramforkommunerna. 1882.html Accessed on August 11, 2017

Singleton Jr, R. A., B. C. Straits, and M. M. Straits. 1993. Approaches to Social Research. New York: Oxford University Press.

Sniderman, P. M., M. G. Hagen, P. E. Tetlock, and H. E. Brady. 1991. "Reasoning Chains." In Sniderman, P. M., Brody, R. A. \& Tetlock, P. E. (eds), Reasoning and Choice. Explorations in Political Psychology, 70-92. Cambridge: Cambridge University Press.

Socialstylsen. 2013. Stimulansbidrag LOV. Delrapport.

Socialstylsen. 2015. Stimulansbidrag LOV. Slutrapport 2011-2014.

SOM-Institutet. 2016. Välfärdspolitik och välfärdsopinion 2016 för bl.a. SR och SVT. Göteborg. Accessed on May 10 , 2017: http://som.gu.se/digitalAssets/1585/1585262_v--lf--rdspolitik-och-v--lf-rdsopinion-sverige-2015---lennart-nilsson.pdf

Soss, J. and S. F. Schram. 2007. “A Public Transformed? Welfare Reform as Policy Feedback.” American Political Science Review 101 (1): 111-127.

SOU (Statens Offentliga Utredningar). 2014. Framtidens valfrihetssystem-inom socialtjänsten. Stockholm.

SOU 2016. Ordning och reda i välfärden. Betäkande av Välfärdsutrredningen. Stockholm. Available at: http://www.regeringen.se/4ab5e0/contentassets/da2ccefb5dc84389b79b48b06a5e000a /ordning-och-reda-i-valfarden-sou-201678

SOU 2017. Kvalitet $i$ välfärden - bättre upphandling och uppföljning. Stockholm. Accessed on June 1, 2017: http://www.regeringen.se/499b50/contentassets/d0b4399223d747f6b4beab9fac72bf61 /kvalitet-i-valfarden--battre-upphandling-och-uppfoljning-sou-201738

Spicker, P. 2014. Social Policy: Theory and Practice. Bristol: Policy Press.

Springer, S., K. Birch and J. MacLeavy. (eds). 2016. The Handbook of Neoliberalism. New York: Routledge, Taylor \& Francis Group. 
Starke, P., A. Kaasch, and F. Van Hooren. 2014. "Political Parties and Social Policy Responses to Global Economic Crises: Constrained Partisanship in Mature Welfare States.” Journal of Social Policy 43 (2): 225-246. doi:10.1017/S0047279413000986

Statistics Sweden (SCB). 2015a. "Antal invånare per kvadratkilometer, 31 december 2014" [Number of inhabitants per square kilometre]. Available at: http://www.scb.se/sv_/Hitta-statistik/Statistik-efter-amne/Befolkning/Befolkningenssammansattning/Befolkningsstatistik/25788/25795/Topplistor-kommuner/290734/

Statistics Sweden (SCB). 2015b. "Skatteunderlag per invånare (skattekraft) kommunvis, taxeringsåret 2014" [Tax base per inhabitant by municipality in the year 2014]. Available at: http://www.scb.se/sv_/Hitta-statistik/Statistik-efter-amne/Offentligekonomi/Finanser-for-den-kommunalasektorn/Kommunalskatterna/11849/11856/67865/

Steinmo, S. 2002. "Globalization and Taxation - Challenges to the Swedish Welfare State." Comparative Political Studies 35 (7): 839-862.

Stolt, R., P. Blomqvist, and U. Winblad. 2011. "Privatization of Social Services: Quality Differences in Swedish Elderly Care." Soc Sci Med 72 (4): 560-67. doi:10.1016/j.socscimed.2010.11.012

Stolt, R. and U. Winblad. 2009. "Mechanisms Behind Privatization: A Case Study of Private Growth in Swedish Elderly Care." Soc Sci Med 68 (5): 903-11. doi:10.1016/j.socscimed.2008.12.011

Strandberg, U. 1995. Självständighet eller statsbundenhet: Den kommunideologiska idédebatten 1962-1974. Göteborgs universitet: Centrum för forskning om offentlig sektor (CEFOS)

Streeck, W., and K. Thelen. 2005. Beyond Continuity: Institutional Change in Advanced Political Economies. Oxford: Oxford University Press.

Suhonen, D., and D. Kessel. 2013. Välfärden är vinsten. Katalys. No.1. Stockholm.

Suleinman, E. 2003. Dismantling Democratic States. Princeton University Press.

Sundell, A., and V. Lapuente. 2012. "Adam Smith or Machiavelli? Political Incentives for Contracting Out Local Public Services.” Public Choice 153 (3-4): 469-485. doi:10.1007/s11127-011-9803-1. 
Sundin, E., and M. Tillmar. 2010. Uppföljning av 'Eget val' inom hemtjänsten i Linköpings kommun: Utförarperspektiv. FOU rapport.

Suzuki, K. 2003. Marketization of Elderly Care in Sweden. EIJS Working Paper Series, 137.

Svallfors, S. 1989. Vem älskar välfärdsstaten?: attityder, organiserade intressen och svensk välfärdspolitik [Who Loves the Welfare State? Attitudes, Organized Interests and Swedish Welfare Policies]. Arkiv avhandlingsserie: 30. Lund: Arkiv.

Svallfors, S. 1996. Välfärdsstatens moraliska ekonomi: välfärdsopinionen i 90-talets Sverige [The Moral Economy of the Welfare State: Public Opinion on Welfare in Sweden in the 1990s]. Umeå: Boréa.

Svallfors, S. 1999. Mellan risk och tilltro: Opinionsstödet för en kollektiv välfärdspolitik [Between Risk and Confidence: Popular Support for Collective Welfare Policies]. Umeå: Umeå Studies in Sociology.

Svallfors, S. 2004. "Class, Attitudes and the Welfare State: Sweden in Comparative Perspective". Social Policy and Administration 38 (2): 119-138.

Svallfors, S. 2011. “A Bedrock of Support? Trends in Welfare State Attitudes in Sweden, 1981-2010." Social Policy and Administration 45 (7): 806-25. doi:10.1111/j.14679515.2011.00796.x

Svanborg-Sjövall, K. 2014. "Privatising the Swedish Welfare State.” Economic Affairs 34 (2): 181-192. doi: 10.1111/ecaf.12071

Sveriges Kommuner och Landsting (SKL). 2015. "Sammanställning styren i kommuner och landsting 1994 tom Available at: http://skl.se/download/18.44c045bc14d99500c85105f8/1433176992847/sklmaktfordelning-kommuner-landsting-regioner-1994-2014-reviserad-2015-06-01.xlsx

Szebehely, M., and G. B. Trydegard. 2012. "Home Care for Older people in Sweden: A Universal Model in Transition." Health Soc Care Community 20 (3): 300-09. doi:10.1111/j.1365-2524.2011.01046.x

Szebehely, M. 2011. "Insatser för äldre och funktionshindrade i privat regi." [Caring for elderly and disabled people in private enterprises]. In: Konkurrensens konsekvenser: Vad händer med svensk välfärd? [The Consequences of Competition: What is happening to Swedish Welfare?], edited by L. Hartman, 215-257. Stockholm: SNS. 
Søren, S. 2003. "Shaping Local Councillor Preferences: Party Politics, Committee Structure and Social Background." Scandinavian Political Studies 26 (4): 327-348. doi:10.1111/j.1467-9477.2003.00092.x

Sørensen, R., and A. H. Bay. 2002. "Competitive Tendering in the Welfare State: Perceptions and Preferences among Local Politicians." Scandinavian Political Studies 25 (4): $357-384$.

Tenelius, H., and N. Selling. 2016. Välfärdslobbyisten: om caremadrevet, vårdvinster och demokratins nya utmaningar. Stockholm: Ekerlids.

Thelen, K., and J. Mahoney, 2010. Explaining Institutional Change: Ambiguity, Agency, and Power. Cambridge: Cambridge University Press.

Thelen, K., and S. Steinmo. 1992. "Historical Institutionalism in Comparative politics.” In S. Steinmo, K. Thelan, and F. Longstreth (eds), Structuring Politics: Historical Institutionalism in Comparative Analysis, 1-32. Cambridge: Cambridge University Press.

Titmuss R. M. 1974. Social Policy: An introduction. London: Allen and Unwin.

Trydegård, G.-B. 2000. "From Poorhouse Overseer to Production Manager: One Hundred Years of Old-age Care in Sweden Reflected in the Development of An Occupation.” Ageing and Society 20 (5): 571-597.

Trydegård, G.-B. 2001. "Välfärdstjänster till salu: privatisering och alternativa driftformer under 1990-talet.” In SOU 2001:52 Välfärdstjänster $i$ omvandling, Antologi till kommittén Välfärdsbokslut, 77-139. Stockholm: Fritezes.

Van Dooren, W., G. Bouckaert, and J. Halligan. 2010. Performance Management in the Public Sector. London: Routledge.

Van Oorschot, W. 2002. "Individual Motives for Contributing to Welfare Benefits in the Netherlands." Policy and Politics 30 (1): 31-46.

Warner, M., and R. Gradus. 2011. "The Consequences of Implementing a Child Care Voucher Scheme: Evidence from Australia, the Netherlands and the USA." Social Policy and Administration 45 (5): 569-592.

Warner, M., and A. Hefetz. 2012. "Insourcing and Outsourcing." Journal of the American Planning Association 78 (3): 313-327. 
Wassenaar, M., T. Groot, and R. Gradus. 2013. "Municipalities' Contracting Out Decisions: An Empirical Study on Motives." Local Government Studies 39 (3): 414-434. doi:10.1080/03003930.2013.778830.

Weaver, R. K. 1986. “The Politics of Blame Avoidance.” Journal of Public Policy 6 (4): 371-398.

Werne, K., and O. F. Unsgaard. 2014. Den stora omvandlingen: en granskning av välfärdsmarknaden. Stockholm: Leopard.

Westholm, A. 1991. The Political Heritage: Testing Theories of Family Socialization and Generational Change. Uppsala: Uppsala University.

Whitfield, D. 2001. Public Services or Corporate Welfare: Rethinking the Nation State in the Global Economy. London: Pluto Press.

Winblad, U., C. Andersson, and D. Isaksson. 2009. Kundval i hemtjänsten-Erfarenheter av information och uppföljning. Stockholm: SKL.

Yankelovich, D.1991. Coming to Public Judgment. Making Democracy Work in a Complex World. New York: Syracuse University Press.

Yeates, N. 2001. Globalization and Social Policy. London: Sage Publications.

Yiannis, G. 2015. "Identity, Choice and Consumer Freedom - the New Opiates? A Psychoanalytic Interrogation.” Marketing Theory 15 (1): 25-30. doi: $10.1177 / 1470593114558525$

Young, S. 2000. "Outsourcing: Lessons from the Literature." Labour and Industry 10 (3): 97-117.

Zaller, J. 1992. The Nature and Origins of Mass Opinion. Cambridge: Cambridge University Press.

Zohlnhöfer, R., H. Obinger, and Wolf, F. 2008. "Partisan Politics, Globalization and the Determinants of Privatization Proceeds in Advanced Democracies 1990-2000." Governance 21 (1): 95-121.

Zuberi, D. 2006. Differences That Matter: Social Policy and the Working Poor in the United States and Canada. Ithaca, N.Y.: ILR/Cornell University Press. 
Appendix 1. Information letter to the survey respondents.

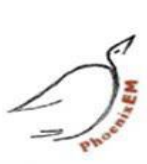

Linköpings universitet

58183 Linköping
Phoenix EM JDP Dynamics of Health and Welfare

\section{Till: svenska kommunpolitiker}

Allteftersom andelen äldre ökar i befolkningen får äldreomsorgen en allt större betydelse i det svenska välfärdssystemet. Sedan införandet av den s k Ädelreformen 1992 har det skett betydande förändringar i äldreomsorgens organisation, bland annat har inslaget av privata vårdgivare ökat markant i många kommuner. Hur stor del av äldreomsorgen som bedrivs av alternativa vårdgivare varierar dock mycket mellan olika kommuner.

Det saknas fortfarande kunskaper om de bevekelsegrunder som legat bakom dessa förändringar. Därför vänder vi oss till de kommunpolitiker som kan bidra till att ge oss ny och ytterst värdefull kunskap inom detta område. Tanken är att denna enkät ska skickas ut till ett större antal svenska kommuner. I första omgången gjorde vi en s.k. pilotenkät för Linköpings kommun, i samarbete med FoU Centrum för vård, omsorg och socialt arbete i Linköping för att testa innehållet och utformningen av enkäten. Det är av mycket stort värde för undersökningens värde om så många som möjligt besvarar enkäten.

Enkäten är en del i en kommande doktorsavhandling som avser att göra en jämförande analys av hur lokalpolitiker och andra beslutsfattare ser på denna utveckling i Sverige respektive Kina. Avhandlingsprojektet sker inom ramen för ett EU-finansierat doktorandprogram (Phoenix EM JDP Dynamics of Health and Welfare) i samarbete med Linköpings universitet, EHESS (Paris) och universitet i Lissabon och Evora i Portugal. (länk till doktorandprogrammet: http://www.phoenix-jdp.eu/ )

Vi kommer inte att redovisa vad enskilda politiker har svarat. Det är naturligtvis helt frivilligt att delta. 
Om du har frågor, kontakta gärna:

Handledare:

Doktorand:

Sam Willner, docent

Ming Guo

sam.willner@liu.se

ming.guo@liu.se

0730896498

0704193699

Linköpings universitet

Institutionen för studier av samhällsutveckling och kultur (ISAK)

58183 Linköping 
Appendix 2. Survey questions in original.

Enkät om äldreomsorgen till kommunpolitiker

A. Först vill vi ställa några frågor om dig och ditt politiska arbete

1. Är du kvinna eller man?

oKvinna

oMan

$\circ$ Vill inte ange

2. Hur gammal är du?

○ 18-29

○ 30-39

○ 40-49

○ 50-64

○ 65 eller äldre

3. I vilken kommun är du kommunpolitiskt verksam?

4. Vilket politiskt parti representerar du i kommunen?

oCenterpartiet

oFolkpartiet

○Kristdemokraterna

○Miljöpartiet

oModeraterna

oSocialdemokraterna

oSverigedemokraterna

○Vänsterpartiet

○Annat, var vänlig ange vilket:

5. Vilket förtroendeuppdrag har du för närvarande i kommunen?

○ Kommunalråd

○Ordförande, vice ordförande i socialnämnd

oLedamot, ersättare i socialnämnd

○Ordförande, vice ordförande i äldrenämnd 
oLedamot, ersättare i äldrenämnd

○Ordförande, vice ordförande i omsorgsnämnd

○Ledamot, ersättare i omsorgsnämnd

○Övrigt, ange vad:

6. Hur länge har du haft ett politiskt förtroendeuppdrag i kommunen?

oDenna mandatperiod

$\circ 2$ mandatperioder

○3 mandatperioder

$\circ 4$ eller flera mandatperioder

\section{B. Här ber vi dig besvara några frågor om äldreomsorgen i din kommun.}

7. Vad anser du om äldreomsorgen i din kommun?

oMycket bra

$\circ$ Bra

○Varken bra eller dålig

oDålig

○Mycket dålig

○Vet inte, föredrar att ej ta ställning

8. Vad anser du om de resurser som avsätts för äldreomsorgen i kommunen?

○Mer än tillräckligt

○Tillräckligt

$\circ$ Otillräckligt

○Mycket otillräckligt

○Vet inte, föredrar att ej ta ställning

9. Tycker du att det bör vara mer eller mindre offentlig äldreomsorg i kommunen?

$\circ$ Betydligt mer

oNågot mer

$\circ$ Bra som det är

oNågot mindre

oMycket mindre 
○Vet inte, föredrar att ej ta ställning

10. Tycker du att det bör vara mer eller mindre privat äldreomsorg i kommunen?

$\circ$ Betydligt mer

oNågot mer

○Bra som det är

oNågot mindre

$\circ$ Mycket mindre

○Vet inte, föredrar att ej ta ställning

Nedanstående två påståenden besvaras endast om det finns möjlighet att välja olika utförare av hemtjänst eller äldreboende inom kommunen.

11. De äldre får tillräcklig information för att fatta välgrundade beslut vid val av utförare av hemtjänst inom kommunen.

$\circ \mathrm{Ja}$, instämmer helt

○Ja, instämmer delvis

○Varken instämmer eller tar avstånd

oNej, tar delvis avstånd

oNej, tar helt avstånd

○Vet inte, föredrar att ej ta ställning

12. De äldre får tillräcklig information för att fatta välgrundade beslut vid val av utförare av äldreboende inom kommunen.

$\bigcirc \mathrm{Ja}$, instämmer helt

○Ja, instämmer delvis

○Varken instämmer eller tar avstånd

oNej, tar delvis avstånd

oNej, tar helt avstånd

○Vet inte, föredrar att ej ta ställning 
13. Hur tycker du en optimal fördelning skulle vara angående olika utförare av äldreomsorg?

(ange procent)

Offentlig regi

$\%$

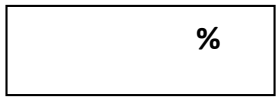

Privat regi med vinstintresse

$\%$

Privat regi utan vinstintresse

$\%$

SUMMA:

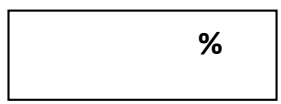

$100 \%$

C. Här ber vi dig ta ställning till några vanliga påståenden som brukar framföras i debatten angående äldreomsorgen.

14. Äldreomsorgen bör i huvudsak finansieras med skattemedel.

$\circ \mathrm{Ja}$, instämmer helt

○Ja, instämmer delvis

○Varken instämmer eller tar avstånd

oNej, tar delvis avstånd

oNej, tar helt avstånd

○Vet inte, föredrar att ej ta ställning

15. Kommunalskatten bör höjas hellre än att servicenivån minskas inom äldreomsorgen.

$\circ \mathrm{Ja}$, instämmer helt

○Ja, instämmer delvis

○Varken instämmer eller tar avstånd

oNej, tar delvis avstånd

oNej, tar helt avstånd

○Vet inte, föredrar att ej ta ställning 
16. Konkurrens mellan privata och offentliga utförare inom äldreomsorgen leder till bättre omsorg.

○Ja, instämmer helt

○Ja, instämmer delvis

○Varken instämmer eller tar avstånd

oNej, tar delvis avstånd

oNej, tar helt avstånd

○Vet inte, föredrar att ej ta ställning

17. Konkurrens mellan privata och offentliga utförare inom äldreomsorgen leder till ett effektivt utnyttjande av skattebetalarnas pengar.

$\circ \mathrm{Ja}$, instämmer helt

○Ja, instämmer delvis

○Varken instämmer eller tar avstånd

oNej, tar delvis avstånd

oNej, tar helt avstånd

○Vet inte, föredrar att ej ta ställning

18. Det är viktigt att äldreomsorgen bedrivs i offentlig regi för att garantera en demokratisk insyn och kontroll av verksamheten.

$\circ \mathrm{Ja}$, instämmer helt

○Ja, instämmer delvis

○Varken instämmer eller tar avstånd

oNej, tar delvis avstånd

oNej, tar helt avstånd

oVet inte, föredrar att ej ta ställning

19. De som bedriver privat äldreomsorg finansierat med skattemedel bör också kunna göra en privat ekonomisk vinst.

$\circ \mathrm{Ja}$, instämmer helt

$\circ \mathrm{Ja}$, instämmer delvis

○Varken instämmer eller tar avstånd

oNej, tar delvis avstånd

oNej, tar helt avstånd

oVet inte, föredrar att ej ta ställning 
20. Vinstutdelning ska inte tillåtas inom skattefinansierad äldreomsorg.

$\circ \mathrm{Ja}$, instämmer helt

$\circ \mathrm{Ja}$, instämmer delvis

○Varken instämmer eller tar avstånd

○Nej, tar delvis avstånd

oNej, tar helt avstånd

○Vet inte, föredrar att ej ta ställning

21. Personalen får bättre arbetsvillkor om det finns både privata och kommunala arbetsgivare inom äldreomsorgen.

○Ja, instämmer helt

○Ja, instämmer delvis

○Varken instämmer eller tar avstånd

oNej, tar delvis avstånd

oNej, tar helt avstånd

○Vet inte, föredrar att ej ta ställning

22. Privata vinstintressen inom äldreomsorgen riskerar att leda till försämrade arbetsvillkor för personalen.

○Ja, instämmer helt

$\circ \mathrm{Ja}$, instämmer delvis

○Varken instämmer eller tar avstånd

oNej, tar delvis avstånd

oNej, tar helt avstånd

○Vet inte, föredrar att ej ta ställning

23. Privata vinstintressen inom äldreomsorgen riskerar att leda till sämre kvalitet.

$\bigcirc \mathrm{Ja}$, instämmer helt

○Ja, instämmer delvis

○Varken instämmer eller tar avstånd

oNej, tar delvis avstånd

oNej, tar helt avstånd

○Vet inte, föredrar att ej ta ställning 
24. Det är viktigt att de äldre har möjlighet att välja mellan både privata och offentliga utförare inom äldreomsorgen.

○Ja, instämmer helt

○Ja, instämmer delvis

○Varken instämmer eller tar avstånd

oNej, tar delvis avstånd

oNej, tar helt avstånd

○Vet inte, föredrar att ej ta ställning

25. Ett problem med den $s k$ kundvalsmodellen är att resurssvaga äldre (exempelvis lågutbildade och vissa invandrargrupper) har svårare att hitta information och fatta välgrundade beslut vid val av utförare inom äldreomsorgen.

$\bigcirc \mathrm{Ja}$, instämmer helt

○Ja, instämmer delvis

oVarken instämmer eller tar avstånd

oNej, tar delvis avstånd

oNej, tar helt avstånd

oVet inte, föredrar att ej ta ställning

26. De anhöriga bör i högre utsträckning än idag ta hand om sina hjälpbehövande gamla.

$\bigcirc \mathrm{Ja}$, instämmer helt

○Ja, instämmer delvis

○Varken instämmer eller tar avstånd

○Nej, tar delvis avstånd

oNej, tar helt avstånd

○Vet inte, föredrar att ej ta ställning

27. De äldre och deras anhöriga bör tillförsäkras en hög grad av inflytande på äldreomsorgens kvalitet.

○Ja, instämmer helt

○Ja, instämmer delvis

○Varken instämmer eller tar avstånd

○Nej, tar delvis avstånd

oNej, tar helt avstånd 
○Vet inte, föredrar att ej ta ställning

28. De äldre och deras anhöriga bör tillförsäkras en hög grad av inflytande på äldreomsorgens innehåll.

$\circ \mathrm{Ja}$, instämmer helt

○Ja, instämmer delvis

○Varken instämmer eller tar avstånd

oNej, tar delvis avstånd

oNej, tar helt avstånd

○Vet inte, föredrar att ej ta ställning

29. De äldre bör ges ökade möjligheter att påverka äldreomsorgens kvalitet och innehåll genom egenavgifter.

$\circ \mathrm{Ja}$, instämmer helt

○Ja, instämmer delvis

○Varken instämmer eller tar avstånd

oNej, tar delvis avstånd

oNej, tar helt avstånd

○Vet inte, föredrar att ej ta ställning

30. En offentlig finansiering är viktig för att motverka ökade sociala klyftor i äldreomsorgen.

○Ja, instämmer helt

○Ja, instämmer delvis

oVarken instämmer eller tar avstånd

oNej, tar delvis avstånd

oNej, tar helt avstånd

○Vet inte, föredrar att ej ta ställning

31. Ansvariga politiker och tjänstemän bör tillförsäkras en hög grad av insyn och kontroll av äldreomsorgen.

○Ja, instämmer helt

$\circ \mathrm{Ja}$, instämmer delvis

oVarken instämmer eller tar avstånd

○Nej, tar delvis avstånd

oNej, tar helt avstånd 
○Vet inte, föredrar att ej ta ställning

32. Den offentligt finansierade äldreomsorgen bör i högre utsträckning än idag inriktas mot personer med störst omsorgsbehov.

$\bigcirc \mathrm{Ja}$, instämmer helt

○Ja, instämmer delvis

○Varken instämmer eller tar avstånd

○Nej, tar delvis avstånd

oNej, tar helt avstånd

oVet inte, föredrar att ej ta ställning

D. 33. Här ber vi dig försöka ange i vilken grad du upplever att olika faktorer har bidragit till din nuvarande syn på äldreomsorgen.

\begin{tabular}{|c|c|c|c|c|c|}
\hline & $\begin{array}{l}\text { I mycket } \\
\text { hög grad }\end{array}$ & $\begin{array}{l}\text { I ganska } \\
\text { hög grad }\end{array}$ & $\begin{array}{l}\text { I ganska } \\
\text { låg grad }\end{array}$ & Inte alls & Vet ej \\
\hline \multicolumn{6}{|l|}{$\begin{array}{l}\text { Personliga erfarenheter } \\
\text { av äldre anhöriga }\end{array}$} \\
\hline \multicolumn{6}{|l|}{$\begin{array}{l}\text { Personliga erfarenheter av } \\
\text { arbete inom äldreomsorgen }\end{array}$} \\
\hline \multicolumn{6}{|l|}{$\begin{array}{l}\text { Via det politiska arbetet } \\
\text { i kommunen }\end{array}$} \\
\hline \multicolumn{6}{|l|}{ Politisk ideologi } \\
\hline \multicolumn{6}{|l|}{ Massmedia } \\
\hline \multicolumn{6}{|l|}{ Forskningsrapporter } \\
\hline \multicolumn{6}{|l|}{ Vetenskapliga artiklar } \\
\hline Annat, ange vad ...... & & & & & \\
\hline
\end{tabular}




\section{E. Vi tacksamma om du besvarar nedanstående öppna frågor:}

34. Saknade du någon fråga? (I så fall vilken/vilka?)

35. Finns det ytterligare några aspekter som du tycker vi har glömt så skriv gärna ned det här: 


\section{Appendix 3. Political parties' 2014 election manifestos regarding elderly care.}

The manifestos listed here were cited directly from official websites of Swedish political parties between November 2014 and January 2015 and their original links are provided. Note that these links might not be valid as of 2017.

\section{Social Democrats (S)}

http://www.socialdemokraterna.se/Var-politik/Var-politik-A-till-O/Aldreomsorg-/

\section{Äldreomsorg}

Vi socialdemokrater vill stärka bemanningen i äldreomsorgen, möta de långsiktiga rekryteringsbehoven i välfärden och samtidigt ge unga arbetslösa jobb och utbildning inom ett framtidsyrke.

Personalen och deras kompetens är avgörande för kvaliteten i välfärden. I dag upplever många som arbetar i äldreomsorgen att det är ett hårt pressat arbete där tiden sällan räcker till. Det påverkar omsorgen om de äldre. Högerregeringen har två lösningar på alla problem: skattesänkningar och privatiseringar. Det är uppenbart att högerregeringen sätter företagens vinster framför de äldres bästa.

Rekryteringsbehovet till äldreomsorgen kommer att öka de kommande åren och det kommer att finnas en brist på utbildade undersköterskor. Samtidigt är ungdomsarbetslösheten hög och många ungdomar fastnar i långtidsarbetslöshet.

Sedan 2006 har antalet platser på äldreboenden minskat med drygt 10000 platser trots ett ökande antal äldre. Privata äldreboenden har lägre bemanning och personalen har sämre villkor.

Cirka 140000 personer mellan 45 och 66 år har gått ner i arbetstid eller sagt upp sig för att ta hand om en anhörig. Detta är en tydlig ökning mot hur det såg ut för 10 år sedan.

Larm om vårdskandaler på äldreboenden har blivit vanligare och Socialstyrelsen gjorde efter en inspektion av 100 demensboenden bedömningen att mer än hälften av boendena hade för låg bemanning. 
Sverige behöver en annan riktning. Människor har rätt att förvänta sig en betydligt bättre välfärd och att deras skattepengar används på ett bättre sätt. Genom att ställa fler och tydligare krav på bland annat bemanning kan kvaliteten förbättras och privata vinster avsevärt begränsas, samtidigt som mångfald och valfrihet i välfärden garanteras.

Högerregeringen går till val på att genom lagstiftning tvinga alla kommuner att privatisera sin äldreomsorg (antingen genom att de inför LOV eller genom upphandling av privata utförare) oavsett om befolkningen där vill det eller inte.

\section{Vi socialdemokrater vill:}

Se skärpta krav på personalens kompetens och en nationell samling för arbetsmarknadens parter och föreslår därför ett äldrelyft i vården.

Investera i traineejobb för 20000 ungdomar i äldre- och funktionshinderomsorgen. Jobben kombineras med relevant yrkesutbildning, främst utbildning till undersköterska.

Höja kvaliteten och stoppa vinstjakten i vård och omsorg. Vi vill lagstifta mot försäljningar till underpris och säger nej till tvångsprivatisering av äldreomsorgen i hela landet.

\section{The Green Party (MP)}

http://www.mp.se/politik/aldrepolitik

Sverige har inte råd att spara mer på de äldre.

Alla äldre ska ha möjlighet att vara aktiva och må väl så länge som möjligt. Alla ska kunna fortsätta göra egna val och känna att livet är innehållsrikt. Det ska också vara lätt för den som är äldre att ta del av sin närmiljö och av samhället.

\section{Miljöpartiet vill:}

att den som inte längre kan eller vill bo själv ska kunna välja mellan olika slags boenden till rimlig kostnad, värna mångfald samt öka kvalitet och bemanning i äldreomsorgen, att småbutiker och närservice ska finnas kvar i levande stadskärnor, med bra kollektivtrafik. 
Många vill arbeta längre. Sveriges befolkning blir allt äldre och friskare. Många vill också kunna arbeta längre. Vi vill att den som kan, vill och orkar ska ha möjlighet att jobba längre än till 67 år.

\section{Att närmiljön fungerar bra är viktigt}

Levande lokalsamhällen med fungerande service och kollektivtrafik gör livet både enklare och roligare för alla som vill hålla sig aktiva längre. Även trygghetsfaktorer som ett fungerande fast telefonnät är viktigt för att kunna bo kvar hemma så länge som möjligt.

\section{Flera alternativ för boende}

Vi vill att det ska finnas flera olika boendealternativ för äldre som inte längre kan eller vill bo hemma. Fler kollektiva boenden i form av hyresrätter behövs.

\section{Bättre vård för äldre}

Och när hälsan sviktar är det viktigt med kompetens om äldres hälsa och åldrande hos sjukvård och annan omsorg. Äldre ska inte behöva vänta långa tider på akuten för en vård som kunnat organiseras på annat bättre sätt.

\section{Varmare omsorg}

Alla ska kunna lita på omsorgen i Sverige, alldeles oavsett vem som utför den. För kvaliteten är det inte avgörande vilken skylt som finns utanför boendet, utan med vilken värme, värdighet och delaktighet man bemöts som omsorgstagare. Miljöpartiet vill öka bemanningen kompetensutveckling och genomföra en arbetstidsförkortning för personalen i äldreomsorgen. Stöd till anhöriga behöver bli betydligt bättre.

Äldrepolitik (Riksdagsmotion)

http://www.riksdagen.se/sv/Dokument-Lagar/Forslag/Motioner/ldrepolitik_H002So596/ 


\section{The Left Party (V)}

http://www.vansterpartiet.se/politik

\section{Vår politik}

Du kan också ta del av Vänsterpartiets politik på lätt svenska och på andra språk. Vissa delar finns också som inläst (Daisy). Allt detta hittar du i spalten till höger.

Vänsterpartiet är ett parti som arbetar för rättvisa och jämlikhet. Vi är en sammanslutning av tusentals människor som arbetar tillsammans för det målet över hela Sverige på många olika sätt: på torget, i bostadsområdena, i kommunen och riksdagen.

Allt vi gör har samma mål: att förändra samhället, att göra män och kvinnor jämlika, att ta bort klasskillnader och andra orättvisor, att skapa hållbara lösningar. Det är därför vi med stolthet kallar oss för ett socialistiskt och feministiskt parti på ekologisk grund.

Vi arbetar mot rasismen på nätet. Vi tar kampen för trygga arbeten. I varje kommun där vi får inflytande satsar vi för att få bort ungdomsarbetslösheten och ser till att skattepengarna går till välfärden istället för till riskkapitalbolag.

Vi finns överallt där det finns människor som arbetar för rättvisa. Vi vill inte bara se en bättre värld - vi gör något för att komma dit också.

\section{Välfärd istället för vinster}

Vänsterpartiet säger nej till vinster i välfärden. Vi tycker att varje skattekrona ska användas där den behövs bäst. Det betyder att vi gärna betalar skatt till verksamhet, men inte till riskkapitalbolag med bankkonton på Jersey.

Jobb åt alla

Vänsterpartiet tycker att ökad sysselsättning ska vara målet för den ekonomiska politiken. Vi vill sätta fler i arbete. Vi vill investera där behoven finns. Det betyder mer pengar till välfärd, infrastruktur och klimatsatsningar.

Klimatet är vår tids ödesfråga 
Vänsterpartiet tar klimatkrisen på allvar. Vi menar att vi måste agera mot utsläppen nu, för imorgon kan det vara försent. Vi vill skärpa utsläppsmålen och se till att Sverige tar ett större ansvar.

Rättvisa och feminism

Vänsterpartiet är den viktigaste feministiska kraften i riksdagen. Vi är trötta på att kvinnor ska göra hela hemarbetet och dessutom få sämre löner och karriärer. Vi tycker att kvinnor ska ha hela lönen och halva makten.

\section{Euron är en dålig idé}

Vänsterpartiet är den hårdaste motståndarna till eurosamarbetet. Vi varnade redan från början för de problem som vi nu kan se när Europas ekonomier krisar. Det finns fortfarande partier som tror att det vore bra för Sverige att införa euron som valuta. Det tror inte vi.

Alla människor är lika mycket värda

Vänsterpartiet står för en generös och human flyktingpolitik. Vi vägrar anpassa oss till rasism och främlingsfientlighet. Vi anser att alla människor har rätt till liv i fred och frihet, och att alla som lever här i Sverige är lika mycket värda.

\section{Äldreomsorg \\ http://www.vansterpartiet.se/politik/aldreomsorg}

Vi vill öka bemanningen inom äldreomsorgen genom en öronmärkt satsning med fokus på demensvården. De kommuner som redan har en god bemanning ska dock kunna använda pengarna till andra delar av äldreomsorgen. När hela vår satsning är fullt utbyggd kommer det att räcka till exempelvis 10000 fler undersköterskor inom äldreomsorgen och demensvården. Vi vill också satsa på hemtjänsten för att öka personaltätheten och kontinuiteten. Vi vill ge de äldre ökat inflytande över sina insatser och vi vill ge dem egna timmar att bestämma över samtidigt som vi inför en maxtaxa på 100 kronor per timme i hemtjänsten.

Personal med rätt kompetens är också en förutsättning för en bra äldreomsorg. I dag saknar runt 20 procent av dem som arbetar på äldreboenden rätt gymnasieutbildning, 
omvårdnadsprogrammet, och i hemtjänsten är siffran ännu högre. Vi satsar därför på fler utbildningsplatser och stöd till kommunerna för att anställa vikarier för dem som utbildar sig.

Äldre ska känna trygghet i tillvaron och få den omsorg de behöver. Därför är det samhällets ansvar att det finns äldreomsorg som är tillgänglig, likvärdig och håller en hög kvalitet.

Andelen äldre över 80 år som får offentlig äldreomsorg har nästan halverats sedan 1980 . Äldreomsorgen är nämligen den del av de kommunala välfärdsverksamheterna som sedan 90talskrisen har fått minst resurser.

Besparingarna och nedskärningarna har försämrat kvaliteten inom äldreomsorgen. Personalen hinner inte ge den hjälp och omsorg som behövs. I värsta fall har det inneburit att äldres säkerhet och trygghet inte tillgodoses. Allt färre får dessutom plats på vård- eller omsorgsboenden. Äldre förväntas bo hemma och klara sig med hemtjänst, som även den får för lite resurser.

Med färre anställda utförs en allt större del av omsorgen av anhöriga, som blir tvungna att ta ett större ansvar när det offentliga träder tillbaka. Många anhöriga har gått ner i arbetstid eller slutat arbeta för att hinna med att vårda en anhörig.

Läs mer i riksdagsmotionen " En jämlik och jämställd vård och omsorg för äldre" http://www.riksdagen.se/sv/Dokument-Lagar/Forslag/Motioner/En-jamlik-och-jamstalldvard-o_H102So594/?text=true 


\section{The Moderate Party (M)}

https://moderaterna.se/var-politik

\section{Vår politik}

Fler jobb är vår viktigaste fråga. Jobben bygger inte bara vår gemensamma trygghet, de bygger också var och en av oss. Vår frihet, vår självkänsla och vårt självbestämmande. Därför viker vi inte från arbetslinjen. För alla behövs i bygget av ett bättre Sverige.

http://www.moderat.se/aldrefragor

Sverige ska vara ett bra land att åldras i. Ett land där varje människa räknas och där vi tar tillvara på de erfarenheter och den kompetens som finns hos dem som levt lite längre. Det innebär inte bara att äldre ska ha en rimlig ekonomisk situation utan också att man ska känna trygghet, gemenskap och delaktighet i samhället. Framför allt ska man ses som en fri och självständig individ med egna intressen och önskemål och behov, inte som del av ett homogent kollektiv.

Målet för vår äldrepolitik är att äldre ska kunna leva ett aktivt liv och ha inflytande över sin vardag, kunna åldras i trygghet och bemötas med respekt samt ha tillgång till god vård och omsorg.

Vår grundinställning är att äldreomsorgen även i fortsättningen ska vara gemensamt, solidariskt finansierad via skatten, präglas av stor valfrihet, hög kvalitet och ett värdigt bemötande, samt vara tillgänglig för alla som är i behov av den.

Alla människor ska kunna åldras i trygghet och med bibehållen värdighet. Därför är det viktigt med ett pensionssystem som är rättvist mellan generationer och en tydlig arbetslinje som leder till hög sysselsättning och därmed stärkta pensioner. 
5. The Centre Party (C)

http://www.centerpartiet.se/var-politik/alla-fragor/vard-och-omsorg/

\section{Vård och omsorg}

Oavsett var i landet du bor ska du ha samma rätt till bra vård. Vi tycker att det är du som patient som ska vara i centrum, inte själva sjukvårdssystemet. Du ska ha valmöjligheter så att du kan välja den vård som passar dig. Kanske vill du gå till en kvällsöppen vårdcentral, eller besöka din läkare en lördag? Då ska det vara möjligt.

\section{Centerpartiet vill:}

Att sjukvården är tillgänglig och likvärdig i hela landet

Att det finns privata vårdalternativ så att du som patient får välja

Se en äldreomsorg med samma valfrihet som i övrig vård och omsorg

Uppmuntra nya idéer och tankar för att höja kvaliteten i vården

\section{The Liberals (previously as Folkpartiet)}

http://www.folkpartiet.se/politik/politik-a-o/aldreomsorg/

\section{Folkpartiet vill:}

Öka självbestämmandet i vardagen. Äldreomsorgen ska präglas av valfrihet för den enskilde och mångfald i utbudet.

Införa en förstärkt omsorgsgaranti med mätbara kvalitetskrav. För att en god äldreomsorg är en rättighet.

Öka antalet vård- och omsorgsboenden, men också fler trygghetsboenden. Äldre ska vara garanterade ett tryggt boende.

Självbestämmande och valfrihet

Självbestämmande och valfrihet är lika viktigt för alla oavsett ålder. Vi har infört en lag mot åldersdiskriminering för att markera att det är behoven som ska styra och inte den kronologiska åldern. Folkpartiet har också drivit på och infört en nationell parboendegaranti, så att par inte tvingas att bo separat när krafterna sviker hos den ene.

Sedan regeringsskiftet 2006 har äldre också fått större inflytande över hemtjänsten och ökad valfrihet i äldreomsorgen genom lagen om valfrihetssystem (LOV). Regeringen har också inlett en satsning på de mest sjuka äldre och infört ett investeringsstöd för om- och 
nybyggnation av äldrebostäder. Även RUT-avdraget för hushållstjänster underlättar vardagen för många äldre.

Folkpartiet anser att äldreomsorgen ska vara serviceorienterad. Den ska underlätta för äldre att utforma sin vardag efter sina önskemål, men inte ta ifrån människor rätten att bestämma. Därför är det så viktigt med valfrihet för den enskilde och mångfald i utbudet. Att det finns olika utförare betyder fler möjligheter för både brukare och anställda, vad gäller omsorgsprofil, språk med mera.

Vi vill utveckla valfriheten på områden där den idag inte finns, till exempel för matleveranser och färdtjänst. Det ska också vara möjligt att välja utförare i alla kommuner. Samma höga krav ska ställas på alla utförare, både privata och offentliga. (Se också avsnittet "Privata alternativ i välfärden".)

En god äldreomsorg är en rättighet

En god äldreomsorg är en rättighet för alla som behöver den, oavsett ekonomi. Detta ska tydliggöras i en omsorgsgaranti med mätbara kvalitetskrav. Om omsorgsgarantin inte uppfylls ska den äldre få ersättning. Individens egna önskningar ska tydliggöras i ett "Leva livet-kontrakt" som ska ligga till grund för innehållet i den dagliga omsorgen.

\section{Anhöriga}

Anhöriga som ger vård och hjälp till äldre ska få det anhörigstöd de har rätt till från kommunen. De ska också kunna påverka stödets utformning. Kommuner bör stimulera etablering av frivilligcentraler och vårdgivare bör öka sitt samarbete med den civila sektorn. De kan hjälpa till sätta guldkant på tillvaron, t.ex. vid promenader.

Fler vård- och omsorgsboenden

Det behövs fler vård- och omsorgsboenden, för dem som behöver omsorg dygnet runt, men också fler trygghetsboenden, med gemensamma utrymmen för sällskap och umgänge.

\section{Partierna till vänster}

Partierna till vänster förespråkar mer makt till politiken och mindre valfrihet. För oss liberaler kommer i stället kvalitet, mångfald och den äldres rätt att bestämma i första rummet. 
Det här har vi gjort:

- Infört en nationell parboendegaranti.

- Givit äldre större möjlighet att styra över innehållet i hemtjänsten.

- Ökat valfriheten i äldreomsorgen genom Lagen om Valfrihetssystem (LOV).

- Satsat på kvaliteten i äldreomsorgen.

- Inlett en nationell satsning på de mest sjuka äldre som kommer att pågå under hela mandatperioden.

\section{Christian Democrats (KD)}

https://www.kristdemokraterna.se/VarPolitik/

\section{Vår politik}

Vårt mål är ett samhälle där friheten att forma sitt eget liv går hand i hand med ansvaret för för sin medmänniska. Vi vill bygga ett samhälle som håller samman.

Mer information om vår politik hittar du under "Korta svar A-Ö", "Faktablad om vår politik" och "Dokument och rapporter".

Kristdemokraternas viktigaste frågor:

Bättre för barn och familjer

Trygga familjer ger barn goda förutsättningar att klara livets olika utmaningar. Vi vill familjesäkra politiken, att alla politiska beslut ska analyseras utifrån vilka konsekvenser de får för familjer och nära relationer.

Vi vill:

- Förbättra för barn och familjer genom att minska barngruppernas storlek i förskolan och på fritids och öka familjers valfrihet att välja barnomsorg. Införa en barnomsorgspeng även för föräldrar som själva har hand om omsorgen för sina barn.

- Förbättra stödet till ekonomiskt svaga barnfamiljer.

- Införa en flexiblare föräldraförsäkring så att barnen får mer tid med sina föräldrar och förbättra stödet till tonårsföräldrar. Vi säger nej till kvotering. 


\section{En god äldreomsorg}

Äldre personer ska få leva ett värdigt liv och känna välbefinnande. Vi måste värna deras rätt att bestämma över sitt eget liv så långt det är möjligt. De har erfarenhet och kunskap som ska tas tillvara.

Vi vill:

- Öka äldres självbestämmande genom att ge personer över 85 år rätt till äldreboende utan biståndsbedömning och införa rätt att välja äldreomsorg var man än bor i landet.

- Utveckla kvaliteten i äldreomsorgen bland annat genom att förbättra maten och måltidssituationen inom äldreomsorgen.

• Fortsätta sänka skatten för pensionärer när ekonomin tillåter.

God och likvärdig vård $i$ hela Sverige

Den som är sjuk har rätt till god sjukvård, var man än bor i landet. Vården måste utgå från människors olika behov och erfarenheter.

Vi vill:

- Att staten tar över ansvaret för sjukhusvården så att varje patient får en god och jämlik vård.

- Korta vårdköerna generellt och inrätta en vårdplatsgaranti. Vi vill också särskilt satsa 500 miljoner per år på förbättrad cancervård.

- Förbättra ungas psykiska hälsa genom att satsa på elevhälsovården, öka stödet till tonårsföräldrar och korta köerna till barn- och ungdomspsykiatrin.

\section{Bättre företagsklimat för fler jobb}

Det privata näringslivet och entreprenörskapet är grunden för Sveriges välfärd. Nya jobb kan inte kommenderas fram av politiker. De skapas när enskilda människor finner det mödan värt att starta eller utveckla ett företag.

Vi vill:

- Fortsätta att förenkla för företag att starta och anställa personal bland annat genom att minska företagens sjuklönekostnader och utveckla RUT- och ROT-avdragen.

- Ha kvar sänkta arbetsgivaravgifter för unga, sänkt restaurangmoms och sänkt skatt på arbete. Vi vill också öka tryggheten vid arbetslöshet. 
- Stärka ungdomars möjlighet att få jobb, bland annat genom att införa en lärlingsanställningsform.

Äldre (https://www.kristdemokraterna.se/VarPolitik/Korta-Svar-AO/\#̈̈)

Det finns ingen åldersgräns som upphäver rätten att bestämma över sin vardag. Äldre ska få känna välbefinnande och ha inflytande över vilka omsorgsinsatser som ges, oavsett i vilken kommun de bor. Alla ska få ett värdigt bemötande, ett tryggt boende och nära till läkarkontakter inom äldreomsorgen. Vi vill även förbättra för äldre genom att sänka skatten så att pension och lön beskattas lika, införa "guldkort" i sjukvården, trygghetsboenden i alla kommuner, höja den demens- och geriatriska kompetensen hos personalen och få in mer kultur i omsorgen.

\section{Sweden Democrats (SD)}

http://sverigedemokraterna.se/var-politik/

\section{Äldrepolitik}

Den äldre generationen som varit med och byggt upp vårt land ska ha möjlighet till en trygg och värdig ålderdom. Dagens situation är oanständig och det krävs att vi genomför rejäla satsningar både för att stärka pensionärernas ekonomi och trygghet. Inom äldreomsorgen krävs personalförstärkningar och kvalitetshöjningar. Den orättvisa pensionärsskatten avskaffar vi omedelbart om vi får inflytande under nästa mandatperiod.

Sänk pensionärernas skatt till samma nivå som löntagare. Fullt finansierat $\mathrm{i}$ vår budget. Höj garantipensionerna med minst $10 \%$. Det motsvarar ungefär 800 kronor i månaden. En stor satsning för god och näringsrik mat med hög kvalitet i äldreomsorgen.

Många fler anställda inom vård och äldrevård inom ramen för Fler händer i vården. 


\section{Appendix 4. Development of the choice model in the Östergötland Region.}

Table A4.1 Municipalities with LOV implemented in Östergötland.

\begin{tabular}{llll}
\hline Municipalities & Published & Title & Responsible \\
\hline Linköping & $2009-10-26$ & Eget val inom daglig verksamhet (LSS) & Omsorgskontoret \\
& $2010-07-01$ & Eget val inom hemtjänsten & Omsorgskontoret \\
Motala & $2010-09-20$ & Kundval inom hemtjänst & Socialfövaltningen \\
Kinda & $2011-08-23$ & Eget val inom hemtjänst - boservice & Socialfövaltningen \\
Finspång & $2013-08-30$ & Hemtjänst/omvårdnad och service/städ & Social Omsorg \\
Söderköping & $2015-08-03$ & Kundval inom hemtjänsten & Vård och Omsorg \\
Norrköping & $2017-05-17$ & Eget val inom hemtjänsten & Vård och Omsorg \\
\hline Source: Valfrihetswebben, https://www.valfrihetswebben.se/ Accessed on June 1,2017.
\end{tabular}




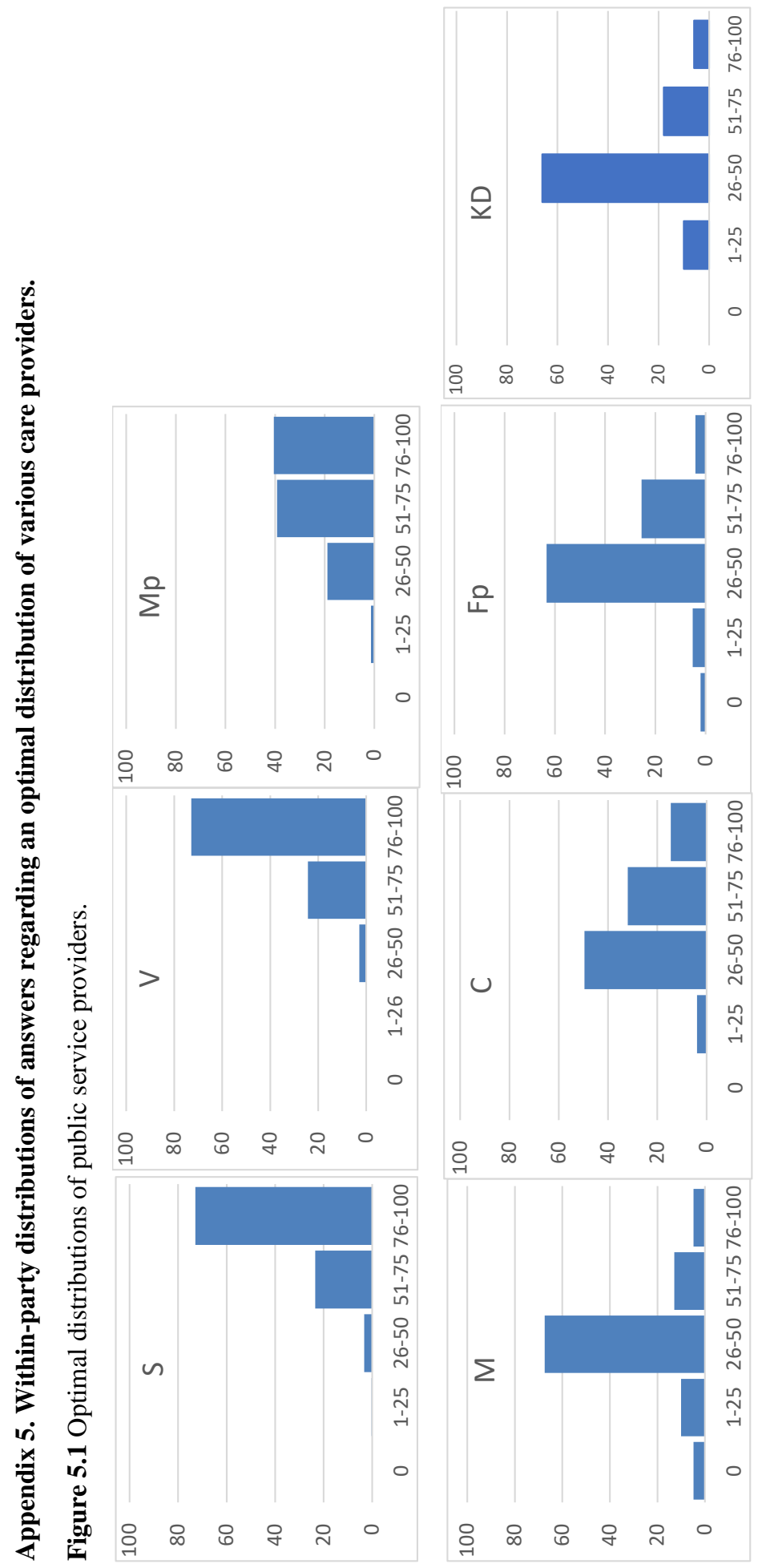




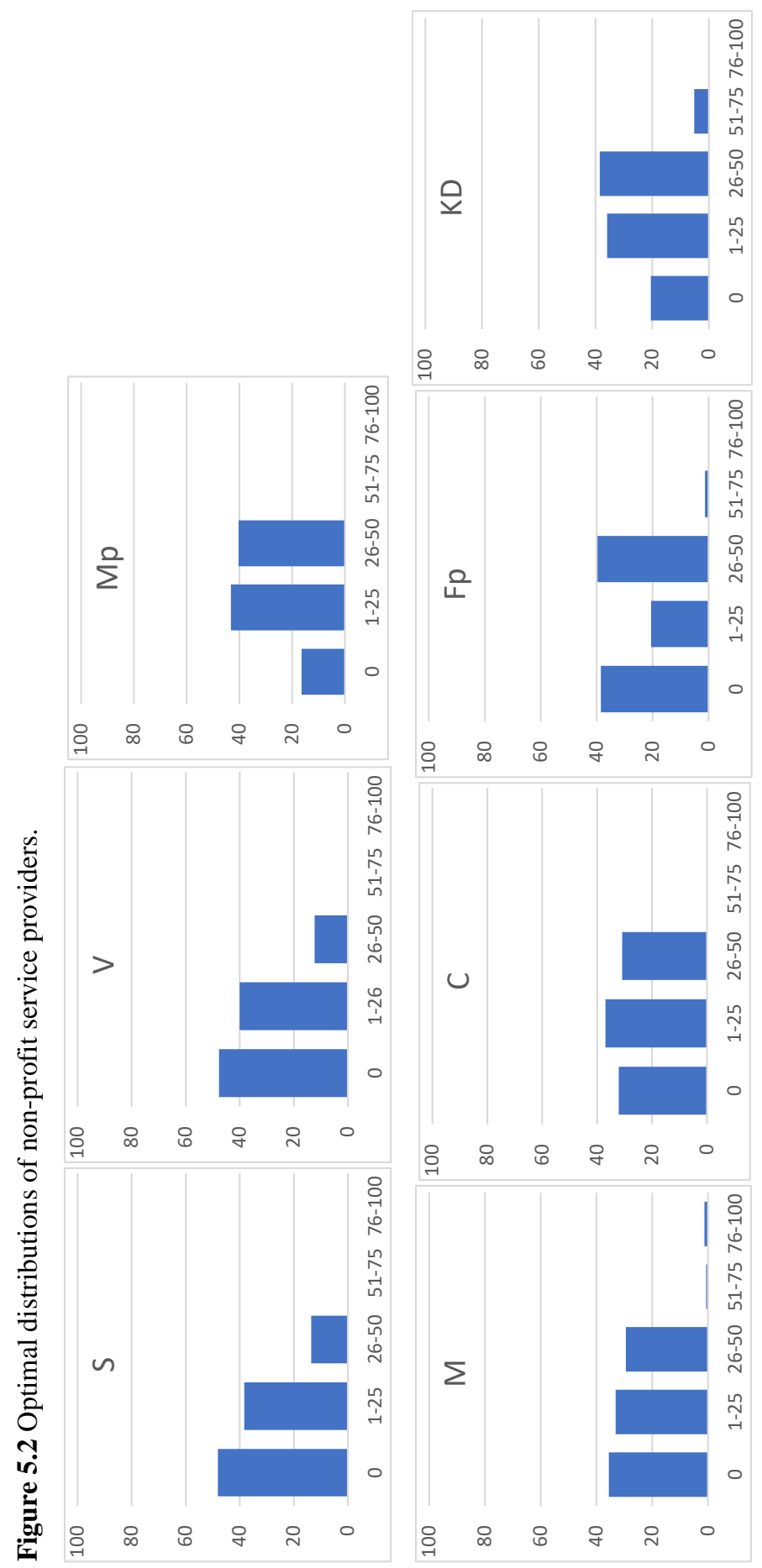



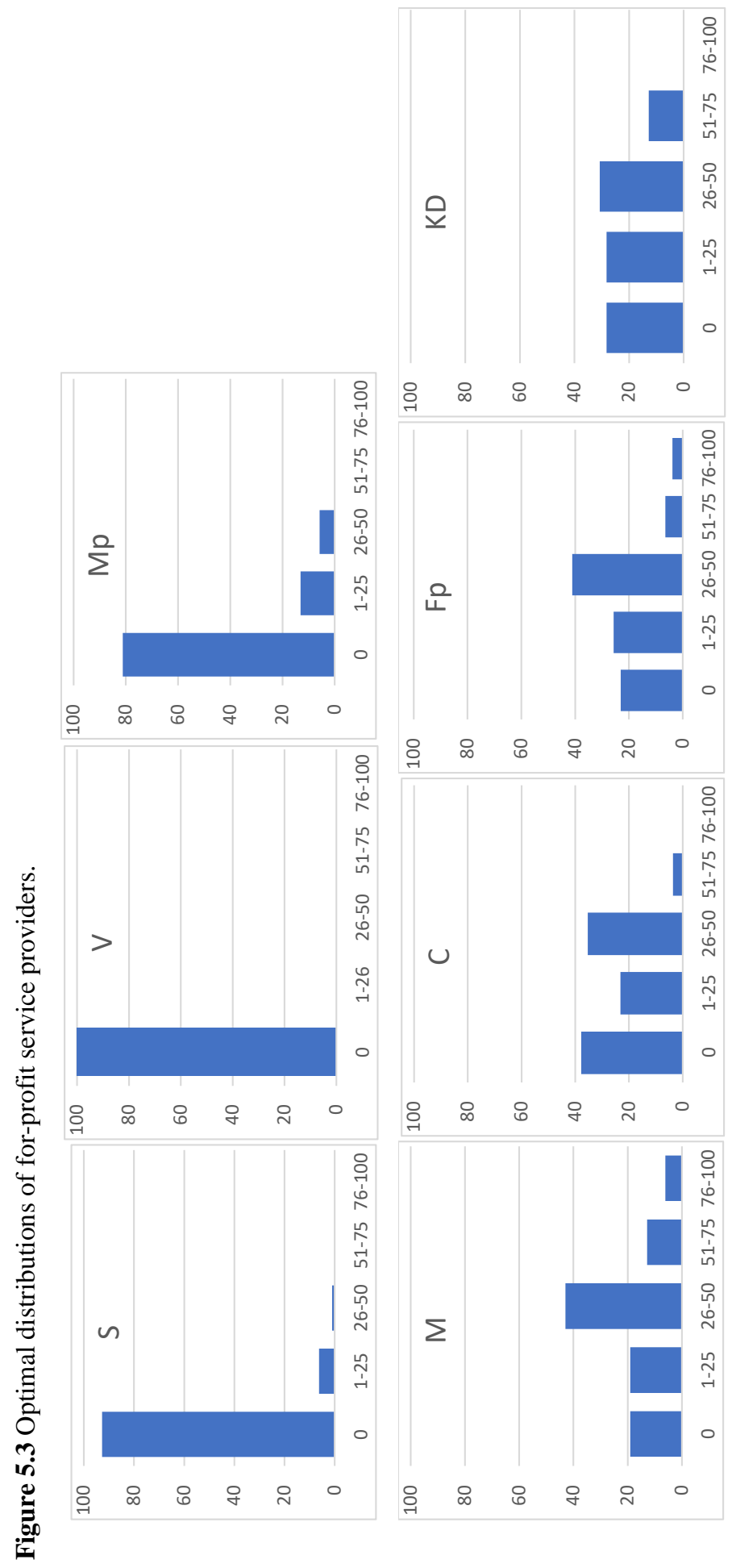


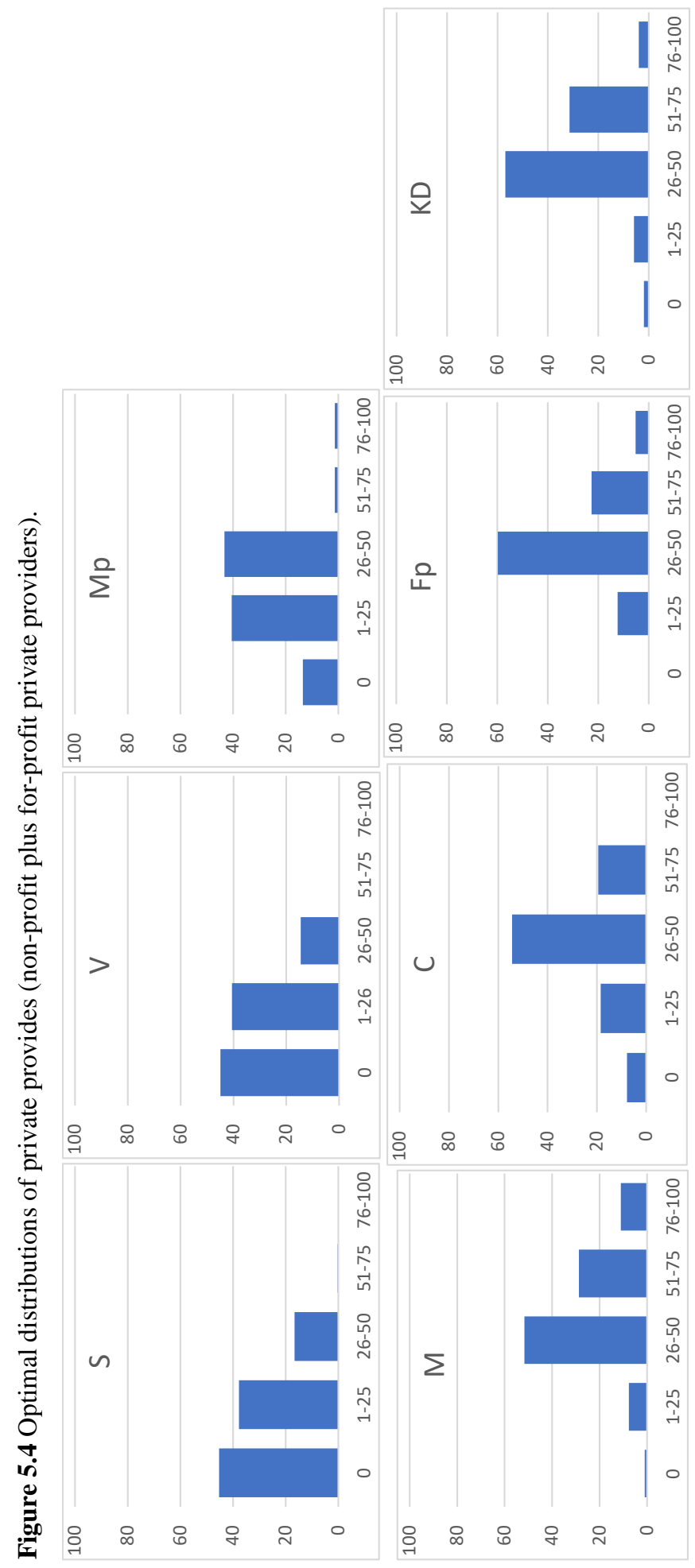




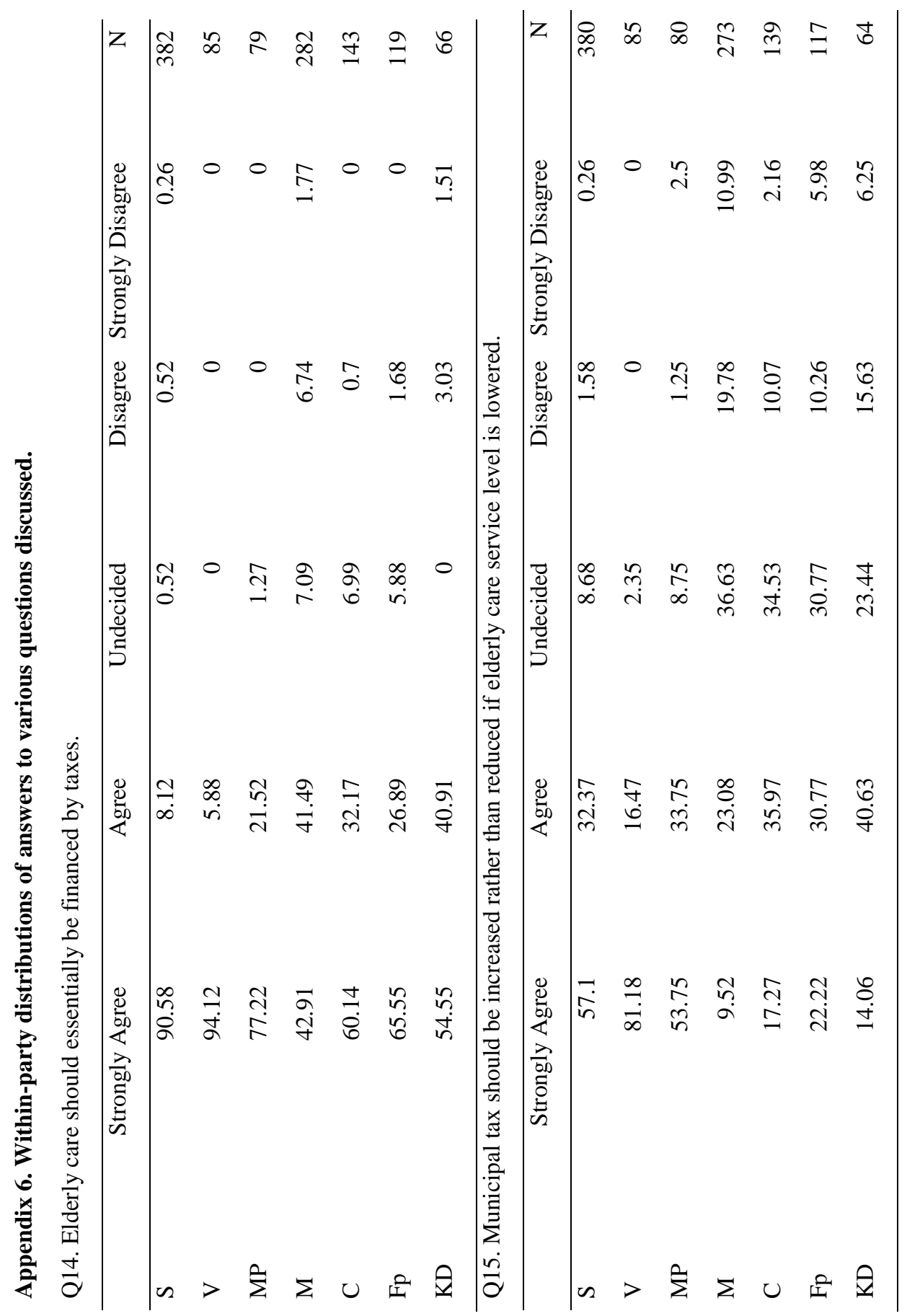



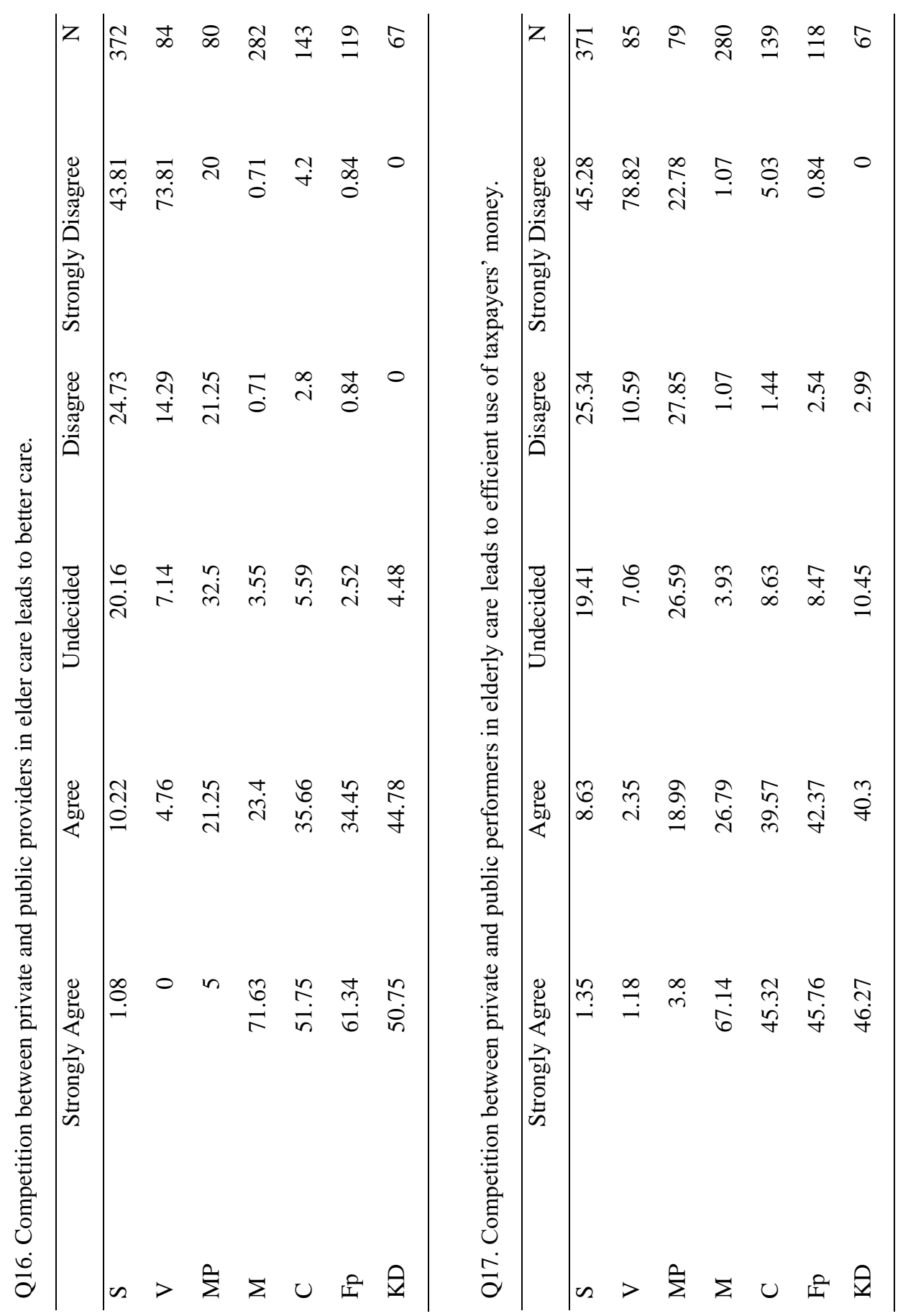

$\stackrel{\infty}{\sim}$ 


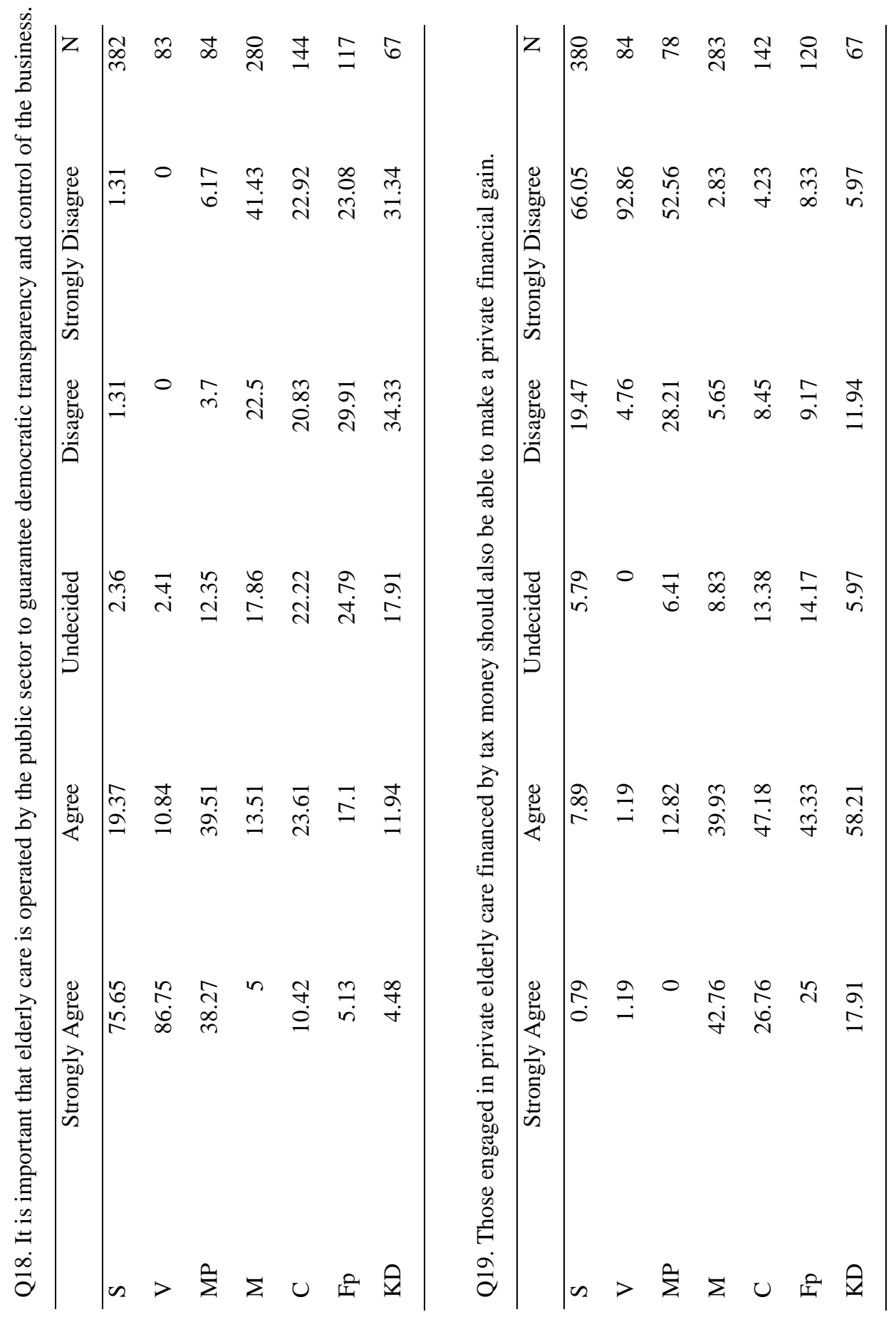

总 


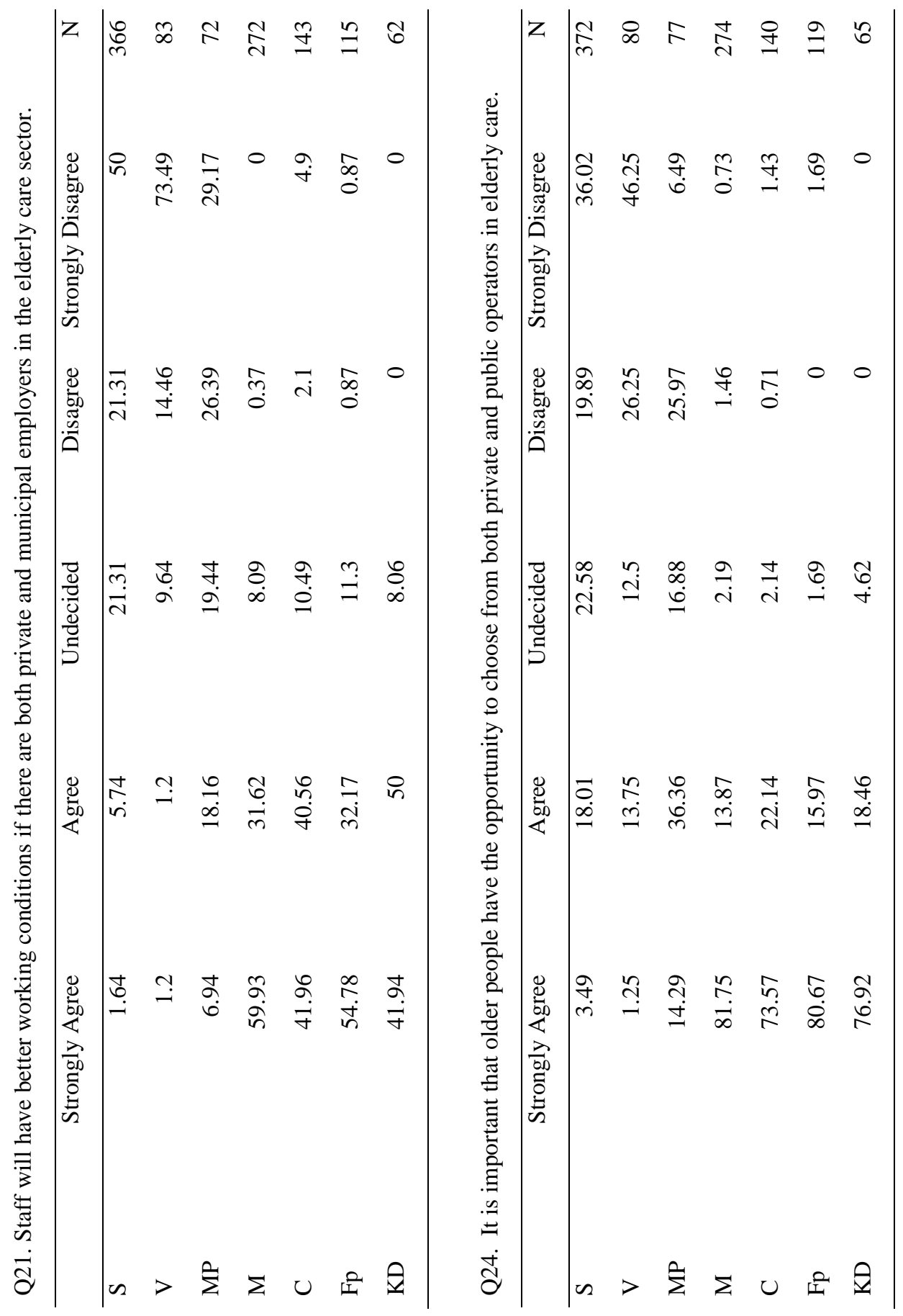

움 


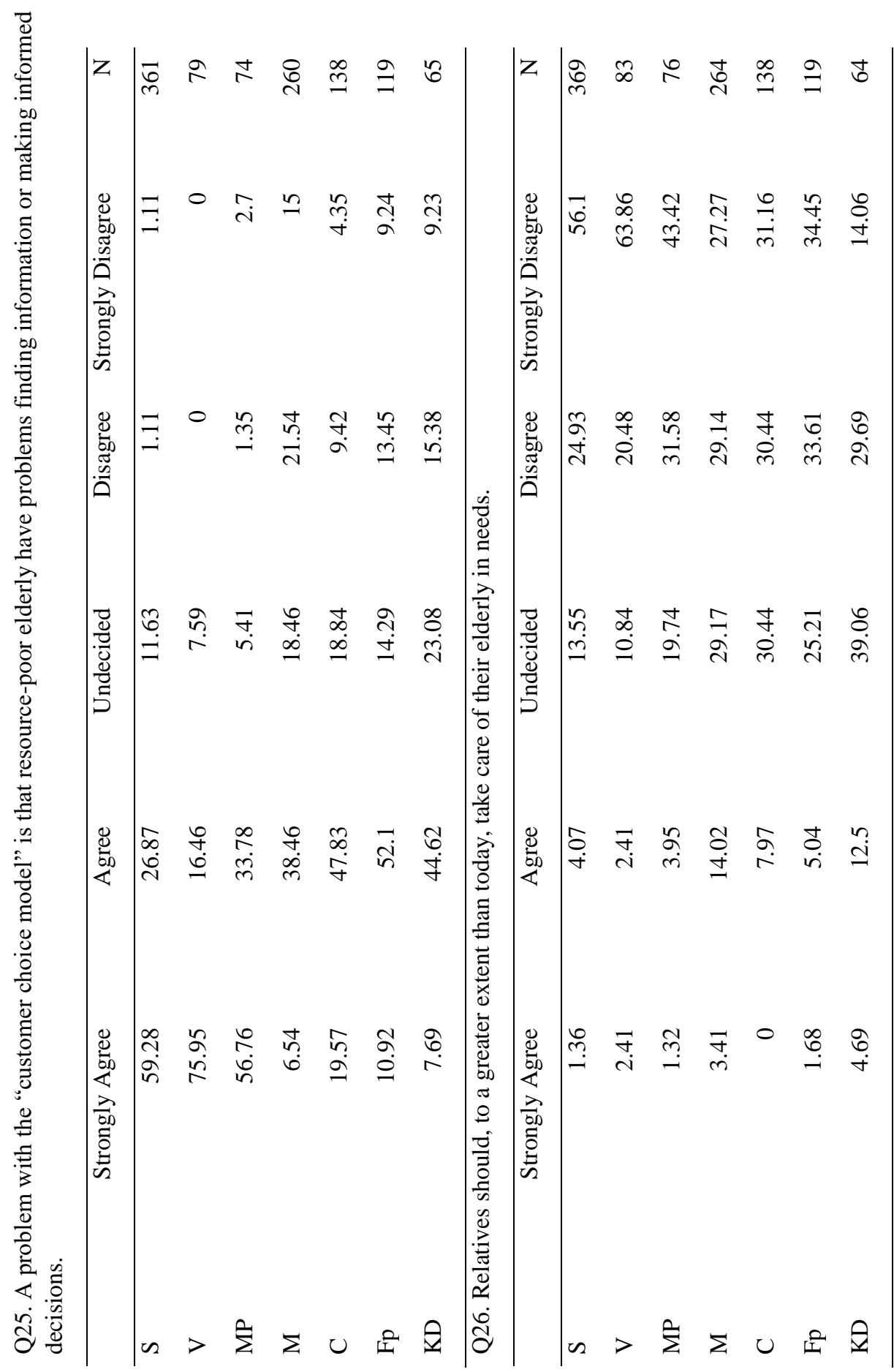



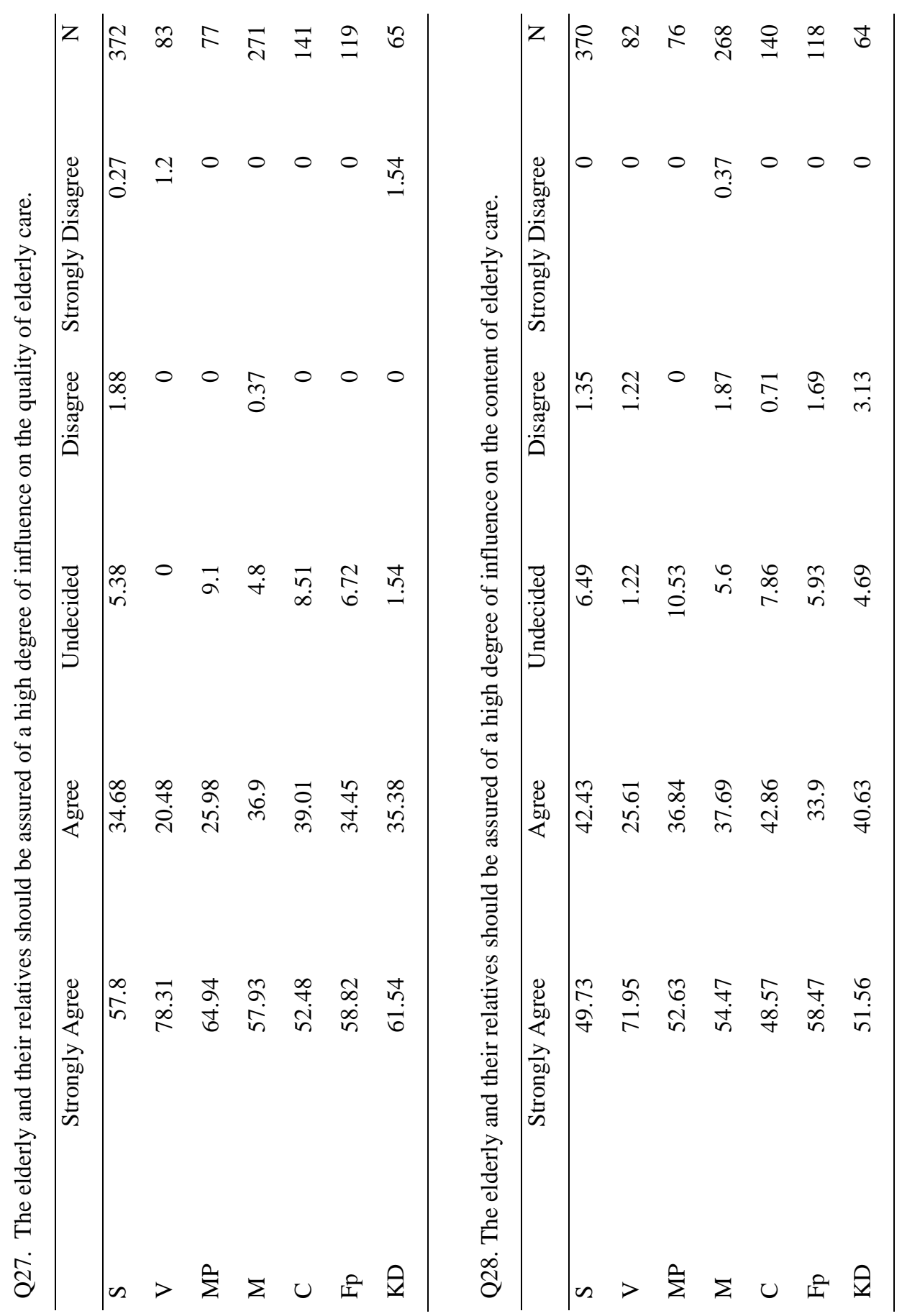


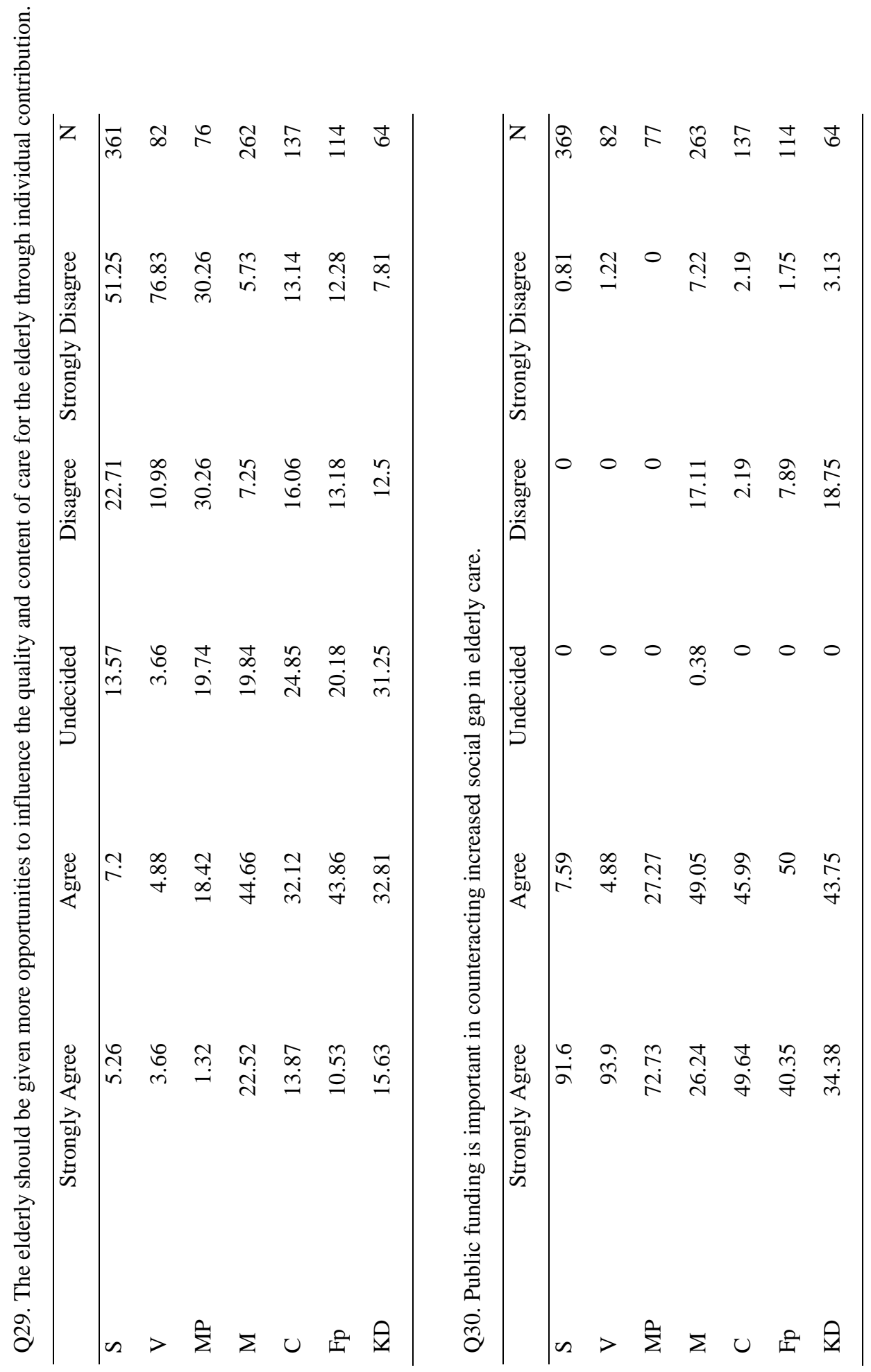




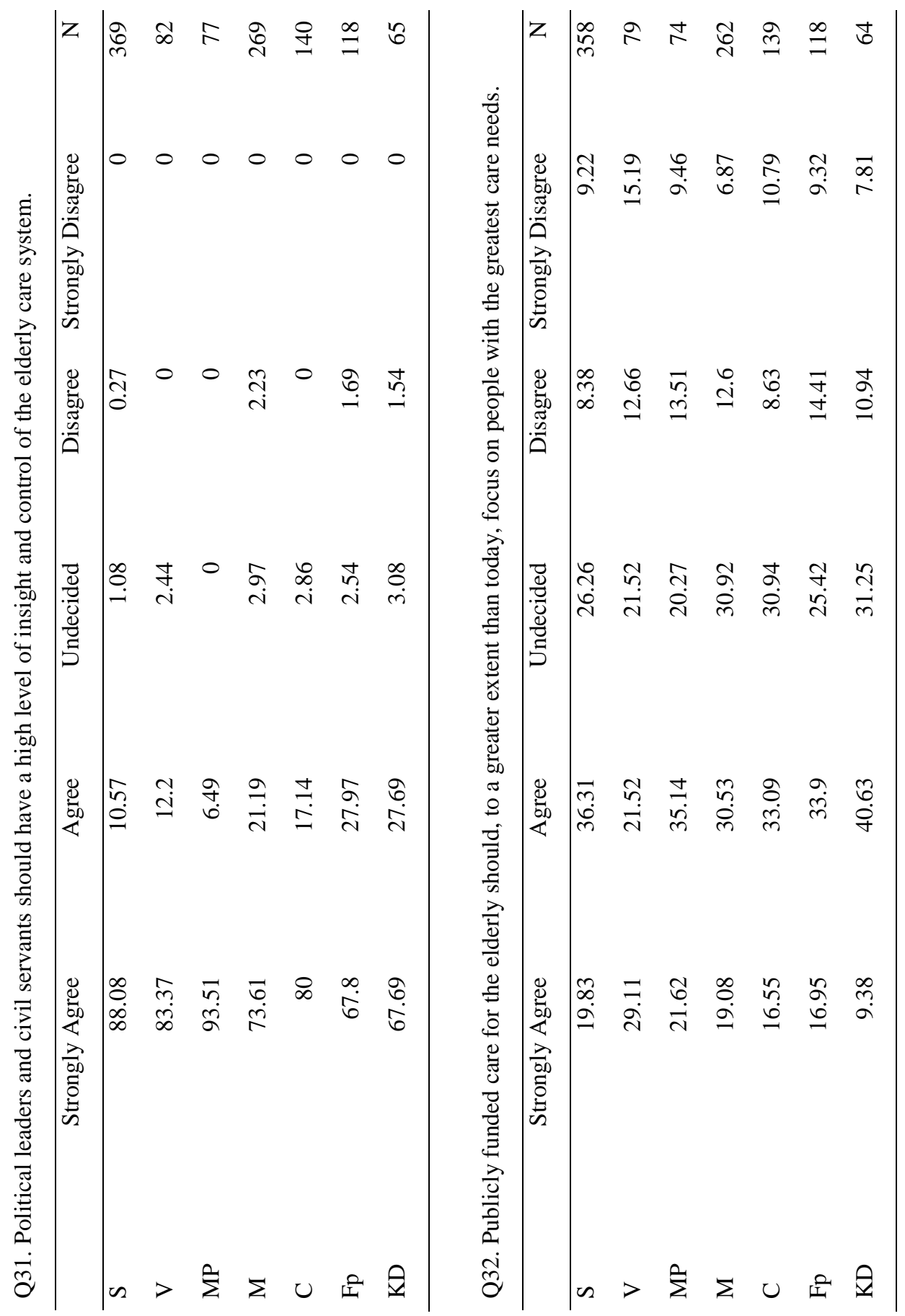


